\title{
Ecotourism \& Community Development: Case Studies From Hainan, China
}

by

\author{
Michael J. Stone
}

\author{
A thesis \\ presented to the University of Waterloo \\ in fulfillment of the \\ thesis requirement for the degree of \\ Master of Arts \\ in \\ Planning
}

Waterloo, Ontario, Canada, 2002

(C) Michael J. Stone, $\underline{2002}$ 
I hereby declare that I am the sole author of this thesis. This is a true copy of the thesis, including any required final revisions, as accepted by my examiners.

I understand that my thesis may be made electronically available to the public. 


\section{Borrower's Page}

The University of Waterloo requires the signatures of all persons using or photocopying this thesis.

Please sign below, and give address and date. 


\section{Acknowledgements}

I owe thanks to many people for their support and encouragement over the last twenty months, as I have traveled, sometimes rambled, along the road towards the completion of this Master's thesis. Much credit goes to my advisor, Dr. Geoff Wall, for his guidance throughout this project and, who from the beginning was confident, when often I was not, that an overseas research experience would materialize for me. Dr. Paul Eagles provided insightful and valued comments during the later stages of this thesis, as did Dr. Susan Wismer and Dr. Noga Collins-Kreiner. Without the financial assistance of the Canadian International Development Agency this project would not have been possible.

The support and cooperation I received while working in China was incredible. I must first thank Dr. Ying Wang at Nanjing University, Mr. Wang Weilu at the Hainan Provincial Labour Management Bureau and Mr. Cai Shidong at the Sanya Tourism Administration for the letters of support that they wrote which were instrumental in helping me to secure funding for this project.

Thanks go to Ms. He Shaoqun at the Department of Lands, Environment and Resources, Mr. Li Shulin at the Hainan Forestry Research Institute (HFRI) and Ms. Du Na at the Hainan Tourism Bureau (HTB), who each provided me with useful information and guidance during the early stages of this research. I am grateful to Mr. Jia (James) Shaodong at Hainan University, who helped me to find a research assistant, who provided valuable research assistance himself on several occasions, and who proved to be one of my closest friends during my time in Hainan.

Ms. Zhou Yanhua and Mr. Su Wenba at the Hainan Forest Bureau (HFB) deserve a great deal of credit for meeting with me on several occasions, for providing a tremendous amount of information and for their patience with my incessant questions. Thanks also go to Dr. Carl-Gustav von Hahn of the Sino-German Forestry Cooperation Hainan Office for his assistance and for allowing me to tagalong on one of his visits to Wuzhishan Nature Reserve.

At the Jianfengling Forest Bureau (JFB), thanks go to Mr. Fang Hong and Mr. Xie Mingdong for taking time out of their busy schedules to speak at length with me. Ms. Wang Yanling at the Tao Hua Yuan Hotel and Ms. Ju at the Tianchi Summer Resort deserve thanks for their cooperation and assistance in attempting to administer a survey to Park tourists. Gratitude is also extended to Dr. Zhong Chonglu of the Chinese Academy of Forestry, whose ability to speak some English (in a place 
where nobody else could) turned a potentially wasted (unaccompanied) first visit to Jianfengling National Park into an informative experience.

I am grateful to Mr. Wang Dongming and Mr. Yu Weisun at the Diaoluoshan Forest Bureau (DFB) for the considerable amount of time each spent with me and for their willingness to share information. I thank Mr. Lu Yongquan and the many others at the DFB who were such gracious hosts. Thanks are also extended to Mr. Wang Zuohuai and all the staff and their friends at the Diaoluo hotel for the hospitality, good food, card games and motorcycle tours of the Park they provided.

During my time in Hainan I had the opportunity to meet with a number of Nature Reserve and Park managers that were not associated with either of the study sites. I am very appreciative of the time they took out of their busy schedules to meet and share information with me and, for the hospitality each provided. In particular, thanks go to: Mr. Zhou Xujian at Bawangling National Nature Reserve, and to Mr. Yang and company, also at Bawangling, for the driving tour of the Reserve they provided; Mr. Li Shanyuan at Datian National Nature Reserve; Mr. Feng Biaojing at Wuzhishan Provincial Nature Reserve; and Mr. Zhang Tao at Nanshan Buddhist Cultural Park.

A great deal of credit goes to Mr. Wang Haijun, my research assistant and friend, for providing excellent translation, for his perseverance and patience, and for helping me to understand and respect local culture and custom. His dedication was essential to the success of this study.

I am indebted to Ms. Wang Yang, her wonderful parents and their many friends, for providing research assistance, but more importantly, for welcoming me into their family and making me feel at home in Hainan from my first day until my last. Their kindness took many forms - transportation, arranging accommodations, meals out (do they serve tofu?) and karaoke nights (is my singing hao buhao?) - and will not be forgotten. Special thanks go to Ms. Wang Yang for her tireless assistance, resourcefulness and for hanging-out with me, when I am sure she had more important things to be doing!

Thank you to all the people I met outside of work - Simon, Amy, Hun Yi, Arthur, Eva, Bear and Margaret - for engaging conversations, meals out, free drinks and good company. Their friendship afforded me with much needed breaks from my research. Many thanks go to Ms. Hu Wei, who spent a great deal of time showing me around both Haikou and Sanya. The staff at both the Haikou Hotel and Jinling Holiday Resort deserves recognition for providing me with excellent room rates and great service, including the occasional complimentary fruit basket. 
In Guangzhou, I am grateful to Fay Wu for showing me around the city and to Mr. Yang Ming and his family for their hospitality and one of the most delicious meals I had while in China. Thanks go to Dr. Zhou Xinqing, Dr. Ying Wang and John at Nanjing University for making my short stay in Nanjing so comfortable and enjoyable.

At home, xiexie ni to Mr. Gu Kai, Ms. Shu Hua and Ms. Wang Yang for translation assistance and for helping me get accustomed to Chinese food, custom and language prior to my departure. Ms. Teresa Chang-Hung Tao provided valuable document translation during the data analysis stage of this study. To all my friends and colleagues here in Kitchener-Waterloo, thank-you, for your support, but more importantly, for the good times that gave me a reason to procrastinate.

Many thanks go to my family, for their support and encouragement, something they have never failed to provide through my many endeavors and adventures. Lastly, and most importantly, loving thanks go to Nicole, my best friend, travel companion and number one nu pengyou. Your unwavering support and words of inspiration, as they have many times before, helped me through a challenging time in my life - thank-you!

A final thanks to everyone, including those I may have forgotten here, that has helped to make the last year and a half a very rewarding and enjoyable experience! 


\begin{abstract}
Ecotourism is one of the fastest expanding tourism markets. It has received much attention in developing countries and economically impoverished regions around the world. As an agent of change, ecotourism has been linked to sustainable development strategies and initiatives in many places. However, ecotourism can induce a variety of both positive and negative environmental, cultural and socioeconomic impacts at a destination. Operating in its ideal form (according to some), ecotourism provides the tourist with a quality nature experience, generates funds and support for conservation efforts, has minimal environmental impact and provides socioeconomic benefits to local host communities. While there is evidence that ecotourism's espoused benefits can be realized, there are equally as many, if not more, cases where ecotourism has fallen short of its proposed objectives. Indeed, ecotourism's impact has been highly variable. At the same time, some have criticized that there have been relatively few practical assessments of ecotourism's status at specific destinations.

This study sought to assess the current status of ecotourism at two destinations where it is being promoted as a regional development strategy. The existing tourism-park/resource-community relationships and impacts are evaluated at Jianfengling and Diaoluoshan National Forest Parks, in Hainan Province, China. Hainan, although endowed with a wealth of natural resources, is one of China's most economically backward provinces. Ecotourism has been identified as an important provincial strategy for balancing economic growth and conservation. The study is intended to enhance the capacity of ecotourism to generate benefits for both the local communities and destinations (the protected areas), and thus contribute to the sustainable development of the region more generally.
\end{abstract}

Given the exploratory nature of the research, qualitative analysis was used. Interviews, observations and secondary sources were the main vehicles of inquiry employed in this study. Basic quantitative analysis was used to aid in the interpretation of interview results. Triangulation, in terms of both data sources (primary and secondary) and methods (document collection, observations, interviews, quantitative analysis), was used wherever possible to limit personal and methodological biases.

Similar results were found in both the Jianfengling and Diaoluoshan case studies. Ecotourism development is at an early stage. As such, socioeconomic benefits for the local communities have been very limited. At the same time, residents have had to cope with reduced access to resources 
since the Parks were established in the mid-1990s. Nevertheless, community residents generally support conservation and are optimistic that tourism growth will yield benefits. Both Parks receive relatively few tourists, and neither Park charges a user fee. As a result, (eco)tourism has not, to date, contributed revenues towards conservation efforts. Although the Parks offer spectacular tropical scenery, facilities are basic and educational opportunities for tourists are few. Planning direction and recommendations are offered based on the study findings and the salient ecotourism literature.

Identified opportunities, constraints and recommendations are used to provide a potential framework for the development of a park (eco)tourism plan at each study site. Results and recommendations could inform planning and management processes, and thus enhance the capacity of ecotourism to generate benefits at the study sites and, more generally, throughout Hainan. 


\section{论文摘要}

作为当今发展最快们旅游巾场之一, 生态旅游在发展中国家和贫穷落后地区得到 了广泛的关注。作为一个动态的系统, 生态旅游和可持续发展战略紧密㕲联, 然而, 生 旅游不仅可以提宂当地们环境、文化和社会经济, 同时也会守致一系列负面的影响。 里想的生态旅游在为旅游者提供向质量坏境休验的同时，会最少的影响现有的生态平 衡; 为当地居民捉供经济帮眇们同时，订进一步捉供白然保护上作们资金米源。众多 队研究指出生态旅游经常我末达到这些理想的目的, 由于实际案例分析的缺区使理论 形分难于深入。

这一论文将分析两个区域的生态旅游实践一中同游南省的尖峰岭和尔岁小同家梨 末公园。旅游公园和资源社区的关系是这一研分的主题。菂南的白然资源丰富，然旧 㹩济发展长期落后十中国大陆, 近年以来, 发展生态旅游已被”地政府确认为平衡经济

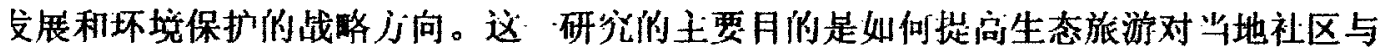

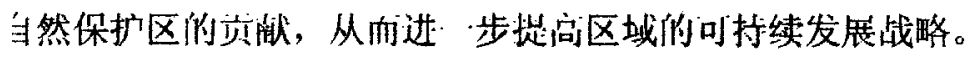

作为一个探案性们研分，定性们人员访问、炠察和相关资料收集是主要似研究j

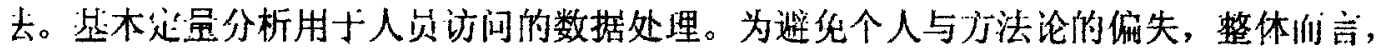
形分中充分结合了第一千和第一于资料与定性分析和定晕分析们j法。

炎于尖峰岭和门少山国家林林公园的研究结论机似。生态旅游发展在当地处士初 台阶段, 对当地们经济与社会方献朴对有限。九十年代中期同家林林公阅们设立, 仗

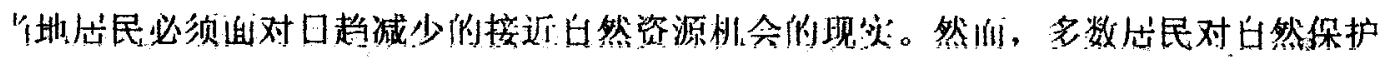

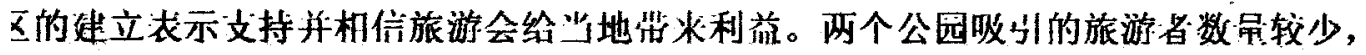

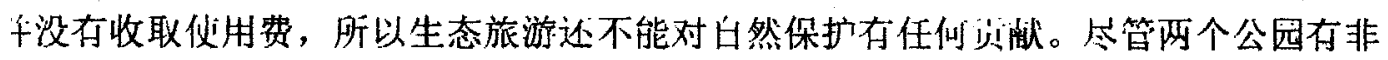
官吸引人们热临风景，但服务旅游者的设施和教育资源们开发非常有限。烧划j向和

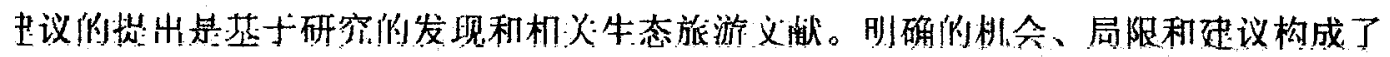

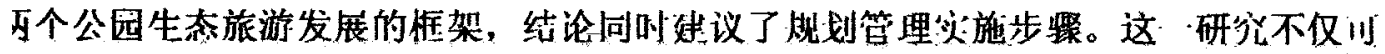

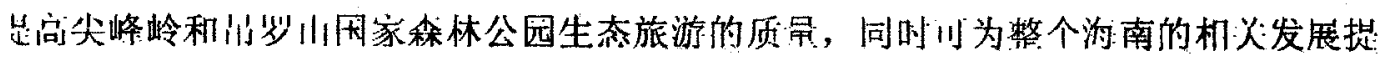
纤供鉴。 


\section{Table of Contents}

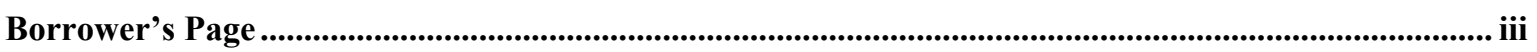

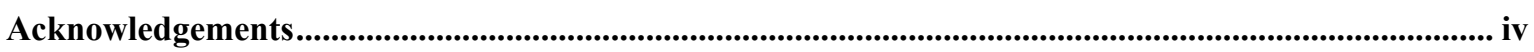

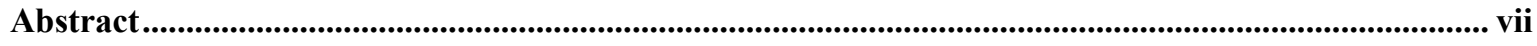

Table of Contents ..................................................................................................................................................... $\mathrm{x}$

List of Figures .............................................................................................................................................

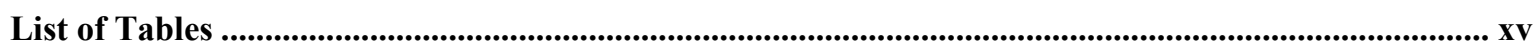

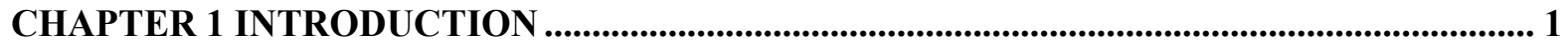

1.1 Ecotourism and Community Development .......................................................................................... 1

1.2 Study Purpose and Research Objectives ......................................................................................................... 2

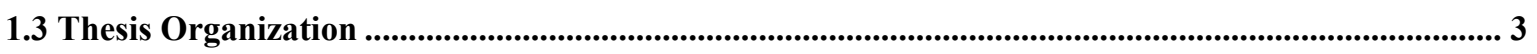

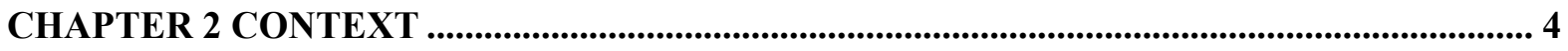

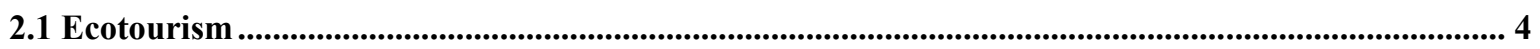

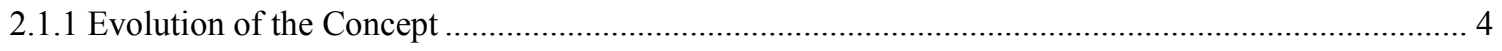

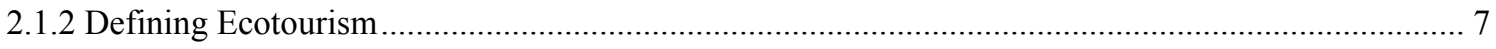

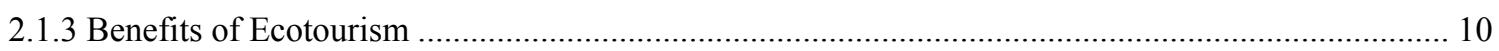

2.2 Ecotourism, Protected Areas and People ....................................................................................................... 12

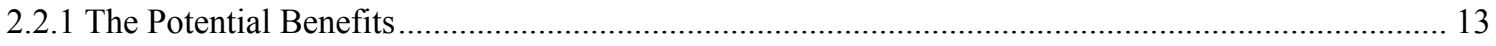

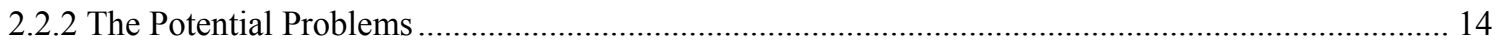

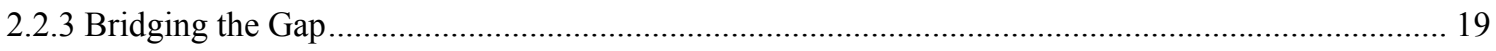

2.3 Summary: Evaluating Ecotourism ............................................................................................................... 24

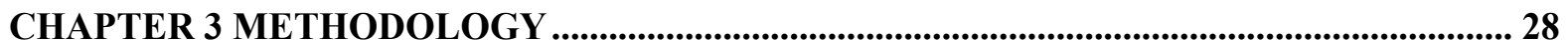

3.1 Study Location and Site Selection Rationale …............................................................................................. 28

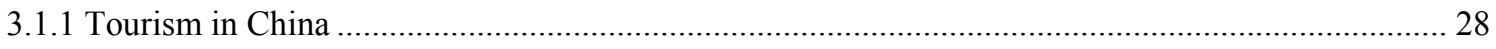

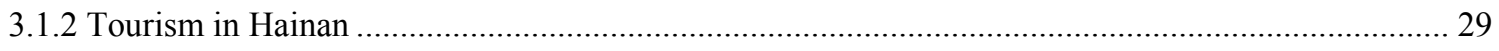

3.1.3 The Canada-China Higher Education Project …........................................................................ 31

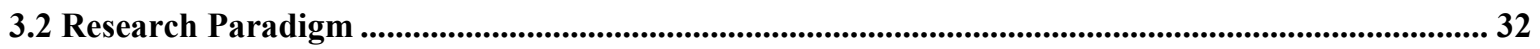

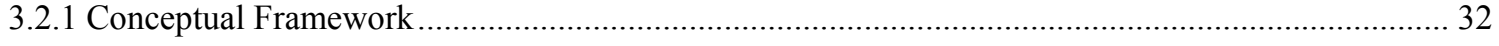

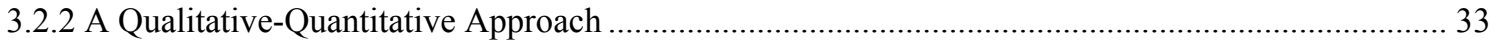

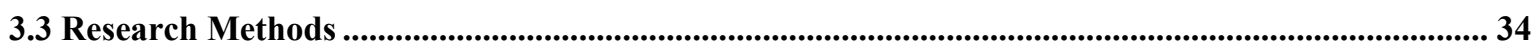

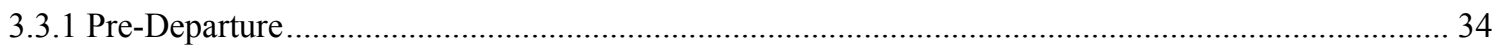




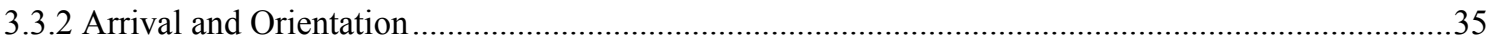

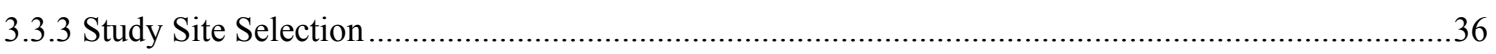

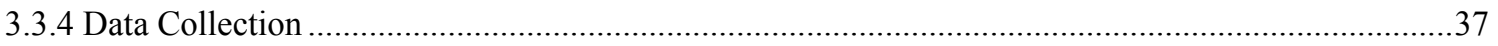

3.3.4.1 Site Level Park Managers....................................................................................................... 38

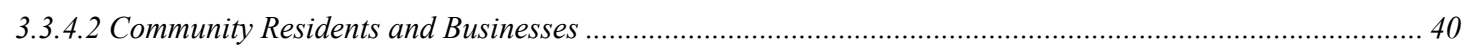

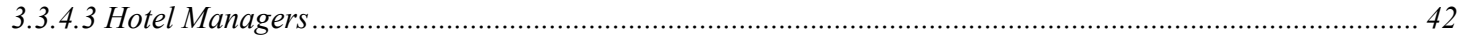

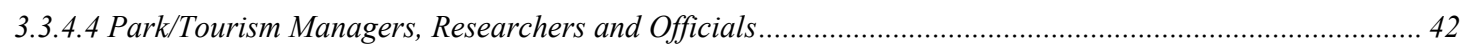

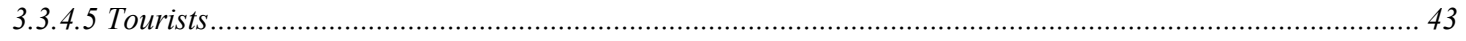

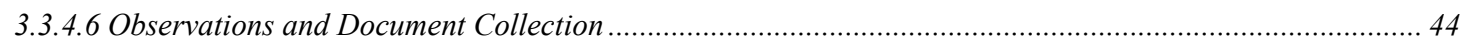

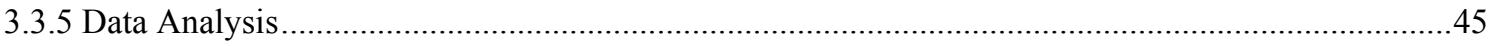

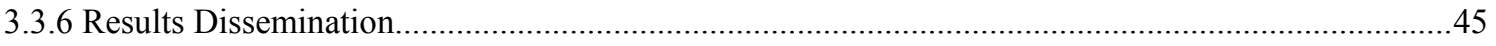

3.4 Summary: Strengths and Weaknesses of the Study Design ...................................................................46

CHAPTER 4 PROTECTED AREAS AND ECOTOURISM IN HAINAN ................................ 48

4.1 Organization and Administration of Hainan's Protected Area System .................................................48

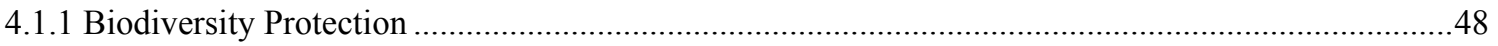

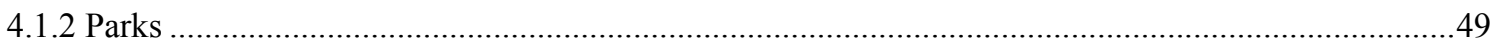

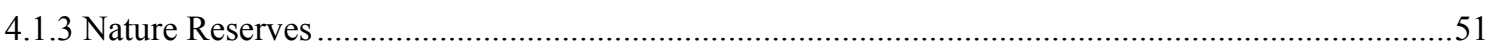

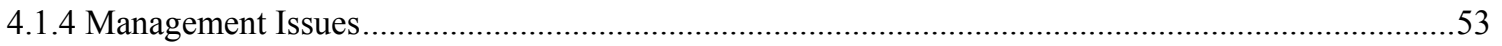

4.2 Interpretations of Ecotourism in Hainan .......................................................................................................54

CHAPTER 5 CASE STUDY I: JIANFENGLING NATIONAL FOREST PARK ......................59

5.1 Site Description - Jianfengling National Forest Park and Provincial Nature Reserve.......................59

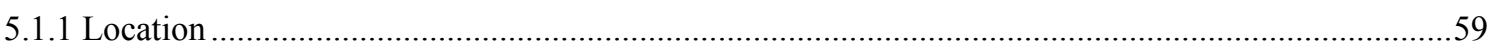

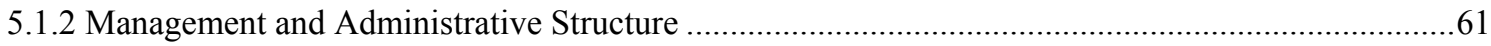

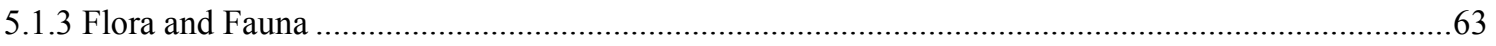

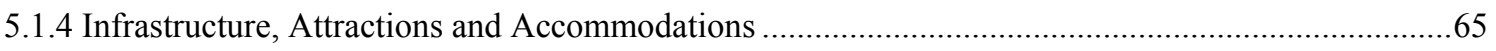

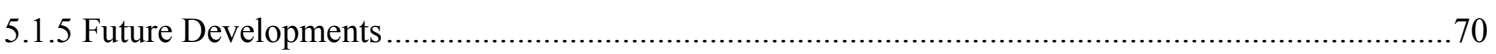

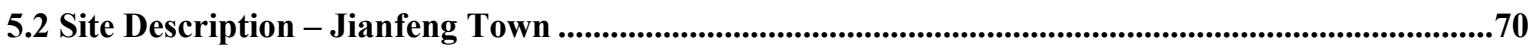

5.3 Relationship Between Local Community and JNFP ...................................................................................73

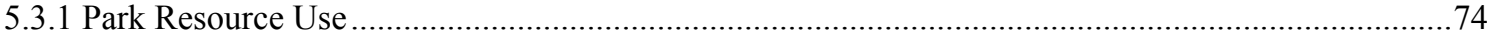

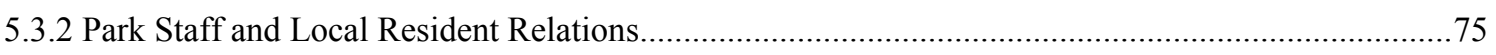

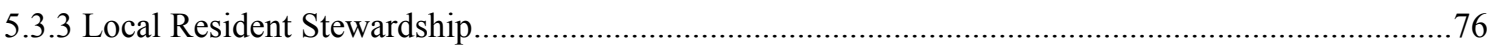

5.4 Relationship Between Local Community and Tourism ...............................................................................78

5.4.1 Economic Benefits ..................................................................................................................

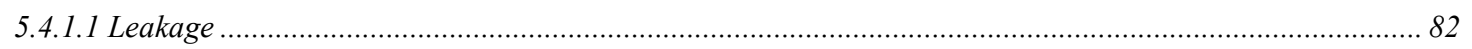




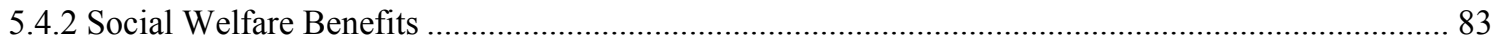

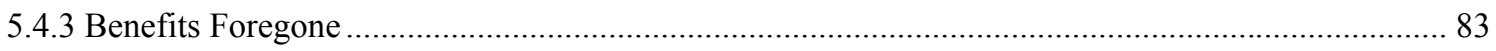

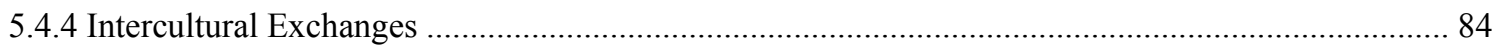

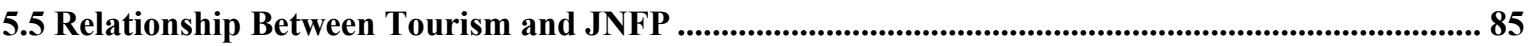

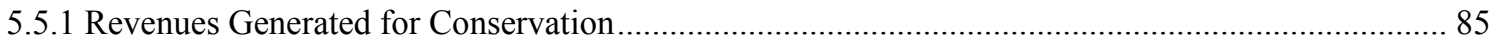

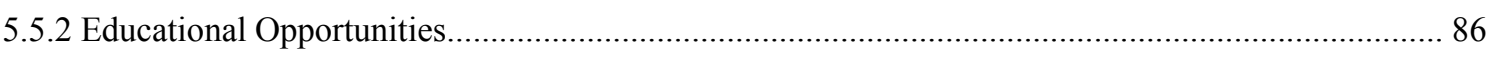

5.6 Summary: Management and Policy Considerations ....................................................................... 88

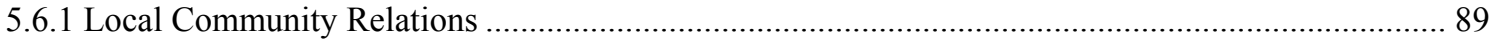

5.6.2 Park/Resource Management ..................................................................................................... 90

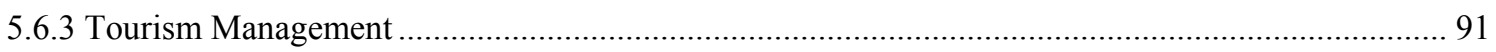

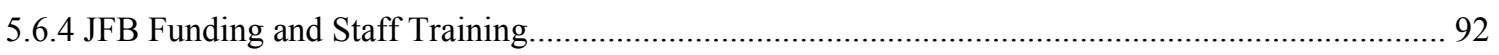

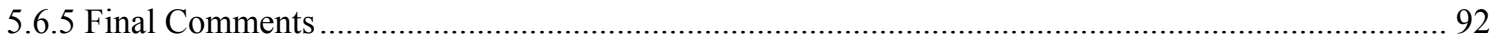

CHAPTER 6 CASE STUDY II: DIAOLUOSHAN NATIONAL FOREST PARK...................... 98

6.1 Site Description - Diaoluoshan National Forest Park and Provincial Nature Reserve........................ 98

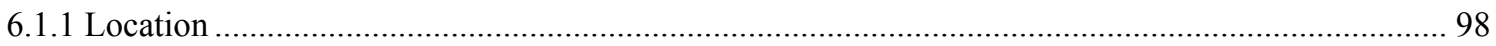

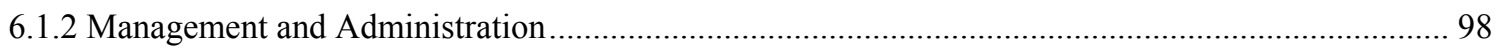

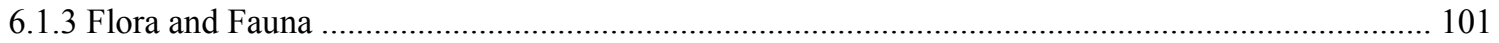

6.1.4 Infrastructure, Attractions and Accommodations ........................................................................... 103

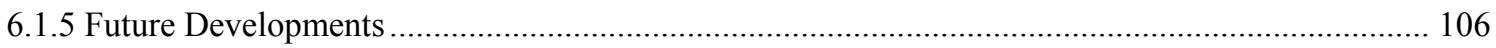

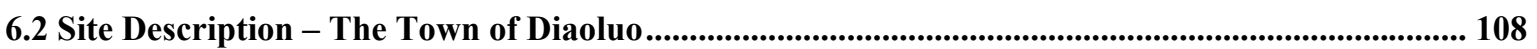

6.3 Relationship Between Local Community and DNFP ................................................................................ 111

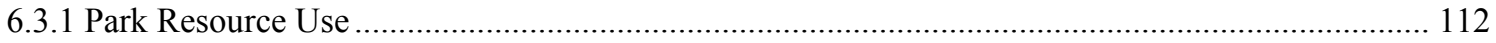

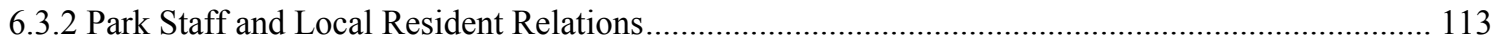

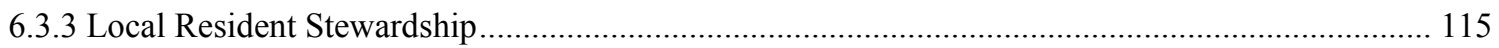

6.4 Relationship Between Local Community and Tourism ................................................................................ 117

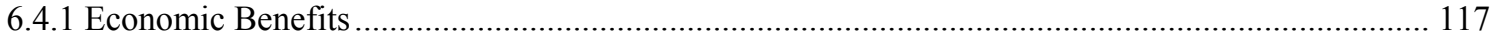

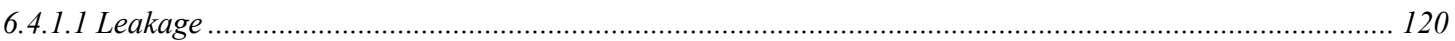

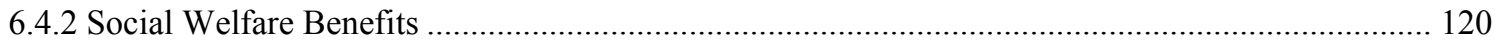

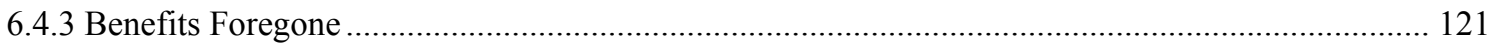

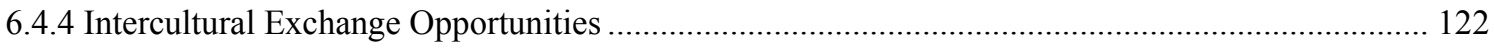

6.5 Relationship Between Tourism and DNFP ................................................................................ 122

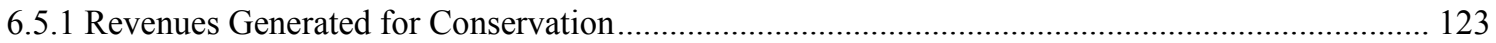

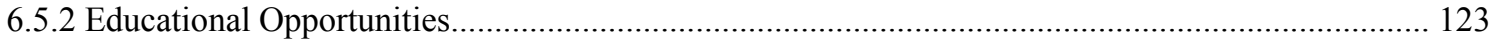

6.6 Summary: Management and Policy Considerations ................................................................................... 125

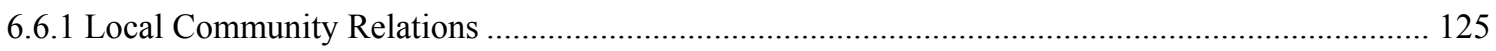




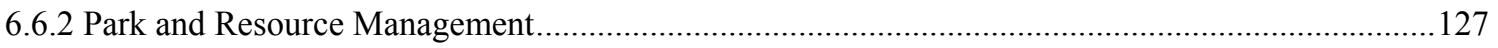

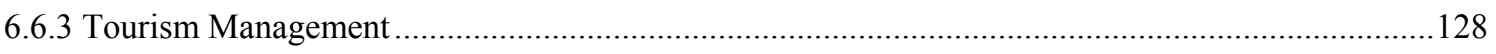

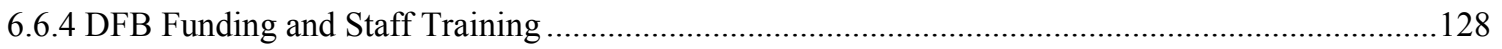

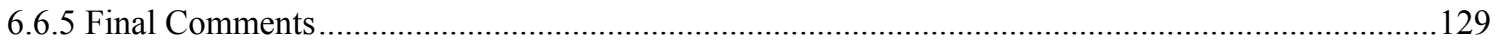

CHAPTER 7 DISCUSSION AND RECOMMENDATIONS.................................................... 134

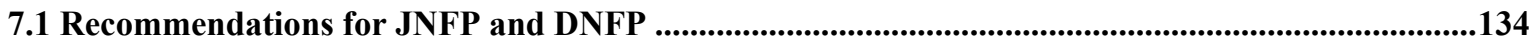

7.1.1 Relationships Between the Local Communities and Parks ............................................................136

7.1.2 Relationships Between the Local Communities and Tourism .......................................................138

7.1.3 Relationships Between Tourism and the Parks.............................................................................140

7.2 Ecotourism in Hainan ...........................................................................................................................142

7.3 Methodological Conclusions, Further Research and Study Contributions........................................144

Appendix A : Park Manager Interview Questions............................................................................................146

Appendix B : Local Resident and Business Owner Interview Questions ....................................................150

Appendix C : Study Description Given to Interviewees ....................................................................................155

Appendix D : Tourist Survey ..............................................................................................................................157

Appendix E : DNFP Tourist Pledge Form ….............................................................................161

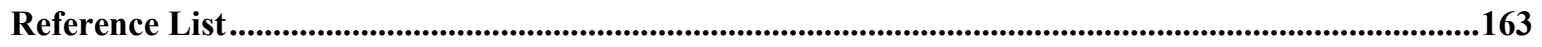




\section{List of Figures}

Figure 2.1: The Continuum of Ecotourism Paradigms ................................................................... 9

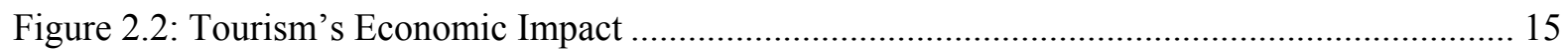

Figure 2.3: A Framework for Conceptualizing and Evaluating Ecotourism..................................... 26

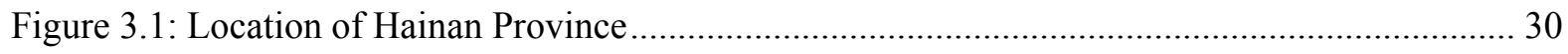

Figure 4.1: Location Map of Hainan's Nature Reserves..................................................................... 52

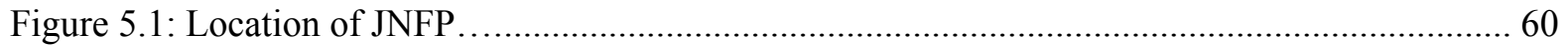

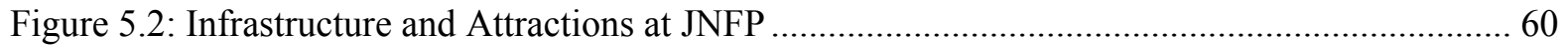

Figure 5.3: A Large Tract of Primary Tropical Forest in JNFP ....................................................... 64

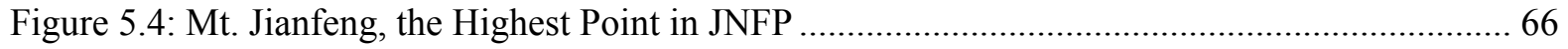

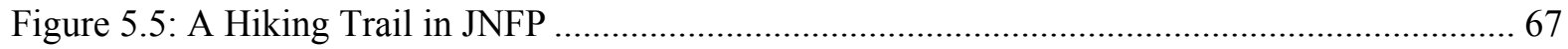

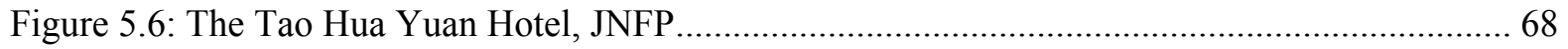

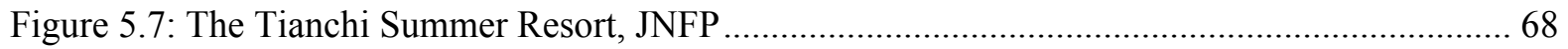

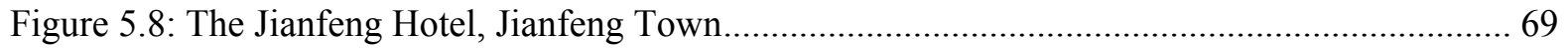

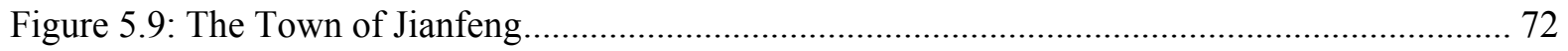

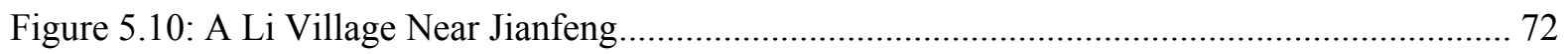

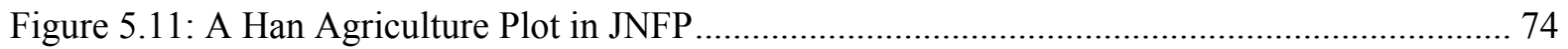

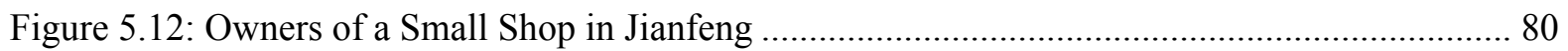

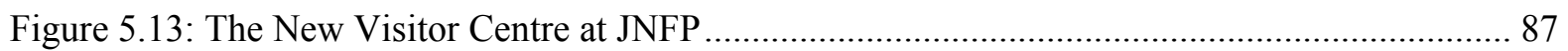

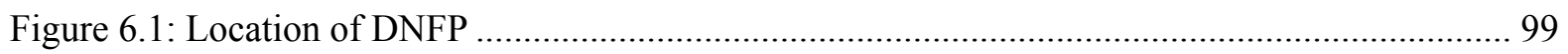

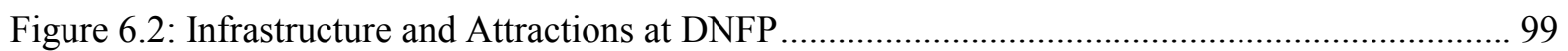

Figure 6.3: Alsophila spinulosa, a Rare Species Found in DNFP ................................................ 102

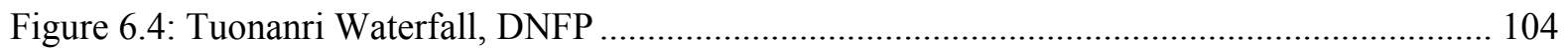

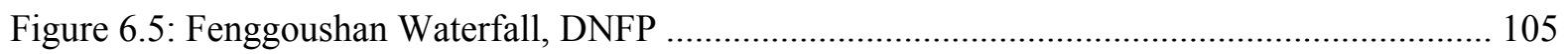

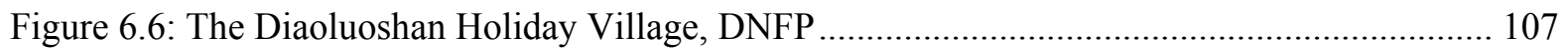

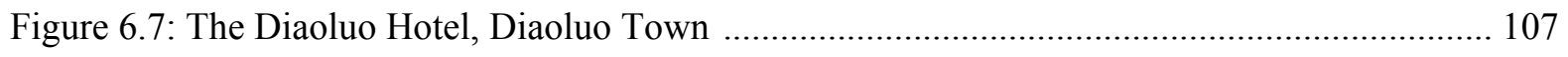

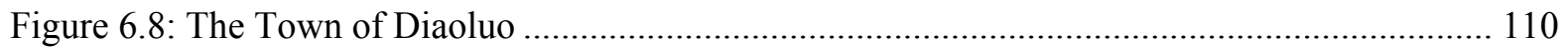

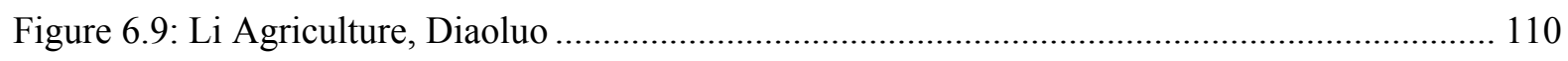

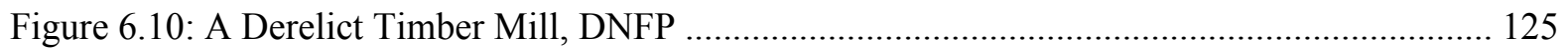

*Photo Credits: All photos taken by Michael J. Stone, (c) 2002

xiv 


\section{List of Tables}

Table 2.1: Potential Indicators of the Relationships at an Ecotourism Destination ............................27

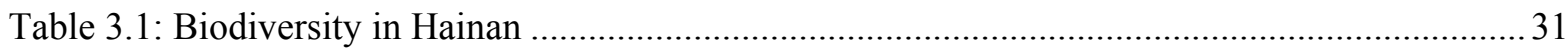

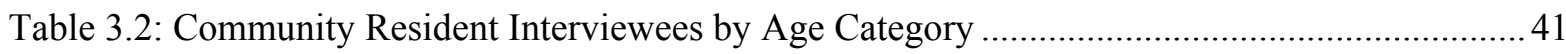

Table 3.3: Community Business Owner Interviewees by Business Type .......................................... 41

Table 4.1: Expansion of the Hainan Nature Reserve System .......................................................... 49

Table 4.2: Interviewees' Interpretations of Ecotourism .................................................................. 56

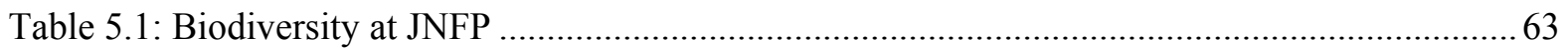

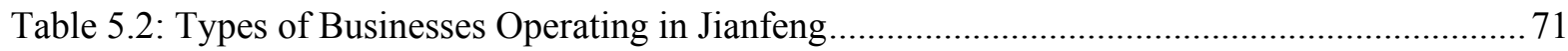

Table 5.3: Summary of the Relationships Between the Community and JNFP ................................ 78

Table 5.4: Summary of the Relationships Between the Community and Tourism ............................ 85

Table 5.5: Summary of the Relationships Between Tourism and JNFP …...................................... 88

Table 5.6: Selected Key Management and Policy Considerations at an Ecotourism Destination........ 89

Table 5.7: Potential Framework for the Development of a Park Tourism Plan at JNFP.................... 94

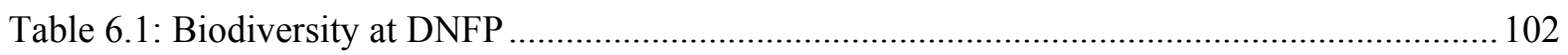

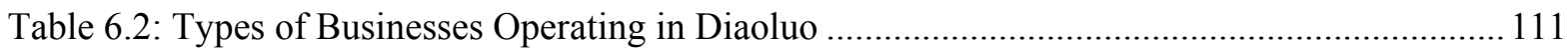

Table 6.3: Summary of the Relationships Between the Community and DNFP.............................. 116

Table 6.4: Summary of the Relationships Between the Community and Tourism ........................... 122

Table 6.5: Summary of the Relationships Between Tourism and DNFP .......................................... 125

Table 6.6: Potential Framework for the Development of a Park Tourism Plan at DNFP ................. 130

Table 7.1: Selected Community Interview Responses at JNFP and DNFP ..................................... 135 



\section{Chapter 1 Introduction}

Tourism is a global phenomenon. It has been hailed by some as the largest industry in the world (Wells, 1997; Lundberg, Krishnamoorthy, \& Stavenga, 1995; Ceballos-Lascurain, 1993). It is an industry that continues to grow (Campbell, 1999). In 2000, a record 699 million international tourist arrivals generated an estimated US\$476 billion in international tourism receipts (World Tourism Organization, 2001). With its highest growth rate in almost a decade, world tourism increased by $7.4 \%$ in 2000 . By 2005, it has been projected that world tourism will generate US\$7.9 trillion in gross output and employ 348 million people (Wheatcroft, 1994).

Developing countries in particular have looked to tourism to help increase national foreign exchange earnings, GDP and employment rates, and to improve socioeconomic conditions in peripheral regions (Weaver, 1998). Indeed, during the 1990s many developing regions, such as Southeast Asia, Asia/Oceania and Africa, consistently experienced international tourism growth rates (receipts and arrivals) higher than averages for the rest of the world (Lindberg, Furze, Staff, \& Black, 1998; Ceballos-Lascurain, 1996). In 2000, East Asia/Pacific, the Middle East and South Asia were the three fastest developing tourism regions (World Tourism Organization, 2001).

Even before the events of September $11^{\text {th }} 2001$, the World Tourism Organization (WTO) (2001) was expecting more moderate growth in 2001. Although major world events, like the Gulf War and September $11^{\text {th }}$, have, and will, cause short-term fluctuations in tourism, the overall trend of growth is expected to continue well into the next decade (Chon, 2000). The WTO, in its long-term forecast Tourism 2020 Vision, anticipates an average annual tourism growth rate of $4.1 \%$ until 2020 (World Tourism Organization, 2001). While the difficulty inherent in the measurement of tourism's growth and impact makes accurate statistics scarce (Wells, 1997), the incredible magnitude of the above best estimates serves to demonstrate that tourism is, and will continue to be, a very important global force.

\subsection{Ecotourism and Community Development}

Although nature-based tourism currently represents a relatively small portion of tourism globally, it is recognized to be one of the fastest expanding markets (Scheyvens, 1999; Eagles, 1997). Ecotourism is a sub-market of nature-based tourism that has received much attention in developing countries and 
economically impoverished regions around the world. Ecotourism is an agent of change (Wall, 1997) and, as such, it has been linked to, resource protection policies, protected area conservation efforts, sustainable development initiatives, and regional and community development strategies in many places (Wells, 1997; Ceballos-Lascurain, 1993; Nenon \& Durst, 1993). Indeed, it has been suggested that community development is an essential consideration in the planning of forms of nature-based tourism such as ecotourism (Eagles, 1997).

While no widely accepted definition of ecotourism exists (Campbell, 1999; Weaver, 1998), at a minimum, it is thought to involve travel to natural environments (Eagles, 1998). Others include more restrictive caveats, such as that it must be environmentally and socially responsible travel, that it should support conservation efforts, and that it should improve the welfare of host communities (Ceballos-Lascurain, 1993; Western, 1993). Parks and other forms of protected areas have been among the most common ecotourism destinations (Eagles, 1997; Boo, 1990).

As with any form of tourism, ecotourism can induce a variety of both positive and negative environmental, cultural and socioeconomic impacts at a destination. Operating in its ideal form (according to some), ecotourism provides the tourist with a quality nature experience, generates funds and support for conservation efforts, has minimal environmental impact and provides socioeconomic benefits to local host communities. While there is evidence that ecotourism's espoused benefits can be realized (Mitchell \& Reid, 2001; Slinger, 2000), there are equally as many (if not more) cases where ecotourism has fallen short of its proposed objectives (Walpole \& Goodwin, 2000; Nepal, 2000a; Ross \& Wall, 1999a). Indeed, ecotourism's impact has been highly variable. This thesis is an exploration of the delicate relationships that exist between tourism, nature (protected areas), people and development.

\subsection{Study Purp ose and Research Objectives}

The central purpose of this study is to assess the current status of ecotourism at a destination(s) where it is being promoted as a regional development strategy, through an evaluation of the existing tourism-environment-community relationships and impacts. More specifically, the following research questions are addressed:

- What is the destination's administrative body's definition and expectations of ecotourism?

- What infrastructure, facilities, programs and attractions exist at the ecotourism destination? 
- What is the current state of management at the destination (active/passive, policies, etc.)?

- What are the host communities' perceptions of tourism at the destination?

- What is the relationship between host communities and natural resources at the destination?

- What is the distribution of socioeconomic impacts at the destination, and what are the sources of leakage?

- What benefits have been foregone in providing a tourism product? and

- What strategies could be used to strengthen the tourism-environment-community relationships at the destination?

In exploring these issues, this study is intended to provide planning direction that will enhance the capacity of ecotourism at the destination to generate benefits for both the local community and the destination, and thus contribute to the sustainable development of the region more generally. This thesis focuses on ecotourism, or at least what is being promoted as ecotourism, in protected areas in Hainan Province, China.

The research is also intended, by extension, to contribute to the growing body of tourism literature on the types of impacts ecotourism can have and how they can be evaluated. Furthermore, a case study approach has the capacity not only to produce specific recommendations for the area under investigation, but also to generate broadly applicable results and strategies for allowing communities/destinations elsewhere to improve their capacity to benefit from ecotourism.

\subsection{Thesis Organization}

This thesis is comprised of 7 chapters. Chapter 2 provides contextual background on ecotourism, protected areas, communities and development. Chapter 3 describes the methodology used to carry out this research project, including site selection and justification, data collection and analytical techniques. Chapter 4 outlines the protected area system in Hainan and explores the interpretations and expectations of ecotourism revealed by various officials and protected area managers on the Island. Chapters 5 and 6 present the research findings of the two case studies. Chapter 7 discusses the case study findings with respect to the literature and provides recommendations. 


\section{Chapter 2 \\ Context}

This chapter provides contextual information on ecotourism, communities, development and protected areas. The concept of ecotourism - its roots, definition and potential - is discussed (2.1), before exploring the relationships that exist between (eco)tourism, protected areas and people (2.2). The chapter concludes by identifying the need to assess ecotourism at specific, developing world, destinations, and with an examination of how the phenomenon can be evaluated (2.3).

\subsection{Ecotourism}

Ecotourism is a confusing term. It is a concept that has its roots in the evolution and reform of tourism planning. It is a term that has been widely contested and hotly debated (Wall, 1997; Orams, 1995) by academics and professionals alike. Depending on one's perspective and priorities government, tourist, entrepreneur, etc. - it can be viewed as a philosophy, a strategy, a product, a marketing ploy or a form of travel. The net result of two decades of discussion and experience is that there continues to be little agreement over what exactly ecotourism is.

\subsubsection{Evolution of the Concept}

The onset of a recession in the early part of the 1970s effectively ended the post-World War II boom in tourism growth (Murphy, 1985), providing an opportunity to reflect on two decades of tourism experience. The result was widespread criticism and the recognition that past efforts at tourism 'planning' had largely failed (Baud-Bovy, 1982; de Kadt, 1979). In 1978, the WTO, based on a survey of 'first generation' tourism plans, concluded that close to half of all plans had never been implemented (Baud-Bovy, 1982). Reasons offered for this widespread failure include: a lack of integration of tourism into the whole economy; little attention to qualitative/social impacts; the inability of plans to adapt to changing conditions (Getz, 1986); a focus on physical planning (Spandouis, 1982); and an 'obsessional showing' of the economic benefits (Travis, 1982). What many began to realize was that in exclusively focusing on the positive economic aspects in the past, the many negative environmental, social and cultural impacts that can arise from tourism were allowed to develop relatively unnoticed. At the same time, the idea of 'limits to growth' was gaining 
popularity (Murphy, 1985), causing some to suggest that more attention needed to be devoted to the economic 'disbenefits', and social and environmental costs of tourism (Travis, 1982).

Partially in response to growing criticism, the World Bank, in association with UNESCO, sponsored a conference in 1976 on the cultural and social impacts of tourism. Out of this conference, came a call for more "vigorous, active, and widespread planning and intervention" (de Kadt, 1979, p.9). Many of the critics from this period echoed similar sentiments. de Kadt (1979) argued for a more proactive, equitable and participatory approach to tourism planning. He suggested that in order to gain the greatest net social benefit, planning that was more closely integrated with broader national policies and that had the mandate to examine alternative tourism development options was required. Baud-Bovy (1982), recognizing the complexity of the tourism industry, called for a more integrative planning process in which, among other things, the opinions of all those affected by a tourism development could be heard. He also supported the addition of monitoring systems to the tourism planning process, reflecting a desire to move away from the static nature of the earlier, often failed, master plan approach. Gunn (1979) was also very critical of the fragmented, purely economic approach of the relatively few, in his opinion, planning efforts up to that point. To promote greater integration, he postulated that planning should be a continuous process of communication, feedback and collaboration among public and private organizations. To supplement 'continuous planning', he suggested that 'regional strategic planning', based on traditional/rational approaches, should also be applied to tourism. Its role would be to provide technical/expert guidance on the physical and program aspects of specific regional tourism planning activities. A two-tier approach would allow for the three goals of tourism planning - satisfaction of users, rewards to owners and protected utilization of resources (Gunn, 1979) - to be more easily met.

The advancement of 'integrated' approaches to tourism planning during the 1980s was an effort to re-orient and more comprehensively define tourism (Gunn, 1988; Murphy, 1985). Ideas on integration that began in the 1970's were more fully articulated during this decade. Baud-Bovy (1982) suggests that one of the major reasons behind the widespread failure of tourism plans up until that point had been the insufficient detail given to problems that arose during the implementation phase. He highlights three 'interdependencies' in tourism - between tourism development and socioeconomic development; between the various elements of the tourism sector itself (resources, markets, infrastructure, people, etc.); and between tourism and outdoor recreation. He suggested that the success of plan implementation would be greatly improved by taking an approach that considered 
these interdependencies. He emphasized that tourism plans must be framed within the context of broader national socioeconomic policies and linked more to the other sectors in the economy (e.g. transportation, construction, industry, etc.) that tourism relies on. There was also an obvious need to better integrate tourism development with site carrying capacities and conservation efforts. Finally, he cited the potentially significant impact that tourism can have on culture and people as cause for greater planning sensitivity and the involvement of all concerned parties in the planning process.

In what was arguably to become one of the most influential works in tourism, Murphy (1985) advocated a community-based approach to tourism, in which there was a shift from an expert driven, technocratic process to a more small-scale, humanistic one. His ideas were a formalization of the growing awareness that the tourism industry was very much dependent on host communities, and that there was a need for greater integration in planning at both regional and local levels. The post-war emphasis on economics had meant that local communities, which typically provided the tourism product and had to "live with the consequences" (p.153), were often ignored. He suggested that by integrating tourism planning with established planning processes, a harmony between industry development and a destination's physical and human capacities could be achieved. A community approach "expected and encouraged" public participation, recognizing that locals, as hosts and tourists themselves, could contribute a wealth of information to planning processes (p.171). He characterized this approach using an ecological analogy, in which tourism, like an ecosystem, was a system of interacting living (tourists and hosts) and non-living (landscapes) elements seeking some sort of balance (symbiosis). He went on to suggest that the widespread use of systems theory in urban and regional planning at the time provided the ideal vehicle for operationalizing an ecological community approach. Each was concerned with "complicated systems where components exhibit a high degree of interdependence" (p.173). The flexibility of a systems approach would allow tourism planning to be integrated with other planning activities at both regional and local levels. He suggested that such an approach was also well suited to tourism in its use of continuous monitoring to detect system stresses.

Despite twenty years of criticism, new ideas and signs of change, Gunn (1988) still characterized tourism planning at the end of the 1980 s as being predominantly concerned with promotion and driven by economic goals. Arguably it is still so today. Overall, the emphasis has been predominantly on plan development, and to a lesser extent implementation, with relatively little attention having been given to subsequent monitoring (Pearce, 2000). Others suggested that most 
plans had been little more than marketing plans, and that a lack of co-ordination between tourism 'players' had resulted in disunity and poor integration in tourism developments (Gunn, 1991). In turn, poorly planned tourism had alienated local populations, brought economic hardships and caused ecological damage (Cork, 1995).

However, there was a growing emphasis being placed on the social, environmental and cultural aspects of tourism. Out of the most critical observations of past practice, a new vision of future tourism planning was beginning to form. Notions of 'sustainable development' that were hatched in the Brundtland Commission's report on environment and development in 1987 were also to find widespread support during the 1990s. The idea that economic growth could serve to both stimulate development and protect the environment appealed to governments, academics and grassroots organizations alike. While 'sustainable development' was not intended to be a planning tool, it can serve as a catalyst for promoting discussion on how development and environment ought to be balanced (Wall, 1997). The philosophy was well suited to tourism, and has arguably had a major influence on how planning has been viewed. This is evident, to some extent, in the proliferation of 'alternative' forms of tourism, including community-based tourism, cultural tourism, sustainable tourism, nature-based tourism, ecotourism etc., that occurred during this period.

\subsubsection{Defining Ecotourism}

Ceballos-Lascurain, in the early 1980s, was one of the first writers to use the term 'ecotourism'. It was subsequently popularized in Boo's seminal work, Ecotourism: The Potentials and Pitfalls (Boo, 1990). He defined ecotourism as:

tourism that consists in traveling to relatively undisturbed or uncontaminated natural areas with the specific objective of studying, admiring, and enjoying the scenery and its wild plants and animals, as well as any existing cultural manifestations (both past and present) found in these areas. In these terms, nature-oriented tourism implies a scientific, aesthetic or philosophical approach to travel... The main point is that the person who practices ecotourism has the opportunity of immersing himself/herself in nature in a manner generally not available in the urban environment. (Ceballos-Lascurain, cited in Boo, 1990, p.2)

More recently, Eagles (1997) has similarly defined ecotourism as "travel for the discovery of and learning about wild natural environments." (p.2). This emphasis on travel to natural places has perhaps been the only consistent element in the debate over ecotourism. Some distinguish ecotourism 
from nature-based tourism in that the former should be small-scale tourism with limited negative impact, whereas the latter is not defined by scale but rather by its focus on nature (Brandon, 1996).

As ecotourism has matured, its impacts have become more evident, and in some instances have been indistinguishable from mass tourism, and definitions have become more elaborate (Campbell, 1999). It is now generally thought to be more complex than "just tourism to natural areas" (Ross \& Wall, 1999b), and is increasingly defined to include aspects of resource conservation and local development. The Ecotourism Society defines ecotourism as "responsible travel to natural areas which conserves the environment and improves the welfare of local people.” (Western, 1993, p.8). Numerous similar definitions that include a community development and/or conservation component can be found in the literature (Cater, 1994; Norris, 1992; Whelan, 1991; Ziffer, 1989). For this study, the quite specific World Conservation Union (IUCN) Commission on National Parks and Protected Areas' (CNPPA) definition of ecotourism has been adopted. The revision of ecotourism's original definition, by the same author, aptly reflects the evolution that the concept has undergone since the early 1980s:

environmentally responsible travel and visitation to relatively undisturbed natural areas, in order to enjoy and appreciate nature (and any accompanying cultural features - both past and present) that promotes conservation, has low visitor impact, and provides for beneficially active socio-economic involvement of local populations (Ceballos-Lascurain, 1993).

Miller and Kaae (1993) have developed an ecotourism continuum (Figure 2.1) upon which the diverse range of definitions that have been put forth can be placed. At one extreme, it is held that all tourism is ecotourism; human beings, like any other living organism, do not have an obligation to consider other living things, and are therefore incapable of unnatural or immoral behaviour. At the other extreme, is the notion that ecotourism is impossible, because all forms of tourism will have negative impacts to some extent on the natural environment. Both extremes represent unrealistic views, with the reality being that most interpretations of ecotourism fall somewhere between the two poles, and are perhaps better thought of in terms of levels of human responsibility (Orams, 1995). High human responsibility definitions include those that stipulate ecotourism must involve active contribution towards conservation and/or the improvement of host community welfare. Low human responsibility, or passive, definitions do not require a behavioural change from the participant, but only that the activity be unobtrusive and not cause negative environmental impact. 
Low Human

Responsibility Pole

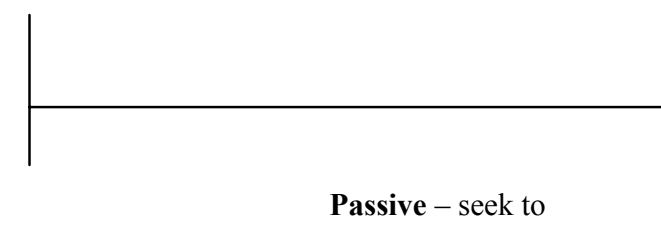

All tourism is

minimize damage
High Human

Responsibility Pole

ecotourism

\section{Active - contribution}

to protect resources

Ecotourism is impossible

\section{Figure 2.1: The Continuum of Ecotourism Paradigms}

Source: Adopted from Orams, 1995

Two decades of definitions and debate have done relatively little to clarify the meaning of ecotourism. It is also doubtful that there will be any widespread agreement in the immediately foreseeable future. At the same time, one finds a substantial portion of the current research agenda preoccupied with semantics (Weaver, 1998). With terms such as sustainable tourism, communitybased tourism, responsible tourism and alternative tourism thrown into the academic ring the confusion runs even deeper. Although site level managers must have sufficient understanding of terminology in order to operationalize definitions for the purposes of data collection, outside of academia, terminology is of less concern. It is the actual manifestation of tourism on the ground that must be managed, regardless of its specific original intended form (mass, eco, community, etc.). Perhaps tourism, in all its forms, is better, or at least more simply and realistically, thought of in terms of objectives - objectives which are scale and site specific, and against which the success, or lack thereof, of tourism in a region or at a destination can be measured. 


\subsubsection{Benefits of E cotourism}

Behind a comprehensive definition of ecotourism, like the one adopted in this study, lie high expectations (objectives) for the generation of a wide variety of benefits. Those frequently associated with ecotourism include the following:

- Its ability to provide high quality tourism experiences;

- Its ability to stimulate national and/or local economic development (Wells, 1997);

- Its ability to diversify/complement the economic base (Notzke, 1999);

- Its ability to create social benefits and infrastructure improvements (Brandon, 1996);

- Its ability to generate funds for the management and conservation of natural areas (Weaver, 1998);

- Its ability to provide economic justification for protection of natural resources (Boo, 1990);

- Its ability to foster environmental awareness/values and support for conservation, among both local residents and tourists, through on-site educational opportunities (Ross et al., 1999a); and

- Its ability to promote cultural preservation (Slinger, 2000).

Arguably, as the definition (objectives) of ecotourism becomes more complex and inclusive, it will be increasingly difficult to realize. However, there is evidence to suggest that ecotourism's (or similar forms of 'alternative' tourism) touted benefits can indeed be realized. Eagles et al. (2001) provide a number of case studies in which protected area tourism has helped to generate conservation and community benefits. Mitchell and Reid (2001) found that community-based tourism on Taquile Island, Peru has had some success in terms of retaining benefits and local control over tourism. Slinger (2000) reviews a case where an indigenous community in the Caribbean worked successfully to develop ecotourism that links economic goals with natural resource protection and cultural preservation. Hatton (1999) reviews a number of community-based tourism cases in the Asia-Pacific region that have generated socioeconomic and environmental benefits. Norris (1992) observes that ecotourism in Rwanda's Parc des Volcans has helped to protect the country's endangered mountain gorillas and local watersheds. 
Although there are success stories, to date, more cases where ecotourism has fallen short of its proposed objectives have been reviewed in the literature. In a study of the distribution of local economic impacts arising from Dragon tourism to Komodo National Park, Indonesia, Walpole and Goodwin (2000) found high levels of revenue and employment leakage (loss of economic benefits from the local area hosting the tourism to outside, distant regions). In a review of tourism to protected areas in the Nepalese Himalaya, Nepal (2000) found an inequitable distribution of economic benefits among local villages and 'outside' areas. Ross and Wall (1999b), in an evaluation of ecotourism in three protected areas in North Sulawesi, Indonesia, found that host communities are "enjoying very few benefits from the tourism development, and the natural ecosystems are not being well-protected." (p.680). Also in North Sulawesi, Lee (2000) found a similar lack of local benefits and high leakage at Bunaken National Marine Park. Even in cases where conditions seem well-suited to developing successful ecotourism - strong community organization, positive perception and support for tourism, presence of a pristine natural environment - it has been found that obstacles to fully realizing benefits still exist (Place, 1991).

Arguably, true ecotourism should operate without any associated negative impacts. However, the reality has been that a variety of socioeconomic and environmental problems, to varying degrees, have arisen in most cases. In essence, poorly developed (eco)tourism results in the exact opposite of the espoused potential benefits, including social/community disruption, environmental degradation, cultural deterioration, reduced economic opportunities and increased dependence on a single industry (Nepal, 2000b; Weaver, 1998; Nenon et al., 1993; Place, 1991; Boo, 1990; Mathieson \& Wall, 1982). This in turn may lead to local resentment towards tourism and tourists (D'Amore, 1983; Doxey, 1976), and will ultimately detract from the tourism experience offered.

While some countries and destinations have benefited from ecotourism, the fact that others have not has led some to conclude that significant gaps exist between ecotourism's potential and actual contributions in many areas (Nepal, 2000b; Ross et al., 1999b; Brandon, 1996; Wells, 1997; Lindberg, 1991; Ziffer, 1989). Nevertheless, countries and regions continue to turn to forms of nature-based tourism and ecotourism as a means of contributing to national, regional, and local development. Given this, one must ask if such tourism is really contributing to sustainable development. What have the socioeconomic, cultural and environmental impacts been? Are the espoused benefits of ecotourism being realized? While these questions have been addressed to some extent in the literature (Walpole et al., 2000; Ross et al., 1999a), Ross and Wall (1999a) have 
criticized the lack of practical assessments of ecotourism's status in specific areas. Indeed, relatively few assessments of ecotourism's impacts at the local level (Lee, 2000) have been performed. To address this research need, the impact of ecotourism at specific destinations in developing areas should be examined.

\subsection{Ecotourism, Protected Areas and People}

Tourism and parks have long had a connection (Boyd, 2000). However, in recent years, the relationships between nature and eco-tourism, parks, people and economics have received heightened attention from academics, as well as both government and non-government conservation and development agencies in many nations. (Nepal, 2000a; Cresswell \& MacLaren, 2000; Brandon, 1996; Wang, 1993; Boo, 1990). Some have even suggested that the relationships are reciprocal - tourism needs parks and parks need tourism (Ceballos-Lascurain, 1996). A variety of socioeconomic reasons are responsible for this interest. Consider the following three trends.

Facing increasing environmental destruction, ecosystem degradation, habitat disappearance and biodiversity decline, most nations have made efforts to protect some portion of their remaining natural spaces (Woodley, 1999). At the same time, competition for, often scarce, resources, is making it increasingly difficult for governments to rationalize the allocation of large areas of land and water for protection. Additionally, in recent years there has been widespread government financial constraint, with environment-related programs and initiatives often being first on the chopping block. Government-run conservation agencies are now facing budget constraints in many places (e.g. Loon \& Polakow, 2001). National parks in developing countries in particular are suffering from funding shortages (Norris, 1992).

With government expenditures falling under ever closer scrutiny, there also exists a growing demand for economic rationalization in public institutions (Outspan Group, 2000). The combined effect in many places has been that protected area systems are under pressure to find new and innovative ways to generate funds for management and conservation (Boyd, 2000). At the same time, there is a growing requirement to provide economic justification that the benefits of protection exceed the associated management and opportunity costs (Dharmaratne, Sang, \& Walling, 2000; Sherman \& Dixon, 1991). Failure to demonstrate financial viability in the face of rising opportunity costs carries the risk of having protected areas converted to other, typically more exploitative, land uses (Loon et al., 2001). 
Secondly, ecotourists are motivated by a desire to observe and learn about tropical forests, mountains, birds, mammals, etc., preferably in an undisturbed wilderness setting (Eagles, 1992). Such settings are often to be found in protected areas. Growing demand for nature-based travel experiences (Scheyvens, 1999) has made parks and protected areas some of the most popular (eco)tourism destinations (Ceballos-Lascurain, 1996; Boo, 1990). Others have noted that this interest in park tourism is unlikely to subside in the near future (Boyd, 2000). In particular, many international tourists are attracted to the 'natural wealth' of the developing countries (Hummel, 1994, p.17).

Thirdly, the protection of biodiversity and provision of public use have long been objectives of national parks (Hvenegaard \& Dearden, 1998). However, in recent years, mandates have also shown increasing support for linking park management and conservation strategies with the needs of local communities that surround protected areas (MacDonald \& Aumonier, 1998; Boo, 1990). Many of the threats protected areas face arise from the needs of local populations to use resources to survive (Norris, 1992; Sherman et al., 1991). Park creation can cause abrupt change for rural, traditionally resource-based, economies (Place, 1991), and often results in reduced access to resources and resident relocation (Lindberg, Enriquez, \& Sproule, 1996). As Wall (1994) notes, "poor people can not afford to be conservationists" (p.8) and, therefore, if ecotourism is to benefit protected areas, it must also benefit local people (Cresswell et al., 2000; Boo, 1990). Indeed, it is now generally recognized that communities and protected areas can not co-exist in the absence of local support for the conservation objectives of the protected area (McNeely, 1992). These considerations are particularly acute in developing countries. The result has been that tourism has come to be widely viewed as a positive means of improving people's standard of living (World Tourism Organization, 1997), principally through the stimulation of economic growth in peripheral areas (Boo, 1990).

\subsubsection{The Potential Benefits}

In light of the above trends, it is not surprising that many have noted that opportunities exist for linking tourism and protected areas for mutual benefit, especially in a developing world context. Widespread support and hopes for mutual tourism-park socioeconomic benefits are aptly reflected in the recommendation of the IVth World Congress on National Parks and Protected Areas (CNPPA) that "global, national and local agencies and organizations concerned with protection of natural areas adopt policies to make tourism a conservation tool." (McNeely, 1992). This is recommended based on CNPPA's belief that "tourism associated with protected areas (can) serve as a tool to advance 
protected areas' objectives for maintaining ecosystem integrity, biodiversity, public awareness, and enhancement of local people's quality of life.” (McNeely, 1992).

The theory behind mutual benefits is relatively straightforward. Parks provide a setting and opportunity for people to recreate and enjoy nature. In a sense, natural ecosystems are the product base for much tourism and it is therefore in the interest of those in the industry to protect that base (Woodley, 1999) in order to maintain its attractiveness to tourists (Ceballos-Lascurain, 1996). In return, tourism to protected areas induces environmental stewardship among visitors and helps to build a conservation constituency for a location; a constituency that provides both moral and financial support. Tourism also generates revenue - through entrance fees, concessions, souvenirs, donations, etc. - that can be channeled back into the management and conservation activities of the protected area agency. In turn, tourism revenues can indirectly induce greater government and donor agency funding at a site (Lindberg et al., 1996). Travel activity also improves the welfare of people living in communities surrounding the protected area by providing employment opportunities and, more generally, by diversifying the local economic base (i.e. direct benefits). Further indirect socioeconomic community benefits are stimulated through infrastructure and service improvements and secondary spending of tourism-related income among local residents and businesses (Figure 2.2). Community benefits resulting from protection encourage local residents to act as environmental stewards and actively support conservation at the site. At the same time, tourism can help to promote greater community empowerment and local pride (Whelan, 1991). Taken together, the potential direct and indirect benefits generated by protected area tourism can provide a powerful economic and social justification for the continued protection of natural resources in a region (Dharmaratne et al., 2000; Brandon, 1996). For these reasons, some have noted that tourism has in many countries played a major role in the establishment of parks and protected areas (Loon et al., 2001; Lindberg et al., 1996).

\subsubsection{The Potential Problems}

The description in the preceding section represents the ideal dynamics of a tourism-park-community relationship. While the theory may be straightforward, others have noted that the actual manifestation of tourism in protected areas is anything but straightforward (Woodley, 1999). Those that have explored the potential benefits of such relationships have also typically tempered their discussions with cautionary comments. Is ecotourism truly 'the national parks' dream?' (Norris, 1992). The economic, tourism and community welfare considerations that have brought parks and tourism 


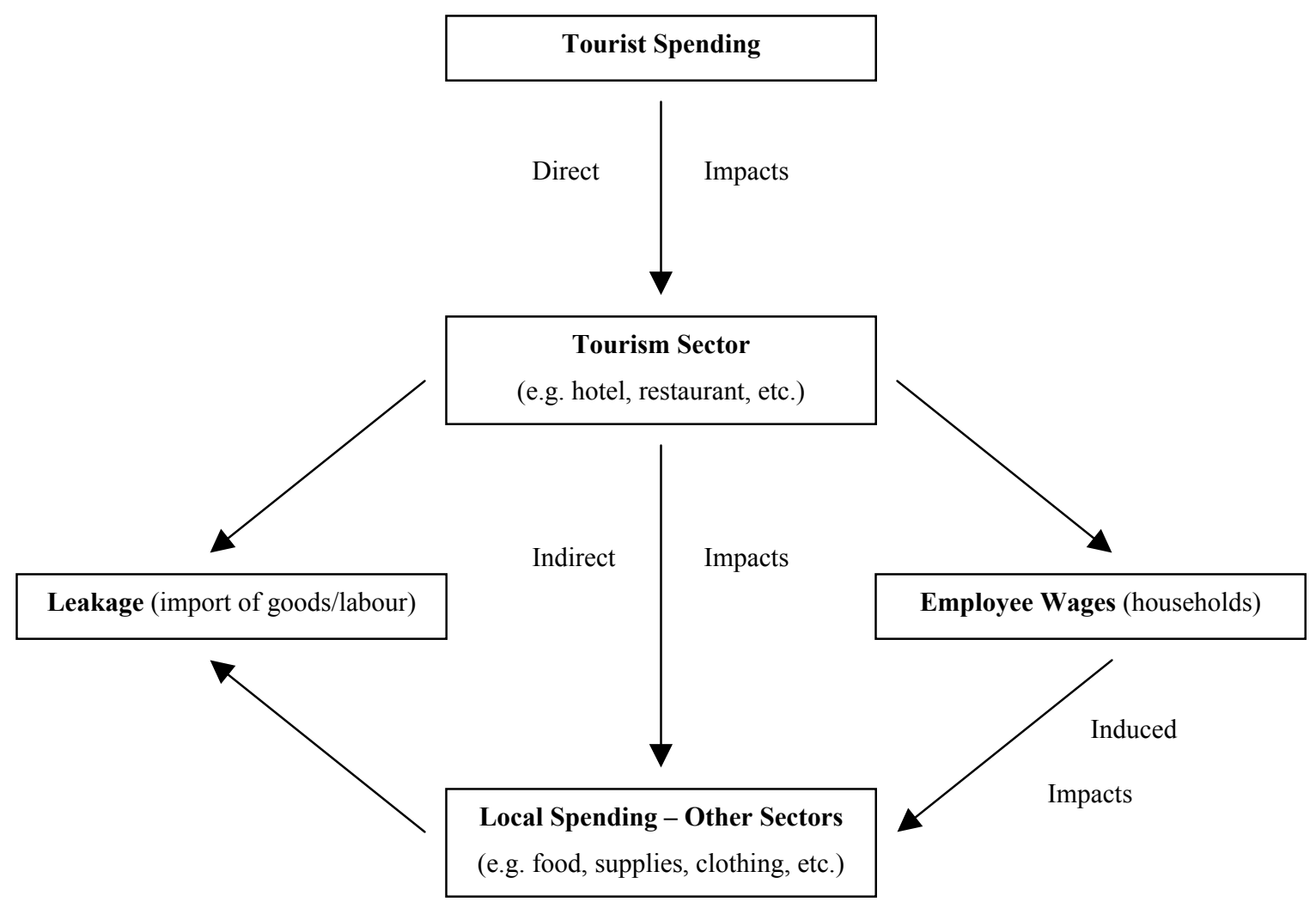

Figure 2.2: Tourism's Economic Impact

Source: Adopted from Lindberg, Furze, et al., 1998

together also provide the basis for a discussion of the potential problems of protected area tourism.

In terms of tourism's ability to generate funds for management and conservation, some have noted that although protected areas supply the most valuable part of the nature experience, they often capture little of the economic value potentially associated with tourism (Wells, 1997). Part of the problem is that despite a documented willingness on the part of tourists to pay for nature experiences (Hvenegaard et al., 1998), protected area use fees, (especially in developing countries) are often nominal (Wall, 1994; Lee \& Snepenger, 1992) or absent altogether (Lindberg, 1991). Others note 
that charging use fees can be a controversial policy, raising issues of equity, accessibility and abilityto-pay (Boo, 1990), and may even result in tourism industry opposition (Lindberg et al., 1996).

Supposing ecotourism's economic conservation benefits could be realized, it is important to recognize that a relatively small minority of protected areas have the characteristics required accessible spectacular scenery and large mammal viewing opportunities with adequate infrastructure - to attract a significant number of tourists (Cresswell et al., 2000). Many sites are too remote, have wildlife that is too elusive, are not actually protected/managed or offer few spending opportunities, prompting some to question whether or not ecotourism can help in such cases (Norris, 1992) (Lindberg, 1991; Boo, 1990). Furthermore, ecotourism, according to some, is small-scale, consisting of relatively few visitors and small group sizes (Wall, 1994). Can significant revenues be generated in such situations? Although every case is unique, there is some recent evidence to suggest that relatively low levels of visitation can raise substantial revenues (Eagles, McCool, \& Haynes, 2002).

The financial contributions to conservation that might be expected from nature-loving ecotourists have been shown to be more significant at a tourist's place of origin, with actual on-site contributions being relatively small (Hvenegaard et al., 1998). These problems may be aggravated by regulations requiring the remittance of any revenues generated at a protected area to a central treasury, rather than funds being retained on-site by the managing agency (Brandon, 1996; Lindberg, 1991). Finally, tourism also has associated costs - operating, environmental, etc. - some of which are difficult to assess or distinguish from non-tourism activities, but nevertheless must be considered to determine the net economic impact at a protected area (Lindberg et al., 1996).

While the potential for tourism to contribute to conservation exists, the economic justification for protected areas is limited by several key factors. The reality is that measuring tourism's economic contribution (especially indirect impacts and non-use values) is very difficult, with the result that few reliable studies of nature tourism's impacts have been completed (Wells, 1997). While part of the problem lies in semantics - different interpretations of what 'nature' tourism includes - greater difficulty is perhaps found in physically distinguishing between nature tourism's impacts from other forms of tourism and from non-tourism economic impacts at a destination (Lindberg, 1991).

Furthermore, some have noted that it is no longer sufficient merely to illustrate protection benefits on paper (assuming these can accurately be shown), but that increasingly, a greater portion of these benefits will actually have to be recovered to help cover management costs (Dharmaratne et al., 2000). 
Although it is generally accepted that protected areas provide suitable and increasingly popular settings for ecotourism, it is equally important to recognize that other forms of tourism may also be appropriate in parks (Boyd, 2000). Others have made similar observations, noting that not all park tourists are ecotourists (Hvenegaard et al., 1998), that not all ecotourism is sustainable, and that not all sustainable tourism takes place in natural areas (Wall, 1994). Identifying the types and level of tourism that are appropriate at a protected area is one of the key park tourism management issues that must be addressed (Valentine, 1992). Some question more fundamentally whether park-based tourism is sustainable, highlighting that from an ecosystem perspective tourism is an industry with environmental impacts, 'just like mining or forestry' (Woodley, 1999, p.160). Indeed, the areas typically sought by ecotourists - remote, pristine and undisturbed wilderness - are often the areas most vulnerable to damage (Wall, 1997), causing some to wonder if ecotourists are not actually more environmentally demanding than mass tourists on a per capita basis (Wall, 1994). Others have suggested that nature-based tourism may be " 'internally contradictory', because 'in order to generate substantial revenue the number of tourists has to be large.' "(Cresswell et al., 2000, p.285).

Recognizing a host of potential impacts, and that ecotourism can detract from as well as contribute to conservation, has caused some to caution that the impacts of ecotourism must be carefully examined against a protected area's mandate before being promoted at a site (Hvenegaard et al., 1998).

Although tourism has the potential to help meet the needs of destination communities through the provision of economic alternatives in isolated and rural areas, people-park relationships are complex, and a number of important issues must be considered. The acknowledgement of the need to address local community needs at park tourism destinations is also generally accompanied by a call for public involvement in the planning process. Indeed, the generation of benefits in conservation-development projects is highly dependent on effective local participation (Campbell, 1999; Wells \& Brandon, 1992). The degree of participation in decision making may directly affect local attitudes towards tourism (Lindberg et al., 1996). Unfortunately, communities adjacent to protected areas have, in practice, frequently been overlooked (Ceballos-Lascurain, 1996; Whelan, 1991). The exclusion of local people in such processes is a major problem, and a key reason behind poorly integrated conservation and development projects that degrade the resource base and reduce tourism's potential at a destination (Cresswell et al., 2000). More effort is needed to involve communities in the tourism development process (World Tourism Organization, 1997), including active participation in the "establishment, management and monitoring of protected areas." (McNeely, 1992, p.81). While the importance of local involvement is widely espoused and generally accepted as good practice, others 
have noted that it is typically a time consuming and difficult process, and one that may be resisted by governments over perceived threats to their authority (Wells et al., 1992). Others have cautioned that it is risky to assume that local people are in a position to make appropriate decisions (Boyd, 2000). Debate over if, and how, local people can be involved has made participation in tourism and protected area planning a very contentious issue.

Public participation issues aside, a host of other problems may be encountered in a tourism-parklocal community context. In such situations there is a danger of prematurely raising the expectations of the community, recognizing that financial viability (and the associated economic benefits) may not occur in the short term, if at all (Loon et al., 2001). Although ecotourists often spend significant sums of money, much of this spending occurs at their place of origin; the often remote locations of interest to ecotourists typically have only basic infrastructure and little for sale, resulting in low levels of spending at the destination (Wall, 1994). Retention of economic benefits at the local level is indeed a major problem (Cresswell et al., 2000; Lindberg, 1991). Off-site spending and high levels of outside investment and goods importation increase the potential that tourism-generated economic benefits will leave the local community. The World Bank estimates that close to $55 \%$ of developing world tourism profits leak back to the developed world (Norris, 1992). Lindberg (1991) provides examples of nature tourism destinations where approximately $90 \%$ of every tourist dollar spent leaves the host community.

Even if economic benefits are stimulated and retained locally, these are often inequitably distributed among community members (Hummel, 1994; Lee et al., 1992), due to existing, pretourism development and income disparities (Nepal, 2000a). Disparities create the potential for social stratification and unrest between and within communities (Nepal, 2000b). Employment opportunities for local people arising from ecotourism may be limited due to the low variety of jobs created guides, guards, cooks, porters, drivers, etc. (Brandon, 1996). If locals are to benefit from ecotourism they must have opportunities to receive training and gain access to capital (Wall, 1994). Unfortunately, outside companies, and arguably governments, are typically unwilling to invest the time or resources necessary to allow locals to acquire the requisite skills necessary to be able to participate more actively in ecotourism developments (Brandon, 1996). Rapid tourism growth can, somewhat paradoxically, limit opportunities for locals to get involved in the tourism business if outside investment outpaces local capacities to accumulate capital for investment or to acquire training (Place, 1991). These problems are aggravated, for both communities dependent on tourism 
and protected area managers in need of funds, by the fact that tourism can be an unstable source of revenue, subject to seasonal fluctuations in visitation, weather, economic leakage and political factors (Norris, 1992).

The diversity of problems facing tourism destination communities - lack of knowledge and training, access to capital, ownership rights, outside competition, leakage, etc. - has led some to conclude that "relatively few local communities have realized significant benefits from nature tourism on their own lands or in nearby protected areas." (Wells, 1997, p.iv). In the absence of some degree of short-term, tangible, benefits, local communities will remain indifferent, at best, to long-term tourism development activities (Nepal, 2000a). As noted earlier, communities that are not receiving benefits can not realistically be expected to support protected areas or conservation efforts. In turn, a lack of benefits may force local people to pursue more resource exploitative activities in order to be able to sustain themselves.

\subsubsection{Bridging the Gap}

Recognizing that ecotourism has not lived up to its full potential in many places, critics have promulgated a variety of strategies designed to help capture a greater proportion of ecotourism's espoused benefits, thus strengthening the tourism-park-people relationships at a destination. An examination of general planning considerations is followed by a discussion of a number of more specific measures.

\section{- Planning and Management}

Successful ecotourism will not materialize on its own. Numerous authors have stressed the importance of careful planning and management if ecotourism is to develop in a beneficial manner at a destination (Boyd, 2000; Boo, 1991; Lindberg, 1991). The failure of many countries to fully exploit the potential benefits of nature-based tourism, to a large extent, has resulted from the low priority assigned to planning and ineffective management (Ceballos-Lascurain, 1996). Boo (1991) highlights the importance of 'preplanning', where various government representatives, with input from the private sector, international funding agencies, native communities and conservation groups, assess whether or not ecotourism is compatible with a nation's development goals. If deemed appropriate, she recommends that an 'Ecotourism Board', with diverse representation, be established to further investigate potential sites, draft an ecotourism strategy, and oversee planning and development. 
Lindberg (1991) makes a similar recommendation, adding that a national board would also determine site visitation levels and fees so as to maximize profit without exceeding a site's carrying capacity.

Ceballos-Lascurain (1996) also discusses the importance of basic planning processes, outlining the standard steps used to produce and implement a tourism plan - preparation of the terms of reference, defining objectives, inventorying existing and potential resources, data analysis, alternative policy formulation, plan adoption, implementation and monitoring. He also emphasizes the need for collaboration between and within different tiers of government, the tourism industry, NGOs, financial institutions, consumers (the tourists) and local communities.

Boyd (2000) identifies some general planning criteria necessary for promoting sustainable tourism development within parks. In light of increasing pressures on natural areas to provide tourism opportunities, tourism planners, although constrained by short-term political mandates, must strive to take a long-term perspective. Planning should be proactive, including the identification of the types, levels and locations of appropriate tourism activities, and the formulation of strategies to address a variety of potential problems. Recognizing that tourism is but one possible land use within a park, planning should also be integrative.

In terms of management, Ceballos-Lascurain (1996) stresses the need to assign tourism management the highest priority in protected areas, recognizing that tourism is a business and that failure to raise revenues and generate community benefits from a tourism venture will create a host of problems for a park. In order to help ensure benefits for all parties, a tourism management strategy and plan for protected areas receiving tourism is absolutely essential (Ceballos-Lascurain, 1996; Boo, 1991). Also recognizing the importance of tourism management in protected areas, Valentine (1992) identifies five main issues for managers:

1. Defining appropriate types of tourism for protected areas;

2. Defining suitable relationships between park managers and tour operators;

3. Establishing partnerships between tourism, protected areas and local communities;

4. Monitoring and minimizing the impacts of tourism on protected areas;

5. Establishing the appropriate carrying capacity levels. 
Acknowledging that tourism in protected areas is "fundamentally problematic" (p.178), Boyd (2000) identifies three key management principles. One, clear lines of responsibility and accountability must be defined among those in charge of managing protected areas and tourism. Two, the diversity of activities that may occur within parks requires managers to take an interdisciplinary perspective, and to remain open to multiple viewpoints and ideas. Three, park tourism management must be integrated with the strategies that exist to manage activities that occur outside, and thus may exert an influence on, protected areas.

\section{- Influencing Tourist Spending}

Devising ways of encouraging tourists to spend larger sums of money at park tourism destinations has the potential to increase both protected area revenues and the pecuniary contributions made to the local community. Hvenegaard and Dearden (1998) recommend encouraging tourists to lengthen their stay in the park and to purchase local products and services (guiding, transportation, etc.) in order to enhance rural development. They also suggest that park authorities should design suitable donation mechanisms in order to capitalize on the apparent willingness of nature tourists to contribute to conservation. Recognizing that it is difficult to spend money in the wilderness, where facilities are often limited (Wall, 1994), Lindberg (1991) suggests that tourists will spend more if they are only given the opportunity. Improving infrastructure and developing new tourist facilities - visitor centres selling interpretive media, food concessions, lodgings and souvenirs for example - may not only induce greater spending, but also serve to encourage tourists to return in the future, thus generating more entrance fee revenues.

\section{- Raising Revenues and Retaining Benefits at the Site}

Lindberg (1991) provides a detailed discussion of how demand curves, competition factors and price mechanisms can be used to set entrance fees that reflect an attraction's value and maximize nature tourism's financial contributions, while limiting the number of visitors at a site to an optimal level. In theory, fees can be raised until excess demand disappears. However, demand curves can be difficult to estimate, especially for a new site, in the absence of historical market data. The ability to set appropriate fees may also be hampered by issues of equitable access to a site for locals that cannot afford to pay. Fortunately, methods do exist for estimating demand curves - willingness-to-pay (WTP) surveys and other contingent valuation methods (CVM) have been used with some success (Outspan Group, 2000; Lee, 1997; Wells, 1997). Furthermore, many countries have successfully instituted multi-tier fee structures that allow locals access to their natural heritage through low fees, 
yet generate revenues by charging foreign visitors more. The overall message is that many destinations, that currently charge nominal or no fees could increase revenues by raising entrance fees.

Aside from visitor fees, Sherman and Dixon (1991) discuss the potential of three other important revenue generating mechanisms. Fees for licenses and lease rights can be charged to individuals and firms that provide services - food, lodging, retail, etc. - to tourists. There is also the potential to charge royalties for products such as films, books and photographs that were produced at the protected area. Taxes can also help to generate additional revenues for a site. Hotel rooms, popular attractions, and the sale of tourist-related goods have all been taxed in some places to raise funds for site maintenance and conservation.

If tourism is to produce benefits for a protected area, it is imperative that an efficient mechanism exists for channeling funds generated back into the park and surrounding communities. While such mechanisms are very site-specific, earmarking revenues for use in park operations, conservation or community development is one method of ensuring tourism-generated funds are retained at a site (Lindberg, 1991; Sherman et al., 1991). Earmarking also has the potential to increase future revenues recognizing that tourists may be willing to pay higher entrance fees if they are confident that the money is to be used to conserve the site they have visited (Lindberg, 1991).

Recognizing that capturing and retaining tourism-generated benefits is a major problem, Lindberg (1991) and Sherman and Dixon (1991) have stressed the importance of using locally produced goods and services whenever possible. Benefit leakages can further be minimized if the host government has the flexibility to impose conditions on imported goods and services - for example, requiring foreign investors to train and employ local residents in exchange for the privilege of opening a hotel or some other facility (Lindberg, 1991). Indeed, maintaining some degree of national control over the industry, through direct public management or the leasing of site management rights to a private enterprise, allows a government the flexibility to manage the tourism industry in a manner that maximizes destination community benefits (Sherman et al., 1991). Similarly, Loon and Polakow (2001) discuss the advantages of ecotourism joint ventures over solely foreign invested developments, where communities have a vested interest and role to play. Training programs can further help to retain benefits, by providing local workers with the skills required for employment in the industry, and should be considered before importing workers from more distant regions (Sherman et al., 1991). 
Market access issues are also of the utmost importance in attempting to maximize local community benefits (Ashley, Roe, \& Goodwin, 2001). Local opportunities to access the market, and thus to benefit from tourism, are influenced by a number of factors, including:

1. Where you are - the location of amenities and activities in relation to the community;

2. Who you are - opportunities and ability to participate in decision making regarding tourism developments;

3. What you know - local understanding of how the industry functions; and

4. What you have - the ability of locals to secure financial and physical assets to be able to enter the tourism sector.

\section{- Compensation}

Acknowledging that local communities often bear the highest costs where resources are protected and a tourism product provided (lost access to resources, land, etc.), some have suggested that compensation may be appropriate (Sherman et al., 1991). Compensation may take a variety of forms, but might include a portion of protected area revenues going to communities or the development of alternative resource supplies outside of the protected area - such as woodlots, plantations, captive breeding areas, etc.

\section{- Education}

Education is an extremely valuable tool for protected area and tourism managers. It can enhance the tourist's experience, direct appropriate behaviour, foster stewardship (Ross et al., 1999b), encourage tourists to return in the future or to donate money to continue educational and conservation programs (Lindberg, 1991). In order to bolster park-tourism support, it is also useful to educate local communities about the importance of conservation and the associated, potential, monetary and nonmonetary benefits of nature-based tourism (Lindberg, 1991).

\section{- Marketing}

Selin (1994) discusses "how the power of marketing can be harnessed to protect natural areas and empower agencies responsible for managing these natural resources.” (p.19). A marketing perspective encourages managers to treat tourists as clients, emphasizing the importance of managing people, not just resources. In determining client needs, identifying markets, and helping to develop 
programs and establish pricing strategies, marketing seeks to create a better fit between people and their environment (Knopf, 1990), and thus helps management to meet its objectives. Marketing is also critical to attracting and securing a tourism market that matches the product offered at a destination (Ashley et al., 2001). On the other hand, demarketing - strategies used to reduce the demand for a product (Churchill \& Peter, 1995) - may also be beneficial in some cases. With respect to tourism, it could be used to encourage potential tourists to consider visiting alternative sites in a case where management was seeking to limit visitation levels at a sensitive or over-used protected area.

\subsection{Summary: Evaluating Ecotourism}

This chapter began by examining the roots of ecotourism, showing that the concept evolved out of two decades of reflection, criticism and change within tourism theory and planning approaches. By the 1990s, the notion that development could be sustainable, balancing economic growth and environmental protection, had been widely popularized. A major tenet of sustainable development, and common to most 'alternative' forms of tourism including ecotourism, was an emphasis on participatory approaches and a concern for conservation. This presented planners with a new and significant challenge (Gunn, 1991). Perhaps in response to this challenge, the 1990s saw the development and formal use of visioning as an important tool in tourism planning (Hatton, 1999; MacDonald et al., 1998). Visioning exercises are intended to produce images of a desirable future and to identify the steps that must be taken to arrive there. In tourism, visions of what it should/could be have found practical application in the development of several frameworks that are intended to help guide tourism development towards some desirable future state (Mitchell et al., 2001; Ross et al., 1999b; Scheyvens, 1999). If one interprets the development of ecotourism as a continuum, then evaluations become critical at all stages. Evaluations at mature destinations can be used to determine if benefits are being achieved. Evaluations at earlier stages of development can check progress and provide critical planning direction, helping destinations to find a path that promotes the development of symbiotic tourism-park-community relationships. The capacity of such frameworks to be used to evaluate the status of tourism development at a site, at any stage, suggests they can play an essential monitoring role, which has traditionally been a very much neglected component of planning processes (Pearce, 2000). 
This chapter has also shown that ecotourism to protected areas in the developing world has been widely promoted and adopted as a strategy for balancing goals of regional economic growth, community development and resource protection. While such an approach holds much promise, there is also significant potential for a host of negative socioeconomic impacts to occur. Although some countries have benefited from ecotourism, many have not. The gaps between ecotourism theory and actual site-level manifestations have been considerable, causing some to question whether or not the relationships between tourism, resources (parks), people and development can truly be sustainable (Boyd, 2000; Collins, 1999; Norris, 1992; Lindberg, 1991). Increasingly, at sites where ecotourism is being promoted, one is compelled to ask if the espoused benefits are being realized. What have the socioeconomic, cultural and environmental impacts been? While these questions have been addressed to some extent in the literature (Ross et al., 1999a), Ross and Wall (1999a) have criticized the lack of practical assessments of ecotourism's status in specific areas. They have identified a need to evaluate the impact of ecotourism in specific destinations in developing regions.

The paucity of ecotourism site-specific and local evaluations is likely due in part to confusion over what constitutes 'eco' tourism; if the term in not understood, it is difficult to know how to evaluate it. It is also the result of a lack of standardized criteria for evaluating ecotourism at a destination (Ross et al., 1999b). The result has been that a variety of approaches have been described in the literature and applied in practice, with no consistent framework for evaluation emerging.

Scheyvens (1999) presents an empowerment framework, which evaluates ecotoursim based on signs of economic, psychological, social and political empowerment. Mitchell and Reid (2000) have postulated a community integration framework for evaluating tourism in terms of local control, ownership and decision making power. Lee and Snepenger (1992) demonstrate the utility of an ecotourism assessment procedure that compares existing site characteristics and impacts with those that would be found in an ideal ecotourism scenario. Nepal (2000) provides a conceptual framework for considering the various interactions and processes between tourism, parks and local communities, and that can be used to anticipate different tourism-park-development scenarios and outcomes. Ross and Wall (1999a) have developed a framework that defines an ideal ecotourism development, and can therefore be used to both help plan, and evaluate the status of, ecotourism at particular sites (Figure 2.3). Properly implemented and managed, the framework has the potential to "help achieve a balance between conservation and development through the promotion of synergistic relationships between natural areas, local populations and tourism.” (p.123). The framework employs a variety of 


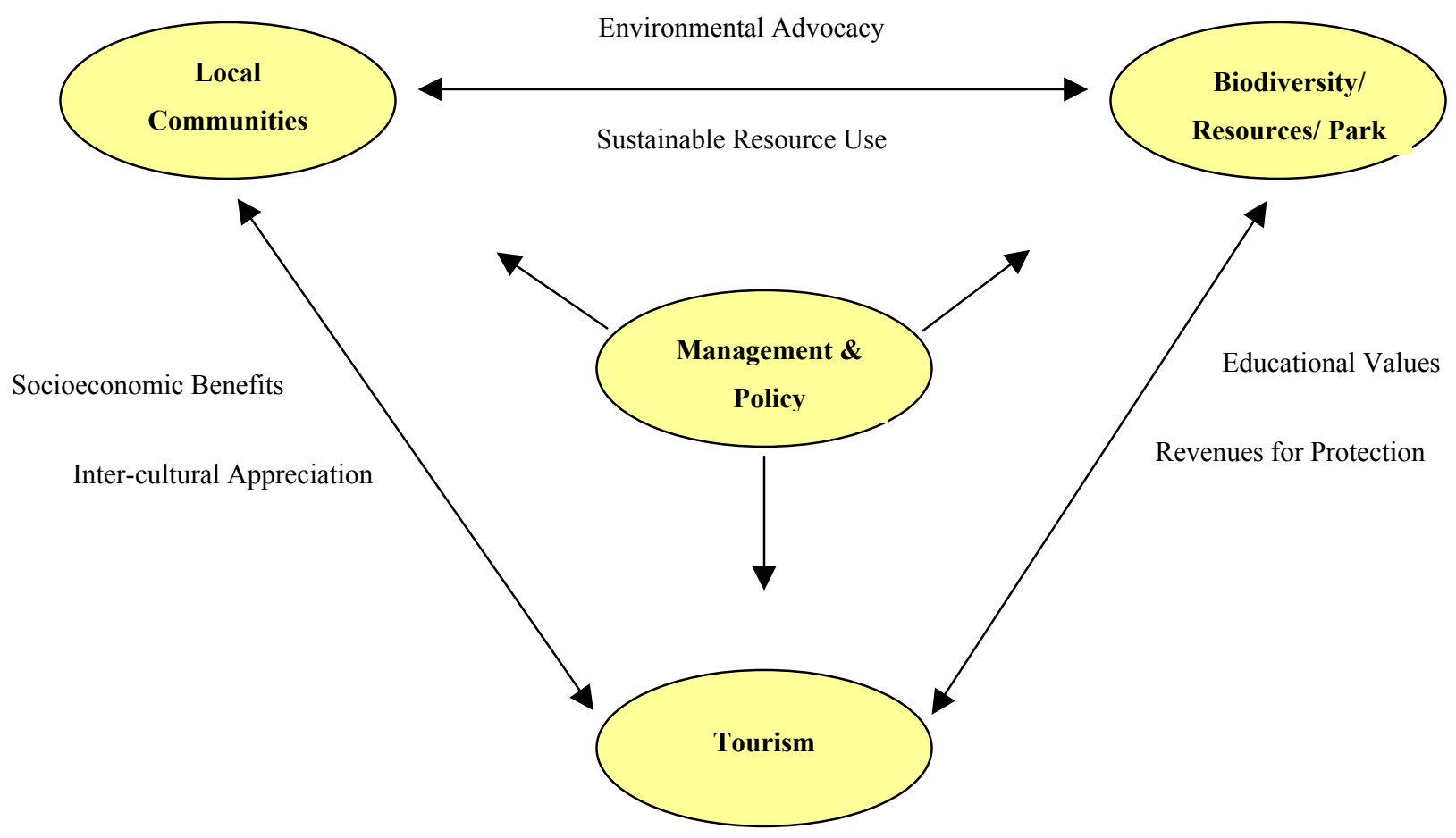

Figure 2.3: A Framework for Conceptualizing and Evaluating Ecotourism

Source: Ross and Wall, 1999

indicators to determine if existing tourism-resource-community relationships are operating in a manner that allows each to make positive contributions to the other (Table 2.1).

Given the lack of practical assessments, there is clearly an opportunity to apply an evaluative framework to assess the current status of ecotourism, and offer planning direction, at a destination where it is being promoted as a sustainable and balanced development strategy. In considering a variety of socioeconomic and environmental aspects of an ecotourism development, the Ross and Wall (1999a) framework is most suited to the objectives of the proposed research (Section 1.2), and has therefore been adopted for the purposes of this study. 
Table 2.1: Potential Indicators of the Relationships at an Ecotourism Destination

\begin{tabular}{|c|c|}
\hline Relationship Between & Potential Indicators \\
\hline 1. Communities \& Protected Areas (PA)/Resources & $\begin{array}{ll}\text { - } & \text { Degree of dependence on PA resources } \\
\text { - } & \text { Local attitudes towards conservation } \\
\text { - } & \text { Extent of local participation in conservation/planning } \\
\text { - } & \text { Nature of relationships between locals and PA staff } \\
\text { - } & \text { Presence of integrated use zones } \\
\text { - } & \text { Local benefits from resource protection }\end{array}$ \\
\hline 2. Communities \& Ecotourism & 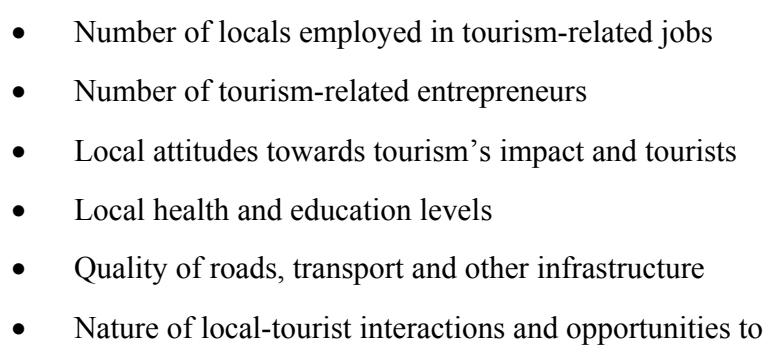 \\
\hline 3. Protected Areas/Resources \& Ecotourism & 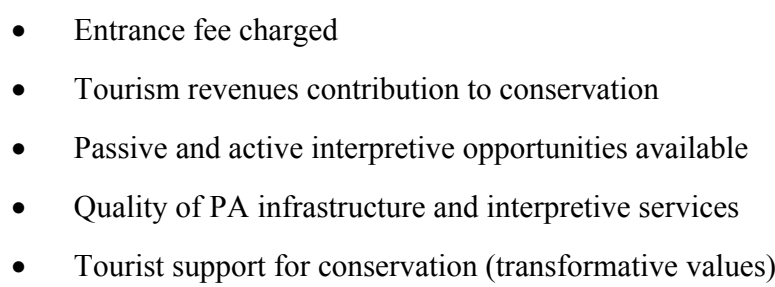 \\
\hline
\end{tabular}

Source: Adopted from Ross and Wall, 1999 


\section{Chapter 3 \\ Methodology}

This chapter describes the methods used to carry out this study. The study location is introduced and a rationale provided for its selection (3.1). The research paradigm and conceptual framework adopted are outlined (3.2) before detailing the data collection process, methods and phases (3.3). The chapter concludes with a discussion of the study's methodological strengths and weaknesses (3.4).

\subsection{Study Location and Site Selection Rationale}

\subsubsection{Tourism in China}

China's Cultural Revolution over the 1966 to 1976 period saw Deng Xiao-Ping and Chen Yun assume leadership of the Communist Party of China. It also left China with serious shortages of economic capital and backward economic conditions in many parts of the country (Zhang, Chong, \& Ap, 1999). In response to deteriorating conditions, and with the goal of generating much needed foreign exchange, economic reform policy, also known as the 'open-door' policy, was introduced in 1978 (Tisdell \& Wen, 1991; Richter, 1983). Recognizing the potentially significant contribution tourism could make to the nation's economic development, after 1978 Deng and Yun began to emphasize the development of tourism (Zhang et al., 1999; Tisdell et al., 1991). This broadened the pre-1978 focus of tourism policy on political promotion and diplomacy to also include concern for economic advancement (Zhang et al., 1999; Richter, 1983).

Over the next decade, China experienced significant overall increases in tourist arrivals and earnings (Guangrui, 1995), suggesting that tourism policy was successfully achieving its economic goals (Zhang et al., 1999) and giving China a false sense of tourism security (Guangrui, 1989). This growth proved to be unstable, with actual rates of change in arrivals and receipts exhibiting large fluctuations from year to year (Tisdell et al., 1991). The Tiananmen Square incident in 1989, and resulting decreases in tourism, further served to demonstrate the volatility of the industry (Guangrui, 1995). At the same time, growth was outpacing China's capacity to accommodate tourists and their ability to manage tourism (Zhang et al., 1999). This created disorder in the industry and resulted in a host of problems in the 1980s, including: rapid hotel construction leading to overcapacity and supply and demand imbalances (Jian, 1989); insufficient transportation infrastructure (Tisdell et al., 1991); 
limited educational opportunities, poorly trained staff and low service quality (Guangrui, 1987); an inequitable distribution of tourism development and activity, concentrated in a few urban centres (Zhang, 1995); and neglect for environmental protection (Guangrui, 1989).

China's attitude toward tourism changed moving into the 1990s, recognizing that if the problems of the 1980s were to be corrected and long-term, stable growth secured, a more organized and planned approach was required. The emphasis of policy shifted to economics over politics, opening China's doors even more and allowing tourism to develop within a socialist market economy model (Zhang et al., 1999). At the same time, and in response to environmental damage, there was growing support for nature conservation and interest in the potential ecotourism offered for linking goals of economic growth and environmental protection (Nianyong \& Zhuge, 2000; Tisdell, 1999; Wang, 1993). In fact, China's Biodiversity Conservation Action Plan specifically calls upon ecotourism to provide income and employment to local communities close to or within protected natural areas (Tisdell, 1996). The development of tourism in China over the last two decades has identified both a broad opportunity and a need to investigate ecotourism.

\subsubsection{Tourism in Hainan}

Hainan has a substantial tourism industry. Located in the South China Sea, off the southwest coast of Guangdong Province (Figure 3.1), the tropical island received approximately 2.5 million tourists in 1992 (Chongyi \& Goodman, 1997). By 1997 tourist arrivals had increased to 7.9 million (Xin, 1998). However, the vast majority of tourism occurs in coastal areas and the Island has been successful in attracting predominantly domestic tourists/holiday-makers from the mainland, Taiwan and Hong Kong. Economic opportunities, from a tourism perspective, for impoverished areas in the interior have been limited. Some of these areas have been disadvantaged by the construction of infrastructure elsewhere, such as the Eastern expressway (Xie \& Wall, 2000).

Ecotourism in Hainan Province has received a significant amount of discussion but, as yet, limited development. The island has been identified as the best environmentally preserved province in China (Department of Lands, 1999), possessing some of the most biologically diverse resources in the world (Weisun, 2000) (Table 3.1). Protected areas are one of the Island's most important tourism resources (Wang, 1993). Endowed with a wealth of natural resources - tropical forests, mountains, mangroves 


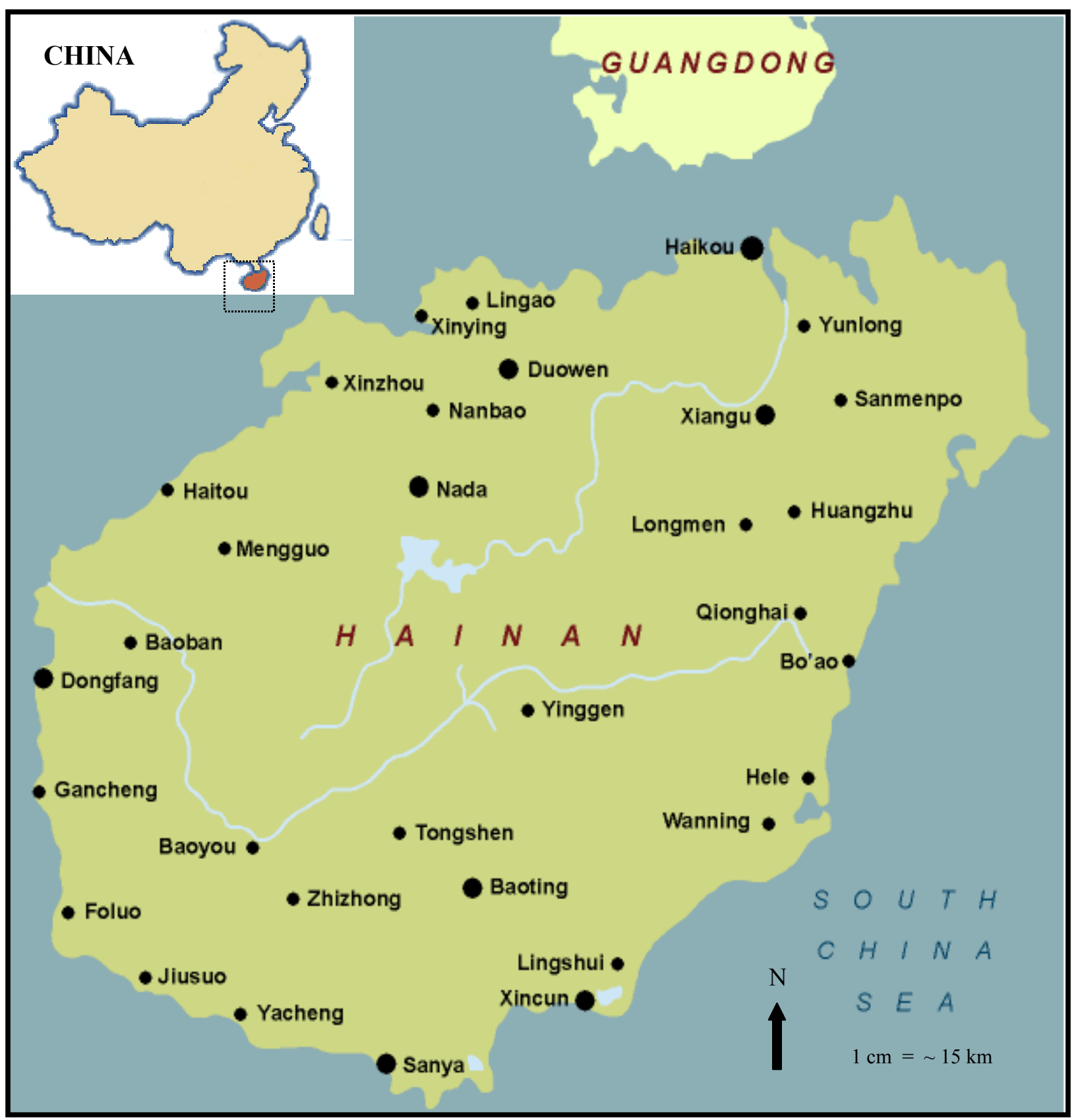

Figure 3.1: Location of Hainan Province

Source: www.hainan-window.com.cn/en/guide/index1.htm; and www.maps-of-china.com/hainan-s-ow.shtml 
and beaches - Hainan is one of the most popular tourism destinations in China (Zhang, 1995) and a region that has been slated for major development (Zhang et al., 1999; Guangrui, 1989). Provincial designation as a Special Economic Zone, and the associated special rules and investment incentives, is intended to accelerate this process (Gormsen, 1995).

Table 3.1: Biodiversity in Hainan

\begin{tabular}{lccc}
\hline Group & Number of Species & As \% of China & As \% of World \\
\hline Plants & 4200 & $15 \%$ & $1.9 \%$ \\
Mammals & 76 & $18.6 \%$ & $1.9 \%$ \\
Birds & 344 & $29.5 \%$ & $3.8 \%$ \\
Amphibians & 37 & $18.8 \%$ & $0.1 \%$ \\
Reptiles & 104 & $33.1 \%$ & $1.7 \%$ \\
\hline
\end{tabular}

Source: Adopted from Ouyang, Han, et al., 2001

Still predominantly rural, Hainan is also one of the most economically backward provinces in China, and in the pursuit of economic development substantial environmental damage has occurred (Department of Lands, 1999; Asian Development Bank, 1995; Cadario, Ogawa, \& Wen, 1992). The 'EcoProvince' initiative, intended to promote sustainable development on the island, identifies ecotourism as an important strategy for balancing economic growth with conservation measures (Department of Lands, 1999). A variety of sites and protected areas are identified under the EcoProvince initiative as having significant potential for ecotourism development, including both Jianfengling and Diaoluoshan National Forest Parks. In light of the above considerations, an evaluation of the current status of ecotourism in Hainan protected areas, and the impacts on surrounding communities, is significant.

\subsubsection{The Canada-China Higher Education Project}

In addition to the real need for work to be conducted in Hainan identified above, there was also a very practical reason for selecting the Island as the study site. Through the Canada-China Higher Education Project on Environmental Training for Integrated Monitoring and Management in the 
Coastal Zone of Hainan Province, a number of studies have been conducted on the Island, especially relating to coastal zone and environmental management, by both Chinese and Canadian universities. Dr. Geoff Wall, my advisor, is the Canadian Director of the project in Hainan. Through his previous work on the island, a wide variety of contacts and information resources have been secured, forming a solid foundation and support network for conducting further research. Continued environmentrelated research will complement studies previously completed under the project. Furthermore, the Hainan Department of Lands, Environment and Resources, a partner in the project and the agency responsible for implementing the Eco-Province initiative, has identified the need for ecotourismrelated research to be undertaken on the Island.

\subsection{Research P aradigm}

\subsubsection{Conceptual Framework}

This research is to be conducted under the broad framework of sustainable development. The concept of ecotourism is consistent with the theoretical tenets of 'sustainability' that promote integrated and balanced socioeconomic, environmental and cultural development. As noted in Section 2.1.2, a fairly strict definition of ecotourism has been adopted for this study, against which each case study will be evaluated:

environmentally responsible travel and visitation to relatively undisturbed natural areas, in order to enjoy and appreciate nature (and any accompanying cultural features - both past and present) that promotes conservation, has low visitor impact, and provides for beneficially active socio-economic involvement of local populations (Ceballos-Lascurain, 1993).

In an evaluation of ecotourism, it is also important to recognize that the impacts identified will differ according to the perspective taken. From an industry perspective, tourism's impacts are mainly assessed in economic terms, including employment rates, income levels and foreign exchange earnings; impacts are evaluated in terms of contributions to the national accounts and multiplier effects. National governments typically hold this perspective, treating tourism like any other industry in the economy. A community-based perspective is also concerned with economic impacts, but in contrast to an industry approach, tourism is treated as a strategy for stimulating positive change at the site level to improve the welfare of local host communities. Impacts are more broadly defined, and may include a variety of socioeconomic, cultural and environmental costs and benefits. As under the 
industry approach, economic impacts in terms of employment and income generation are important. However, there is also concern for the types of opportunities created (e.g. skilled vs. non-skilled), who benefits and loses (i.e. differential impacts on, and opportunities for, women and men), and the distribution (leakage) of economic benefits. In addition, there is an explicit recognition that economic impacts are interrelated with, and often responsible for, social, cultural and environmental impacts (Mitchell et al., 2001; Ross et al., 1999b). This study evaluates ecotourism from a community-based perspective.

\subsubsection{A Qualitative-Quantitative Approach}

The central purpose of this study is to assess the current status of ecotourism at protected areas in Hainan, through an examination of the current tourism-park/resource-people relationships and resulting community impacts. Qualitative analysis was deemed most appropriate given the exploratory nature of the research. Indeed, qualitative approaches have a history of use in travel and tourism research within certain disciplines (Decrop, 1999). Interviews, observations and secondary sources are the main vehicles of inquiry used in this study. Basic quantitative analysis is used to aid in the presentation and interpretation of interview results.

It is important to recognize that the macroeconomic, quantitative, techniques (such as input-output analysis) typically used to evaluate tourism's (economic) impacts from an industry perspective are generally inappropriate and not very meaningful at the local community level (Walpole et al., 2000). A recent study by the same authors effectively demonstrated the utility of employing surveys, key informant interviews and secondary sources to evaluate the local level economic impacts and the distribution of benefits resulting from park tourism on Komodo Island, Indonesia. A similar approach is adopted in this study given the community-based perspective taken.

In light of the emphasis placed on community and local level impacts in this study, it was also deemed appropriate to take a participatory approach. To the extent possible, the researcher visited ecotourism sites and participated in the activities that were offered. In addition, local residents, businesses and officials were given the opportunity to participate in this project through semistructured interviews. These groups have a significant role in the collection of the information necessary for an evaluation of ecotourism's impacts and relationships. By participating, these groups also had the opportunity to voice any tourism-related concerns they may have. 
In an effort to limit personal and methodological biases, triangulation - looking at a phenomenon or research question from multiple perspectives and sources of data - is used wherever possible. Triangulation has been proposed as a means for improving the credibility (how truthful are findings?), dependability (are results reproducible?) and objectivity (how neutral are the research methods?) of qualitative study findings (Decrop, 1999). Four basic types of triangulation can be identified - data, method, investigator and theoretical (Denzin, 1989). In this study, an effort is made to address the first two types. In terms of data triangulation - the use of a variety of data sources - both primary and secondary sources of information are used. Primary sources included observations and interviews, and were complemented by a variety of secondary media, including academic literature, newspapers, official documents and promotional materials. In terms of method triangulation - the use of multiple methods to study a single problem - this study employed collection of documentary evidence, observation (site and participant), semi-structured interviews, casual conversations and quantitative interpretation of some interview results.

Finally, and perhaps most importantly, an adaptive approach was taken. Recognizing that relatively little was known about the study sites, that data availability would perhaps be limited and that language/translation barriers would be encountered, a flexible approach was deemed essential to the success of this study.

\subsection{Research Methods}

\subsubsection{Pre-Departu re}

This study began in September 2000 with an extensive review of literature relating to a variety of topics, including, but not limited to, tourism, ecotourism, development, protected areas and China. Academic journals, books, theses, consultant reports and newspaper articles were included in this review. Consultations with my advisor and a number of students who were either from, or had conducted research in, China were also very important in defining and narrowing the focus of this study. These talks identified a list of key contacts in Hainan that could potentially provide support for the study. Literature review and consultations eventually led to the development of a proposal entitled Evaluating the Impacts of Ecotourism at the Local Level: Case Studies from Hainan, China, which was submitted to the Canadian Bureau for International Education for consideration in the Canadian International Development Agency Awards Program for Canadians competition. The proposal was successful in receiving an Innovative Research Award to cover the costs associated with 
conducting four months of fieldwork in China. In March 2001 I began, very informally, listening to Mandarin language tapes in an effort to acquire some basic phrase competency before departure. In April 2001 a working overseas orientation session put on by the International Programs Office at the University of Waterloo was attended. This afternoon session covered a variety of topics, including trip planning, being a Canadian ambassador, health and safety, culture shock and adaptation, communications and returning home. All required immunizations were obtained prior to departure in early May 2001.

\subsubsection{Arrival and Orientation}

Shortly after arriving in Hainan I had the fortunate opportunity of attending a week-long series of meetings on the Canada-China Higher Education Project. Officials from the Hainan Department of Lands, Environment and Resources and researchers from Nanjing University, the University of Waterloo and University of Guelph were all present. Discussions and presentations covered a variety of topics pertaining to environment and resource management, including tourism, in Hainan Province. The meetings supplied valuable contextual information for this study, and provided the chance to meet with and make new contacts. During this week, I also had the opportunity to make a presentation to the group on ecotourism theory, my research interests and objectives for the four months I would be spending in Hainan. Feedback from the presentation provided me with useful input and direction for the research subsequently completed.

Dr. Geoff Wall, my thesis advisor, was present for these meetings, which gave the opportunity to visit a couple of potential study sites (see below) and discuss my research in some detail before his return to Canada. The structured talks, introductions, discussions and site visits that occurred during this two-week period eased my transition into what was to be a much more independent life in Hainan, and left me feeling very comfortable with my surroundings and confident with the direction and objectives of my study.

Through contacts established at the Project meetings I was able to hire a research assistant/translator. Mr. Jia Shadong, an English language instructor at Hainan University, agreed to identify and screen a number of potential students from the University's English program. His efforts resulted in my interviewing, and subsequently hiring, Mr. Wang Hai Jun, an English major at Hainan University. 


\subsubsection{Study Site Selection}

Based on readings and discussions prior to departure for China, and because of its apparent rural location, wilderness setting, and the fact that it is a site being promoted by the Hainan Government as an ecotourism destination, Jianfengling National Forest Park (JNFP) was identified as the principal candidate study site. However, as relatively little was known about the Park, it was decided that a number of sites would be visited to determine which site(s) would best lend themselves to the study given the defined research objectives. In light of the definition of ecotourism adopted and community-based perspective taken in this study, the desired site(s) would ideally provide a relatively remote wilderness setting, adjacent to an underdeveloped community, where (eco)tourism is occurring and/or being promoted. Shortly after arrival in Hainan I began visiting a number of protected area and tourism sites. Over a period of about one-month the following sites were explored:

$\begin{array}{ll}\underline{\text { Date }} & \underline{\text { Site }} \\ 05 / 14 & \text { BoAo Aquapolis Development } \\ 05 / 20 & \text { Mount Bawangling National Nature Reserve } \\ 05 / 23 & \text { Nanshan Buddhist Cultural Park } \\ 05 / 24 & \text { Boating County Thermal Springs Development Area } \\ 05 / 25-26 & \text { Diaoluoshan National Forest Park and Provincial Nature Reserve } \\ 05 / 28-30 & \text { Jianfengling National Forest Park and Provincial Nature Reserve } \\ 05 / 30 & \text { Datian National Nature Reserve } \\ 06 / 09-10 & \text { Wuzhi Mountain Provincial Nature Reserve } \\ 06 / 12 & \text { Xinglong Tropical Botanical Gardens } \\ 06 / 13 & \text { Xinglong Tropical Gardens }\end{array}$

During this period a number of interviews were also conducted with protected area, tourism and environment officials and researchers to identify their perceptions of ecotourism on the Island generally, but also at specific sites. Those interviewed include the following:

$\begin{array}{lll}\text { Date } & \text { Interviewee } & \text { Position } \\ 05 / 20 & \text { Mr. Yang } & \text { Vice-Director of Projects, Bawangling Forest Bureau } \\ 05 / 28 & \text { Dr. Zhong Chonglu } & \begin{array}{l}\text { Associate Professor \& Researcher, Chinese Academy of } \\ \text { Forestry (CAF) }\end{array}\end{array}$




$\begin{array}{lll}06 / 03 & \text { Ms. He Shaoqun } & \begin{array}{l}\text { Deputy Director, Department of Lands, Environment \& } \\ \text { Resources of Hainan }\end{array} \\ 06 / 04 & \text { Ms. Du Na } & \begin{array}{l}\text { Associate Dean \& Professor, Department of Geography, } \\ \text { Hainan Normal (Teachers) University; and Tourism Planner, } \\ \text { Hainan Tourism Bureau }\end{array} \\ 06 / 05 & \text { Mr. Li Shulin } & \text { Director, Hainan Forestry Research Institute } \\ 06 / 09 & \text { Dr. Carl von Hahn } & \begin{array}{l}\text { Director, Sino-German Forestry Cooperation Hainan, } \\ \text { Rehabilitation and Protection of Tropical Forests }\end{array} \\ 06 / 15 & \text { Ms. Zhou Yanhua } & \begin{array}{l}\text { Deputy Director, Division of Development Planning \& } \\ \text { Finance, Hainan Forest Bureau }\end{array} \\ & & \end{array}$

The site assessment and interview process ultimately led to the conclusion that JNFP most closely matched the site selection criteria and would be the most suitable site for the purposes of this study. The Park provides a semi-pristine wilderness setting in the predominantly rural southwest of the Island. The town of Jianfeng, a community traditionally dependent on the region's natural resources, lies immediately adjacent to JNFP. JNFP currently receives relatively few tourists, but is being promoted and developed as an ecotourism destination.

Diaoluoshan National Forest Park (DNFP), next to the town of Diaoluo, was also determined to be very suitable, possessing almost exactly the same characteristics as JNFP. At this point, it was considered a potential site should there be sufficient time to explore a second ecotourism site, allowing a site comparison with JNFP to be made. Site visits were not only necessary for identifying a suitable study location, but also provided valuable, more general, contextual information about (eco)tourism in Hainan.

\subsubsection{Data Collection}

In order to assess the current status of ecotourism at JNFP and DNFP, and thus be able to provide planning direction, the existing tourism-park-community relationships and impacts were explored. This required obtaining input from the various stakeholders at each site. More specifically, the purpose of site-level data collection was to gather information on park management, operations and 
facilities, community perceptions of the park and tourism, and tourists' expenditures. Groups targeted for interviews included the following:

- Site Level Park Managers

- Community Residents and Businesses

- Hotel Managers

- Park/Tourism Managers, Researchers and Officials (not directly associated with the study sites)

\section{- Tourists}

As very few study participants spoke English, translation assistance was required. For all interviews, translation was performed in situ. This was performed principally by Mr. Wang Hai Jun, the hired research assistant, and to a lesser extent by Ms. Wang Yang and Mr. Jia Shadong. Their essential contributions to this study were not limited to translation, but also included their role as inter-cultural mediators, helping a foreign researcher to understand and respect the subtleties of local customs. The interview process was complemented by site and participant observations, and by the collection of resource materials and documents unavailable in Canada.

The question sets designed by the researcher were reviewed by the project advisor before being employed in the field to help ensure that interviews would be both comprehensive and ethical. Prior to beginning the interview process, all question sets were tested with the research assistant to ensure that they were clear, easily translated, culturally sensitive and not repetitive.

\subsubsection{Site Level Park Managers}

Input from park and nature reserve managers was sought in order to acquire specific details about the protected areas and to gain insight into the current state of resource and tourism management at each study site. Prior to departure, top officials at the Park management agency (known as Forest Bureaus) were contacted by telephone to describe the study, inform them of our arrival date and request a tentative interview time. Upon arrival at each site, a visit was made to the Forest Bureau to meet local officials and confirm interview times. In-depth, semi-structured interviews covered a variety of topics relating to: 
- Park operations - biophysical details, management issues, funding, facilities, staff, etc.

- (Eco)Tourism - visitation levels, concerns, expectations, future developments, etc.

- Local relations - resident displacement, outreach efforts, local tourism benefits, etc.

The complete list of questions used to guide the interviews with park managers is provided in Appendix A. A similar set of questions was used in interviews with the Nature Reserve managers at each site (the Reserves are managed separately from the Parks - see Section 4.1 below), with less emphasis on facility and tourism aspects, as these areas generally do not receive tourists. In order to complete the fairly extensive question list, multiple-interviewees and/or multiple-sessions were required. More specifically, the following officials were interviewed at each site:

\section{$\underline{\text { Date }} \quad \underline{\text { Interviewee }} \quad \underline{\text { Position }}$}

Jianfengling National Forest Park and Provincial Nature Reserve:

06/20 \& Mr. Fang Hong Director, Jianfengling Forest Bureau and JNFP $07 / 01$

06/22 Mr. Xie Mingdong Vice-Director, Jianfengling Forest Bureau and JNFP

06/22 Mr. Zhang Zhencai (Ex) Manager, Jianfengling Provincial Nature Reserve

Diaoluoshan National Forest Park and Provincial Nature Reserve:

07/07 Mr. Wang Dongming Director, Diaoluoshan Forest Bureau and DNFP

07/11 Mr. Lin Weifu Manager, Diaoluoshan Provincial Nature Reserve

07/12 Mr. Yu Weisun $\quad$ Vice-Director, Diaoluoshan Forest Bureau and DNFP

While the names of interview participants are listed here, they have been purposely omitted in the results chapters, where much of the information they provided is found, so as to ensure some degree of anonymity. 


\subsubsection{Community Residents and Businesses}

Local community impacts comprise the major focus of this research and, as such, local residents at each study site had a significant information provision role to play. Semi-structured interviews were used to ascertain community perceptions on park establishment, conservation, tourism's existing and potential impacts, and family spending habits. Both local residents and business owners were targeted in the interview process. While both groups are in fact community residents, and were asked the same questions, a distinction is made in that for the tourism-related questions, business owners were asked to respond with respect to tourism's impact on their business specifically (as opposed to personal impacts for residents). Business owners were also asked a couple of additional questions relating to volume of tourism-generated business and staff. Interviews were designed to be relatively short, and typically lasted between 5 and 15 minutes. The local resident and business owner question sets are provided in Appendix B.

Prior to interviewing, a walking tour of each town - Jianfeng at JNFP and Diaoluo at DNFP - was completed in order to become familiar with the location of residential areas, and the number and types of businesses. Sampling strategies were based on these initial surveys and designed to be representative of the various residential areas and businesses in operation. Similarly, an effort was made to capture the responses of both males and females, across a range of age categories. As opportunities arose, local residents were approached in the street and in residential areas and, after a verbal description of who the researchers were and what was being studied, were asked if they would be willing to participate in an interview. Interviews with business owners were sought so as to capture representation from the variety of different business types in each town but, for any given type, owners were opportunistically approached (e.g. restaurant owner responses were desired, but individual restaurants were not specifically targeted). As for residents, business owners were provided with details regarding the study and asked if they would participate. A verbal study description and consent was used given that each area is relatively poor and that some residents may not be able to read or write. However, in all cases, a written explanation of the research being conducted was offered to respondents (Appendix C). Very few residents or business owners, at either study site, refused to participate in interviews. The majority of those that did decline were women.

A total of 65 local residents and business owners were interviewed in the Town of Jianfeng between June $19^{\text {th }}$ and $26^{\text {th }}$. The town of Jianfeng has a core town population of about 10,000 . The Town of Diaoluo is substantially smaller than Jianfeng, with a core population of about 3,700, and 
fewer interviews were conducted. Between July $8^{\text {th }}$ and $13^{\text {th }}, 35$ residents and business owners were interviewed in Diaoluo. Tables 3.2 and 3.3 show the detailed breakdown of resident and business owner response categories for each town. The small number of business owners interviewed in Diaoluo is due to the fact that there are very few businesses in operation in the town.

Table 3.2: Community Resident Interviewees by Age Category

\begin{tabular}{|c|c|c|c|c|}
\hline \multirow[b]{2}{*}{ Age Category } & \multicolumn{2}{|c|}{ Town of Jianfeng $(n=40)$} & \multicolumn{2}{|c|}{ Town of $\quad$ Diaoluo $(n=30)$} \\
\hline & Male & Female & Male & Female \\
\hline$<25$ & 4 & 2 & 3 & 0 \\
\hline $25-29$ & 5 & 1 & 1 & 2 \\
\hline $30-34$ & 5 & 3 & 7 & 2 \\
\hline $35-39$ & 3 & 3 & 2 & 2 \\
\hline $40-44$ & 0 & 1 & 0 & 2 \\
\hline $45-59$ & 4 & 1 & 1 & 2 \\
\hline $60>$ & 5 & 3 & 4 & 2 \\
\hline Total & $26(65 \%)$ & $14(35 \%)$ & $18(60 \%)$ & $12(40 \%)$ \\
\hline
\end{tabular}

Table 3.3: Community Business Owner Interviewees by Business Type

\begin{tabular}{|c|c|c|}
\hline Business Type & Town of Jianfeng $(n=25)$ & Town of Diaoluo $(n=5)$ \\
\hline Restaurant & 5 & 1 \\
\hline Food Shop & 5 & 2 \\
\hline Beauty/Hair/Massage & 2 & 1 \\
\hline Motorcycle Taxi & 5 & N/A \\
\hline Miscellaneous (hardware, toys, & 5 & 1 \\
\hline Clothing & 2 & 0 \\
\hline Pharmacy/Medical & 1 & 0 \\
\hline Total & 25 & 5 \\
\hline
\end{tabular}


Recognizing that the Li ethnic minority comprises a substantial proportion of the population in each study region, an effort was also made to receive input from this group at each site. Although time, access and language factors did not permit an in-depth survey of Li villages and their residents, at both JNFP and DNFP at least one local Li village leader was interviewed. As village leaders, their opinions were deemed to be somewhat representative of the people they represent and the greater $\mathrm{Li}$ population in each region. However, it is unlikely that their opinions fully reflect the views of all $\mathrm{Li}$ people living in the Jianfeng region. Interviews followed the same format as that used for local resident and business owners, probing their views on (eco)tourism, the Park, and conservation.

\subsubsection{Hotel Managers}

The input of hotel managers at each site was sought in order to document what facilities currently exist, the number of people that can be accommodated, current guest occupation levels and peak periods, staff details and purchasing behaviour. Managers were also asked a series of questions, similar to those used for local residents and business owners, designed to capture their opinions on the park, conservation and (eco)tourism.

Hotels located in the Park and in the town were visited at each site to tour the grounds and facilities, and to request an interview with the resident manager. Interviews were eventually held with the manager or assistant manager at four of the five hotels at JNFP/Jianfeng and the assistant manager of both the hotels at DNFP/Diaoluo.

\subsubsection{Park/Tourism Managers, Researchers and Officials}

A series of key-informant interviews were conducted with a variety of tourism and environment government officials, academics and researchers to gather contextual and supporting information for this study. These people were not associated directly with either of the two study sites. Topics discussed varied to some extent depending on the interviewee, but generally revolved around (eco)tourism in Hainan, planning and management issues, administrative structure of parks and nature reserves and rural community development. A number of other tourism site and park managers were also interviewed in an effort to collect as much information as possible about a variety of tourism sites in Hainan, and to support the more in-depth research conducted at JNFP and DNFP. These interviews typically followed the same question format that was used for the park managers at each study site. A total of 13 supporting interviews (14 interviewees) were conducted. In addition to the 
seven key-informant interviews listed in Section 3.3.3, the following people also provided valuable information for this study:

\begin{tabular}{|c|c|c|}
\hline Date & Interviewee & $\underline{\text { Position }}$ \\
\hline \multirow[t]{2}{*}{$06 / 22$} & Dr. Wu Zhongming & Associate Professor \& Researcher, Chinese Academy of \\
\hline & & Forestry (CAF) \\
\hline \multirow[t]{3}{*}{$06 / 28$} & Ms. Zhou Yanhua & Deputy Director, Division of Development Planning \& \\
\hline & & Finance, Hainan Forest Bureau (HFB) \\
\hline & Mr. Su Wenba & Nature Reserves, Rare Plant \& Animal Branch, HFB \\
\hline $07 / 01$ & Mr. Li Shanyuan & Director, Datian National Nature Reserve \\
\hline $07 / 14$ & Mr. Feng Biaojing & Vice-Director, Wuzhishan Provincial Nature Reserve \\
\hline $07 / 26$ & Mr. Cai Shidong & Director, Sanya Tourism Administration \\
\hline 08/04 & Mr. Zhou Xujian & $\begin{array}{l}\text { Director, Bawangling Forest Bureau \& National Nature } \\
\text { Reserve }\end{array}$ \\
\hline
\end{tabular}

As for the interviews with park managers at each study site, names are withheld in the results chapters for confidentiality reasons.

\subsubsection{Tourists}

As one of the main stakeholders at a tourism destination, tourists must be considered in an assessment of the current status of (eco)tourism. Their input is imperative for establishing a park visitor profile and for determining spending habits and satisfaction levels. However, initial site surveys at both JNFP and DNFP revealed that relatively few tourists were present at either Park, and that it would be a time-consuming process to survey personally a meaningful number of tourists at any one site. This could have only been done at the expense of collecting data at a second study site. Given the study's emphasis on community impacts, it was determined that the researcher's (and translator's) time would be better spent conducting interviews with local residents, businesses and officials to permit a comparison between two study sites. 
To ensure the most efficient use of time, yet allow for tourist input, a visitor survey was created and, with the help of Mr. Jia Shadong, translated into Chinese to allow for self-administration (Appendix D). Although both Parks apparently receive similar numbers of tourists, site visits suggested that the hotels at JNFP were slightly busier than the hotels at DNFP at the time of research. It was therefore determined that the survey would be attempted at JNFP only. As there is no entrance gate at either Park, the hotels were deemed to be the easiest way to contact tourists. The managers of the two main hotels in JNFP were approached at the end of June to solicit their help in distributing the tourist survey. With both agreeing, they were asked to give out the survey to one member of all groups arriving independently and to several, random, individuals in larger tour groups. Managers agreed to convey these instructions to their staff. Managers were given the flexibility to decide how to distribute the surveys most effectively (from the front desk, left in rooms, etc.). The managers were called periodically throughout July and August to provide a progress report and to resolve any difficulties being encountered. They were also provided with envelopes and postage for returning the surveys by a specified date in early September.

Unfortunately, by the time fieldwork was completed and departure for Canada, an insufficient number of surveys (less than ten) had been completed to permit meaningful analysis. As a result, none of the information collected through the survey is presented in this thesis. The failure to capture a significant number of respondents over the course of two months reflects, to some degree, the current level of tourism at the site.

\subsubsection{Observations and Document Collection}

To complement the interview process, field observations were conducted and various park/tourismrelated documents collected. Wherever possible, observations and information from documents is used to support (triangulate) interview findings. Significant effort was made at each site to 'see' the Park, its attractions, facilities, trails, etc. Each site was visited on multiple occasions over the course of the summer. As the Parks are large and at some distance from the town in each case, this required (and it was no small task) finding and hiring transportation and a guide (official or impromptu) for trips into the Parks. Much time was also spent at each site becoming familiar with the lay of the town and watching residents, business owners and local officials interact on a daily basis. Observing interview participants - facial expressions, behaviour, etc. - as they were engaged in discussion with Mr. Wang Hai Jun, the translator, also proved insightful at times. As translator, and one familiar with 
Chinese custom and culture, the impressions of Mr. Wang Hai Jun were also very important during both interviews and site observations.

Where deemed appropriate, local park and outside agency officials were asked if they could provide any relevant documents relating to park management or tourism at the site, and/or in Hainan more generally. Only relatively small, or portions of, documents were collected or copied given the practical limitations of having large documents translated upon return to Canada. These consisted mainly of summary reports, statistics, guidelines and promotional materials. The China Daily, an English newspaper, was also reviewed periodically in search of tourism-related articles.

\subsubsection{Data Analys is}

Although some in situ analysis of data was conducted in order to identify missing information and to prepare for a presentation made upon completion of fieldwork in Hainan, the majority of analysis was performed in Canada between September and December 2001. This involved reviewing and interpreting interview responses in light of the defined research objectives (Section 1.2) and ecotourism evaluative indicators outlined in the Ross and Wall Framework (Table 2.1). Local resident and business owner interview responses were categorized, and then quantified (counted), for each question, to allow patterns to be identified.

Ms. Teresa Chang-Hung Tao provided valuable document translation, allowing information gaps to be filled and some findings to be confirmed or contested. Results are framed (presented and discussed) in terms of the relationships that exist between people, parks and tourism at a destination.

\subsubsection{Results Diss emination}

In an effort to disseminate some of the researcher's preliminary impressions and findings a presentation was organized in the capital city of Haikou prior to departure for Canada. Park managers from each site and key officials from various outside agencies, all of whom had participated in interviews over the course of the summer, were invited to attend. Despite giving one month's notice and making every effort possible to accommodate those invited, it proved impossible to coordinate the busy schedules of a number of officials. Although only four people managed to attend in the end, the presentation was well received. 
The absence of an organized community group or any other readily identifiable avenue for conveying preliminary (or final) results to local residents, along with the inability to secure translation assistance, made it infeasible to hold a presentation at either Jianfeng or Diaoluo.

A number of those not in attendance at the Haikou presentation, including the managers at both JNFP and DNFP, expressed an interest in receiving a translated summary of the study results once they become available. The Hainan Forest Bureau, Sino-German Forestry Cooperation Hainan Office and Nanjing University have all requested full copies of this thesis upon its completion. Although cost and translation barriers exist, every effort will be made to accommodate these requests.

\subsection{Summary: Strengths and Weaknesses of the Study Design}

This study employs interviews, observations and secondary sources to evaluate the existing tourismpark-people relationships at JNFP and DNFP. While the information collected and presented in this study is believed to be factual, reproducible and objective, a consideration of the study design's potential weaknesses and strengths is, nevertheless, important.

Language was one of the most significant barriers this study had to overcome. Although the hiring of a very competent research assistant allowed interviews to be successfully completed, the nature of translation is such that the possibility still remains that some responses were simplified and/or misinterpreted. Furthermore, not all documents - large park master plans for example - could feasibly be translated into English, meaning that potentially valuable information may be missing in this thesis; in the absence of complete information there is a risk of drawing erroneous observations and conclusions. The inability to work without the assistance of a translator left me at the mercy of their, often busy, schedules, and to some extent limited the number of tasks that could be completed over the course of the summer.

While interviews are one of the most widely used methods in social science investigation, they also potentially suffer from a number of problems. In a developing world context, where educated, typically white, foreign males conduct interviews, intimidating power relationships may exist "upper-lower dominance" - resulting in a distorted reality or response bias (Chambers, 1997). In such situations, respondents "often know or sense the replies they are meant to give" (p.94). The potential for politically correct responses is perhaps even greater in a socialist country like China, and where the government largely controls tourism. Although I do not consider myself overly intimidating, I am an educated white male from a foreign country. Although a Chinese translator was 
used to conduct interviews, I was still present. However, when these concerns were raised with the research assistant at one point, he assured me that he was confident that local residents and business owners were expressing their genuine opinions.

Early on in the interview process it became apparent that women (especially young women) were often very reluctant to share their opinions, instead preferring to defer to their husbands, male neighbours, etc., or decline outright. Table 3.2 shows that women (at least the more timid personalities) were somewhat under-represented compared to men in interviews at both JNFP and DNFP, and as a result their views may not be fully reflected in this thesis.

Although they did not comprise the primary focus of this study, tourist input was not successfully captured at either site. While this may be partially due to the survey methodology employed, it is more likely the result of relatively low levels of visitation at both JNFP and DNFP, especially during off-peak/non-holiday times. In either case, the absence of information on tourist demographics, spending habits and satisfaction levels of the 20,000 to 30,000 tourists that senior Park management staff indicated visits each park annually, to a minor degree, limits the study's ability to evaluate tourism's economic impact at each destination. However, where possible, other sources have been used to be able to comment on the current level and location of tourist spending.

While a number of potential weaknesses exist, the study design also has several strengths. Given that relatively little was known about individual tourism sites in Hainan, it was imperative that flexibility be built into the research design. Adapting to existent realities and changing circumstances was a key to the success of this study.

This study is also strengthened by the use of triangulation, in terms of both data sources (primary and secondary) and collection methods (interviews, observations and literature), to limit personal and methodological biases.

In an assessment of the status of ecotourism at a destination it is necessary to consider the diversity of interests that exist. Recognizing this, the study sought to capture input from a broad range of groups with an interest in (eco)tourism at each site - park managers, local residents and business owners, hotels, Li minority groups, provincial government tourism/park/environment officials, academic researchers and tourists. With the exception of tourists (perhaps because there are so few), all of these interest groups contributed in some capacity to this research, thus strengthening the study. 


\section{Chapter 4 \\ Protected Areas and Ecotourism in Hainan}

\subsection{Organization and Administration of Hainan's Protected Area System}

\subsubsection{Biodiversity Protection}

Hainan Island has been recognized as one of the most important biodiversity conservation areas in the world (Ouyang et al., 2001; Weisun, 2000; Asian Development Bank, 1995). Table 3.1 compares Hainan's species diversity with the rest of China and the World. The Island's biological richness and high degree of endemism result from the globally unique tropical forest, mangrove, marine and grassland ecosystems found on Hainan, that exhibit species structures and ecological processes much different from those found in other tropical regions (Ouyang et al., 2001). Close to 600 of the 4200 species of plants found in Hainan are endemic to the Island. Unfortunately, a history of development and activity on the Island has meant that its spectacular resources have long been subjected to human resource use pressures (Shangji, 1994).

Although commercial logging can be traced back to the Tang and Song Dynasties (618-1297), it was not until 1949, and the founding of the People's Republic of China (PRC), that the rapid development of a major timber industry began (Wandi, 1999). Prior to provincial designation in 1988, Hainan, and its wealth of natural resources, was controlled by the Guangdong Provincial Government and Central Government (Chongyi et al., 1997). In the mid-1950s the Guangdong Government set up Forestry Bureaus/Farms in various locations on the Island to oversee and manage the growing timber industry. Around this same time, the Central Government began setting aside tracts of virgin tropical forest in several logging areas where timber harvesting was prohibited. Nevertheless, the logging industry has taken its toll. While close to $52 \%(1,763,840$ ha) of Hainan remains forested (Department of Lands, 1999; Wandi, 1999), only about 4\% (135,680 ha) of the Island is covered in primary rainforest, down from 26\% in the mid-1950s (Ouyang et al., 2001; Department of Lands, 1999). Estimates of the Island's remaining natural forest coverage during the 1990s range from about 300,000 hectares (Wandi, 1999) to just over 600,000 hectares (Department of Lands, 1999). 
Although the establishment of Reserves began in the 1950s, it was not until the 1990s that efforts to protect the Province's biodiversity and unique ecosystems really intensified (Table 4.1). This decade witnessed a growing concern over the impact economic development was having on the environment throughout China, including in Hainan. In response, the Province began to take a more integrated approach to resources management in the early 1990s. This led to the formulation of the 'EcoProvince' strategy, a sustainable development plan for the Island moving into the twenty-first century, and an expanded protected area strategy. The protected area system in Hainan is generally referred to as the Nature Reserve Network, but in reality includes a variety of protected area types, including both Parks and Reserves, across different levels of jurisdiction.

Table 4.1: Expansion of the Hainan Nature Reserve System

\begin{tabular}{lcccc}
\hline & $\mathbf{1 9 7 9}$ & $\mathbf{1 9 8 5}$ & $\mathbf{1 9 9 8}$ & $\mathbf{2 0 1 5 *}$ \\
\hline Total No. of Nature Reserves (NR) & 5 & 30 & 72 & $2,856,312$ \\
Total Area of NR (ha) & 13,786 & $2,569,543$ & $2,683,455$ & 52 \\
No. of Terrestrial NR & 5 & 23 & 59 & 331,172 \\
Total Area of Terrestrial NR & 13,786 & 104,781 & 157,881 & $9.8 \%$ \\
Terrestrial NR as \% of Island area & $0.4 \%$ & $3.1 \%$ & $4.6 \%$ & \\
\end{tabular}

Source: Ouyang, Han, et al., 2001

* Figures were not included in the original Table, but were compiled from information within the source, and represent the targets for the Reserve Network upon completion in 2015.

\subsubsection{Parks}

In response to rapidly declining forest coverage, the Provincial Government banned all logging in natural forests in 1994. This effectively put an end to most commercial harvesting on the Island and initiated major reforms within the Hainan Forest Bureau (HFB). The eleven Forest Bureaus originally established to operate as timber enterprises saw their mandates switch from profit-oriented harvesting to conservation. The eleven regional Forest Bureaus are now responsible for implementing the National Natural Forest Protection Project (NNFPP), which was initiated in 1993 in Hainan and adopted nation-wide in 1998. Four of the eleven former Forest Farms, including those at 
both Jianfengling and Diaoluoshan, were designated as Parks during this period of restructuring. The responsibilities of these four Forest Bureaus were expanded to encompass park management as well as implementation of the NNFPP. All eleven Forest Bureaus, including the Parks, fall under the administration of the Planning and Finance Division of their parent body, the HFB. This Division also manages fifteen Forest Farms - fourteen reforestation plantations and one deer protection area and is responsible for 'forestry ecotourism' in Hainan.

A sustainable management approach is taken in the Parks, balancing protection with opportunities for human use. One official indicated that their main purpose was to provide for ecotourism. In addition to tourism, the Parks are zoned to allow certain resource extraction activities. While no tree cutting is allowed in natural forests, plantations that existed prior to park establishment are still harvested according to a cut cycle. Aggregate mining is still in operation in at least one park due to prior contract obligations, but will not be permitted in the future. Bamboo and rubber plantations, fruit farms and hydro-electricity operations are all permitted in certain areas, and used to generate funds for parks through the commercial sale of products. The Forest Bureau does not necessarily operate these enterprises directly, but leases land rights and/or takes a share of profits. There are four National level Parks in Hainan, including both Jianfengling and Diaoluoshan (although the latter was originally a Provincial Park).

National designation is granted by the State (National) Forest Administration (SFA). To change the status of a park to 'National', the HFB must apply to the SFA with certain documentation. Although the SFA has ultimate authority over the National Parks, it seems as though most management decisions are made by the HFB in conjunction with the local Forest Bureaus. The HFB's responsibility for forest and park management, of which tourism is a growing component, also requires that management be coordinated, to some extent, with the Hainan Tourism Bureau and the Hainan Department of Lands, Environment and Resources. Site-level master plans exist for at least two of the four National Parks and, although they are not updated on a regular basis (due to fund shortages), the plans can be amended if conditions change or the government deems it necessary. Both the HFB and SFA must approve site-level plans. Future developments in the parks are to be guided by weighing investors' proposals against the master plan criteria.

Prior to the logging ban, the Forest Bureaus relied almost exclusively on the sale of timber to generate funds for operations and management. The ban has required the Bureaus/park management agencies to find new sources of funding. In part, these have come from the commercial sale of 
products grown on fruit farms and rubber, timber and bamboo plantations. Funds have also come from the Provincial Government and, to a lesser extent (originally), the Central Government. While most government funding came from the Province between 1993 and 1999, such funding was not guaranteed for the Bureaus. They were required to make an application for funds to the HFB, which was reviewed also by the Provincial Department of Economic Planning and the Bank(s), for feasibility, benefits, impacts, etc. With increased Central Government investment in forest protection under the NNFPP, as of 2000 the local Forest Bureaus have been guaranteed a more stable source of funds over the next ten years, the duration of the project. The Central Government is to provide $80 \%$ of the total 300 million RMB ( $\$ 57.7$ million $\mathrm{CDN}$ ) that is to be invested under the project, with the remaining 20\% coming from the Provincial Government.

\subsubsection{Nature Rese rves}

Nature Reserves comprise the heart of the protected area system in Hainan. Although a number of important Reserves were established in the mid-1950s, the Reserve system did not really develop until the 1990s (Table 4.1). Five National, 22 Provincial and 45 county-level Reserves are managed under a number of different governmental agencies (Ouyang et al., 2001). The Hainan Provincial General Protection Station of Wild Animals and Plants, an organization of the HFB, is responsible for 23 Reserves (Figure 4.1). Among this group are 3 National and 16 Provincial level Reserves, 17 of which were established to protect tropical forest and 2 for animal protection. Jianfengling and Diaoluoshan Provincial Nature Reserves are included in the group of Reserves that fall under the administration of the HFB, and are designed to protect tropical forests. System-level planning (e.g. Ouyang et al., 2001) and a system Master Plan are complemented by site level plans at each Reserve.

The primary purpose of Nature Reserves is protection. Permitted uses are much more restricted compared with Parks. Reserves are generally divided into 3 zones - a core area where no activities are permitted, a buffer in which scientific research is conducted and an experiment/multi-management zone that permits a wider range of activities and infrastructure including, for example, planting and ecotourism. Reserves are also intended to serve an educational function for University students.

Research projects undertaken within the Reserves have been widely varied. For National Reserves, prospective researchers - academics, Chinese Academy of Forestry (CAF), etc. - must apply to the SFA for approval. Those interested in conducting research in Provincial Reserves apply through the HFB. 


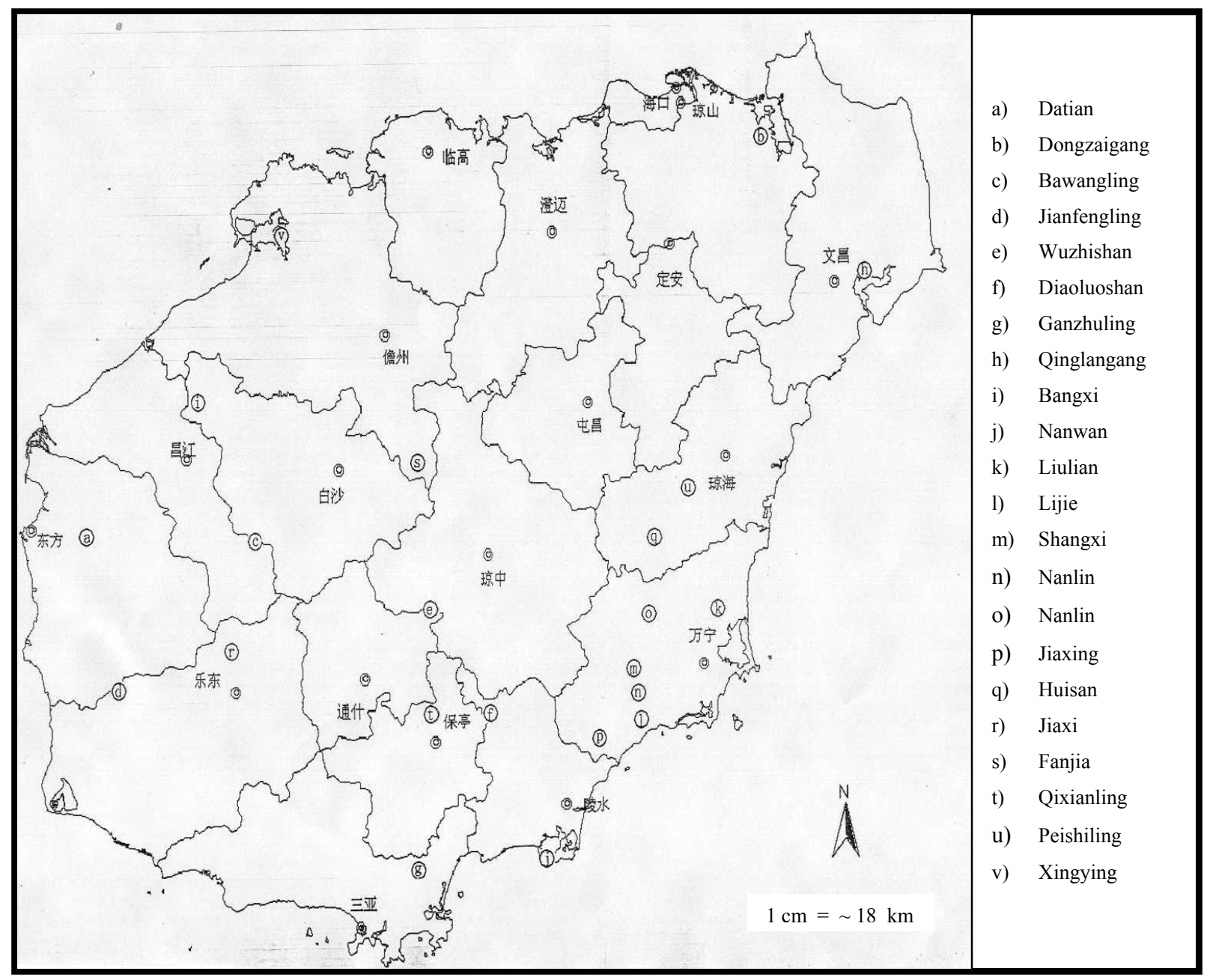

Figure 4.1: Location Map of Hainan's Nature Reserves

Source: Hainan Forest Bureau

If the Province wishes to change the status of a Reserve to 'National', the government must submit an application to the State Council (Central Government). Simultaneously, the HFB submits the same documentation to the SFA. State Council reviews the application along with the SFA's recommendations before making a final decision. As for Parks, applications are received once per year.

Since 2000, the Central Government has increased investment in National level Reserves. However, unlike Parks, the Reserves apparently will not receive funds under the NNFPP. All 
Reserves receive some Provincial government funding for salaries, with the specific amount dependent on the number of staff at a particular Reserve. In addition, National Reserves may also receive Central Government funding. There is no fixed annual amount, or guarantee, of Central funds; funding is dependent on projects that are proposed for an individual Reserve in any given year.

\subsubsection{Management Issues}

A number of important general management issues affecting the Parks and Reserves were raised during interviews with key officials. One of the biggest management challenges facing all protected areas, and noted by numerous officials and managers interviewed, is funding shortages. Although Reserves have fewer options compared to Parks in terms of raising money, both have suffered, and still suffer, from limited funds. While relations between the two have generally been good, the fact that Parks have more opportunities to raise monies has, in some cases, been a source of conflict between managers. Where the two must co-exist, as at Jianfengling and Diaoluoshan, conflict and confusion have also occasionally arisen over the different regulations governing each, and the different ideas and views on management and development that exist as a result.

There has also apparently been some confusion among tourists as to the differences between Parks and Reserves, with some believing they are free to travel in Reserves to observe the often more pristine, natural sights. Similarly, people living adjacent to protected areas do not necessarily understand or respect the differences between Parks and Reserves. Many of the people living near protected areas, especially the Li and Miao ethnic minority groups, are very poor. Traditionally, local people were allowed to use the resources in some of the areas now protected in Reserves or Parks. These habits have persisted in some places, resulting in continued pressures on, now officially protected, natural resources.

Such pressures may be aggravated by the fact that about 6,000 people, of the roughly 15,000 workers employed by the Provincial Forest Farms in the early 1990s, lost jobs when the logging ban was imposed in 1994. While some relocated to find employment, the ban has increased the number of people living in regions adjacent to newly protected areas that are without a means of supporting themselves and their families. Where Parks buffer Nature Reserves, as at Jianfengling and Diaoluoshan, these pressures have tended to be less severe and less damaging.

A number of officials also indicated that local-level protected area managers have insufficient education and training. This is partially due to the fact that those employed by the former Forest 
Farms, many of whom have now taken on new roles in the protected area agencies (Forest Bureaus), have training suited to the timber industry, not conservation or protected area management. Some also suggest the education problem stems from the inadequacy of the programs and training currently offered in universities. Others noted the inability of local level agencies to attract highly skilled professionals as a key problem.

Finally, one official commented that, while some form of management plan exists for most Parks, they are typically not very comprehensive. Furthermore, there is apparently no provincial or national legislation governing park planning and management, or no management criteria or standards.

Although some note that local Bureaus are doing their best to adapt to new conditions, they also caution that their efforts need to be evaluated against international standards.

\subsection{Interpretati ons of Ecotourism in Hainan}

This thesis highlights that there exists little consensus among professionals and academics over what exactly constitutes 'ecotourism' (Section 2.1.2). Arguably, at any particular destination where ecotourism is being promoted, there must be some degree of consensus on the term's meaning, and associated strategies, if benefits are to be reaped - what are the expectations and objectives behind the development of ecotourism in a region? In an effort to gauge the interpretation and expectations for ecotourism in Hainan, and to determine if some degree of consensus exists, park and government agency officials were asked for their views on the concept during interviews. Some of their thoughts are presented here to provide contextual background for the case study discussions that follow this chapter.

Hainan's EcoProvince proposal identifies ecotourism as a tourism development strategy for the Island, noting that ecotourism destinations are to be developed and marketed nation-wide (Department of Lands, 1999). Although no clear definition is provided in the proposal, the following excerpts suggest that ecotourism is intended to be a sustainable form of tourism that allows people to enjoy nature, while at the same time protecting some of the Island's more precious natural resources. "A good environment and natural ecology are basic conditions for achieving sustainable development of tourism" (p.34); "Tourist development should be subordinated to the protection of the ecological environment" (p.35); and "we should take the initiative to develop the ecological tourism designed to know, enjoy and protect the nature" (p.35). The proposal also acknowledges that education plays an important role in raising the public's awareness about the importance of the environment. While it 
does stress protection, the proposal does not mention low visitor impact or environmentally responsible travel as important aspects of ecotourism. Furthermore, ecotourism is not specifically called upon in the document to improve the socioeconomic conditions of people living in close proximity to ecotourism sites. However, it is, more generally, identified as one of the main strategies under the EcoProvince initiative, the Island's policy framework for "improving the ecological environment, accelerating economic development, raising people's living standards and achieving modernization" (p.3).

With a little reading between the lines, it appears as though most of the key elements of a comprehensive definition of ecotourism, like that adopted for this study, are recognized by the Provincial Government (at least by the Department of Lands, Environment \& Resources). However, the EcoProvince proposal goes on to subdivide ecotourism into marine ecological tourism, equatorial rainforest tourism and tourism for exploring/investigating plants, animals and mountains. Under this division, a number of sites are identified for the development of ecotourism, ranging from undeveloped, fairly remote wilderness areas/parks (consistent with a restrictive definition of ecotourism) to botanical gardens, beaches, and facility-laden wildlife/ocean and cultural theme parks (more commonly associated with other forms of tourism). This suggests that perhaps there is some confusion over what exactly ecotourism is or what ecotourists would be attracted to. On the other hand, the identification of a diversity of sites could be interpreted as that the Province has opted for a loose definition of ecotourism, that would perhaps be more aptly described as broad-based nature tourism. Such an interpretation is consistent with Brandon's (1996) distinction between ecotourism, as small-scale, impact sensitive tourism, and nature-tourism, where scale is not the defining factor, but rather the focus on nature.

Based on 16 interviews with site-level managers and key park/tourism officials from Provincial Government and research agencies, it appears that overall $(n=16)$ there is fairly broad consensus that ecotourism involves travel in natural areas (50\% of respondents), resource protection $(50 \%)$ and socioeconomic benefits for local populations (56\%) (Table 4.2). Less noted overall were cultural aspects $(19 \%)$ and that ecotourism is a form of responsible/low-impact travel (13\%) that, unlike mass tourism, may involve limiting the number of tourists an area receives (13\%). Although half of the respondents associated nature protection with ecotourism, only $19 \%$ overall specifically noted that tourism-generated dollars can be put back into conservation efforts. 
Table 4.2: Interviewees' Interpretations of Ecotourism

\begin{tabular}{|c|c|c|c|c|c|c|}
\hline Response & $\begin{array}{c}\text { Provincial } \\
\text { Officials } \\
n=7\end{array}$ & $\begin{array}{c}\text { As a } \\
\%\end{array}$ & $\begin{array}{c}\text { Site Level } \\
\text { Officials } \\
n=9\end{array}$ & $\begin{array}{c}\text { As a } \\
\%\end{array}$ & $\begin{array}{l}\text { Total } \\
n=16\end{array}$ & $\begin{array}{c}\text { As a } \\
\%\end{array}$ \\
\hline Nature focused travel & 2 & $29 \%$ & 6 & $67 \%$ & 8 & $50 \%$ \\
\hline Learn about/enjoy nature & 1 & $14 \%$ & 5 & $56 \%$ & 6 & $38 \%$ \\
\hline Environmental education & 2 & $29 \%$ & 4 & $44 \%$ & 6 & $38 \%$ \\
\hline Low impact/responsible travel & 0 & $0 \%$ & 2 & $22 \%$ & 2 & $13 \%$ \\
\hline Cultural attractions & 2 & $29 \%$ & 1 & $11 \%$ & 3 & $19 \%$ \\
\hline Local economic benefits & 7 & $100 \%$ & 2 & $22 \%$ & 9 & $56 \%$ \\
\hline Tourism $\$$ for conservation & 2 & $29 \%$ & 1 & $11 \%$ & 3 & $19 \%$ \\
\hline Protects nature/good for park & 4 & $57 \%$ & 4 & $44 \%$ & 8 & $50 \%$ \\
\hline Form of sustainable development & 4 & $57 \%$ & 1 & $11 \%$ & 5 & $31 \%$ \\
\hline Limits \# of tourists & 0 & $0 \%$ & 2 & $22 \%$ & 2 & $13 \%$ \\
\hline Planning/management important & 6 & $86 \%$ & 1 & $11 \%$ & 7 & $44 \%$ \\
\hline Increasingly popular trend & 1 & $14 \%$ & 2 & $22 \%$ & 3 & $19 \%$ \\
\hline Is a buzz-word & 2 & $29 \%$ & 0 & $0 \%$ & 2 & $13 \%$ \\
\hline Cited potential negative impacts & 3 & $43 \%$ & 3 & $33 \%$ & 6 & $38 \%$ \\
\hline
\end{tabular}

Compared to provincial and other officials, site level managers placed greater emphasis on ecotourism's focus on nature travel (67\% vs. $29 \%)$, that it involves learning about and enjoying nature (56\% vs. $14 \%$ ), and the importance of educational aspects (44\% vs. $29 \%)$. Site level managers were the only group to recognize that ecotourism should be low-impact travel $(22 \%)$ and that the number of tourists permitted at a site may need to be controlled (22\%). Conversely, outside officials stressed local economic benefits ( $100 \%$ vs. $22 \%)$, that ecotourism is related to sustainable development (57\% vs. $11 \%$ ), and that planning and management will be important in developing successful ecotourism ( $86 \%$ vs. 11\%). One provincial official indicated that the goal of forest ecotourism is to raise monies for the Provincial Government, site level Forest Bureaus and local people through increased employment opportunities. Another high-ranking provincial official said 
that tourism is to help create new jobs for the people who lost them with the imposition of the logging ban in 1994.

Only one-third of site level officials, and just over $40 \%$ of provincial and other agency officials, noted that ecotourism has the potential to also generate negative impacts. Negative effects cited include increased waste, reduced animal health and general environmental damage or pollution resulting from too many or uneducated tourists. One official recognized that promoting ecotourism could limit other developments at a site, suggesting a concern for benefits foregone. However, those that did suggest potential negative impacts generally felt that the potential benefits would outweigh any associated costs. Indeed, the predominant feeling among those interviewed was optimism; the belief that ecotourism will generate broad-based benefits for Hainan.

As under the EcoProvince document, a variety of sites were identified by officials - forest parks/reserves, a cultural botanical garden, and a monkey reserve/zoo - as good examples of, or potential sites for, ecotourism. At least one interviewee contested the suitability of a site commonly referred to by the Provincial Government as an example of ecotourism, suggesting that there are too many man-made features and that the cultural themes being showcased are not provincially significant.

A number of officials provided their thoughts on the barriers facing Hainan in its pursuit to develop ecotourism. Some noted that local people living in areas where (eco)tourism is being promoted might not support its development due to resentment and bitterness over lost jobs and the ban on cutting trees. Similarly, local education levels may limit people's ability to understand how they might benefit from the development of (eco)tourism. When asked if local education levels might also limit people's ability to participate in, and thus benefit from, ecotourism, one official agreed it may present a barrier, but that locals often have greater knowledge of the local area and may therefore have more employment opportunities than outsiders. Nevertheless, it was noted that local training/retraining will be important, even though such efforts typically suffer from limited funds and the unwillingness and ability of employers to invest the requisite time.

Others noted that at present, ecotourism sites cater to domestic tourists, and that attracting a foreign market is an important issue the Island faces. Hainan is not well known to most of the world. This is one of the main reasons that the World Tourism Organization (WTO) was invited to produce a tourism master plan for the Province. It was also noted that domestic tourists do not distinguish between 'eco' and other forms of tourism, that there are few domestic ecotourists, and that it is the 
government that is emphasizing the 'eco' aspect of tourism. Another official suggested that the reason ecotourism is currently not so profitable is that infrastructure and services are inadequate. It was suggested that many of the sites identified for ecotourism development suffer from poor roads, unreliable power supplies, basic lodging facilities, poor service quality, no educational/interpretive programs, improperly trained staff and the inability to attract and pay high quality staff.

Overall, it seems that there is fairly wide consensus that ecotourism is a form of nature-focused travel that balances protection with human enjoyment of, and learning about, special/beautiful places. Although much less noted among site level managers, it also appears that officials are looking to ecotourism to generate economic benefits for the Province, protected area agencies and local people. Also less common at the site level, but nevertheless present, is the recognition that planning and management is imperative to the development of successful ecotourism. However, based on the diversity of sites identified as existing or potential ecotourism destinations, there seems to be some confusion over what exactly constitutes ecotourism, what ecotourists are motivated by, and what market the Province is trying to appeal to. This may in turn make it difficult for Hainan to attract a foreign ecotourist market, and thus to achieve the economic and protection benefits it is seeking. The challenges are compounded by the jurisdictional complexities of Park and Reserve status and the lack of reliable resources for their management. 


\section{Chapter 5}

\section{Case Study I: Jianfengling National Forest Park}

This chapter presents and discusses the findings of the research undertaken in Jianfengling National Forest Park and Jianfeng Town. The purpose of the case study is to evaluate the local, communitylevel, impacts of ecotourism development in the Jianfengling region, through an assessment of the current status of ecotourism. The Ross/Wall framework (Figure 2.3) and associated indicators (Table 2.1) are used to help guide the evaluation. A study site description is provided for Jianfengling National Forest Park and Provincial Nature Reserve (5.1) and Jianfeng Town (5.2). These sections provide the context for a discussion of the relationships between the local community and the Park (5.3), the local community and tourism (5.4), and the Park and tourism (5.5). The chapter concludes with a discussion of management and policy issues, and their influence on the relationships between the various stakeholders (5.6).

\subsection{Site Descri ption - Jianfengling National Forest Park and Provincial Nature Reserve}

\subsubsection{Location}

Jianfengling National Forest Park and Provincial Nature Reserve (JNFP) is located in the mountainous, largely undeveloped, southwest part of Hainan Island in Ledong County (Figure 5.1). The Park sits at latitude $18^{\circ} 23^{\prime}-18^{\circ} 52^{\prime} \mathrm{N}$ and longitude $108^{\circ} 36^{\prime}-109^{\circ} 05^{\prime} \mathrm{E}$, and comprises a total area of approximately 447 square $\mathrm{km}$, of which $96 \%$ is forested. Established in October 1992 by the SFA, Hainan's first National Park consists largely of secondary forest, the result of extensive selective logging prior to 1993, interspersed with fragments of primary tropical rainforest (Asian Development Bank, 1995). This includes a roughly 17 square km Provincial Nature Reserve, or 'core' area, of intact virgin tropical forest located within the Park boundary. The Reserve, the first on Hainan, was established in 1960 by the $1^{\text {st }}$ Peoples Standing Committee of China, around the time that logging began in the region, as an area of strict protection where cutting was forbidden. Surrounding the Park is an extensive buffer area where a wider variety of economic activities and sustainable livelihood/production activities is permitted and experimented with. JNFP has an average annual temperature of $25^{\circ} \mathrm{C}$ at sea level and $19^{\circ} \mathrm{C}$ at an altitude of $800 \mathrm{~m}$, where much of the Park lies. The highest peak in the park is $1412 \mathrm{~m}$ (Figure 5.2). Hainan experiences moderate to severe 


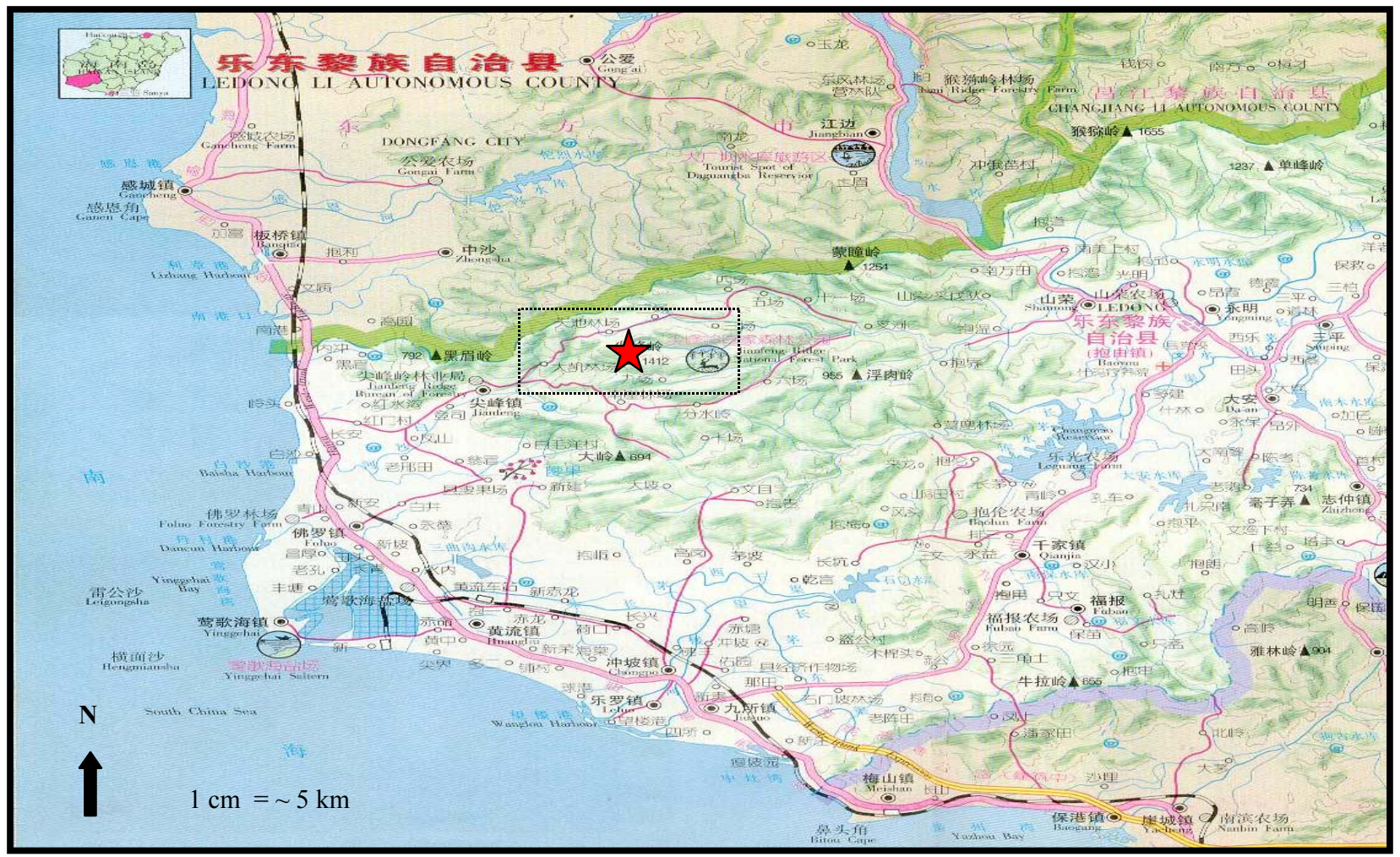

Figure 5.1: Location of JNFP

$\star \quad--$ area enlarged below

Source: Hainan Tour Atlas, 1997

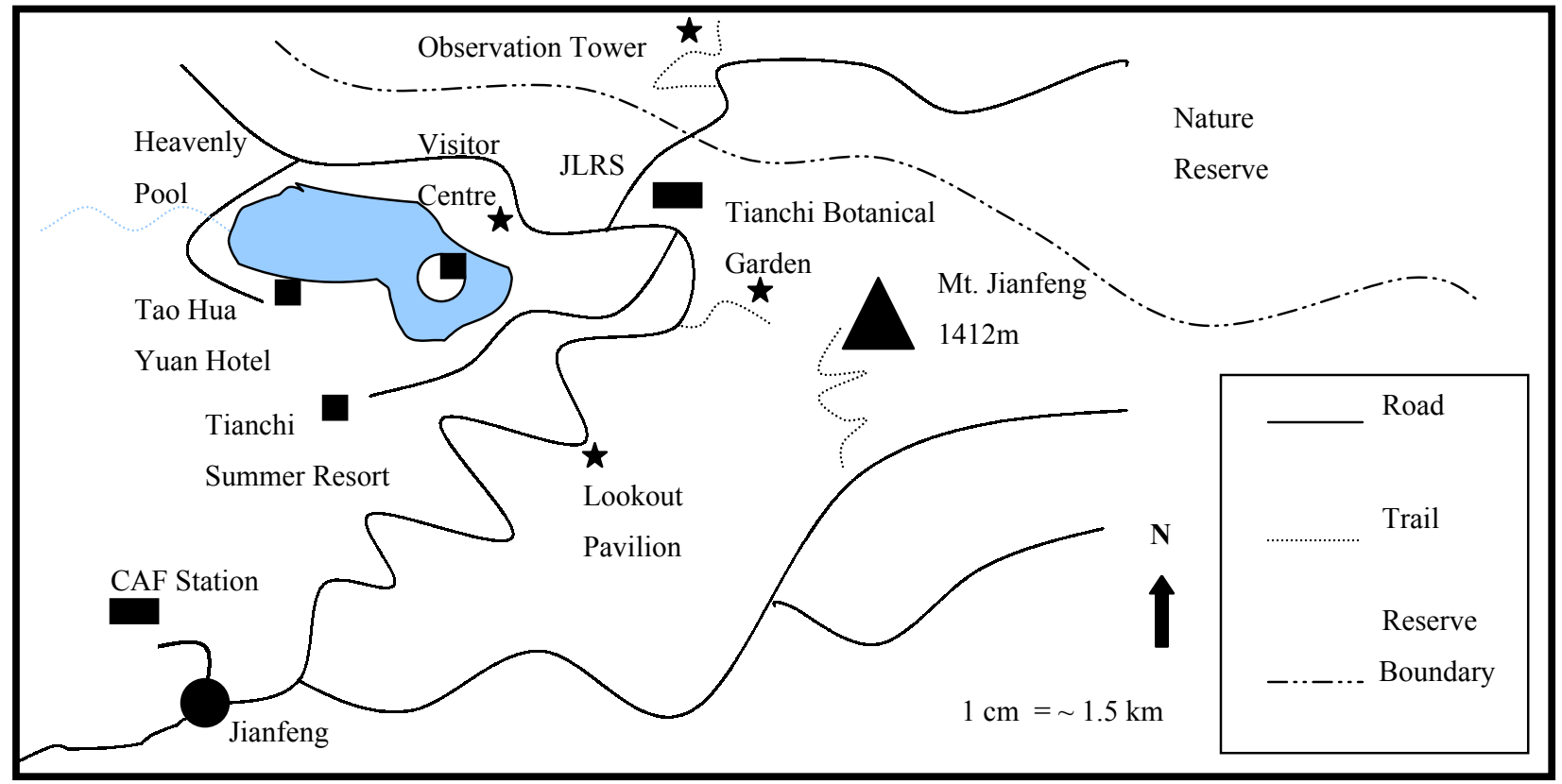

Figure 5.2: Infrastructure and Attractions at JNFP 
continental northwestern, maritime southwest and southeast typhoons between June and November that affect all parts of the island. The Jianfeng region receives between 1000 and $2000 \mathrm{~mm}$ of rainfall each year (Asian Development Bank, 1995).

\subsubsection{Management and Administrative Structure}

The Guangdong Provincial Government, the administrative body responsible for Hainan prior to provincial designation in 1988, established the Jianfengling Forest Bureau (JFB) in the early 1950s to manage the timber industry in the region (Chongyi et al., 1997). With the imposition of a Provincewide ban on all logging in natural forests in 1994, the management mandate of the Forest Bureau in the Jianfengling region shifted from that of a profit-oriented forestry enterprise to one of forest protection and resource conservation. Lands previously subjected to selective logging have become the lands protected within the boundaries of JNFP. The JFB is now responsible for the implementation of the National Natural Forest Protection Program (NNFPP) and park management. This includes tourism management, on which they must collaborate with the Hainan Tourism Bureau (Administration) and the Hainan Department of Lands, Environment and Resources.

Two park management plans exist to guide development and management at JNFP. The Institute of Architectural Design and Research of Tsinghua University in Beijing completed the first plan in 1994. The Asian Development Bank formulated the second in 1997 as part of a technical assistance program they funded. No new plan for JNFP is currently scheduled, however the plans are flexible enough that amendments can be made when deemed necessary. While no separate site-level tourism plan exists for the Park, tourism is apparently addressed in both of the park management plans.

The JFB has a staff of approximately 235. Three or four of the 30 top-level managers, researchers and 'experts' work at the JFB, with the remainder residing abroad (i.e. international experts) or working from central government offices in Beijing. Three or 4 women hold positions on the higher level management team. The JFB has a protection and security staff of about 120 working and living throughout the region (Associates in Rural Development, 1998). Forty-five middle and lower level managers and staff work out of the JFB offices in Jianfeng, with an additional 41 working within the Jianfengling Forest Travel Development Company (which includes the staff of the 2 Bureau-operated hotels). Education levels in the JFB reflect the agency's previous role as a timber management enterprise, with top local officials generally having training in business and economics, rather than in 
biology or natural resource management. While the training of national and international 'experts' was not determined, education levels in the lower levels of management are apparently limited.

Prior to Park establishment, JFB relied almost exclusively on the sale of timber to generate funds for operations and management. The logging ban has required the Bureau to find new sources of funding. In part, these have come from the commercial sale of products grown on fruit farms (mango and banana) and rubber, timber, and bamboo plantations. Park zoning permits the operation of such enterprises in certain areas. At Jianfengling, such operations have raised between 1 million RMB and 6 million RMB ( $\$ 192,300$ and $\$ 1.15$ million CDN) for the JFB annually according to different estimates. Funds have also come from the Provincial and, to a lesser extent, Central Governments. While most government funding came from the Province between 1993 and 1999, such funding was not guaranteed. The JFB was required to make an application for funds to the Hainan Forest Bureau (HFB), which was reviewed also by the Provincial Department of Economic Planning and Bank(s), for feasibility, benefits, impacts, etc. With increased government investment in forest protection under the NNFPP, as of 2000 the JFB is guaranteed to receive approximately 10 million RMB (\$1.9 million CDN) annually until 2010; $80 \%$ of this amount will come from the Central Government.

The Provincial Nature Reserve within the Park is managed by a different section of the Hainan Forest Bureau (HFB), and has its own management plan, staff and funding arrangements. The Reserve's staff of 19 is made up of 9 managers and a security team of 10, and includes 3 women. Four have formal university training (one in each of biology, forestry, computers and accounting). The recently retired top manager, formerly a logger for the JFB, had high school education, supplemented with a series of university courses in biology taken upon appointment to a managerial position. Reserve staff occasionally have the opportunity to attend relevant conferences to upgrade their training. As a Provincial Reserve, funding comes almost solely from the Province, and is dependent on the number of staff. In recent years, annual funding has averaged approximately $250,000 \mathrm{RMB}(\$ 48,000 \mathrm{CDN})$, most of which goes towards salaries.

Financial resources and staff education levels were the main management constraints identified for both the Park and Reserve. While no major conflicts between the various bodies involved in Park, Reserve, and tourism management have surfaced to date, tourism development is currently limited, and the potential for disagreement may increase in the future if tourism and the pace and scale of development grow. 


\subsubsection{Flora and Fauna}

Hainan Province is recognized as one of the most biologically diverse regions in the world (Ouyang et al., 2001; Weisun, 2000), and is home to China's only mountainous rainforest region (Wandi, 1999). With an extensive area of intact primary tropical forest (Figure 5.3), JNFP contains one of the best preserved and protected, rainforests in China (Hainan Forest Bureau \& Chinese Academy of Forestry, 2000; Wandi, 1999; Asian Development Bank, 1995). Both lowland and mountainous rainforest are found within the Park (Hainan Forest Bureau et al., 2000), providing for an incredibly rich range of plant and animal species. Since the 1960s, the Chinese Academy of Forestry (CAF), Hainan Forestry Research Institute (HFRI), and various other organizations, universities and scientists from both China and abroad have been actively involved in completing resource inventories and tropical forest research in the region. Table 5.1 shows a breakdown of currently known species diversity at JNFP compared to the rest of Hainan Province and China.

Table 5.1: Biodiversity at JNFP

\begin{tabular}{|c|c|c|c|c|c|}
\hline & $\begin{array}{c}\text { Number of } \\
\text { Species } \\
\text { Jianfengling }\end{array}$ & $\begin{array}{c}\text { Number of } \\
\text { Species } \\
\text { Hainan }\end{array}$ & $\begin{array}{c}\text { Jianfengling } \\
\text { as } \\
\% \text { of Hainan }\end{array}$ & $\begin{array}{c}\text { Number of } \\
\text { Species } \\
\text { China }\end{array}$ & $\begin{array}{c}\text { Jianfengling } \\
\text { as } \\
\% \text { of China }\end{array}$ \\
\hline Ferns & 133 & 362 & 36.7 & 2,600 & 5.1 \\
\hline Gymnosperms & 13 & 17 & 76.5 & 200 & 6.5 \\
\hline Angiosperms & 2,075 & 2,767 & 75.0 & 24,357 & 8.5 \\
\hline Birds & 215 & 344 & 62.5 & 1,116 & 19.3 \\
\hline Mammals & 68 & 82 & 82.9 & 499 & 13.6 \\
\hline Amphibians & 38 & $>50$ & 76.0 & 279 & 13.6 \\
\hline Reptiles & 50 & 104 & 48.1 & 376 & 13.3 \\
\hline Insects & 2,222 & - & - & 34,000 & 6.5 \\
\hline Butterflies & 449 & 609 & 73.7 & - & - \\
\hline Spiders & 162 & - & - & $>1,000$ & 16.2 \\
\hline Macro-fungus & 312 & 651 & 47.9 & 5,080 & 6.1 \\
\hline Ganodermataceae & 38 & 60 & 63.3 & 90 & 42.2 \\
\hline
\end{tabular}

Source: Adopted from Hainan Forestry Bureau et al., 2000 


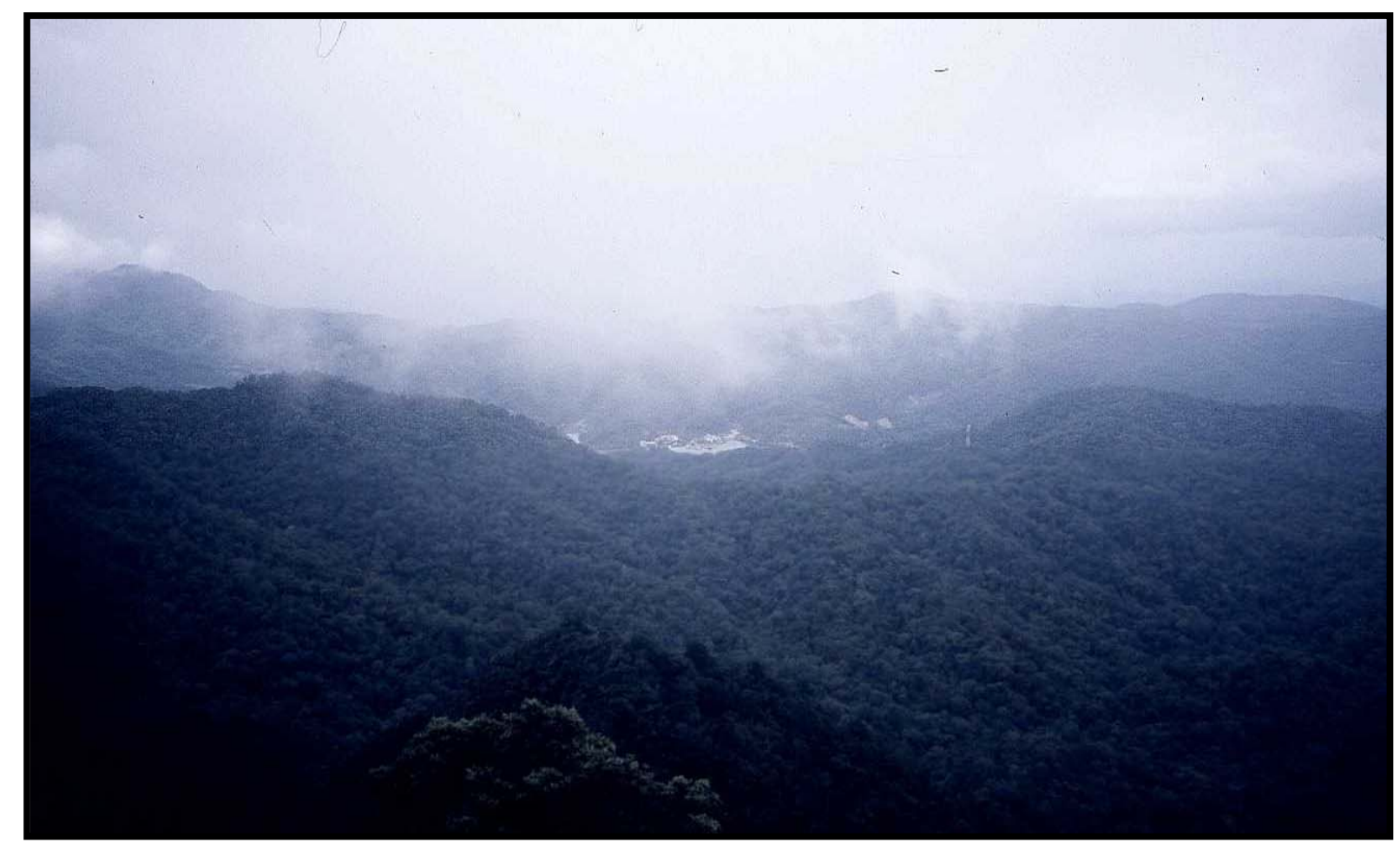

Figure 5.3: A Large Tract of Primary Tropical Forest in JNFP

Of the more than 2,200 species of plants in the Park, 78 are on China's top-priority list for protection, with an additional 600 on the rare species list, including a species of tree fern from the dinosaur age (Alsophila spinulosa Tryon) (Weisun, 2000). JNFP contains 54 animal species that are found on China's top-priority list for protection, including the Cloud Leopard (Neofelis nebulosa Griffith) and other important species like Rhesus monkey (Macaca mulatta brachyurus Eliot) and Chinese Egret (Egretta eulophotes Swinhoe).

These figures suggest impressive biodiversity and good ecotourism potential, recognizing that ecotourists generally wish to travel to biologically important and exotic places (Brandon, 1996). However, it is important to note that many of the species lists still used today are based on inventories completed in the 1950s and 1960s (Ouyang et al., 2001). Four decades of land use change have likely had a major affect on the biodiversity of the Island. Indeed, tourists to the Park are not guaranteed a wildlife (large mammal) sighting. Some officials and local residents were of the opinion that the chances of observing a rare, or for that matter any, mammal species in the wild are poor. 


\subsubsection{Infrastructure, Attractions and Accommodations}

Major infrastructure in the Park is minimal and generally limited to an area surrounding a small manmade/enlarged lake - the 'Heavenly Pool' - which adjoins the western boundary of the Nature Reserve at $800 \mathrm{~m}$ asl. (Figure 5.2). Located immediately outside the Reserve's western gate, is the Jianfengling Long-Term Research Station (JLRS). It is 1 of 4 stations administered by the State Forest Administration of China, where a wide variety of biological, hydrological, agricultural and socioeconomic research related to tropical forests is undertaken. Some interpretive media (some of which is in English) - photos and butterfly specimens - can also be found at the station. A few kilometers into the Reserve, along a rough dirt track, sits an observation/fire tower that tourists may climb for a fee (20 RMB/\$3.85 CDN) to gain views over the Park and Reserve core area.

Within walking distance of the hotel/lake area is the Tianchi Botanical Garden, a roughly 30 hectare trailed area of tropical forest which tourists can explore. The lake is also the site of the newly built, but as of the time of this research, unopened, tourist centre. The centre houses a scale model of the Park and some interpretive media (mainly photos). When opened, tour guides are to be available for hire from here. Tour guides are recommended for some of the approximately $10 \mathrm{~km}$ of trails that exist in the Park, including the hike to the summit of Mt. Jianfeng (Figure 5.4), the highest peak in the park at $1412 \mathrm{~m}$.

The trails observed were in variable condition. Despite a lack of trail markers, the Mt. Jianfeng summit trail is well trodden, and the generally flat (but in places steep) track is relatively easy to follow (assuming someone directs you to the unmarked trailhead). While the trail is not surfaced or obviously maintained, erosion and widening appeared limited. Litter was largely absent along the trail which is a good sign given its apparent popularity. Some simple rope handrails constructed in the more precarious places near the top and an abandoned army barracks on the summit are the only constructed infrastructure on the trail. A second trail hiked was in much poorer condition. Although trail damage and litter was largely absent, the trail was in serious need of maintenance. Following along a river, there were no trail markers or, in many places, an actual trail. Aside from the occasional rustic ladder, there was little evidence to suggest that one was on a trail. The hike was more a bushwhacking and river-bouldering (in places dangerous) obstacle course than an actual trail hike (Figure 5.5), making a guide mandatory. No interpretive media are provided along either trail. Indeed, interpretive opportunities and media are limited throughout the Park. The same is true for basic information and signage. A small number of regulatory signs (in Chinese) were observed along 


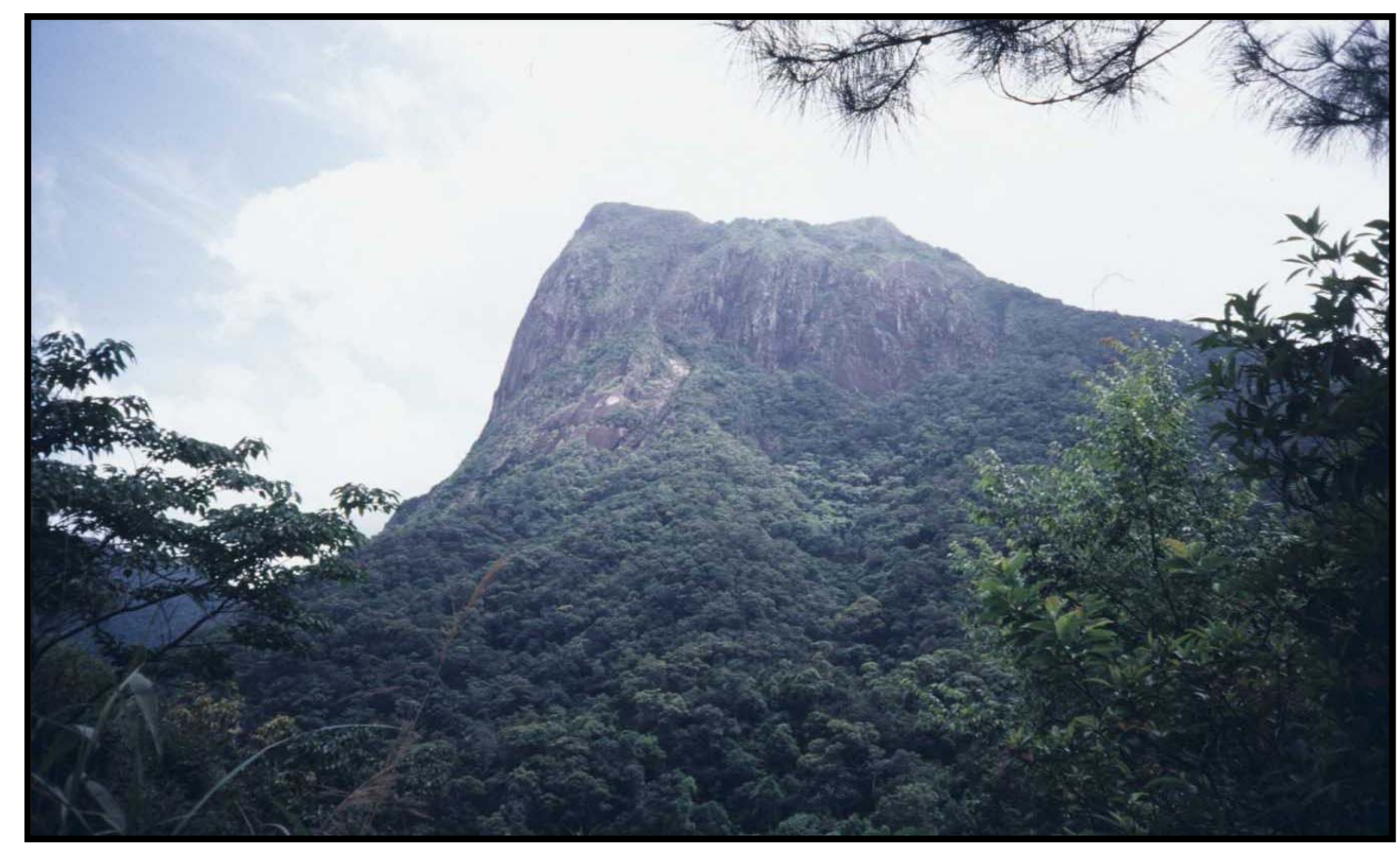

Figure 5.4: Mt. Jianfeng, the Highest Point in JNFP

the main road from town to the lake area. An observation pavillion has been constructed halfway between town and the lake, which offers tourists views over Jianfeng and the surrounding hills.

Three hotels surround the lake in the Park. The largest and most popular - the Tao Hua Yuan Hotel - is a privately owned facility sitting on the edge of the lake (Figure 5.6). It opened in March 1995. The hotel can accommodate up to 106 people in 61 rooms that range from 120 RMB to 880 RMB ( $\$ 23$ - \$169 CDN) per night. All rooms provide televisions, some with private bath, but none with air conditioning (instead relying on 'natural' air conditioning). Facilities include 1 Chinese food restaurant, 1 coffee lounge, 1 multi-function room/karaoke hall, 1 motorboat, 4 paddleboats and numerous fishing rods. A second restaurant and a beauty shop are to be added to the facilities by the end of the year. Although not currently rated, the hotel is striving to attain a 3-star rating from the Hainan Provincial Tourism Administration.

The JFB owns the Tianchi Summer Resort (Figure 5.7), which opened in 1998. It is the second main hotel in the area. Sitting in the hills surrounding the lake, it provides 35 beds in 21 rooms ranging in price from $150 \mathrm{RMB}$ to $180 \mathrm{RMB}(\$ 29$ - \$35 CDN) per night. All rooms are equipped with televisions and private bath, but do not have air conditioning or telephones. The hotel is 


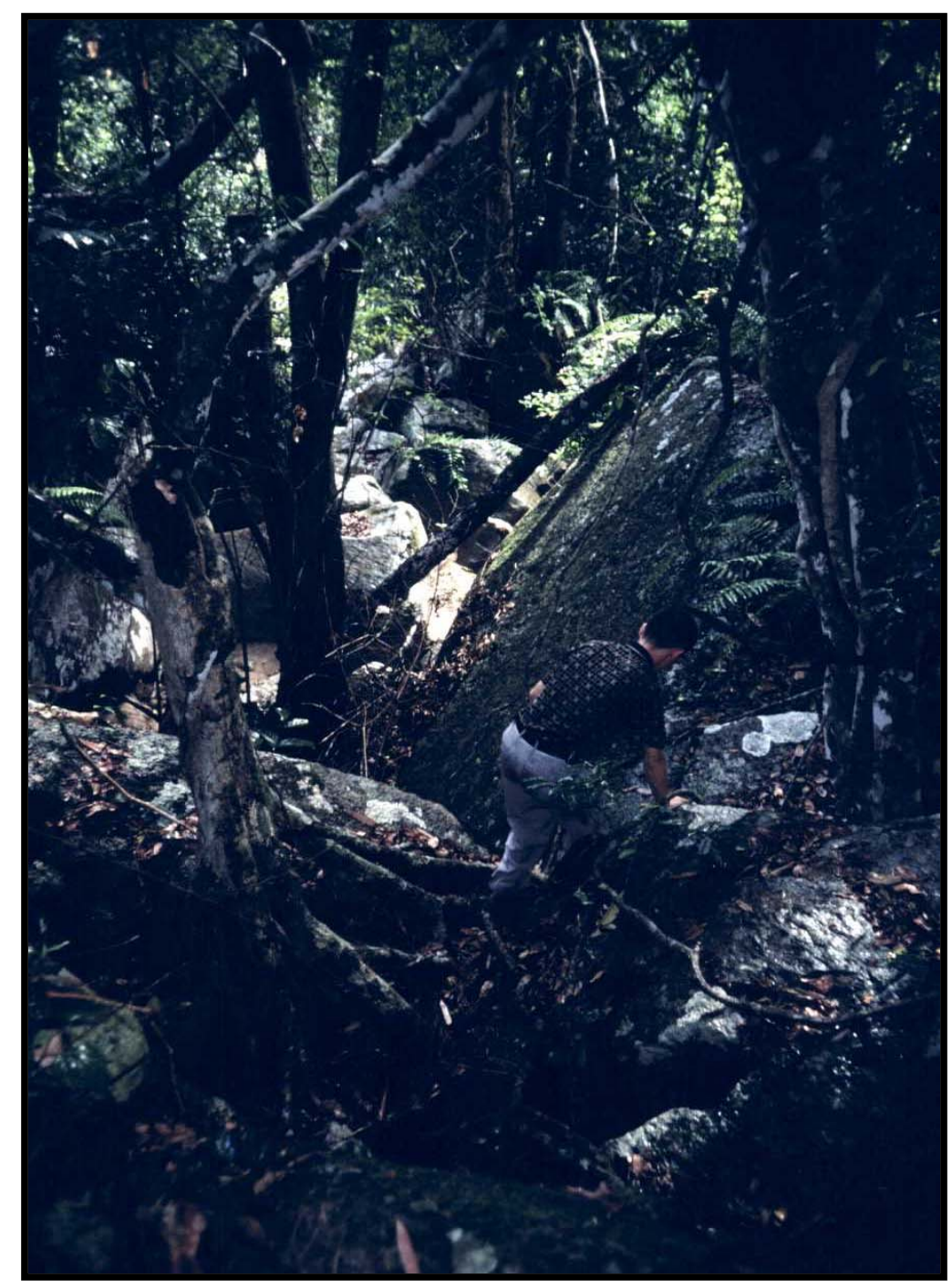

Figure 5.5: A Hiking Trail in JNFP

equipped with 1 restaurant, 1 meeting room and an entertainment/disco hall. The Resort is planning to expand the number of rooms in the future and is also trying to obtain a 3-star rating.

The third hotel, the smallest, least frequented and obviously in the poorest condition, sits on a small island in the middle of the lake. Management could not be contacted to provide details on accommodation types and rates but, based on observations, facilities appeared to be limited and very basic.

In addition to the 3 hotels in the Park, the Town of Jianfeng offers 2 accommodation choices. The JFB-owned Jianfengling Hotel opened in 1999 in a former JFB building from the 1960s, and has 28 


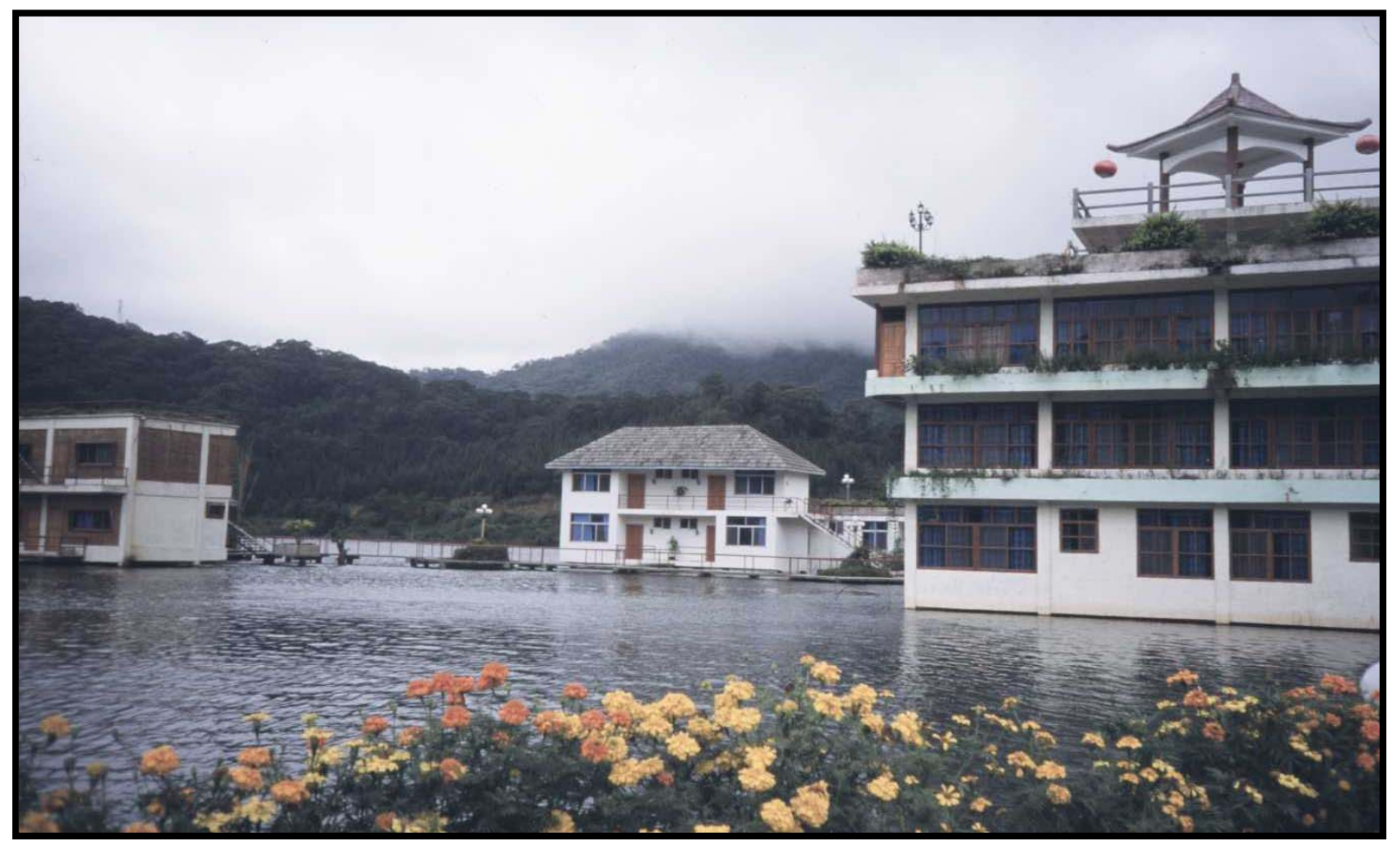

Figure 5.6: The Tao Hua Yuan Hotel, JNFP

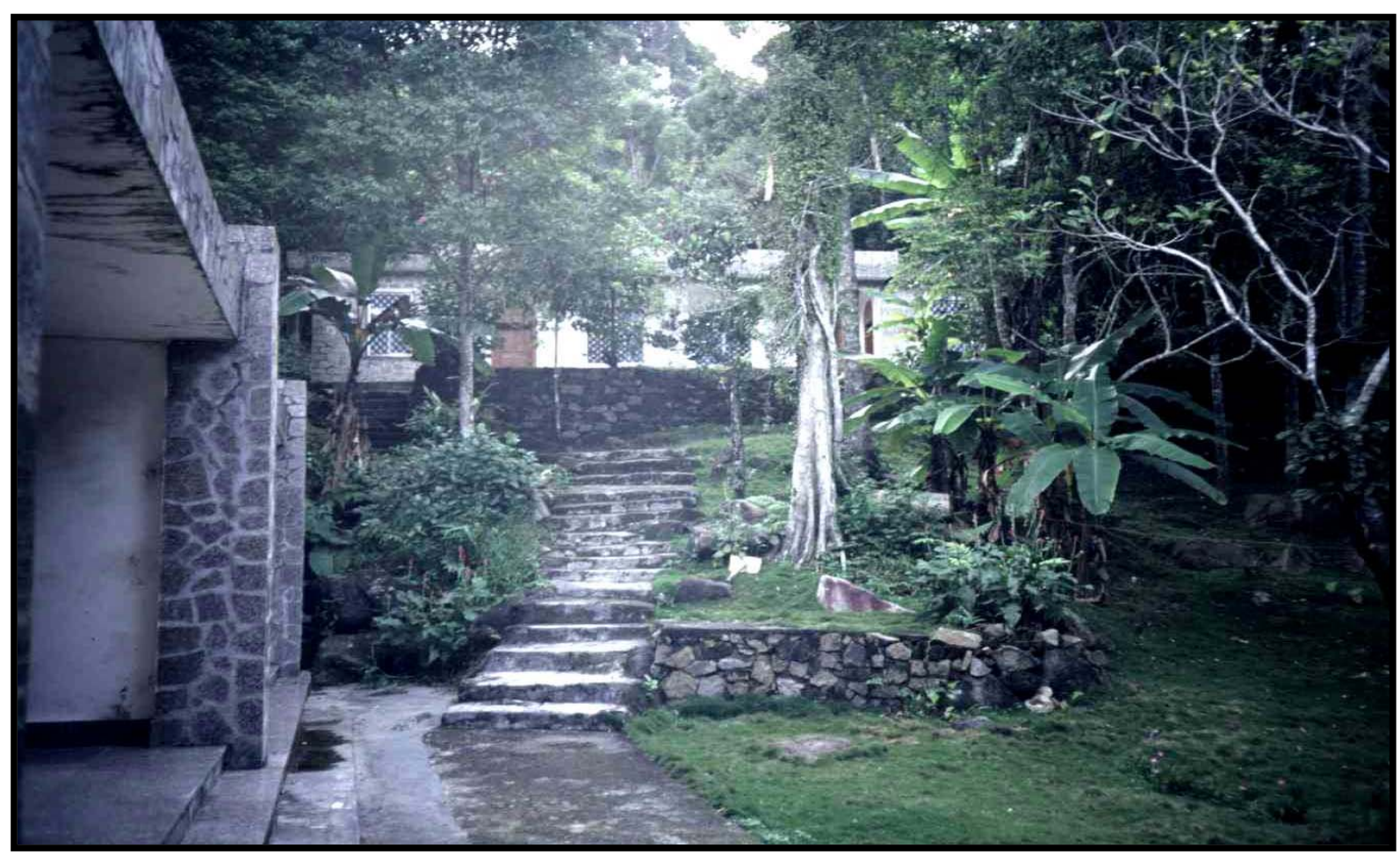

Figure 5.7: The Tianchi Summer Resort, JNFP 
rooms each with 2 beds (Figure 5.8). Rates for rooms with private bath and fans are $40 \mathrm{RMB}, 60$ RMB or $80 \mathrm{RMB}(\$ 8, \$ 12$ or $\$ 15 \mathrm{CDN})$ depending on whether or not a television and/or heater are provided. The restaurant and dance hall were closed for renovations at the time of this research. The Jianfengling Hotel does not carry a star rating. The second accommodation choice is the CAF Research Station just outside of town. Owned by the CAF, but with management responsibility leased privately, the facility offers 30 beds and has been in operation for 15 years (catering mostly to researchers working in the Jianfengling region). The hotel has no restaurant or star rating. Rooms with television and private bath are available for $100 \mathrm{RMB}$ with air conditioning and $50 \mathrm{RMB}$ without ( $\$ 19$ and $\$ 10 \mathrm{CDN})$.

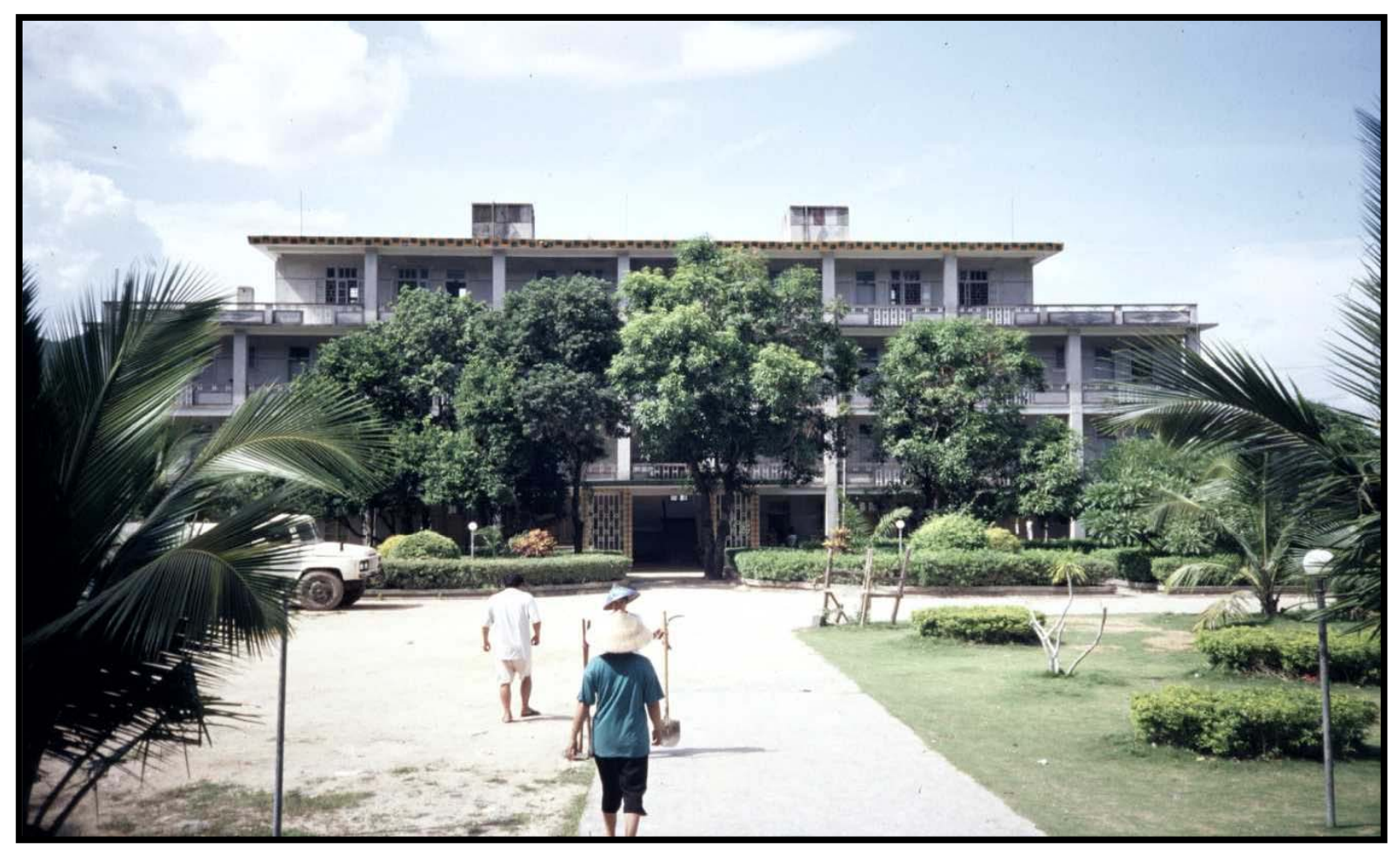

Figure 5.8: The Jianfeng Hotel, Jianfeng Town

The current state of infrastructure development and accommodations raises some concerns recognizing that management is aiming to attract a relatively wealthy, and high-spending, foreign market. Will such a market be content with 3-star (or less) facilities? Are the highest-spending tourists even likely to visit a site like JNFP in the first place? If, more specifically, management is after foreign 'ecotourists', perhaps current mid-range accommodations will be sufficient given that 
such tourists often place greater emphasis on the experience than on accommodation quality (Eagles, 1998; Norris, 1992). However, ecotourists do demand a high quality experience and the opportunity to learn about and observe nature (Eagles, 1992). JNFP arguably does not currently adequately provide such an opportunity for foreign (or domestic) tourists.

\subsubsection{Future Developments}

According to the original development plan, the bulk of new facilities were to be located inside the Park. However, the government has more recently begun to rethink future development strategies, recognizing the importance of minimizing impact on the Park. In terms of accommodation expansion, a potential strategy example was given that $70 \%$ of all new rooms could perhaps be built in Jianfeng Town, with the remaining 30\% at the lake area inside the Park. Future developments will be guided by two main factors; proposals provided to the government by investors will be evaluated against guidelines and regulations laid out in the JNFP Management Plan(s).

A promotional document obtained for the Park contains a 'Program and Estimate of Investment', revealing planned (potential) future developments (Jianfengling Forest Bureau, 2000). Included are the following: a wild animal zoo, an elevated sky/canopy restaurant, an ecological food restaurant, an ecological sports slide, a water sports complex, a tropical forest exhibition/ecological park, an earth village, production of ecological travel products/souvenirs and a water pollution/garbage treatment plant. Some of these developments are arguably not well suited to an ecotourism destination, as defined for this study, and suggest that there may be some confusion as to which type of tourism market is being sought.

\subsection{Site Description - Jianfeng Town}

The Town of Jianfeng is located in the mountainous, and largely rural, southwest part of Hainan Island in Ledong County. Approximately $90 \mathrm{~km}$ from Sanya City and $260 \mathrm{~km}$ from the capital of Haikou, the town sits immediately outside the Park boundary for lands over which the JFB has jurisdiction (but is within the greater boundary for the JNFP Plan area). Founded in the early 1950s, Jianfeng is composed of both Han Chinese and people of the Li ethnic minority, and has a population of between 17,500 and 20,000 according to different estimates. Close to 10,000 reside in the town proper (Figure 5.9), with the remainder distributed among the (at least) $7 \mathrm{Li}$ and 4 Han villages that 
surround the town. Li people, the earliest inhabitants of the area, represent approximately $70 \%$ of the total population.

The majority of Li people in the Jianfeng region live in villages that lie outside of town and the Park (or at least the lands managed by the Forest Bureau) (Figure 5.10). The livelihood strategies of the Li people are very limited, with most engaged in agriculture and animal husbandry. Traditionally, agricultural activities have been based on subsistence, but have in recent years also been expanded to include crop production for sale in local markets. Limited numbers of Li are employed in local government and by the JFB. Based on 1993 data, Li annual household incomes in the region range from 2,240 RMB to 4,416 RMB ( $\$ 430$ to $\$ 850 \mathrm{CDN}$ ), or $417 \mathrm{RMB}$ to $630 \mathrm{RMB}$ ( $\$ 80$ to $\$ 120 \mathrm{CDN}$ ) per capita (Asian Development Bank, 1995).

While many Han Chinese are also involved in agriculture, the Han residents of Jianfeng are engaged in a wider variety of livelihood activities, and are essentially the sole operators of small businesses in town. Similarly, Han people hold the vast majority of positions within the Jianfengling Forest Bureau. Table 5.2 contains a breakdown of the types and number of businesses that are located in the core area of town (as observed on May $29^{\text {th }} 2001$, along the 2 main streets, between $4 \mathrm{pm}$ and $5 \mathrm{pm})$.

\section{Table 5.2: Types of Businesses Operating in Jianfeng}

\begin{tabular}{ll|ll}
\hline Type of Business/Facility & Number Counted & Type of Business/Facility & Number Counted \\
\hline Restaurant \&/or Tea House & 9 & Pharmacy \& Herbal Medicine & 4 \\
Clothing and Shoe & 10 & $\begin{array}{l}\text { Miscellaneous Shop (plumbing, } \\
\text { hardware, toys, etc.) }\end{array}$ & 23 \\
Hair, Beauty \& Massage & 13 & Small Food Shop & 20 \\
Tailor & 1 & Magazine \& Book & 3 \\
Music \& Video & 2 & Auto Repair \& Supply & 13 \\
Video Arcade & 2 & Billiards Hall & 1 \\
Bottle/Jug Water Shop & 1 & Propane & 1 \\
Chair \& Stool Weaving Shop/Factory & 2 & Bank & 3 \\
School & 2 & Hotel & 1 \\
Street Vendors - Food \& & Numerous; Varied & Motorcycle-Taxi & Numerous; At least \\
Miscellaneous & daily & Post Office & 30 \\
Medical Clinic & 1 & Fruit, Vegetable \& Meat Market & 1 \\
Dentist & 1 & Public Security Bureau (Police) & 1 \\
Hospital & 1 & & 1 \\
\hline
\end{tabular}




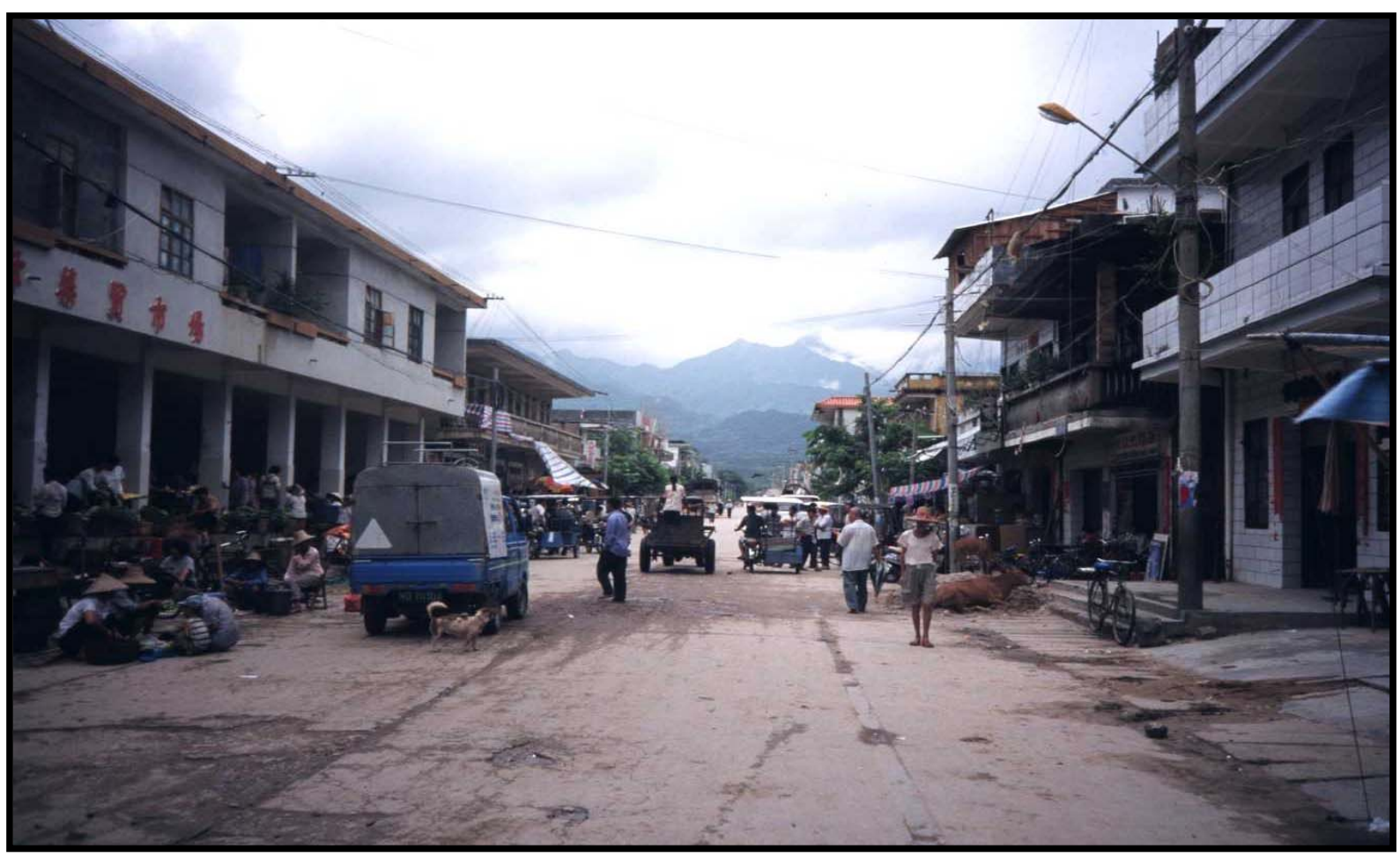

Figure 5.9: The Town of Jianfeng

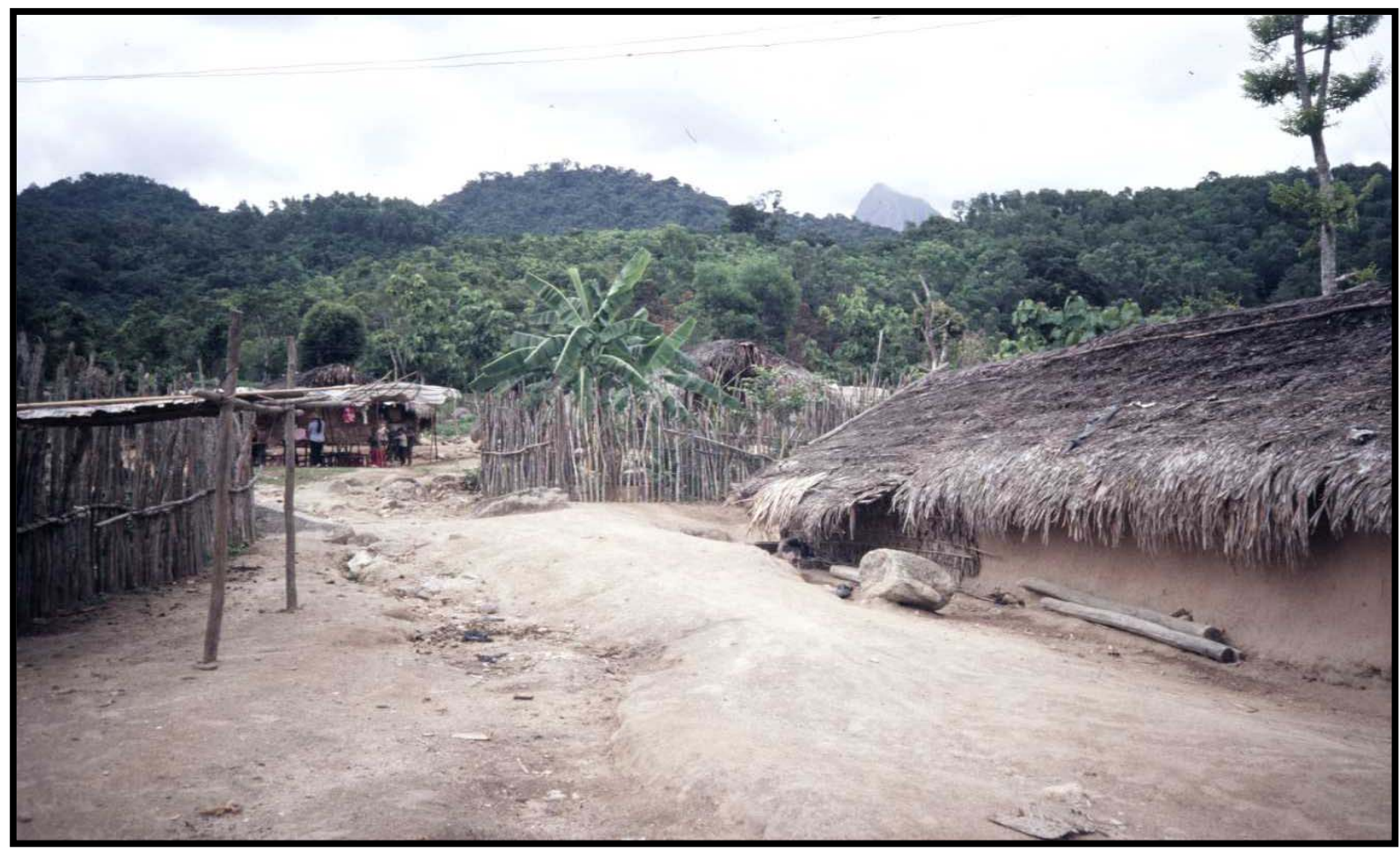

Figure 5.10: A Li Village Near Jianfeng 
The Table reflects the kinds of non-agricultural employment activities that local Han residents are engaged in. However, it is not intended to represent the complete range of activities that residents of Jianfeng participate in. Han annual household incomes in the region range from 6,268 RMB to 15,918 RMB ( $\$ 1205$ to $\$ 3060$ CDN) (Asian Development Bank, 1995). These figures reveal the significant income gap that exists between the Li and Han in the region.

The town centre of Jianfeng is quite small, comprised of 2 main business streets and a series of smaller, mainly residential, streets and alleys. Major infrastructure is minimal, but includes 1 hospital, 1 China Post office, 1 hotel, 1 Public Security Bureau, 2 schools, 3 banks and a research station operated by the CAF (which includes hotel accommodations) located just outside the centre of town. The majority of streets in and around town are dirt, and in poor condition. The approximately $10 \mathrm{~km}$ road linking Jianfeng to the western highway is in a similarly poor state, but was undergoing repairs at the time this research was being conducted. This will likely make the Jianfeng region more accessible. In April 2001, a roughly $16 \mathrm{~km}$ cement road from town to the hotel area of the Park was completed, making travel to the lake area much easier. However, in the process of constructing the road, substantial road cut damage was produced in a number of spots.

Local transport around town and the immediate surrounding area is by foot or motorcycle-taxi. For transport to more major centres along the western highway, locals must take small covered truck-taxis to the village of Lingtou roughly $10 \mathrm{~km}$ west of the highway, where they can catch small mini-buses to a variety of destinations. Alternatively, locals can be dropped at the western highway to wait for buses travelling along the highway destined for Sanya or Haikou. One regular-sized bus leaves Jianfeng nightly for Haikou. However, there are no regular buses that run direct to Jianfeng from anywhere on Hainan. Regular buses travelling along the western highway between Sanya and Haikou will drop people at the highway exit for Jianfeng, where they must wait for a Jianfeng-bound covered truck-taxi. Travel to the Jianfeng region without a private automobile is currently inconvenient and time consuming.

\subsection{Relationship Between Local Community and JNFP}

If ecotourism is to function effectively, there must be a positive relationship between residents living in or near the Park (the host community) and the Park itself, including both natural resources and the staff that manage them. Ideally, local residents act as stewards of the Park, supporting protection and 
conservation efforts. In return, residents benefit from resource protection through sustainable access to resources that support and, ideally, improve their livelihoods.

\subsubsection{Park Resource Use}

From the 1950s to early 1990s, the majority of Han families in Jianfeng had at least one member employed by the JFB in timber extraction-related positions. The logging ban imposed in 1992 in Jianfengling saw between 400 and 500 Bureau workers lose their jobs. Indeed, 35\% of residents surveyed $(n=40)$ said that they themselves or someone in their family had lost a job as a result of Park establishment. While some retired and others moved elsewhere in search of work, many remained, along with their dependents, and are either unemployed or underemployed. This has made supporting a family much more difficult for many in Jianfeng. Many residents rely on subsistence farming (Associates in Rural Development, 1998), with some apparently supplementing this with minor commercial sale of surplus at the local market. Han agriculture is permitted in certain areas within the Park (Figure 5.11), but permission must be applied for through the JFB. Former logging workers

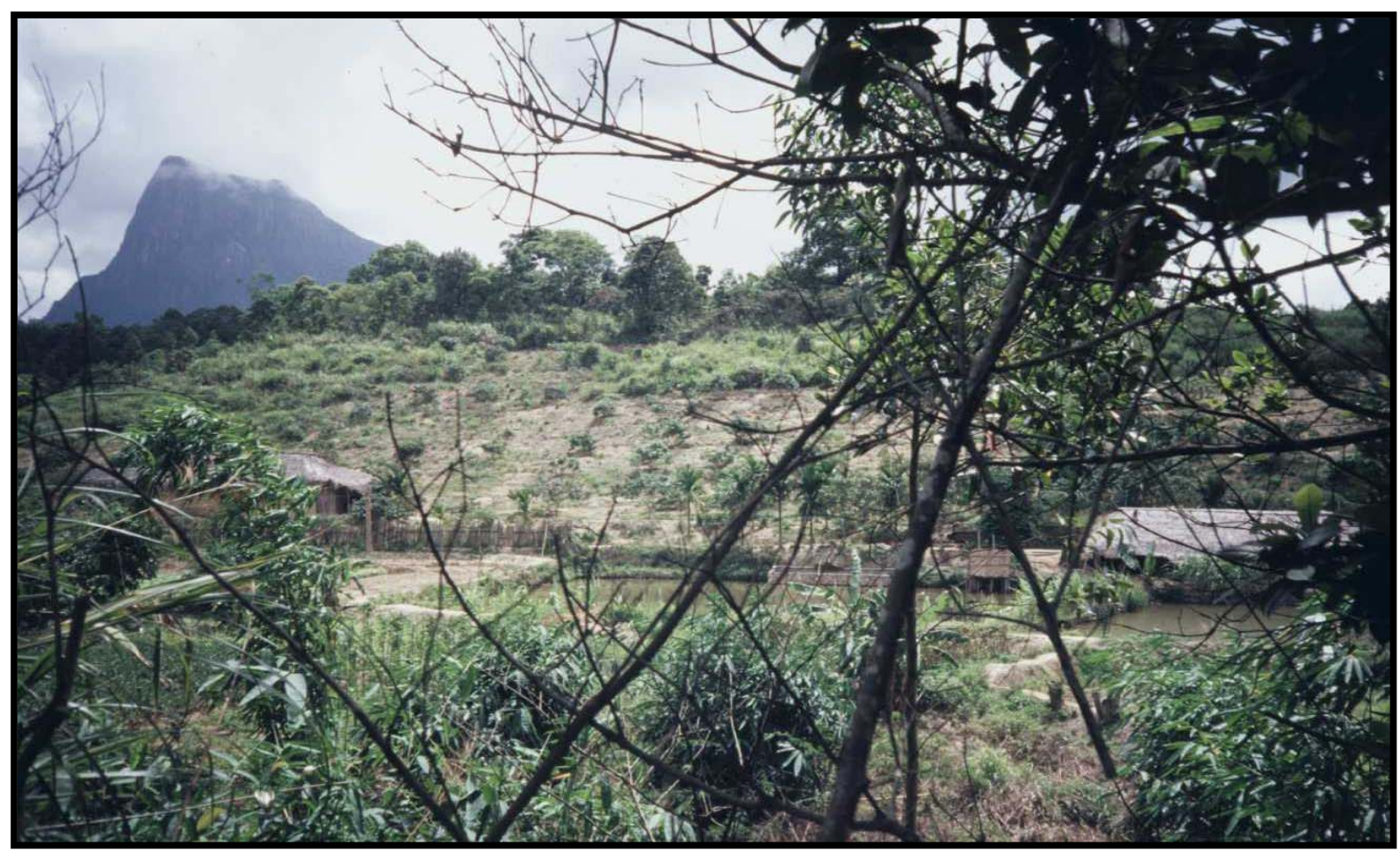

Figure 5.11: A Han Agriculture Plot in JNFP 
are also apparently allowed to cultivate subsistence plots within the Park (Associates in Rural Development, 1998). While Table 5.2 illustrates that some are employed in a variety of small business operations, dependence on the resources in and around JNFP remains high.

The Li living in the region, who are roughly $70 \%$ of the area's total population, are almost exclusively engaged in subsistence and, to a lesser extent, commercial agriculture; they are no longer legally permitted to cut trees. Their dependence on natural resources is extremely high. One senior JFB official suggested that protecting the Park from the economically impoverished Li villages that surround the Park is the biggest management pressure they face. As one CAF researcher noted, many of the Li villages are so poor that they have no choice but to cut trees and hunt, regardless of restrictions, in order to be able to provide for their families.

Despite logging and hunting bans, illegal harvesting (likely by both Li and Han) still occurs, and is thought to be driven primarily by commercial markets, especially furniture manufacturing, locally, provincially and on the mainland and the need for protein supplements (Associates in Rural Development, 1998). However, Bureau officials do not generally recognize illegal resource use as a major problem, especially in the Reserve, which is buffered by the Park. Park and Reserve security staff is stationed in several areas, and patrols the region to guard against illegal activities. Penalties for illegal harvesting and resource damage include fines and prison sentences depending on the severity of the offence. The efficiency of security patrols and enforcement were not evaluated in this study but, according to a report by the consulting firm, Associates in Rural Development (1998), resource protection and security patrolling are insufficient.

An extensive buffer zone of 369 square $\mathrm{km}$ has been established by the Provincial Government in order to provide an area of land upon which alternative livelihood strategies can be experimented with for those affected by the logging ban and establishment of JNFP (Asian Development Bank, 1995). The buffer zone is in keeping with on-going socioeconomic and agricultural research by the International Tropical Timber Organization (ITTO), CAF and JLRS aimed at reducing pressures on the Park's natural resources. The capacity of the buffer zone to do this will be critical to the continued protection of JNFP.

\subsubsection{Park Staff and Local Resident Relations}

According to JFB officials, information has been provided to local residents about the importance of protecting the forest. This is somewhat in keeping with local interview findings, which revealed that 
$47 \%$ of residents ( $n=38 ; 2$ no response) and $50 \%$ of business owners ( $n=24 ; 1$ no response) noted they had been given some information related to the Park. However, $72 \%$ of residents and $25 \%$ of business owners that indicated they had been given information could not recall the content of that information. Of those that did have some recollection of the content, most stated it related to the logging ban, reasons for park establishment and/or the importance of forest/ecology protection.

Interviews also revealed that bitterness remains among some residents over lost jobs and land, and the perceived subsequent lack of attention given to local people's welfare. Many (53) comments were recorded that suggested (regardless of whether personal views of the park were favorable overall) some are upset over 'lost jobs', that it is now 'harder to make a living', that 'only local officials benefit' and 'make decisions' and, that 'locals are neglected' and 'treated like dogs'. While some that lost land were provided with new houses (apparently of poor quality), several residents indicated they were never financially compensated in any way for lost land or jobs.

In an effort to encourage the Li to support the JFB's conservation efforts, all villages in the region were apparently provided with information, seeds and approximately 10,000 RMB (\$1920 CDN) shortly after Park establishment. However, a local Li village leader interviewed disputed this, saying that the Bureau has never made any effort to provide them with information or ask for their input, and that his village was not given any financial compensation/incentive when the Park was established. In the case of both Li and Han residents, it is apparent that neither group has had the opportunity to actually provide input or participate in Park planning matters.

While Park officials interpret local relations to be generally good, interview results suggest that park-local relations are variable.

\subsubsection{Local Resid ent Stewardship}

Local residents have a good understanding of why JNFP was created. Only 1 person out of all resident and business owners interviewed $(n=65)$ did not know that a park existed in the area and, of those that did know, only $8(13 \%)$ were unsure of the reasons behind the Park's establishment. In the case of both residents and business owners, the 2 most commonly cited reasons for 'Park' designation were to protect the forest/ecology/animals ( $63 \%$ of residents and $58 \%$ of business owners) and to develop tourism $(28 \%$ and $50 \%)$.

Local residents also generally support the Government's decision to create JNFP. Over half (58\%) of residents and three-quarters $(76 \%)$ of business owners saw 'Park' designation as a 'good thing' 
overall. An additional 25\% of residents and $8 \%$ of business owners saw it as good overall, but added qualifying comments like some lost jobs, the government will be the main beneficiary, and/or that they would not personally benefit but others in the community would. Only $5 \%$ of residents and $12 \%$ of business owners saw 'Park' designation as a 'bad thing' overall.

Interviews also revealed widespread recognition that forest/resource protection is important. All ( $100 \%$ ) respondents ( $\mathrm{n}=64 ; 1$ no response) indicated that protecting the forest at JNFP was important to them. The top 2 reasons cited by both residents and business owners were that protection positively influenced local climate ( $46 \%$ of residents and $44 \%$ of business owners) and water resources (36\% and 52\%) in the region. An influence on the climate of Southeast Asia and on human health were the next most common reasons given by residents and business owners for why protecting the forest is important. A local Li village leader interviewed also acknowledge that forest protection is important, citing water resources, climate and the needs of future generations as the main reasons.

When asked if Park establishment had impacted their livelihood in a positive and/or negative way, $38 \%$ of residents responded positively. Of those that cited positive effects, local economic benefits (36\%) and improved roads (27\%) were the 2 most common responses. More than a quarter (28\%) indicated the Park has had a negative impact on their lives, with lost jobs (78\%), only officials benefit $(28 \%)$ and forced to move/lost agricultural land (22\%) being the most common negative impacts. Almost one-fifth (18\%) suggested that the Park has had both positive and negative effects, with another $18 \%$ indicating that the Park has had no influence, positive or negative, on their lives.

Business owners were asked the same question, but with respect to the Park's influence on their business specifically. Responses were somewhat different from the residents, with $74 \%$ indicating that the Park has had a positive impact on their livelihood/businesses. No owners suggested that the Park had negatively influenced their business. One respondent indicated both positive and negative effects, with the remaining $22 \%$ stating that they had noticed no effect whatsoever.

While there is generally a good understanding among local residents of the reasons behind the establishment of JNFP and that forest protection is important, genuine widespread stewardship or advocacy for the Park can not really be said to exist. Some have noted positive effects, but others have not, and are less convinced of the Park's value. There would seem to be potential for the development of stewardship, however much will depend on the Park's ability to provide sustained 
benefits to Jianfeng residents on a wider scale in the future. Table 5.3 summarizes some of the existing relationships between the local community and JNFP.

Table 5.3: Summary of the Relationships Between the Community and JNFP

\begin{tabular}{ll}
\hline \multicolumn{1}{c}{ Indicator } & \multicolumn{1}{c}{ Assessment } \\
\hline Greater Town Population & $17,500-20,000$ \\
Local Resident Dependency on Natural Resources & High \\
Access to Park Resources & Restricted; Some Land for Agriculture \\
Access to Resources in Buffer Area & Potentially High \\
Illegal Resource Use & Minimal \\
Enforcement Capacity & Weak \\
Benefits from Resource Protection & Climate, Water Resources and Ecological Protection \\
& (perceived) \\
Conservation Attitude & Positive \\
Potential for Stewardship & Good \\
Staff-Local Relations & Variable \\
Participation in Planning & None; Provided with Information Only \\
\hline
\end{tabular}

\subsection{Relationship Between Local Community and Tourism}

Of critical importance at an ecotourism destination is the relationship between local community residents and tourism/tourists. If ecotourism is to develop successfully, community support must be strong. Positive local attitudes towards tourism depend on whether or not residents (the hosts) are receiving socioeconomic benefits or some form of compensation in return for restricted access to resources they may have been dependent on prior to (eco)tourism development/park establishment. If residents are content, there is a much greater opportunity for enhanced tourist experiences through positive intercultural interactions with local residents.

\subsubsection{Economic Benefits}

Tourism at JNFP is at an early stage of development. As such, tourist numbers, and the economic benefits they can induce, have been very limited. Senior officials at the JFB estimate (using hotel records) that close to 20,000 people visited the Park in 2000; this number is predicted to increase to 30,000 by the end of 2001 due to recent road improvements. The overwhelming majority of visitors 
are domestic tourists. Interviews with Park officials and hotel mangers revealed that the average length of stay for tourists is one night, with some visiting only as a day trip; weekends and holidays are the busiest times. Most (75\%) arrive by personal automobile or on tour buses organized by employers. There was also general consensus among Park officials, hotel managers (and residents) that most tourists stay at one of the Park hotels, roughly $16 \mathrm{~km}$ from the Town of Jianfeng, and that the 2 hotels in town generally only receive overflow business during busy holiday seasons. As it currently stands, it is quite feasible that many (if not most) tourists do not even stop in town. Instead, they drive straight through town and up to the lake area of the Park, where they stay, recreate and eat, before driving straight back through town and out to the western highway. Aside from holiday overflow times, there is currently little reason for a tourist to JNFP to stop in the town of Jianfeng. Visiting family or friends, the purchase of snacks and bottled water or general curiosity may prompt some tourists to stop in town en route to the Park or highway.

The result has been very limited tourism-related employment and income in Jianfeng. Interpretive guide training was provided for 10 residents in 1997 through a technical assistance program sponsored by the ADB (Associates in Rural Development, 1998). Local Bureau officials suggested that between 40 and 50 people have had some form of guide training, but that only 3 or 4 are employed by the JFB on any sort of regular basis. One guide interviewed indicated that he leads about 6 trips per month, and receives $20 \mathrm{RMB}(\$ 3.85 \mathrm{CDN})$ per trip - representing $20 \%$ of the 100 RMB fee charged by the JFB for a guided excursion in the Park. On occasion, a Li Bamboo Dance group that exists in the area is asked to perform for special guests to the Park. A village leader indicated that in addition to being paid for such performances, dancers receive free food and accommodation.

Aside from this, the hotels (only 2 of which receive significant numbers of tourists outside holiday times) and the Bureau-operated Jianfengling Forest Travel Development Company, are the only businesses in the Jianfeng region that have been established purely as a result of tourism, or that cater mainly to tourists. Combined, they employ about 90 people (not accounting for the staff at the Park hotel that could not be contacted). Taken together, tourism directly employs only about $0.5 \%$ of the regions approximate 17,500 residents. This increases to $1.9 \%$ if one includes the 235 JFB staff, which, among many other duties, are involved in tourism management. These figures rise to $0.9 \%$ and $3.3 \%$ respectively if only the town's core population of 10,000 , predominantly Han residents, is considered. 
Tourism-related entrepreneurship and income are essentially non-existent in Jianfeng. Business owners' estimates of annual sales revenues generated from tourism support this observation. Almost half $(45 \%)$ of business owners that responded to this question ( $n=22 ; 3$ could not estimate) indicated that $5 \%$ or less of their total sales came from tourism-related expenditures (Figure 5.12). This increases to $82 \%$ of owners if one includes those that responded non-quantitatively with answers like, 'not so much', 'almost none' and 'insignificant' (assuming these can be equated to 5\% or less).

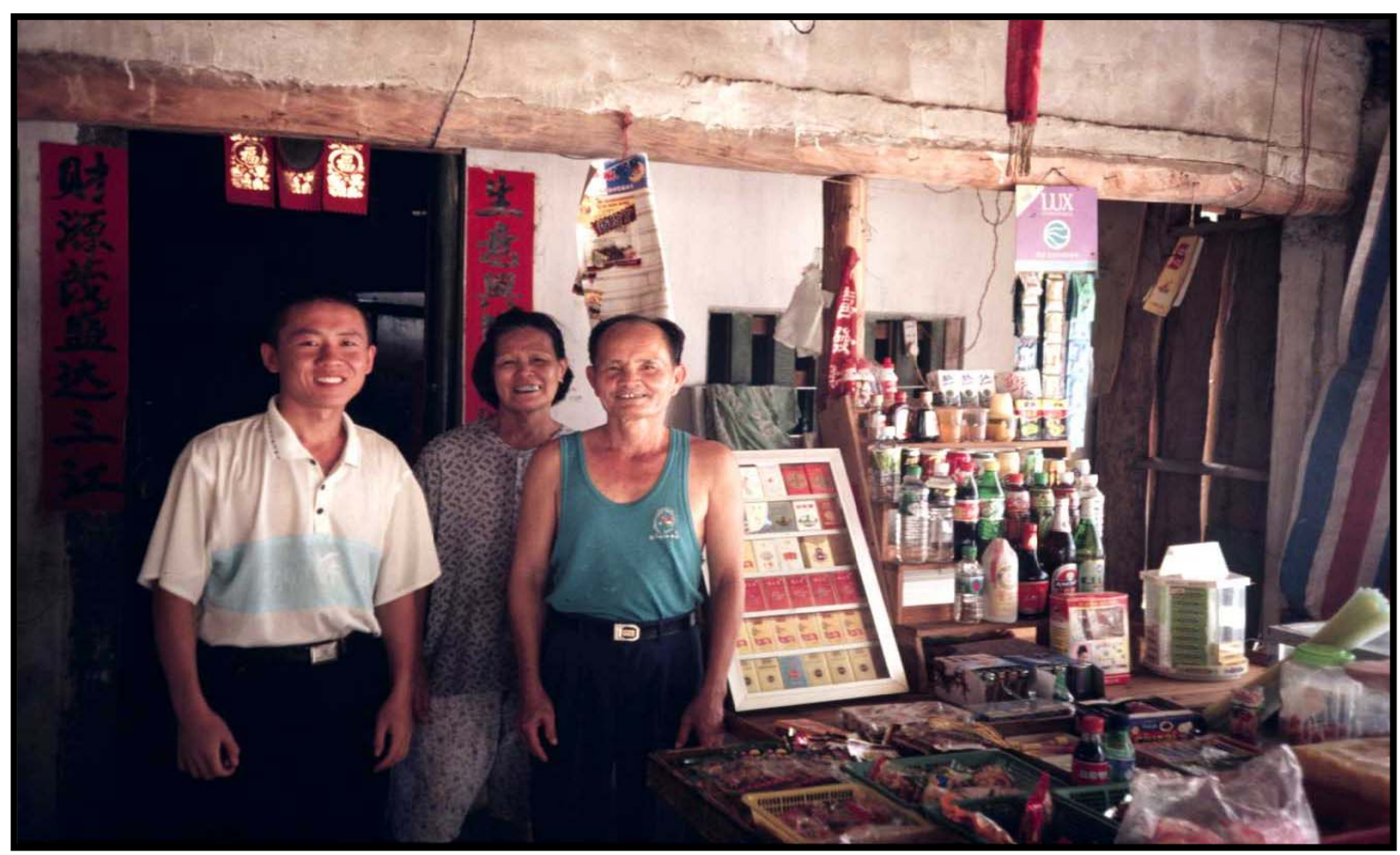

Figure 5.12: Owners of a Small Shop in Jianfeng (shown with research assistant Wang Hai Jun)

Nevertheless, as noted above (Section 5.3 .3 ), $38 \%$ of residents and $74 \%$ of business owners perceive that the Park has only positively affected their lives since establishment, mainly in terms of local economic benefits. This sentiment is shared among top officials in the JFB. This is significant, recognizing that attitudes towards tourism development are largely based on perceived, as opposed to actual, costs and benefits (Lindberg et al., 1996). When asked about their feelings on tourism and potential future increases in tourism to JNFP, $70 \%$ of residents and $84 \%$ of business owners said they 'welcome more' (generally based on the belief that local economic benefits will increase). An 
additional $23 \%$ of residents and $8 \%$ of business owners said they also welcomed more tourists, but added comments such as that they would not personally benefit, planning and management will be important, and that roads/park hotels need to be improved to attract more tourists.

Similarly optimistic sentiments were expressed when local residents were asked if they saw any benefits or negatives, to both themselves and the community, if tourism was to increase. Close to two-thirds $(63 \%)$ of residents who responded to this question ( $n=35 ; 5$ no response) saw only personal benefits, mainly in the form of increased job opportunities and indirect benefits (i.e. the community/local economy benefits, therefore every individual does). The remaining $37 \%$ of resident respondents saw neither personal benefits nor negatives if tourism were to increase. In terms of community impacts, $66 \%$ of residents saw only benefits if tourism were to increase, with the vast majority citing a stronger local economy and/or increased business opportunities as the main source of community gain. An additional $23 \%$ of residents predicted both benefits and negatives for the community; potential negatives cited included higher prices for locals, environmental damage and drugs/reduced safety. A minority (11\%) of residents saw no positives or negatives, for either the community or themselves; this view was generally accompanied by the sentiment that only the JFB, travel agencies or government officials stand to benefit from tourism.

Business owners were asked the same question in terms of benefits/negatives to their business and the community. Almost all $(92 \%)$ owners $(n=25)$ predicted only benefits for their businesses, with the remaining $8 \%$ indicating they saw no positives or negatives for their business should tourism increase. Of the 23 (92\%) owners that saw only benefits, 21 were confident their business would increase, one was hopeful that business would increase and another predicted only small increases if tourism was to grow. With respect to community impacts, $88 \%$ of business owners predicted only benefits, mainly in the form of a stronger local economy, increased business opportunities and more 'lively' local life (from playing host to foreign tourists). Another $8 \%$ saw both positive and negative impacts, with negatives potentially including garbage pollution, increases in the number of non-locals and reduced safety in the community. Only 1 business owner (representing $4 \%$ of respondents) predicted there would be neither benefits nor negatives, for either the community or themselves, if tourism were to increase. As for residents, this view stems from a belief that only government officials will benefit from tourism, not the public.

When a top Bureau official was asked a similar question relating to potential tourism benefits/negatives, their response was that more job opportunities would become available for young 
people and that local spending/tourist consumption would increase. No negative effects were predicted. A Li village leader interviewed was equally optimistic, citing opportunities for increased fruit sales and a generally stronger local economy as benefits if tourism was to increase. He, like most others interviewed, could see no negative impacts associated with tourism growth in the region.

The overwhelming pattern in interview responses was optimism. This is perhaps not surprising given the early stage of development, somewhat reminiscent of Doxey's 'Stage of Tourist Euphoria' (Doxey, 1976) or Butler's 'Exploration Stage' (Butler, 1980) of a tourism development. Although tourism-related benefits have been limited thus far, most officials, residents and business owners seem confident that tourism growth at JNFP will generate economic benefits for the Jianfeng community.

\subsubsection{Leakage}

With limited tourism-generated income to date, the loss of economic benefits to areas outside of the Jianfeng community (leakage) has also been limited. Nevertheless, it is noteworthy that the hotel currently most heavily used is privately owned, with the principal shareholder residing in Beijing. Furthermore, much of the produce and poultry consumed at the hotel is grown and raised on hotel grounds, not purchased from the Jianfeng market. Close to half of the staff are originally from outside the region, but like all staff (including locals), they reside for the most part at the hotel in staff accommodations. Secondary spending of income in town is likely limited. While $100 \%$ of the staff at the second most popular hotel in the Park are local Jianfeng residents, they also typically stay in staff accommodations on the hotel grounds. On a more positive note, the vast majority of local residents interviewed $(n=40)$ indicated they purchase regular household items such as food, clothing, kitchen/miscellaneous supplies, etc. from the shops and market in Jianfeng. However, big-ticket items like furniture and appliances are purchased in larger centres such as Sanya and Haikou. This suggests that, if disposable income levels were to increase in the future due to tourism, much of the spending would occur outside the Jianfeng community (unless more goods became available locally). Just over a quarter (28\%) of business owners indicated they purchased their supplies/raw materials from local shops or suppliers. About one-third (32\%) made these purchases from out-of-town suppliers, with the remaining $40 \%$ using both local and outside sources. The potential for leakage is even higher when one considers that 'local suppliers' are really only extensions, or the go-between, of suppliers originating in Haikou. Indeed, all imported goods on the Island can likely be traced back to 
distribution companies in the capital of Haikou. Multiple sources of leakage make it difficult for the community to benefit from secondary, tourism-related, spending.

\subsubsection{Social Welfa re Benefits}

Residents and officials have also recognized some non-economic, tourism-related, benefits. These include a recently completed (April 2001) concrete road from town to the lake area in the Park to replace the previous dirt track, and in-progress road repairs between Jianfeng and the western highway. Many residents also acknowledged the connection between forests, climate and water resources, suggesting that forest and watershed protection provide valued benefits to the Jianfeng community.

While perhaps not a direct or obvious benefit, the buffer zone that has been established around JNFP may provide future opportunity for compensation to some for loss of access to resources within the Park. This would come in the form of access to lands upon which, for example, agriculture and animal husbandry for subsistence or commercial sale could be undertaken. Continuing research by the ITTO, CAF and others into relieving pressures on the Park and allowing for sustainable, alternative livelihood strategies for the Li and Han residents who surround JNFP will be critical in this respect.

As noted above (Section 5.3.2), some compensation for resource use restrictions was provided to the Li people in the form of seed and financial disbursements from the JFB, although at least one Li village leader contests that the Bureau provided such assistance. While some Han residents were apparently provided with new houses to compensate for lost land, one resident interviewed complained they were of poor quality. No financial compensation has been provided to those Han residents who lost jobs or land as a result of Park establishment. These considerations make the need for tourism-related benefits, or some form of compensation for resource use restrictions, all the more important if (eco)tourism is to develop effectively in the Jianfeng region.

\subsubsection{Benefits Foregone}

In establishing a Park and providing a tourism product at JNFP what benefits have been foregone? Would an alternative use of the resources protected in the Park yield greater socioeconomic benefits for the stakeholders involved? Such considerations are important when determining if ecotourism should be pursued - if its benefits are greater than its costs (Sherman et al., 1991). At Jianfengling, 
the most obvious alternative is an extractive use of resources, such as the commercial logging that occurred prior to Park establishment. Given the rural state of the region, commercial and other, urban-related, developments would be unlikely at the present time. Although logging generated larger revenues, employed a greater number of local people and allowed the community greater access to resources than ecotourism and protection currently does, it was dependent on finite tropical forest resources and had high costs in terms of forest decline, ecosystems degradation and, most likely, species loss. From a short-term, economic perspective, logging arguably appears more attractive. However, tropical forest conservation also provides benefits - biodiversity maintenance, watershed protection and pollutant filtering for example. The difficulty inherent in assigning a monetary value to such, more intangible, benefits, if indeed it is possible at all, makes cost-benefit comparisons with alternatives such as logging, extremely problematic. Nevertheless, the government has recognized the importance of conservation and committed itself to forest protection for the immediate future. Local residents also recognize the importance of conservation (Section 5.3.3), and associate it with climate and water resource benefits. At the present, the benefits that have been foregone in establishing a Park and pursuing ecotourism are substantial, at least from an economic perspective. In the longer-term, and from a broader perspective, benefits foregone will likely be minimal, especially if ecotourism develops successfully and community members are provided with compensation, or alternatives, for reduced access to resources.

\subsubsection{Intercultural Exchanges}

Limited numbers of tourists at JNFP, combined with the fact that most visitors stay in the Park, have meant that host-tourist interactions have been very limited. Currently, most residents of Jianfeng are optimistic and 'welcome more' tourists, suggesting that potential exists for positive intercultural exchanges. Indeed, when asked about tourism during interviews, a number of responses were recorded, from both residents and business owners, indicating they thought tourists to JNFP/Jianfeng would 'broaden their view', 'make locals happy' or 'make local life lively'.

Currently, there are no easily accessible ways to learn about or experience Li culture at JNFP. While performances have been put on in the past, it has been largely for special visitor groups or events. A local Bamboo Dance Group exists, but only performs upon request of the JFB; there are no regularly scheduled performances for tourists. When asked about this, the Li village leader interviewed responded that they had given some thought to promoting Li minority agriculture as a cultural tourist attraction. As the first inhabitants of the Island, and the group that comprises $70 \%$ of 
Jianfeng's total population, Li culture is an important part of the region's history and appears to offer an opportunity for fostering positive intercultural exchanges. Cultural promotion, in turn, could potentially provide a means of financial compensation for loss of access to certain resources. Table 5.4 summarizes some of the existing relationships between the local community and tourism.

Table 5.4: Summary of the Relationships Between the Community and Tourism

\begin{tabular}{ll}
\hline \multicolumn{1}{c}{ Indicator } & \multicolumn{1}{c}{ Assessment } \\
\hline Number of Tourists & $\sim 20,000$ (in 2000) \\
Tourism Employment & Very limited \\
Tourism Income for Local Community & Very limited \\
Tourism Related Entrepreneurship & None \\
Host Attitudes Towards Tourism's Impact & Positive; Optimistic; Some concern for environment, \\
& safety \& potential for only government to benefit \\
Social Welfare Benefits & New Roads; Climate; Water Resources \\
Intercultural Exchange Opportunities & Very limited \\
Potential for Positive Intercultural Exchange & Good \\
\hline
\end{tabular}

\subsection{Relationship Between Tourism and JNFP}

The provision of quality educational materials and interpretive media at an ecotourism destination is an essential responsibility of Park managers. Interpretation is critical to enhancing the experience of the ecotourist. It can convey information that can instill greater environmental awareness and foster support for conservation activities, among both tourists and community residents. As a key component of a quality experience, educational programs can help justify entrance and other site fees. In turn, tourism revenues generated at a site can make a valuable contribution towards conservation and general management activities. Thus, in an ideal scenario, the tourist receives a quality experience and, in return, provides both financial (through fees) and moral (through greater awareness) support for the conservation activities at the site.

\subsubsection{Revenues G enerated for Conservation}

In recent years, approximately 3 million RMB $(\$ 576,920 \mathrm{CDN})$ annually has been put towards conservation activities at JNFP. However, it is unlikely that any of this amount has come from 
tourism-generated revenues. While about 20,000 tourists are estimated to have visited the Park annually in the last few years, no entrance fees have ever been collected. Furthermore, senior officials indicated that both the JFB operated hotels, and the Jianfengling Forest Travel Development Company, have operated at a loss in recent years, and therefore have been unable to contribute financially towards conservation or management efforts.

At the Nature Reserve, annual contributions to conservation activities have ranged between 50,000 and 60,000 RMB $(\$ 9,615$ and $\$ 11,540 \mathrm{CDN})$ in recent years. While tourists who wish to enter the outer Reserve 'experiment' zone to climb the Observation Tower are charged 20 RMB ( $\$ 3.85$ CDN), the former Reserve manager indicated that the revenues generated from this are insignificant.

Both Park and Reserve managers suggested that insufficient funds are their biggest management limitation. It would seem that there is both a need and an opportunity for tourism to contribute funds towards conservation and general management activities at JNFP. Park management suggested they have considered implementing an entrance fee in the near future (20 RMB was suggested), however, new fees apparently must first receive approval from the Provincial Price Bureau.

\subsubsection{Educational Opportunities}

Interpretive materials and educational opportunities are limited at JNFP. What little is available, for the most part caters to the Chinese-speaking tourist. Based mainly on observations, the Park offers the following:

- A pamphlet with basic information about the Park (some in English), its sights and a (sketch) map;

- A number of, mainly regulatory, signs (in Chinese) along Park roads. For example, 'whoever burns trees will go to prison' and 'protect the mountain/reserve zone';

- A display of Park photos, butterfly specimens and research activities at the JLRS (some in English);

- A new tourist centre which houses a model and photos of the Park (a complete inventory of the centre could not be made as it was unopened at the time of research) (Figure 5.13);

- Guides available for hire, to lead nature hikes (Chinese language only). 


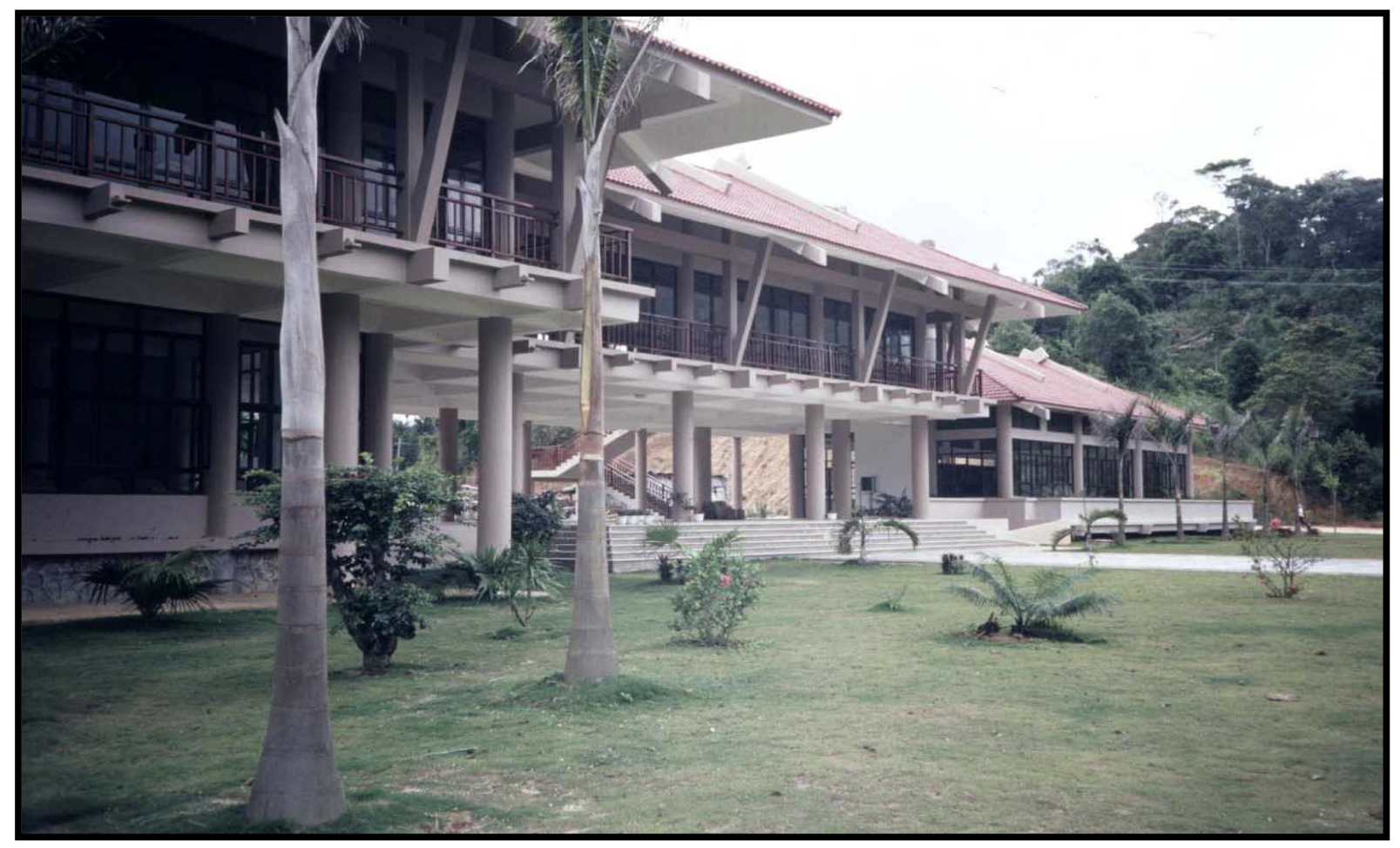

Figure 5.13: The New Visitor Centre at JNFP

No actual interpretive media were observed on any of the trails the researcher hiked, including the Mt. Jianfeng summit trail, which is the most popular walk in the Park. No interpretive media were available at the Observation Tower. There was no obvious sign marking the entrance to the Park, nor was there a sign at the new interpretive centre indicating that it was a visitor's centre. Similarly, it was not immediately obvious that the JLRS houses some interpretive media. There was no sign in Jianfeng indicating where tourists could go to organize a guide, or to obtain an information pamphlet. There was no sign to point tourists in the direction of the Jianfengling Forest Travel Development Company office. Basic signage, along with both active and passive educational opportunities, is extremely limited, especially for the foreign tourist.

Given current levels of foreign tourism, it is not surprising that only Chinese-speaking guides are available. No assessment was made of the level of knowledge that the 3 or 4 guides currently employed on a regular basis possess. However, if observing one of the guides discard garbage into a river in the Park is any indication of their abilities or values, then one might conclude that the guide service at JNFP has some weaknesses. 
The current state of educational opportunities at JNFP is somewhat surprising given that a Nature Interpretation Plan was developed by a group of consultants in 1997 as part of a technical assistance program sponsored by the Asian Development Bank (Associates in Rural Development, 1998). However, the former Reserve manager did note that while educational information does exist, they simply do not have the funds to make it widely available to tourists.

Equally surprising, is how difficult it is to actually access the Park's attractions without the use of a personal automobile. Although there is a Travel Company and guides, there are apparently no vehicles officially for hire or tour buses that transport tourists around the Park, should this be deemed appropriate at an ecotourism destination. One official indicated that the Travel Company is not able to afford to run bus trips into the Park, and that although it would be possible to arrange a vehicle for hire through them, they had never done so in the past. If one stays at the Lake area, the Observation Tower and Botanical Gardens can be reached on foot, however, other attractions, like the popular Mt. Jianfeng summit trail, require the use of a vehicle to access. Perhaps a backpacking trail, that provided camping facilities, would be more appropriate and appealing to an ecotourist. Table 5.5 summarizes some of the existing relationships between tourism and JNFP.

Table 5.5: Summary of the Relationships Between Tourism and JNFP

\begin{tabular}{ll}
\hline \multicolumn{1}{c}{ Indicator } & \multicolumn{1}{c}{ Assessment } \\
\hline Park Entrance Fee & None \\
Reserve Observation Tower Entrance Fee & 20 RMB \\
Tourism's Financial Contribution to Conservation at JNFP & None \\
Availability of Educational Materials/Opportunities & Limited; Pamphlet; Guides; New Visitor Centre \\
Quality of Educational Materials/Opportunities & Needs to be Evaluated \\
\hline
\end{tabular}

\subsection{Summary: Management and Policy Considerations}

'Ecotourism', and the positive interactions between the various stakeholders that are ideally associated with it, will not materialize unaided (Boo, 1991). The role of management in nurturing successful ecotourism is critical. If the relationships between tourism, resources and local communities are to develop in a symbiotic manner, a wide variety of management and policy strategies must be present. A competent and qualified management team to formulate, implement and 
enforce such strategies is equally important. Table 5.6 identifies some of the key management and policy considerations at an ecotourism site, including zoning, community outreach, research, law enforcement, tourism management and service provision.

Table 5.6: Selected Key Management and Policy Considerations at an Ecotourism Destination

\begin{tabular}{llll}
\hline \multicolumn{1}{c}{ Policies } & \multicolumn{1}{c}{ Management Strategies } & \multicolumn{1}{c}{ Employee Duties } & Manager Characteristics \\
\hline Entrance fees & Active management plan & Monitoring & Training in: \\
Taxes & Regular updates of: & Enforcement & $\bullet$ Conservation \\
Earmarking & $\bullet$ species inventories & Tour guiding & $\bullet$ Ecology \\
Regulations/restrictions & $\bullet$ tourist statistics & Research coordination & $\bullet$ Public relations \\
Penalties & $\bullet$ conflicts/threats & Public relations & $\bullet$ Law enforcement \\
Employee training & Integrated use zones & Fee collection & Business/economics \\
Community involvement & Community outreach & Tourist statistics & \\
Zoning/buffers & Participatory planning & & \\
& Tourist management & & \\
& Education programs & &
\end{tabular}

Source: Adopted from Ross and Wall, 1999

\subsubsection{Local Comm unity Relations}

In terms of outreach strategies aimed at the local Jianfeng community, efforts have generally been limited to information provision. Management has obviously provided some information about the reasons for the Park's establishment and the importance of protecting the forest. However, only about half of residents and business owners interviewed could recall being provided with information (Section 5.3.2), many of whom could not remember the content of what was provided.

With the expansion of the lake around the time of Park establishment, a number of Han residents engaged in agriculture lost their land and homes. In return, the Bureau provided new houses outside of the Park. While such compensation is appropriate, and would seem to be a positive step on the part of management to maintain good community relations, at least one resident interviewed complained that the houses were of poor quality. Similarly, one Li village leader contested the claim of JNFP management that they had been provided with information, seeds and 10,000 RMB ( \$1920 CDN) shortly after Park establishment. 
Neither Han nor Li residents have apparently been given the opportunity to provide input or actively/meaningfully participate in the planning process. The failure to include local people in such processes has been a major factor behind failed conservation and development projects, projects that result in damaged resources and reduced tourism potential (Cresswell et al., 2000). Information provision is a tokenistic form of public participation (Arnstein, 1969). The above suggests that management's outreach efforts have only been moderately successful.

While Park zoning does exist to regulate agro-forestry enterprises and tourist activities, local residents' access to Park resources is highly restricted with the exception of some Bureau-approved Han agriculture within the Park. An extensive buffer zone surrounding JNFP has been created and would seem to have significant potential for providing some community members with increased access to natural resources and reducing demand for Park resources. It will be important for management to continue to support research by various groups into alternative and sustainable livelihood strategies that do not rely on Park resources, especially in light of very limited tourismrelated socioeconomic benefits to date for local residents. Even if management is able to induce community benefits from tourism on a wider scale in the future, tourism employment and income should complement (not become) the local economic base alongside a variety of alternative/sustainable livelihood strategies (Notzke, 1999). Community benefits will, in turn, help to foster stewardship for JNFP among the local population.

\subsubsection{Park/Resource Management}

Although a management plan, resource access restrictions, zoning measures, illegal activity penalties and a Park security staff of 120 all exist at JNFP, a report by ARD consultants concluded that Park security and law enforcement were inadequate for assuring the protection of the natural resource base (Associates in Rural Development, 1998). While some suggested that protecting the Park from the surrounding, extremely poor, Li villages poses a major management challenge, others pointed out that illegal resource harvesting activities occur infrequently.

JNFP seems to have a strong history of research. Through the efforts of the CAF, HFRI and numerous other organizations and individuals since the 1960s, JNFP has compiled the most extensive resource inventory of any protected area in Hainan. This has been complemented through a variety of on-going, applied biological, hydrological, agricultural and socioeconomic research projects. However, it is unclear whether or not any sort of monitoring program exists, or how often resource 
inventories are updated. Indeed, inventories have been criticized as being outdated (Ouyang et al., 2001). Monitoring is essential to maintaining up-to-date and accurate information about the Park, and will become increasingly important if the number of tourists to JNFP increases in the future as expected. The JFB should investigate opportunities to coordinate with the CAF, HFRI and ITTO on updating inventories and implementing a monitoring program. Management may also want to consider applying for a grant from the Global Environment Facility (GEF) to be used for biodiversity conservation projects.

Finally, the Park has never collected a visitor's fee from any of the estimated 20,000 tourists that have visited JFNP annually in recent years. This is somewhat surprising given the financial constraints management has faced since logging was banned. An appropriate fee policy needs to be researched, developed and implemented. Although a senior official indicated they were considering implementing a $20 \mathrm{RMB}(\$ 3.85 \mathrm{CDN})$ fee in 2001 , it was unclear how this amount was determined.

\subsubsection{Tourism Management}

In light of the numbers of tourists received at JNFP, it is perhaps not surprising that the provision of tourism-related services is extremely limited. However, with the goal of increasing tourism as one of management's main objectives, service provision and service quality considerations, especially educational opportunities, deserve more attention than they currently appear to be receiving. While management does have rough estimates of the number of tourists the Park receives annually, and on how long they stay (based on hotel records), a number of key questions about Park tourists apparently remain unanswered. Where do most tourists originate? What are the ages of JNFP tourists? What are their education levels? How much money do tourists spend? Where do they spend it - in the Park or in Jianfeng? What activities do tourists most commonly engage in while at the Park? Are visitors satisfied with their JNFP experience? Would tourists be willing to pay an entrance fee? What market have they captured? What market are they after? The list could go on, but the point is that basic data about tourists are critical to management efforts. If the JFB is to be able to effectively cater to, and control, a (predicted) growing number of tourists, it must know much more about the JNFP tourists than they currently do. As tourism grows, management will want to consider adopting a set of rigorous, and widely accepted, guidelines for the measurement and reporting of visitor statistics (e.g. Hornback \& Eagles, 1999). 


\subsubsection{JFB Funding and Staff Training}

Many of the community, resource and tourism issues that the JFB currently faces are exacerbated, if not caused, by two main factors - inadequate funding and limited education/training among Bureau staff. Both local JFB and provincial HFB officials have acknowledged these limitations as key barriers. As outlined in Section 5.1.2, the education levels of much of the staff that work from the JFB office are limited. Many staff remained at the Bureau when its mandate shifted from that of timber harvesting and sales to forest protection and tourism management. While training in business management and economics among senior officials is a valuable skill set for Park managers, such training alone is insufficient and must be complemented by staff with expertise in ecology, marketing, recreation and sociology, to ensure effective protected area and tourism management (Payne \& Graham, 1993; Rollins, 1993). Furthermore, the various 'experts' that apparently contribute to JNFP management, but reside in Beijing or overseas, are of limited value in day-to-day operations, during which many important decisions have to be made. Learning from more experienced park agencies, as some of the JFB staff had the opportunity to do on a visit to Taiwan in 1998 (Associates in Rural Development, 1998), is one way in which management's capacity can be improved.

Without timber sale revenues to support them, the JFB has come to rely on government funding, supplemented by the sale of some agro-forestry products; tourism generated revenues are essentially non-existent. Local and Provincial authorities have stated that funds are currently very limited. These shortages have likely affected every aspect of Bureau operations, from staff training to law enforcement to community outreach efforts and tourism service provision. The existence of adequate funds, of course, assumes that the management team has both the desire and ability (training) to solve the problems it faces. It will be interesting to see how the recently approved annual guarantee of 10 million RMB (until 2010) will affect the effectiveness with which the JFB addresses the management issues confronting them. Given the assurance of a more stable source of funds, the JFB may wish to consider developing detailed annual budgets that allocate funds for investment in conservation, facility expansion, community development initiatives, staff training and biodiversity research.

\subsubsection{Final Comments}

Ecotourism, as defined for this study and assessed under the adopted framework, does not currently exist at JNFP. The case study revealed that most community members have a good understanding of why the Park was created and that forest protection is important because of its influence on climate 
and water resources. The majority of respondents think that the Park is a good thing overall, and would welcome more tourism. There is the perception, among some, that the Park has had a positive influence on roads and the local economy. However, it is also noteworthy that over one-quarter of residents indicated that the Park has had only negative effects on their lives, mainly in terms of lost jobs and land. In reality, it seems as though community socioeconomic benefits, to date, have been very limited. Similarly, (eco)tourism has not generated revenues for conservation. Nevertheless, the overwhelming pattern in interview responses was optimism, with most officials, residents and business owners seeming confident that tourism growth at JNFP will generate benefits for the Jianfeng community. This is perhaps not surprising given the early stage of development at JNFP, somewhat reminiscent of Doxey's 'Stage of Tourist Euphoria' (Doxey, 1976), D'Amore's model of tourist-resident relationships (D'Amore, 1983) or Butler's 'Exploration Stage' (Butler, 1980) of a tourism development. A limited number of residents qualified their optimism with concerns over environmental damage/pollution and community safety. The few who were more pessimistic generally held the belief that only Bureau officials and the government would benefit from future tourism growth.

Even if (eco)tourism was to increase in the future, this chapter has identified a number of important factors - weaknesses in the tourism-park-community relationships - that stand to limit its ability to generate benefits. Few tourists currently stop in the town of Jianfeng, and there are relatively few spending opportunities, for either tourists or locals, suggesting a significant potential for economic leakage. Community residents are not actively involved in Park/tourism planning processes. Relatively little is known about the tourists that visit JNFP. Monitoring programs to provide up-todate biophysical data are not apparently in place. JFB staff has little expertise in park/tourism management. Fortunately, sound planning and management strategies can help to overcome many of these issues (Chapter 7). This, coupled with fairly widespread community support and recent funding increases, suggests that there is significant potential for ecotourism to develop in a manner that will provide benefits on a broad scale.

Finally, and perhaps most importantly, the opportunities and constraints identified in this case study could be used to provide the framework for the development of a park (eco)tourism plan. The creation of such a plan will be imperative if ecotourism is to develop successfully at JNFP. Table 5.7 outlines potential planning responses and strategies for some of the main opportunities and constraints identified in this case study. 
Table 5.7: Potential Framework for the Development of a Park Tourism Plan at JNFP

Opportunity/Constraint

Potential Planning Response/Action

\section{Opportunities}

- $\quad$ The Park's tropical setting, features and attractions

- The JFB has a large number of staff

- The NNFPP will increase funding, providing a stable source of funds over the next 10 years

- $\quad$ Existing jurisdictional responsibilities requires coordination with other government bodies

- The government controls the Park and tourism

- There is an existing hotel infrastructure

- There is broad community support for the Park, tourism development and forest protection
- $\quad$ Formulate and implement a marketing strategy based on the Park's unique features and the desired tourist market (clientele)

- $\quad$ Provide training opportunities, incentives and, rewards for dedication and outstanding work

- Develop a detailed budget that allocates funds for investment in conservation, facility/amenity expansion, community development projects, biodiversity research and staff education

- Ensure clear lines of responsibility and accountability, so as to make the most efficient use of institutional capacities and resources

- Ensure future developments are located in areas that minimize environmental damage and maximize community benefits through the imposition of conditions on foreign investment that requires the use of local labour and goods

- For the immediate future, invest in improving the quality of existing hotels, not hotel expansion

- Renew and maintain community outreach efforts re. the benefits of forest protection, current initiatives, etc.

- Foster community stewardship through public involvement in planning and decision making resident advisory committees, participation in conservation activities, etc.

- Community residents perceive social welfare benefits climate, water resources, roads

- Highlight benefits through outreach efforts to demonstrate the value of forest protection

- The presence of Li culture
- Work with the Li people to develop cultural attractions, over which they have substantial control, that will enhance tourist experiences and provide the $\mathrm{Li}$ with an 
alternative source of income/compensation for reduced

access to resources

\section{Constraints}

- Staff have limited and/or inappropriate training

- Resource inventories are outdated

- The Park and its attractions are difficult to access

- Educational opportunities for tourists are very limited

- Little is known about Park tourists
- Provide (re)training opportunities for management, security and interpretive staff

- Coordinate with the Diaoluoshan Forest Bureau and Hainan University on the development of a special training program for future Park staff

- Work with research agencies (CAF, HFRI, ITTO) and universities to update inventories

- Develop and implement a resource monitoring program

- Investigate the opportunity to apply for a biodiversity conservation grant from the Global Environment Facility (GEF)

- Continue with recent road improvements

- Work with travel agencies and bus companies to establish regular transport links to and from Jianfeng

- Consider constructing a backpacking trail network with camping facilities that would allow tourists to access Park attractions without an automobile

- Construct a Park entrance gate to provide a central location for tourists to register, obtain information on accommodations and attractions, hire a guide, etc.

- Implement the interpretive plan developed by ARD Inc.

- $\quad$ Support (second) language training for interpretive staff

- Design and conduct a tourist survey to collect information on demographics, activities undertaken, spending patterns and satisfaction levels

- Analyze survey information and prepare a marketing strategy

- Adopt and implement a set of guidelines for the measurement and reporting of visitor statistics (e.g. 
Hornback and Eagles, 1999)

- Tourism has not contributed funds to conservation

- Tourism-related employment and income are very limited, and the potential for economic leakage is high

- Local dependency on natural resources remains high, illegal harvesting continues to occur and some community residents remain bitter over lost jobs, land and/or the governments apparent lack of interest in their welfare
- Implement a Park user fee based on an analysis of budgets, the desired level of visitation and willingnessto-pay information from tourists

- Establish donation mechanisms and consider implementing a special conservation tax on the sale of tourist-related goods

- Expand the amenities available in the Town of Jianfeng, thereby providing more spending opportunities for tourists and community residents

- $\quad$ Provide training opportunities and hire preferentially from the community for Park/tourism positions

- Provide information on how to start/operate a tourism business and consider developing a small grant/loan program to help community residents to do so

- Impose conditions on new/foreign-invested developments that require the use of local labour and goods

- Encourage tourists to stay longer at the Park through reduced room rates for extended stays, multi-day sightseeing itineraries and the provision of interpretive facilities/programs

- Work with community members to develop satisfactory compensation arrangements for reduced access to Park resources

- $\quad$ Renew and maintain community outreach efforts that explain and document the benefits of forest protection

- Support diversified, not purely subsistence based, agriculture and invest in research that experiments with alternative livelihood strategies in the buffer zone 
- $\quad$ Provide training and skills development opportunities for community residents

- Encourage community stewardship for the Park through public involvement in planning and decision making

- Develop a monitoring program and implement the law enforcement strategy developed by ARD Inc. 


\section{Chapter 6 \\ Case Study II: Diaoluoshan National Forest Park}

Using the same format as in Chapter 5, the findings of the research undertaken in Diaoluoshan National Forest Park and Town of Diaoluo are presented and discussed. The purpose of this case study, as at JNFP, is to assess the existing tourism-park-community relationships and impacts, and thus be able to provide planning direction. A study site description for Diaoluoshan National Forest Park and Provincial Nature Reserve (6.1) and the Town of Diaoluo (6.2) is followed by a discussion of the relationships between the local community and the Park (6.3), the local community and tourism (6.4), and the Park and tourism (6.5). The chapter concludes with a discussion of management and policy issues, and their influence on the relationships between the various stakeholders (6.6).

\subsection{Site Description - Diaoluoshan National Forest Park and Provincial Nature Reserve}

\subsubsection{Location}

Diaoluoshan National Forest Park and Provincial Nature Reserve (DNFP) lies in the mountainous, predominantly rural, southeast of Hainan in Lingshui Li Autonomous County (Figure 6.1). Diaoluoshan was first designated a Provincial Park in October 1994, before being upgraded to a National Park in May 1999. DNFP sits at latitude $18^{\circ} 43^{\prime}$ to $18^{\circ} 58^{\prime} \mathrm{N}$ and longitude $109^{\circ} 43^{\prime}$ to $110^{\circ} 03^{\prime} \mathrm{E}$, and has a total area of close to 387 square $\mathrm{km}$. Approximately $87 \%$ of the Park is forested, consisting of both primary and secondary tropical rainforest. Inside the Park sits a 33 square $\mathrm{km}$ Provincial Nature Reserve, which includes a core area of virgin tropical forest. The area was established as a Provincial Reserve in 1985. DNFP has an average annual temperature of $20^{\circ} \mathrm{C}$ at an altitude of 900m, where much of the Park, including the Diaoluoshan Holiday Resort, lies. The highest peak in the Park is $1290 \mathrm{~m}$. The region is affected by the continental northwest, maritime southwest and maritime southeast typhoons the Island experiences between June and November, and receives approximately $2160 \mathrm{~mm}$ of rainfall annually.

\subsubsection{Management and Administration}

The Diaoluoshan Forest Bureau was (DFB) established in the mid to late 1950s under the authority of the Guangdong Provincial Government, the administrative body immediately responsible for the 


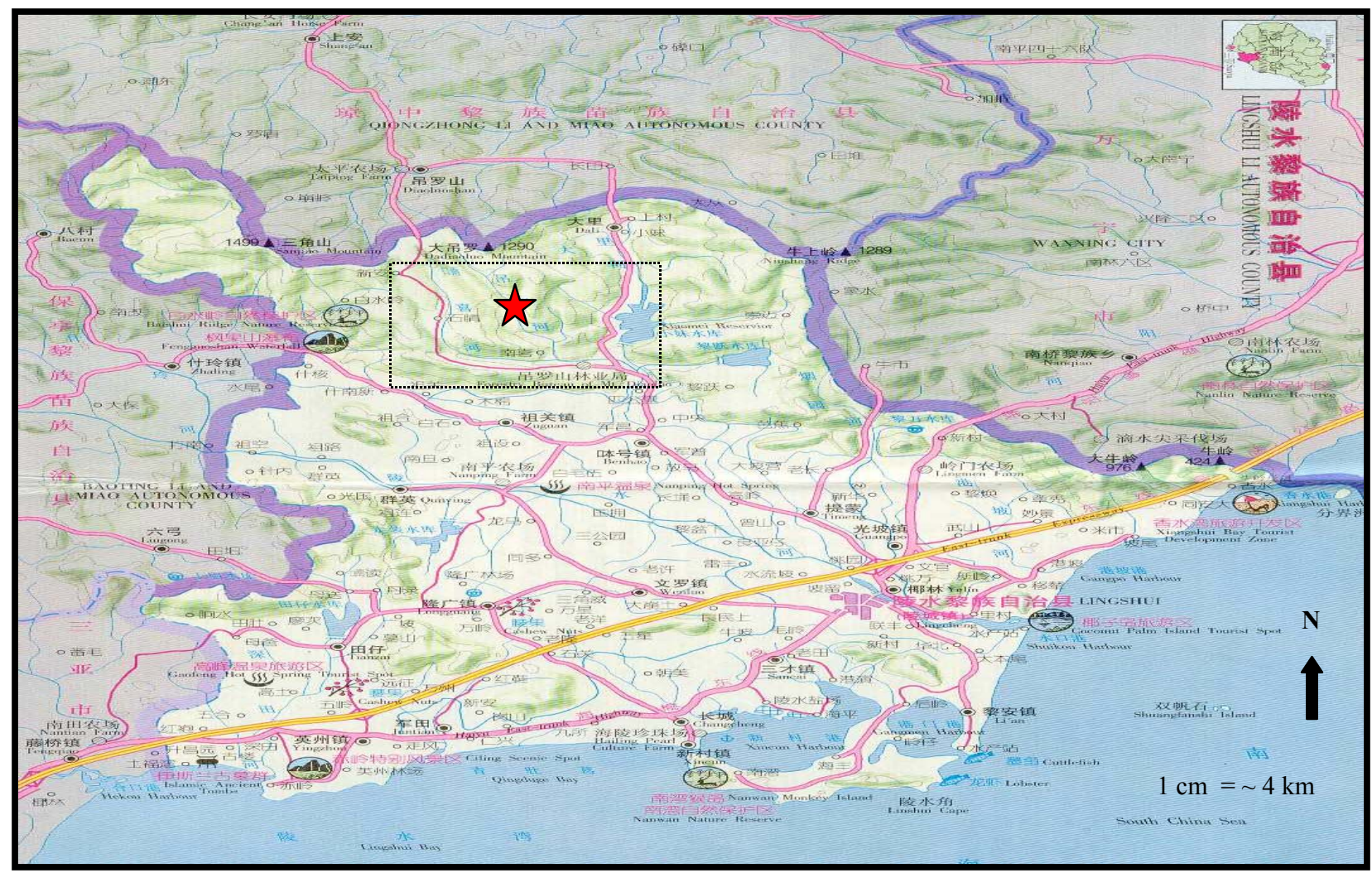

Figure 6.1: Location of DNFP

$\star \quad-$ - area enlarged below

Source: Hainan Tour Atlas, 1997

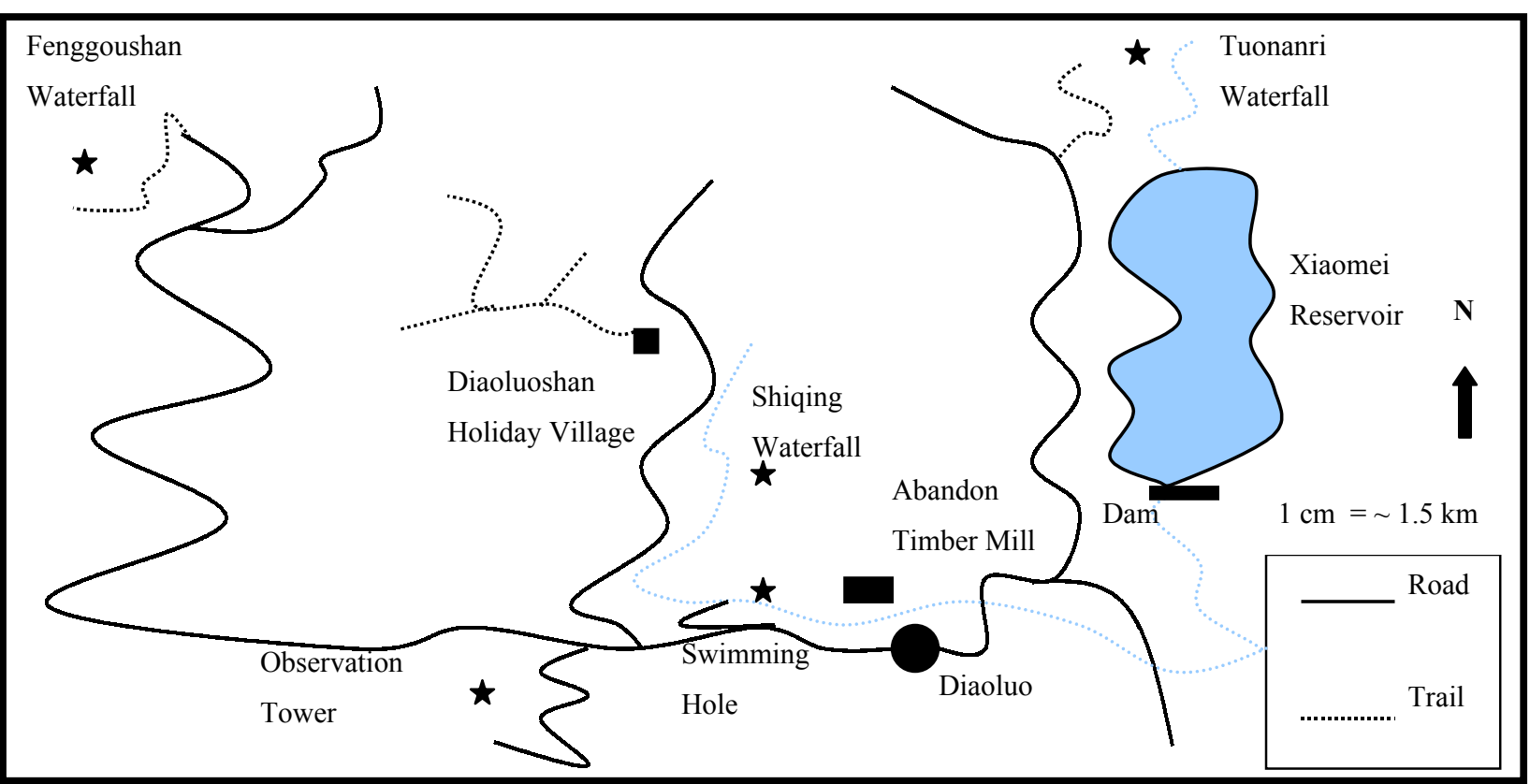

Figure 6.2: Infrastructure and Attractions at DNFP 
Island and much of its natural resources (Chongyi et al., 1997). The 1994 logging ban transformed the Bureaus mandate from profit-oriented forestry to forest conservation, and resulted in the creation of a Park and the protection of lands that had historically been logged. The DFB is now responsible for the implementation of the NNFPP and park management, which includes forestry ecotourism. Tourism management requires the DFB to collaborate with the Hainan Tourism Bureau (Administration) and the Hainan Department of Lands, Environment and Resources.

DNFP is currently in the process of producing a National Park management plan. Until this is completed, management will continue to be guided by the Provincial Park management plan that was created in 1995. Site level park plans are generally created at the site, but must be approved by the HFB and the SFA. Although site level tourism plans apparently do not exist, tourism management is supposedly covered in a park's management plan. Furthermore, site level tourism management is also to be addressed, to some degree, in the forthcoming WTO Tourism Master Plan for Hainan.

The DFB has a staff of approximately 170. This includes a local management and office staff of 40 and security team of 80 . Seven top-level managers head the local office. Although there are no women on the higher management team, there are at least 5 or 6 employed in middle or lower management. The Diaoluoshan Forest Travel Company employs about 51 people, which includes the staff of the 2 Bureau operated hotels. There are also apparently an additional 150 Bureau workers employed in agriculture that have some security responsibilities, which, if considered to be true staff, brings the total DFB staff to about 320. At least 2 top Bureau officials have training in Business Management and Administration, reflecting the agency's former role as a profit-oriented enterprise. One senior official, although generally pleased with the staff's commitment, suggested that education levels within the DFB are limited and should be better. However, at least one top manager has taken the initiative to begin teaching himself in basic ecology and environmental issues. Furthermore, there is apparently an initiative underway to develop a specialized 3-year training program in association with Hainan University to prepare future Bureau/park management staff for key positions.

Like all regional Forest Bureaus prior to 1994, the DFB was a self-funded enterprise, dependent on the sale of timber to generate revenues to cover operating costs. Between 1994 and 2000, the Bureau relied on variable Provincial and Central Government funding. This was supplemented by the sale of tropical fruit, bamboo and hydro-electricity, which raised, according to different estimates, between 3 million RMB and 7 million RMB annually (\$576,900 and \$1.35 million CDN). Increased government funding under the NNFPP will guarantee the DFB 6 million RMB ( $\$ 1.15$ million CDN) 
annually until 2010. Funds distributed under the NNFPP are to be split 80:20 by the Central and Provincial Governments respectively.

The Provincial Nature Reserve at DNFP, like all Reserves, is managed separately from the Park and under a different section of the HFB. Although in the process of making a new management plan, the Reserve continues to be run according to the original plan, made in 1985 when Provincial designation was assigned to the Reserve. A total staff of 11 is comprised of a 9-member security team and 2 managers, and includes 3 women. While the Reserve manager has a university education in ecology, the majority of staff has only high school education, supplemented by some special training provided by the HFB. Although no regular on-going training is provided, the Reserve staff takes advantage of any opportunities that become available to them. As a Provincial Nature Reserve, their funding is provided by the Provincial Government according to the number of staff employed. Annual funding has averaged around 100,000 RMB $(\$ 19,200 \mathrm{CDN})$ in recent years, with most going towards staff salaries.

\subsubsection{Flora and Fauna}

The tropical forests of Hainan have been recognized as some of the most biologically diverse in the world (Asian Development Bank, 1995). The species rich forests at Diaoluoshan are one of the Island's most valuable biological regions (Ouyang et al., 2001; Weisun, 2000). Monsoon, lowland and mountainous rainforest are all found at DNFP, giving rise to a diverse range of plant and animal species. Although some resource/species inventories have been conducted, comprehensive inventories apparently have yet to be finished. One official suggested that the CAF is considering establishing a research station in the Diaoluoshan region. Table 6.1 shows some of the currently known species diversity at DNFP compared to Hainan Province and China.

The Park provides protection for rare species such as the 'living fossil' tree fern, Alsophila spinulosa Tryon (Figure 6.3) and Dacrydium pierrei Hickel. The Park is home to 4 species of rare animals found only in the Diaoluoshan region, and protects nationally important species such as Cloud Leopard (Neofelis nebulosa Griffith), Indian Python (Python melurus Schlegel) and Hainan Partridge (Arborophila ardens styaw) (Diaoluoshan Forest Bureau, 1998).

Recognizing that many ecotourists are motivated to see biologically important and exotic places (Brandon, 1996), it would seem that DNFP has significant ecotourism potential. However, as previously noted, many of the species lists referred to today are based on inventories, or partial 
Table 6.1: Biodiversity at DNFP

\begin{tabular}{lc|cc|cc}
\hline & $\begin{array}{c}\text { Number of } \\
\text { Species } \\
\text { Diaoluoshan }\end{array}$ & $\begin{array}{c}\text { Number of } \\
\text { Species } \\
\text { Hainan }\end{array}$ & $\begin{array}{c}\text { Diaoluoshan } \\
\text { as } \\
\text { \% of Hainan }\end{array}$ & $\begin{array}{c}\text { Number of } \\
\text { Species } \\
\text { China }\end{array}$ & $\begin{array}{c}\text { Diaoluoshan } \\
\text { as }\end{array}$ \\
\hline Plants & 3,500 & 4,200 & 83.3 & 28,000 & 12.5 \\
\multicolumn{1}{c}{ Orchids } & 250 & - & - & - & - \\
Mammals & 34 & 76 & 44.7 & 409 & 9.3 \\
Birds & 112 & 344 & 32.5 & 1166 & 9.6 \\
\hline
\end{tabular}

Source: Figures taken from Ouyang et al., 2001 and Weisun, 2000

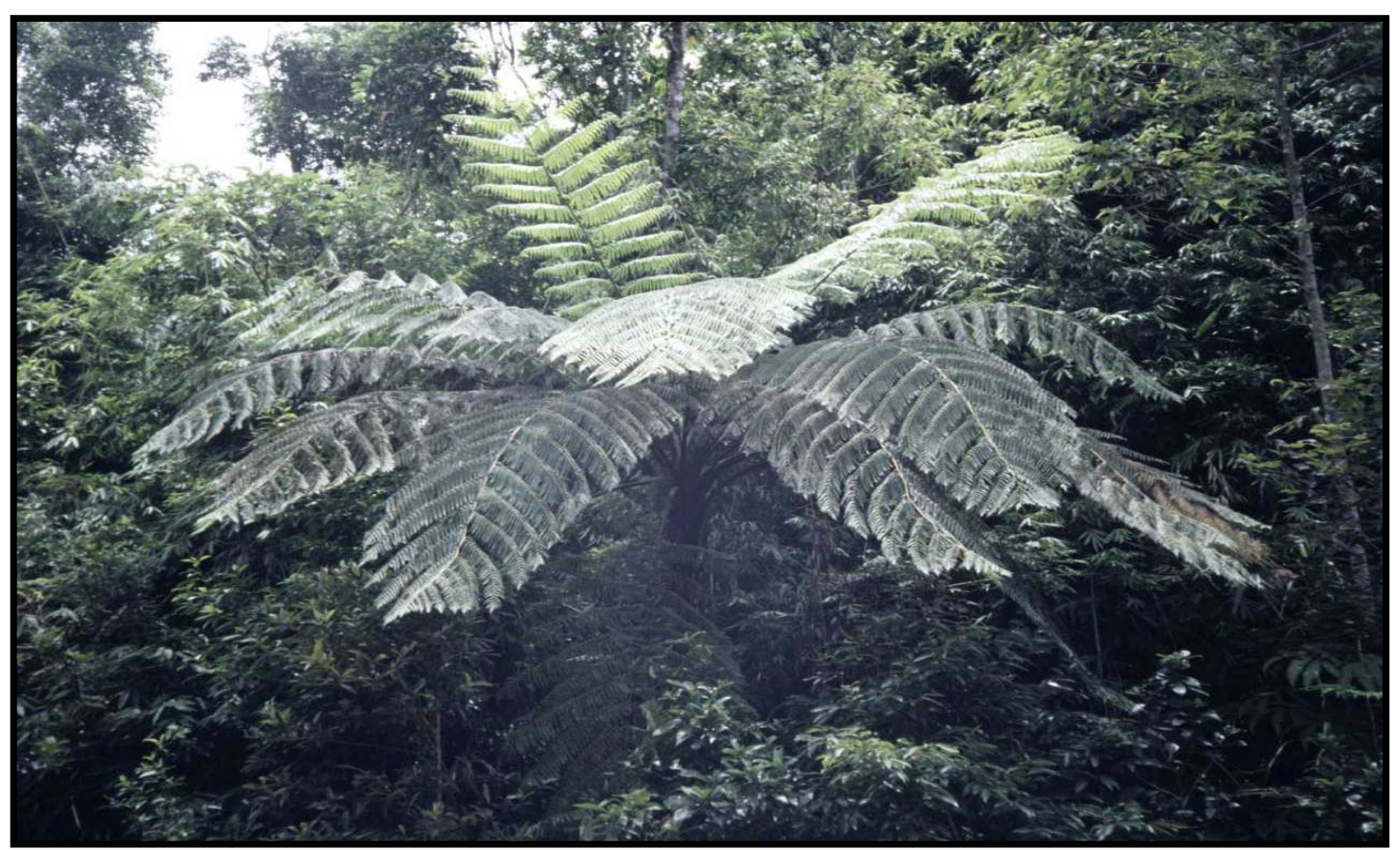

Figure 6.3: Alsophila spinulosa, a Rare Species Found in DNFP

inventories, completed in the 1950s and 1960s (Ouyang et al., 2001). The effect of 40 years of human activity and logging on the region's biodiversity has yet to be fully documented. As at JNFP, tourists to the Park are not guaranteed a wildlife sighting. No major wildlife was encountered during the time this researcher spent at the Park. While at least one local official has seen large mammals, it seems unlikely that the average, short-stay, tourist would have such an encounter at the Park given the 
areas that would typically be visited. Nevertheless, ecotourists may be equally attracted to the tropical forest scenery, waterfalls and other animals, such as insects, that are more readily visible in the Park.

\subsubsection{Infrastructure, Attractions and Accommodations}

DNFP is relatively undeveloped. Infrastructure in the Park is limited to one hotel, a fire/observation tower, a sightseeing platform, a China Telecom tower and some hiking trails (Figure 6.2). The Park is also currently home to 3 , soon to be 4 , hydroelectric dams. Only one dam, the largest for the time being, was immediately obvious when travelling in the Park. This dam has created the 0.5 square $\mathrm{km}$ Xiaomei (Younger Sister) Reservoir, which is billed as one of the Park's 8 main attractions for its emerald waters and picturesque mountainous surroundings (Weisun, 2000).

Just north of the Reservoir is the 70 m-high Tuonanri Waterfalls, the largest falls in the Province, and another of the Park's major tourist attractions (Figure 6.4). Easily accessed via a short dirt track connected to the road that runs north alongside the Reservoir, Tuonanri is 1 of 3 large waterfalls found at DNFP. Shiqing Waterfalls can be observed from the road leading to the Diaoluoshan Holiday Village. The equally impressive Fenggoushan Waterfalls (Figure 6.5) lies a considerable distance from town but is easily reached from the trailhead along a short, recently constructed, stoneconcrete path. The path crosses the river atop the Falls, before descending a railed staircase that leads to an observation platform near the bottom of Fenggoushan. Popular swimming spots, at least among locals, include the pool at the base of Tuonanri and a natural river pool that lies a short distance from town.

The only other trails observed or hiked at DNFP ran through the forest immediately behind the Diaoluoshan Holiday Village. Although the total length or ultimate destination of this trail network was not determined, the paths follow a picturesque stream, through impressive tropical forest, passing apparently one of the oldest and largest trees in the Park. A short, grassy path from the hotel leads to a memorial, of some cultural and historic interest, commemorating 2 men from the Miao ethnic minority group for their role in fighting against the Kuomintang. Aside from the path at Fenggoushan, all trails hiked were natural dirt tracks. One official suggested that they would like to harden all trail surfaces, but do not have sufficient funds for such a project. It was not determined if officials had considered that such a project might be inappropriate for an ecotourism destination. 


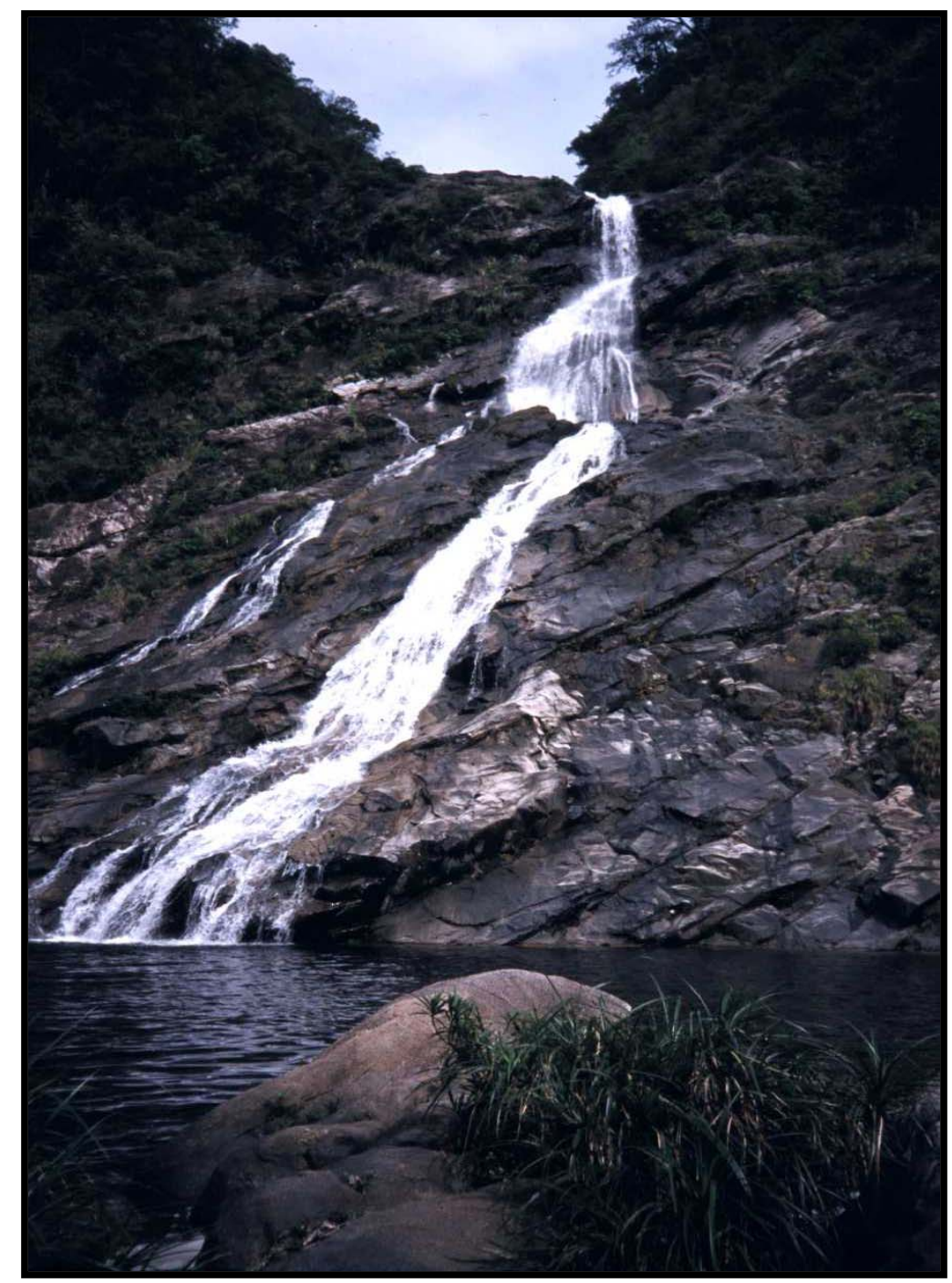

Figure 6.4: Tuonanri Waterfall, DNFP

Although some garbage was observed and maintenance appeared minimal, the trails seemed to be in reasonably good condition, and could generally be walked without the aid of a guide, assuming one knew where they began. No interpretive media are provided on any of the trails the researcher observed or hiked. Indeed, interpretive media and signage of any sort, regulatory, informative, etc., are conspicuously absent at DNFP.

Not far from town sits a fire/observation tower that provides good views of the Park and surrounding mountains. However, as the tower was locked on each of the 3 occasions it was visited, 


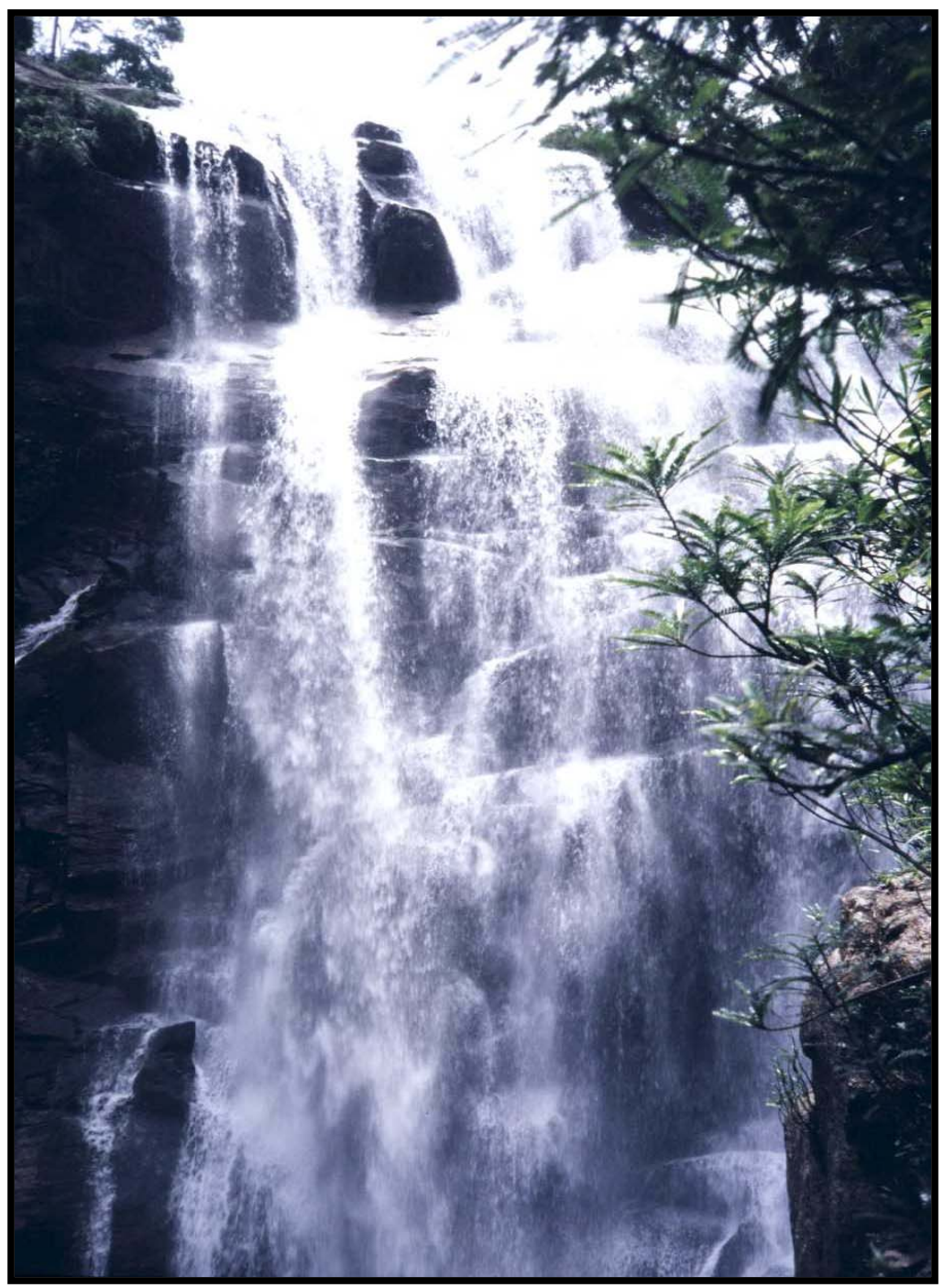

Figure 6.5: Fenggoushan Waterfall, DNFP

it is not clear if, or at what times, it is accessible to tourists. Although it was not visited, a sightseeing platform is apparently located in the vicinity of the Diaoluoshan Holiday Village that offers views of the forest, mountains, clouds and, on clear days, the distant ocean (Weisun, 2000).

DNFP offers 2 accommodation choices, both of which are owned and operated by the DFB. The 3star Diaoluoshan Holiday Village (Figure 6.6), where currently most tourists stay, is located approximately 10 to $15 \mathrm{~km}$ from the town of Diaoluo. Formerly the housing quarters of the employees of a now closed tree factory in the area, the hotel offers around 100 beds ranging from 170 RMB to $260 \mathrm{RMB}$ ( $\$ 33$ to $\$ 50 \mathrm{CDN}$ ) per night. All rooms are basic, providing a private bath and 
television, but no telephone or air conditioning (which is not necessary at the $900 \mathrm{~m}$ altitude). Two styles of rooms are available, bamboo huts or white tile bungalow units. The Village has one restaurant and a multi-function hall for meetings or entertainment.

The relatively new Diaoluo Hotel is found in the town of Diaoluo (Figure 6.7). Although not officially open, the hotel still receives some guests. The restaurant on the premises is the largest and most popular in town. Once funds permit its completion, the hotel will provide about 35 beds, in 18 basic rooms equipped with private bath, television and air conditioning, for around 180 RMB (\$35 $\mathrm{CDN}$ ) per night. The Diaoluo Hotel is striving for a 3-star rating.

Although true ecotourists would appreciate the Park's undeveloped state, and may be content with mid-range accommodations (Eagles, 1998; Norris, 1992) like those provided at DNFP, they do demand high quality nature experiences (Eagles, 1992). Although the Park offers spectacular scenery and the potential opportunity to view wildlife, it is arguable whether or not it can now provide an adequate overall ecotourism experience given the lack of interpretive media, in either English or Chinese.

\subsubsection{Future Developments}

The relatively limited range of facilities and services outlined in the previous section is a reflection of the early stage of tourism development that DNFP is currently in. Interviews with local officials revealed that there are plans to continue to develop the Park's infrastructure. Future hotels, for example, will likely be built in the town, not the Park, for the sake of environmental protection. However, such developments will depend on consultation with 'experts' and the Park's management plan. The majority of future developments are apparently intended to be joint ventures.

A new hydroelectric dam, larger than any currently operating, is supposedly scheduled for construction. Under the joint venture, the Forest Bureau is to receive approximately $14 \%$ of profits. The dirt road running between the Town of Diaoluo and the Diaoluoshan Holiday Village in the Park is to be hardened in the near future. A local official emphasized that every effort will be made to maintain tree coverage right up to the edge of the road to protect against typhoon damage. A new restaurant is also currently in the process of being built in town. 


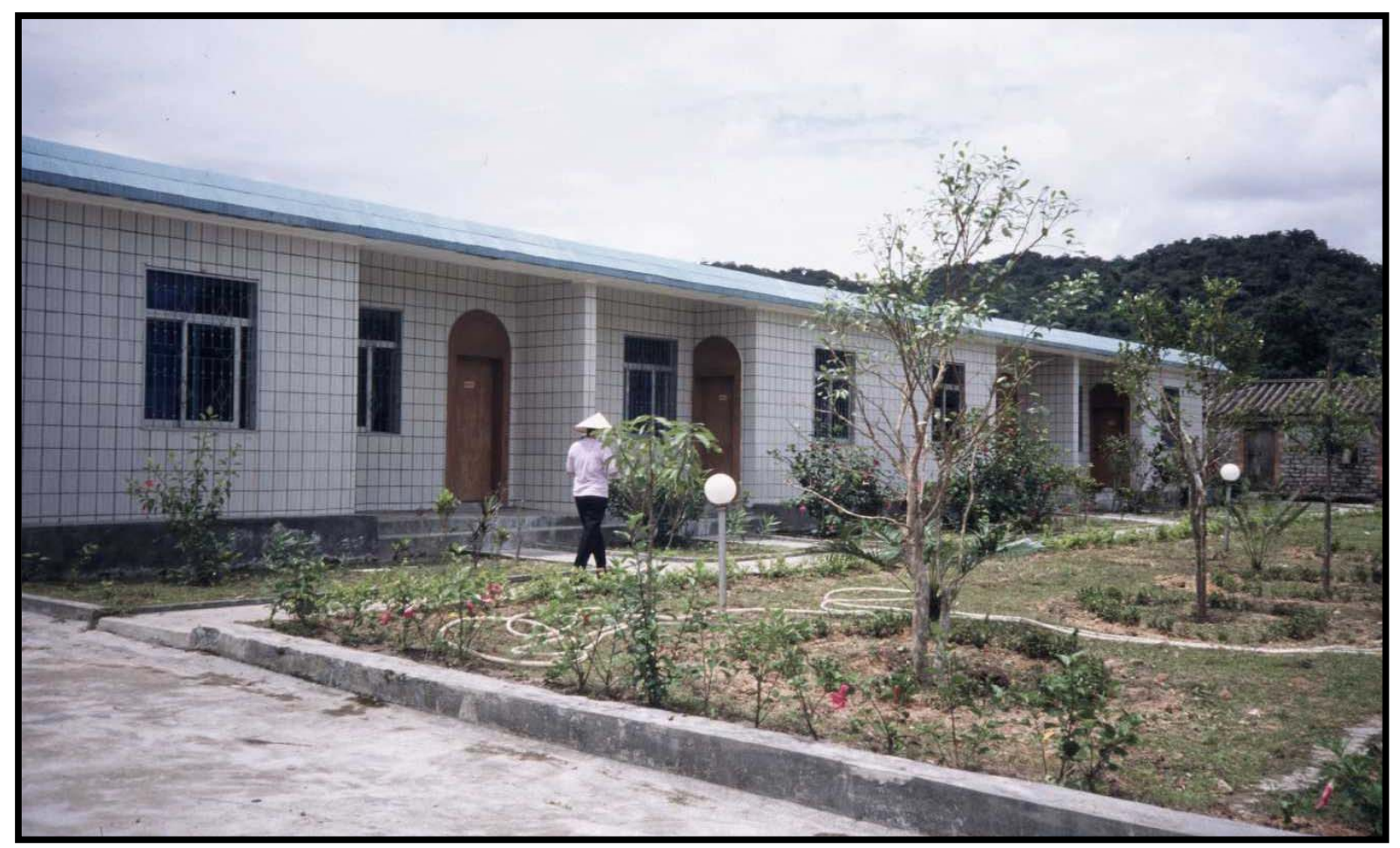

Figure 6.6: The Diaoluoshan Holiday Village, DNFP

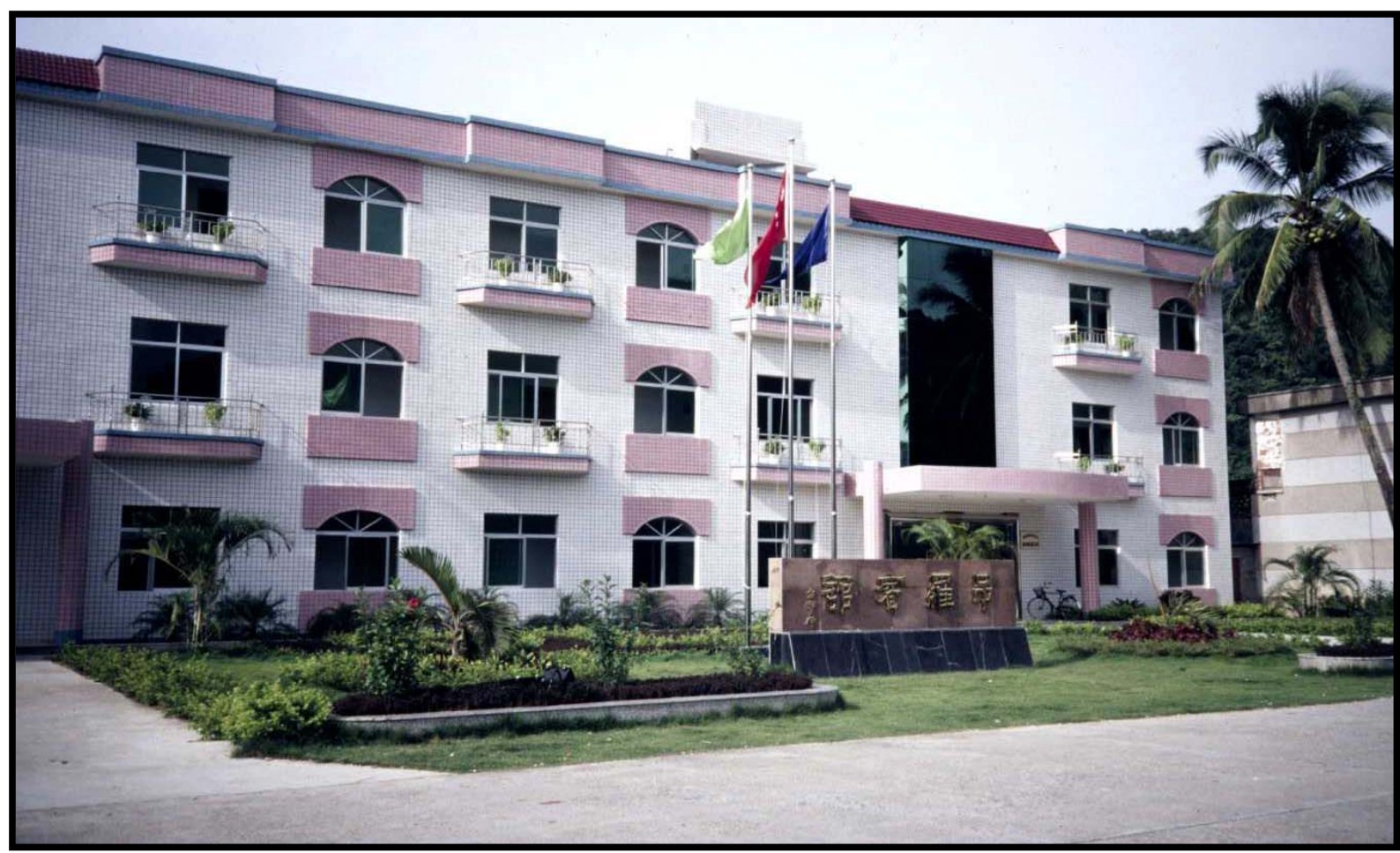

Figure 6.7: The Diaoluo Hotel, Diaoluo Town 
In terms of tourism-related services, local officials suggested that some of the management responsibility for the currently Bureau owned and operated hotels might be transferred to private interests in the future to inspire better service. One interviewee also noted that there are plans to develop Miao cultural attractions, of which there are currently none, at DNFP. Both of these measures have the potential to contribute towards improving the (eco)tourism experience offered at the Park.

In addition to the above, an information booklet obtained about the Park reveals a number of planned developments for the 2001-2005 period (Diaoluoshan Forest Bureau, 1998). Included are the following: hotel expansion/completion, a trail and platform at Fenggoushan Waterfalls (almost complete at the time of research), a specimen collection museum, a 2000-ton capacity water supply system and a pedestrian/tourist shopping street. To accomplish development goals, management will continue to reform government enterprises, by reducing the number of employees, increasing efficiency, collecting capital and incorporating more businesses. The continued development of highvalue commercial forests/plantations and a focus on processing industries, hydro operations and tourism is also intended to help management to complete their construction agenda. Also noteworthy, is the identified need to conduct scientific research on tropical genetics. Encouragingly, this list reveals the desire to improve both tourist facilities and quality of life for the community.

Although management seems cognizant of the need to consider the environment in future developments, it was unclear whether or not the new hydroelectric operation was subject to any sort of environmental assessment. It remains to be seen how its construction will affect the regional environment, and the Park's ability to attract (eco)tourists. Furthermore, while joint ventures may be beneficial in terms of raising development funds and improving service quality, they also raise the potential for the leakage of economic benefits to areas outside of the local community.

\subsection{Site Description - The Town of Diaoluo}

The Town of Diaoluo is located in the mountainous, and largely rural, southeast part of Hainan Island in Lingshui Li Autonomous County. The Park is approximately $20 \mathrm{~km}$ from the Island's Eastern Expressway, $70 \mathrm{~km}$ from Sanya City and $260 \mathrm{~km}$ from the capital of Haikou. The town sits within the boundaries of DNFP (Figure 6.8). Diaoluo was essentially formed in the 1950s when the DFB was established to manage logging operations in the region. The town still today consists largely of 
Forest Bureau workers, retired and employed, and their families. Both Han Chinese and people of the $\mathrm{Li}$ and Miao ethnic minorities live in Diaoluo and the surrounding areas, giving the region an approximate population of 21,700. Close to 3,700, predominantly Han Chinese, reside in the town proper, with the remaining 18,000, predominantly Li and Miao, distributed among the numerous villages that surround the town and Park. The town of Dali, a conglomeration of 4 Li villages and about 1,300 people, sits on the northern border of the Park and is one of the largest concentrations of $\mathrm{Li}$ in the region. Based on these estimates, ethnic minorities, the earliest inhabitants of the area, comprise about $83 \%$ of the total population.

The majority of Li and Miao rely on agriculture and animal husbandry to sustain their families (Figure 6.9). Such activities are largely based on subsistence, but may also include crop production for sale in local or regional markets. Limited numbers of Li and Miao are employed by the DFB. Although Li and Miao income levels were not available for Diaoluo, per capita incomes can be expected to fall somewhere between the Jianfeng range of $417 \mathrm{RMB}$ to $630 \mathrm{RMB}$ ( $\$ 80$ to $\$ 120 \mathrm{CDN}$ ) and the Provincial rural average of 1,031 RMB (\$198 CDN) (Asian Development Bank, 1995).

The Han Chinese of Diaoluo, in addition to agriculture, are engaged in a somewhat wider variety of livelihood activities. Han people also hold the vast majority of positions within the DFB. Table 6.2 contains a breakdown of the types and number of businesses that are located on the town's single main street (as observed on July $8^{\text {th }} 2001$ between $4 \mathrm{pm}$ and 5pm). The Table reflects some, but not necessarily all, of the kinds of non-agricultural employment activities that local Han residents participate in. Although Han income figures were not available, they can be expected to be substantially higher than for the $\mathrm{Li}$, as is the case throughout the Province. Han annual household incomes in Diaoluo are likely similar to those in Jianfeng, which range from 6,268 RMB to 15,918 RMB (\$1205 to \$3060 CDN). (Asian Development Bank, 1995). For DFB employees, the average annual wage has risen 20\%, from 4265 RMB (\$820 CDN) in 1997 to 5118 RMB (\$984 CDN) in 2000 (Diaoluoshan Forest Bureau, 1998). The Bureau is aiming to increase this to 8000 RMB (\$1538 CDN) by 2005 . 


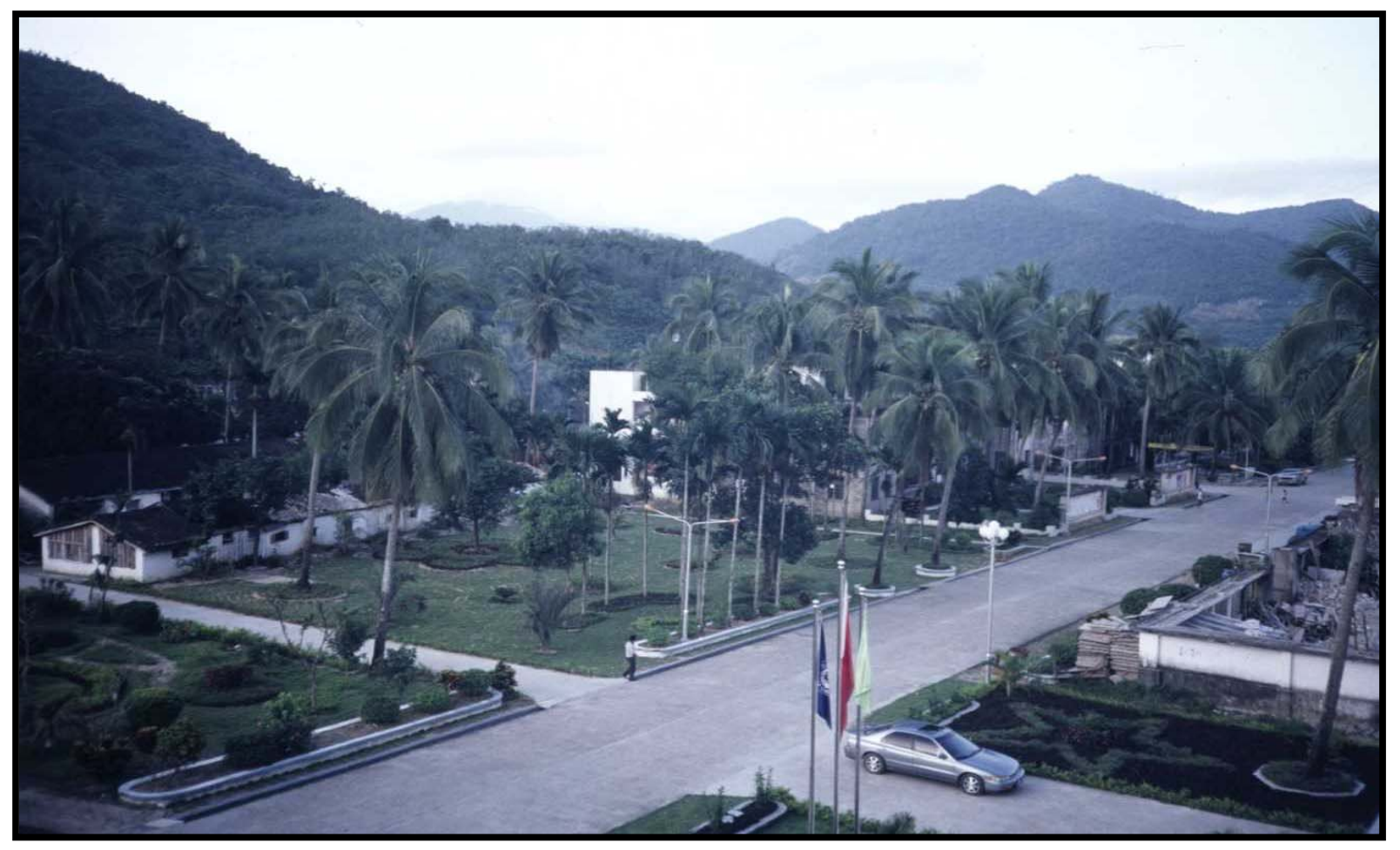

Figure 6.8: The Town of Diaoluo

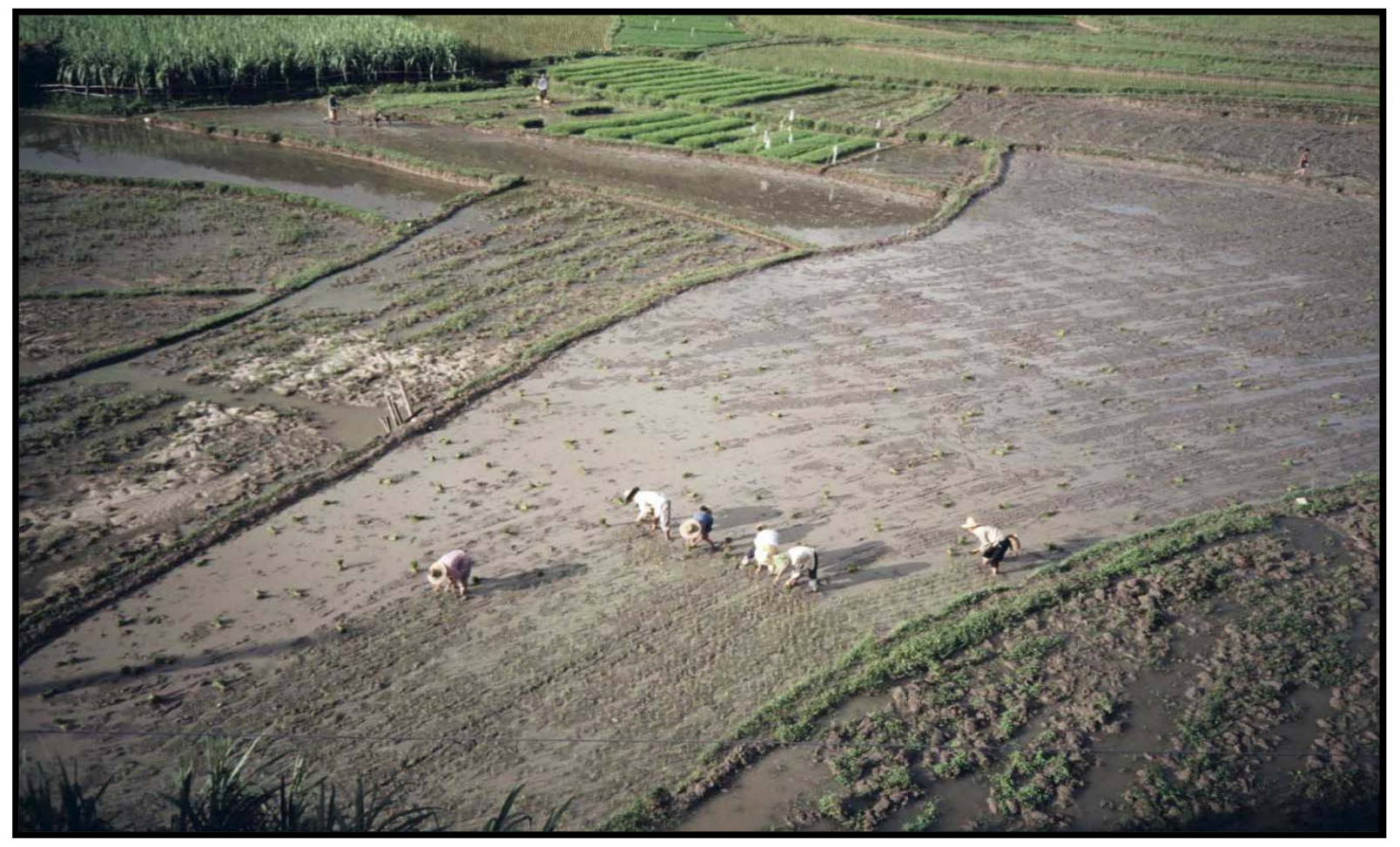

Figure 6.9: Li Agriculture, Diaoluo 
Table 6.2: Types of Businesses Operating in Diaoluo

\begin{tabular}{ll|ll}
\hline Type of Business/Facility & Number Counted & Type of Business/Facility & Number Counted \\
\hline Restaurant \&/or Tea House & 3 & Fruit, Vegetable \& Meat Market & 1 \\
Small Food Shop & 6 & Auto Repair \& Supply & 2 \\
Hair, Beauty \& Massage & 3 & Hotel & 1 \\
School & 1 & Post Office & 1 \\
Street Vendors - Food \& & Numerous; Varied & Miscellaneous Shop (plumbing, & 2 \\
Miscellaneous & daily & hardware, toys, etc.) & 1 \\
China Telecom Store & 1 & Public Security Bureau (Police) & \\
\hline
\end{tabular}

The town of Diaoluo consists of one main business street and a number of residential roads, lanes and alleys. Infrastructure is limited and includes 1 China Post office, 1 hotel, 1 school, 1 Public Security Bureau, 1 China Telecom Store and the DFB offices. A medical clinic was not observed, but is likely present. While the main street has fairly recently been hardened, the remainder of the roads in and around town are dirt, and in reasonably good condition. Diaoluo is connected to Lingshui, the nearest major centre, by about $20 \mathrm{~km}$ of dirt and concrete roads, which are also generally in good condition. The road linking the town to the Diaoluoshan Holiday Village in the Park is to be hardened in the near future. The vast majority of roads the researcher traveled in the Park are dirt tracks in reasonably good condition.

Transportation around Diaoluo and the surrounding area is by foot or personal automobile. For those without a private automobile, travel to nearby towns/villages seemed dependent on whether or not someone with a personal vehicle happened to be going in that direction and had room to spare. The exception is the one, apparently daily, mini-bus that leaves for Lingshui, travelling through Benhao, which is also somewhat larger than Diaoluo. Lingshui is a transportation hub for travel to destinations along the Eastern Expressway, south towards Sanya, and north towards Haikou. To reach Diaoluo, one must first get to Lingshui, where somewhat regular mini-buses head north (inland) to various destinations that include stops in Diaoluo.

\subsection{Relationship Between Local Community and DNFP}

In an ideal ecotourism scenario there should be a symbiotic relationship between local residents (the host community) and the protected area, including both its resources and the staff that manage them. Local residents are more liable to support conservation efforts, and may even act as stewards for the 
resource(s), if they benefit from protection through sustainable harvesting and the conservation of important resources such as forests and watersheds.

\subsubsection{Park Resource Use}

Diaoluo is essentially a purpose-built, forestry town that was formed when the Guangdong Provincial Government established the DFB in the mid-1950s to manage the timber industry in the region. The vast majority of Han families living in Diaoluo therefore traditionally had at least one member employed by the DFB. When logging was banned in 1994, about half of the roughly 1300 workers employed by the DFB at that time lost their jobs. Although job loss was initially a problem for many families, top officials stressed that overall it has not been a major issue and that most residents now understand why logging was banned and the Park established. This is consistent with local resident interview results, which revealed little concern over lost jobs: only $13 \%$ of respondents $(n=30)$ commented that some people had lost jobs, income was now lower or that people had left Diaoluo after the ban. Of the approximately 600 laid-off workers, some were re-employed in new (nontimber) factories, some workers' expired contracts were not renewed, some retired and others left Diaoluo in search of work elsewhere.

In certain areas of the Park, individuals and companies have rented land from the DFB for agricultural use. Fishing in the river and Xiaomei Lake is also permitted, apparently because there are no rare species present, and therefore fishing poses no danger. However, there are some restrictions on fishing in terms of minimum fish size and how fish are caught (for example, no 'bomb' fishing is allowed). Although Table 6.2 illustrates that some residents are employed in small business operations, the majority of families are still dependent to some degree on employment in the DFB or agriculture, both of which rely on the resources found in the Park and surrounding region. Resource dependency among the Han can therefore be considered to be relatively high.

The majority $\mathrm{Li}$ and Miao population in the region is almost exclusively engaged in subsistence agriculture and animal husbandry. Although no Li can apparently afford to rent Park land, there are conflicting interpretations of whether or not they own any land within the Park. In one area, Li people, although they do not reside there, are using Park land, a grassy floodplain, for livestock grazing. In another area of the Park a member of the Li minority was observed to be growing fruit. One official also indicated that within the Park there is some agricultural land belonging to the Li, but that they do not live there. Similarly, there is a Li village and agricultural fields immediately adjacent 
to Diaoluo (Figure 6.9); while a local official suggested that their fields are within the Park, the village leader insisted that they are not within its boundaries. This same village lost some land when the Diaoluo Hotel, which backs onto their fields, was built. The 24 square $\mathrm{km}$ of land owned by the town of Dali lies outside or just inside the Park's borders, depending on whom you ask. A village leader indicated that while they had never lost any land to the DFB, that the Forest Bureau has taken all their guns so that they can no longer hunt. Although hunting was apparently illegal even prior to the 1994 logging ban, the local Government tended to turn a blind eye to such activity. Regardless of boundaries, dependency on natural resources in the vicinity of the Park for the ethnic minority groups continues to be extremely high.

Opinion is also divided on the degree to which illegal resource use poses a threat. One official suggested that although the situation has improved in recent years, with a broadened environmental awareness among the Li, illegal hunting and cutting by the Li minority is still the greatest threat to the Park. The same official also noted that while the Li do harvest in the Park illegally, it is the Han who hunt and cut illegally in the Reserve, not the Li. Another top DFB official was of the opinion that although some people occasionally cut trees, illegally resource use by the $\mathrm{Li}$ is not a big threat. The DFB has apparently made contracts with a number of the villages/towns surrounding the Park that stipulate that a village agrees to protect the forest. Local security and police handle relatively small offenses, where penalties might include a fine or prison sentence up to a maximum of 15 days. The Haikou police are responsible for prosecuting major offenses.

\subsubsection{Park Staff and Local Resident Relations}

According to a Nature Reserve official, information has been provided to the Li and Han people of the region with respect to the importance of the Reserve and the rare animals it protects. On the contrary, a DFB official suggested that when the Park was built it was not necessary to provide people with information because the Forest Bureau owns the land. However, the same official went on to say that the DFB had taken the initiative to make contracts with the Li Government and surrounding villages that essentially ask them to recognize the importance of forest protection.

Local interview results reveal that Diaoluo residents have been provided with some information. Close to $87 \%$ of local residents $(n=30)$ and $100 \%$ of business owners $(n=5)$ indicated they had been given information. While about $19 \%$ of residents could not recall the content, those that could said it related primarily to why the park was created/logging banned, the sightseeing places offered in the 
Park or the importance of protection/ecology. Three-fifths (60\%) of business owners were unable to recall the content of the information they were given; those that did remember, suggested it was with respect to forest/ecology protection or the beautiful sightseeing places found in the Park. A small number of residents who recalled receiving information qualified this with comments like 'it was not a good effort/more should be done', 'it was not an effective message', or that 'locals don't care what officials say because the government is corrupt'.

More generally, interviews revealed that some people distrust the DFB or are unhappy with the current situation in Diaoluo. A number of comments (15) were made relating to lost jobs, decreased incomes, corrupt government or that only the Forest Bureau benefits. Comments such as these suggest that some degree of displeasure is present among Diaoluo residents.

A leader from the town of Dali indicated that they had been given some information (instructions) that they were not to cut trees or harm the forest, and that they support the Forest Bureau and its mandate to protect the forest. However, the town leader also commented that they have never been asked for their opinion because the land belongs to the DFB. Conversely, the Li people residing immediately adjacent to Diaoluo have apparently not been given any information since 1994. A local leader indicated that they are very upset with the Forest Bureau, but that they have no means to express their anger except through complaints. Their feelings stem from a perception that the DFB has not cared about the Li minority in the process of establishing the Park, and the fact that the village lost some land when the Diaoluo Hotel was built. However, the leader did indicate that no people were forced to move when the Park was created and that they now receive free electricity and 300 RMB ( $\$ 58 \mathrm{CDN})$ per year for each mu $(1 \mathrm{mu}=0.0667 \mathrm{ha})$ of land they lost. While the Li feel that this is a fair deal, the leader also commented that they were given no choice in the matter. This compensation arrangement was not mentioned by any of the DFB officials interviewed. On the other hand, neither Li village leader noted they had entered into a forest protection contract with the DFB.

Overall, Park and Reserve officials were of the opinion that relations with locals are 'O.K.' or 'generally good', and that although there were some problems initially, most people have now come to see the Park as a good thing. Although both Li and Han residents have been provided with some information, neither group has apparently had the opportunity to provide input or participate in the Park planning or management process. Furthermore, there is some evidence of displeasure among the local population, suggesting that park-local relations are, in actuality, variable. 


\subsubsection{Local Resident Stewardship}

There is widespread understanding among residents on why DNFP was established. All resident and business owners interviewed $(n=35)$ know that a Park has been created. To protect forest/ecology/animals ( $57 \%$ of residents and $80 \%$ of business owners), to develop tourism (57\% and $80 \%$ ) and to develop the local economy ( $30 \%$ and $40 \%)$ were the most commonly cited reasons for designation in both groups. Only 2 people interviewed (representing $6 \%$ of the sample) could not suggest a reason for the establishment of DNFP. Both Li leaders cited forest/ecology protection as the main reason for the creation of DNFP.

Interviews with local residents and business owners also revealed broad support of the Government's decision to establish DNFP. More than two-thirds (70\%) of residents and $100 \%$ of business owners see 'Park' designation as a 'good thing' overall. The remaining 30\% of residents also saw designation as a good thing. However, they added comments like 'there were problems initially', 'it will be good in the long-run', 'planning will be important', 'it is good for the forest but not my family', and that 'there will be no benefits/negatives for non-business people'. No residents or business owners interviewed indicated they saw Park designation as a bad thing overall. While one Li leader indicated he thought the Park was a good thing overall, the other leader interviewed responded, with an air of indifference, by saying that his people were angry with the DFB, that they 'do agriculture' and the Bureau 'does forest protection'.

The residents of Diaoluo recognize the importance of protecting the forest/resources. All of those that responded to this question ( $\mathrm{n}=34 ; 1$ no response) indicated that forest/resource protection was important to them. The most common reasons cited were that forests are related to water resources ( $55 \%$ of residents and $40 \%$ of business owners) and ecological protection ( $41 \%$ and $40 \%$ ). Both groups also recognized the link between forests and climate (17\% and $40 \%)$ and forests and flood/natural disaster prevention ( $21 \%$ and $20 \%)$. The Li village leaders interviewed also recognized the importance of protecting the forest. While both leaders noted that protection promotes 'more water', one leader also added that forests help prevent soil erosion and will benefit the following generation.

Half (50\%) of local residents indicated that Park establishment has positively impacted their lives. Increased income (29\%) and improved water resources (19\%) were the top 2 impacts cited among those that indicated a positive effect. A stronger local economy, increased jobs/business, improved roads, houses and living conditions (all 14\%) were the next most commonly identified positive 
impacts. Close to $7 \%$ of respondents indicated that Park establishment has had a negative impact on their lives. Among those who cited negative effects, only officials benefit (25\%), wages/incomes have decreased (25\%), and some lost jobs after designation (13\%) were the most common impacts identified. One-fifth (20\%) suggested that the Park has both positively and negatively influenced their lives. Just less than one-quarter $(23 \%)$ of residents said the Park has had neither a positive or negative affect on them.

Two-fifths (40\%) of business owners indicated that the Park has had a positive impact on their business. One owner (20\%) said that the Park has had a negative effect, suggesting that fewer business people visit Diaoluo since logging was banned and that, as a result, their business has decreased overall. The remaining $40 \%$ thought that the Park has had neither a positive nor negative effect on their businesses. Similarly, a Li leader from Dali indicated that the Park had no effect on their lives. The Li leader from the village close to town identified only negative impacts, in the form of lost land and general indifference on the part of the DFB towards their community's needs.

\section{Table 6.3: Summary of the Relationships Between the Community and DNFP}

\begin{tabular}{ll}
\hline \multicolumn{1}{c}{ Indicator } & \multicolumn{1}{c}{ Assessment } \\
\hline Greater Town Population & $\sim 21,700$ \\
Local Resident Dependency on Natural Resources & High \\
Access to Park Resources & Restricted; Some Land for Agriculture; Fishing; Rental \\
Access to Resources in Buffer Area & Not Determined if a Buffer Zone Exists \\
Illegal Resource Use & Minimal \\
Enforcement Capacity & Not Determined \\
Benefits from Resource Protection & Water Resources, Ecological Protection, Climate \& \\
& Disaster/Flood Prevention (perceived) \\
Conservation Attitude & Positive \\
Potential for Stewardship & Good \\
Staff-Local Relations & Variable \\
Participation in Planning & None; Provided with Information Only \\
\hline
\end{tabular}

The residents of Diaoluo have a good understanding of why DNFP was created and that protecting the forest is important for a variety of biophysical reasons. Overall, close to half (49\%) of all respondents $(n=35)$ indicated that the Park has had only positive impacts. However, the other half of 
respondents cited negative, both positive and negative, or no effects whatsoever from the establishment of DNFP. It is therefore unlikely that widespread stewardship for the Park exists. The current situation seems to be more a case of broad (passive) acceptance, mixed with more active support from some members of the community. If the Park were able to provide on-going benefits to the community in the future then there would seem to be the potential for true stewardship or advocacy to develop in Diaoluo. Table 6.3 summarizes some of the existing relationships between the local community and DNFP.

\subsection{Relationship Between Local Community and Tourism}

For ecotourism to develop successfully at a destination there must be widespread support from within the community (the hosts). If local residents are receiving socioeconomic benefits from tourism and have been compensated for loss of access to resources they may have been dependent on before tourism developed, then they are more likely to have a positive attitude towards (eco)tourism activity near their community. If residents are benefiting and able to sustain themselves, there is a greater chance that tourists' experiences may be enriched through intercultural exchanges with locals.

\subsubsection{Economic Benefits}

Tourism at DNFP is at an early stage of development and, as a result, there have been very limited economic benefits to date. DFB officials, using hotel records, estimate that more than 30,000 tourists visited the Park in 2000. Officials also suggested that this number had already been surpassed in the first 6 months of 2001. The average length of stay is 1 night, with about half of visitors arriving by personal automobile and half in groups that have been organized by a travel agency. A hotel manager interviewed suggested that although the Diaoluo Hotel in town receives some weekend and holiday business, that the majority of visitors stay in the Park at the Diaoluoshan Holiday Village, about 10 $\mathrm{km}$ from the town. It is quite possible that most tourists to DNFP do not stop in the town of Diaoluo. Aside from holiday overflow, the only reason a tourist might stop in town en route between the Eastern Expressway and Park would be to pick up some snacks, visit family or friends, or out of general curiosity. This suggests that relatively few tourist dollars are being spent in Diaoluo.

An early stage of development has also limited tourism-related employment. The DFB employs 4 or 5 guides, and although they are not officially licensed, they have received some training. A limited number of Li and Miao people are employed by the DFB. The 2 hotels and the Diaoluoshan Forest 
Travel Company are the only businesses in operation that have been established purely as a result of tourism development. Together, the employ about 50 people. Entrepreneurship related to tourism is essentially non-existent. Only about $0.3 \%$ of the regions total population of approximately 21,700 is directly employed in tourism. If the DFB staff of 170 , which has some tourism-related duties, is included this figure increases to $1.0 \%$. Using the town's core population of 3,700 , tourism employment increases to $1.5 \%$ and $6.1 \%$ respectively under the two scenarios.

Business owners' estimates of sales revenue suggest that tourism-related income is very limited. Two-fifths (40\%) indicated that that 'almost $0 \%$ ' of their total sales came from tourists. Three-fifths $(60 \%)$ of owners estimated tourism-related revenues to be $10 \%$ or less. This jumps to $80 \%$ of owners if one equates the response, 'mostly locals', to also be less than $10 \%$. Only one respondent suggested that more than $10 \%$ of their business is generated from tourism. Although one Li leader said they did sell a limited number of products in Diaoluo, the percentage of sales to tourists can be expected to be insignificant given current levels of tourism.

Nevertheless, as noted in Section 6.3.3, about half (49\%) of all residents and business owners interviewed ( $n=35$ ) suggested that the Park has had only a positive influence on their lives, mainly in terms of increased incomes. Senior managers at the DFB similarly identified the Park as having had predominantly only positive effects to date. When asked for their feelings on tourism and the potential for it to increase at DNFP in the future, $83 \%$ of residents and $100 \%$ of business owners indicated that they 'welcome more'. A further $13 \%$ of residents suggested they also would welcome more tourists, but qualified this with comments such as 'planning and management will be important', 'tourism is not well developed presently' and 'that it is not so easy for foreigners to get to DNFP'.

Despite support for more tourism, just over one-third (37\%) of residents thought they would personally benefit if tourism were to grow. The main potential benefits cited by residents were indirect benefits (i.e. the community benefits, therefore individuals will benefit) and increased job opportunities. The remaining $63 \%$ of residents suggested that they would not be personally affected in any way, good or bad, by tourism growth at DNFP. Residents were somewhat more optimistic in terms of benefits to the community, with $67 \%$ indicating that the community would benefit should tourism increase. By far the most common potential community benefit cited was a stronger local economy and the resultant increase in local incomes. Just less than one-third (30\%) suggested that future tourism growth would have both positive and negative impacts. Potential community 
negatives cited included the potential for environmental damage, garbage and drug use among tourists. Only 1 resident thought that there would be neither positives nor negatives should tourism at DNFP increase.

Business owners were asked the same question and proved to be more optimistic than residents in terms of both personal/business and community impacts. All business owners thought that tourism growth would benefit their business, and all but one suggested that there would be only benefits for the community. Potential community benefits cited included a stronger local economy/increased business opportunities and the possibility that investors will be attracted to the area.

When asked a similar question, a senior DFB official responded by saying that more tourists will require more guides and staff, and that local people will be used to fill these positions. While no major negative impacts resulting from tourism growth were predicted, he did express some concern over the education levels of staff and the quantity and quality of the existing tourism infrastructure. Another official interviewed was equally optimistic that tourism will generate community benefits, citing a Provincial Tourism Bureau statistic that one tourist spends enough money to employ six people.

Both Li village leaders interviewed were also fairly optimistic. The leader of the village closest to Diaoluo indicated that although they have not given much thought as to how specifically they might benefit, they welcome more tourists because tourism growth will benefit the whole town. The leader from Dali recognized that their town is some distance from Diaoluo and the main area of tourist activity, but hoped that tourism benefits would extend to their town. He suggested that, if tourism develops quickly, they might receive some benefit because Tuonanri Waterfall, one of the Park's major attractions, is fairly close to Dali.

Although tourism-related economic benefits have been limited to date, local officials, and the majority of residents and business owners interviewed, support tourism growth and are optimistic that it will bring benefits. Although the majority of residents did not think they would personally benefit from tourism growth, most did predict benefits for the greater community, mainly in terms of a stronger local economy, increased incomes and job opportunities. Widespread support and optimism is characteristic of an early stage of tourism development (Doxey, 1976). 


\subsubsection{Leakage}

Given that tourism-related employment and income has been limited to date, the loss of economic benefits to areas outside of the Diaoluo region (leakage) has also been limited. Currently, both hotels and the Travel Company are owned and operated by the DFB, suggesting that a significant proportion of tourists' direct expenditures on food and accommodation would be captured locally. While a large percentage of these tourism-related revenues will likely be used for management and operating costs, some would be transferred to the community through the payment of wages and subsequent local secondary spending. Although most residents purchase everyday food items, some clothing and basic supplies locally, secondary spending will be greatly limited because there are very few businesses in operation in Diaoluo. Residents do much of their shopping in Lingshui, the closest major centre, or Benhao, a substantially larger town near Diaoluo. Similarly, most business owners (4 out of 5) indicated that they purchase their supplies outside of Diaoluo. One of the hotel managers indicated that while vegetables are purchased locally, fish and meat are bought from Lingshui and other surrounding towns, with supplies coming from Sanya or Haikou. He did note that tables and chairs are made locally. Nevertheless, the potential for secondary spending leakage would seem to be fairly high. The potential for leakage is even greater when one considers that future developments are to be primarily joint, or private, ventures. However, in developing countries and rural areas with simple economies, leakage from any industry can be expected to be relatively high. On a positive note, some have argued that leakage from ecotourism may be less significant than with other forms of tourism (Cater, 1993).

\subsubsection{Social Welfare Benefits}

Local residents and authorities recognize that a number of non-economic, tourism/park-related, benefits have been created. One DFB official suggested that the recent creation of a new road has been one of the biggest benefits since the Park was created. A number of residents also indicated that road improvements, along with improved buildings/houses and general living conditions, have been some of the positive effects resulting from the creation of the Park. Residents also acknowledge the link between forest protection and water resources, climate and natural disaster prevention, suggesting that the benefits from ecological and watershed conservation are valued by the Diaoluo community. 
A document obtained for DNFP reveals that a 2000-ton water supply system is scheduled for construction before the end of 2005, which is likely intended to provide residents with a clean and reliable supply of water. The operation of hydroelectric dams in the region, although potentially environmentally damaging, helps to ensure a regular power supply for the Diaoluo community.

As noted in Section 6.3.2, the Li village next to Diaoluo receives free electricity, in addition to monthly financial payments, for lost agricultural lands when the Diaoluo Hotel was built. The manager of the Diaoluoshan Forest Travel Company also suggested that the Li (and Miao) do not pay for water or pay an education fee for children attending school. However, these benefits were not noted by either of the Li village leaders interviewed. The on-going generation of social benefits, in addition to economic ones, will be essential to the development of successful ecotourism in the region.

\subsubsection{Benefits For egone}

In establishing a Park and developing an (eco)tourism product at DNFP, the community, in theory, is giving up the benefits of other potential uses of the local resources - the benefits foregone, or opportunity costs. Such costs should be considered when evaluating whether or not forest protection and (eco)tourism development are an appropriate use of an area's resources (Sherman et al., 1991). At DNFP, where there are no pressures from urban expansion, the only other likely alternative use of local resources would be logging, as was the case prior to 1994. To date, the benefits foregone have arguably been significant. Logging generated greater revenues, employed more people and allowed the community greater access to resources. However, logging also carried with it substantial environmental costs and was based on essentially finite tropical forest resources. It is inherently difficult to compare extractive resource uses, such as logging, with non-consumptive activities like conservation when the benefits generated by the latter are more intangible and difficult to value in monetary terms. Nevertheless, forest protection does provide benefits, in terms of biodiversity maintenance and watershed protection for example, some of which have been acknowledged by local residents (Section 6.3.3). From a perspective that considers more than just economics, the benefits foregone in protecting the forest and developing ecotourism are less significant. Opportunity costs will be further minimized if ecotourism develops in a manner that provides broad-based benefits to the community, and if residents are compensated in some fashion for reduced access to resources. 


\subsubsection{Intercultural Exchange Opportunities}

Although local host-tourist interactions have been quite limited to date due to the limited number of tourists (especially foreign tourists), the potential for positive exchanges seems to be high. The vast majority of residents and business owners said they 'welcome more' tourists, and a number of comments were recorded that indicated locals believe tourism/tourists will 'broaden their view' and 'make life more active'.

If tourism at DNFP does grow, but the pattern of most tourists staying in the Park continues, there will continue to be limited opportunities for intercultural exchanges. Although a DFB official suggested that Miao cultural attractions would be developed in the future, there are currently no real opportunities to learn about $\mathrm{Li}$ or Miao culture at DNFP. It is important to remember that cultural attractions are often highly valued by ecotourists (Eagles, 1992). Furthermore, the Li and Miao are the earliest inhabitants of the area, and comprise about $83 \%$ of the region's population. Their culture is an important part of the region's history. The promotion of local culture may enhance tourist's experiences and potentially provide a source of financial gain for the $\mathrm{Li}$ and Miao. Table 6.4 summarizes some of the existing relationships between the local community and tourism.

Table 6.4: Summary of the Relationships Between the Community and Tourism

\begin{tabular}{ll}
\hline \multicolumn{1}{c}{ Indicator } & \multicolumn{1}{c}{ Assessment } \\
\hline Number of Tourists & $>30,000$ (in 2000) \\
Tourism Employment & Very limited \\
Tourism Income for Local Community & Very limited \\
Tourism Related Entrepreneurship & None \\
Host Attitudes Towards Tourism's Impact & Positive; Optimistic; Some concern for environment, \\
& safety \& potential for only government to benefit \\
Social Welfare Benefits & New Roads; Building Improvements; Water Resources \\
Intercultural Exchange Opportunities & Very limited \\
Potential for Positive Intercultural Exchange & Good \\
\hline
\end{tabular}

\subsection{Relationship Between Tourism and DNFP}

In an ideal ecotourism scenario, tourism generates funds for park management and conservation, and tourists receive a high quality experience. An important component of such an experience is the 
provision of opportunities to learn about the destination's biophysical and cultural attractions. Interpretation programs can promote greater awareness and generate support for conservation activities among both tourists and local residents. Furthermore, if a quality experience is provided, tourists will likely be more willing to pay entrance or other use fees, that can be channeled back into management and conservation activities.

\subsubsection{Revenues Generated for Conservation}

Conservation spending resulting from tourism-generated funds at DNFP has been extremely limited, if not non-existent. Although the Park has received between an estimated 20,000 and 30,000 tourists annually in recent years, entrance fees have never been collected. It is also unlikely that either of the Forest Bureau owned hotels have contributed monies towards conservation. While a top DFB official indicated that both facilities make a small profit, another official noted that the Diaoluo Hotel remains unfinished due to insufficient funds. Indeed, a senior manager suggested that limited funds are the biggest management constraint faced by the DFB. Although the Park will receive 6 million RMB (\$1.15 million $\mathrm{CDN}$ ) annually over the next ten years under the NNFPP, most of which is intended for forest protection, these funds have not been generated from tourism activity.

An official from the Nature Reserve also indicated that conservation activities suffer from funding shortages, with most monies going towards staff salaries. Financial limitations are aggravated by the fact that the Reserve is not intended, for the most part, for tourists, and therefore opportunities to raise funds through tourism in the future will continue to be very limited.

Given that insufficient funds are the most significant management limitation at DNFP, there would seem to be both a need and an opportunity for tourism to contribute towards conservation activities. One official interviewed suggested that a $50 \mathrm{RMB}(\$ 9.60 \mathrm{CDN})$ entrance fee will be implemented beginning in 2002. However, it was unclear how this fee level was determined, if it will be sufficient, or if any portion of it will be put towards conservation efforts.

\subsubsection{Educational Opportunities}

Opportunities to learn about the biophysical and cultural features present at DNFP are extremely limited, and cater primarily to the Chinese-speaking tourist. This is perhaps not surprising given the current levels of foreign tourism at the Park. The following interpretive materials/opportunities are currently available at DNFP: 
- A pamphlet with basic information about the Park (some in English), pictures of its sights, and a sketch map of the location of attractions;

- A Park sketch map and actual topographic map are posted at the Diaoluoshan Holiday Village, and provide information on the attractions (in Chinese);

- Guides available for hire (Chinese language only).

A visitor centre apparently does not exist, and no interpretive media were observed on any of the trails hiked. There was no entrance gate for the Park, and no indication of where one might go to obtain a pamphlet or hire a guide. Indeed, signage of any sort was generally absent, as were trail markers. The researcher did not meet any of the 4 or 5 guides employed by the DFB on a regular basis, and therefore no comment on their skills can be made. However, a DFB official did note that although the guides are not provincially licensed tour guides, they have received some training.

Aside from the limited educational opportunities, the attractions themselves are difficult to access without the use of a personal automobile. A tourist arriving by public transport would currently find it difficult to find a means of transportation around the Park. As far as could be discerned, there are no vehicles officially for hire (although I did managed to hire the hotel restaurant cook and his motorcycle to take a Park tour) or tour buses of any sort that visit the Park's attractions. Recognizing the importance of the tourist experience, Park authorities should consider how educational opportunities could be expanded and attractions more easily accessed. For example, although it was not explored, the derelict timber mill that sits on the river immediately outside of Diaoluo (Figure 6.10), could potentially be developed into a visitor centre, housing interpretive media on the Park's biophysical and cultural history and resources. Whether it is at this site or some other, DNFP is in need of a visitor centre. Although it would likely require the development of camping infrastructure, a backpacking trail linking town, the Diaoluoshan Holiday Village and several of the Park's attractions could also potentially prove valuable. It would provide ecotourists with access to the Park's sights without having to rely on tour buses or a personal vehicle, which may not be appropriate, on a large scale, for an ecotourism destination. Table 6.5 summarizes some of the existing relationships between tourism and DNFP. 


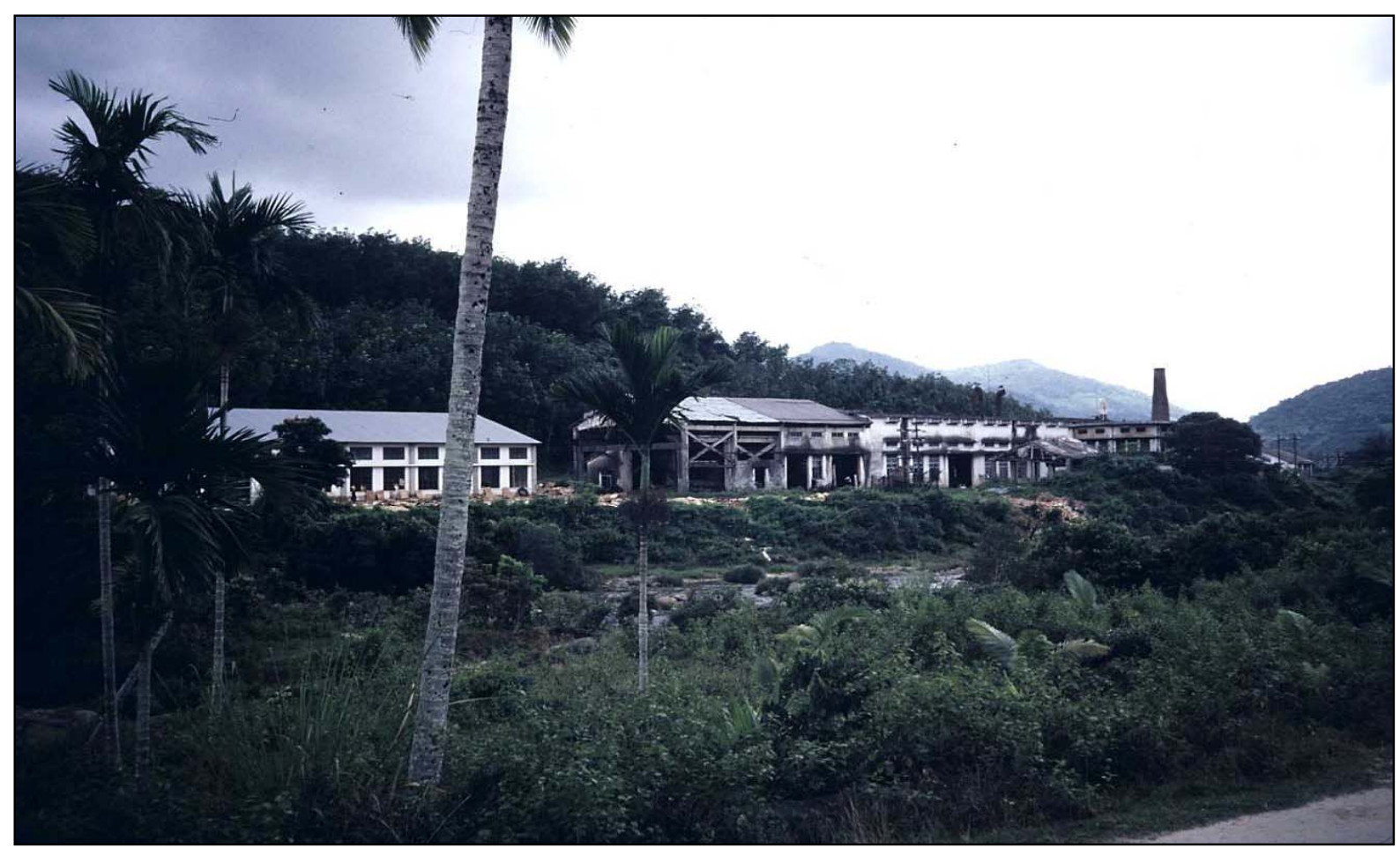

Figure 6.10: A Derelict Timber Mill, DNFP

Table 6.5: Summary of the Relationships Between Tourism and DNFP

\begin{tabular}{ll}
\hline \multicolumn{1}{c}{ Indicator } & \multicolumn{1}{c}{ Assessment } \\
\hline Park Entrance Fee & None \\
Tourism's Financial Contribution to Conservation at JNFP & None \\
Availability of Educational Materials/Opportunities & Limited; Pamphlet; Guides \\
Quality of Educational Materials/Opportunities & Needs to be Evaluated \\
\hline
\end{tabular}

\subsection{Summary: Management and Policy Considerations}

A wide variety of management strategies and policies are required if the relationships between tourism, parks and communities are to develop in a symbiotic fashion (Table 5.6). Active management is essential to the success of ecotourism at any destination (Boyd, 2000; Boo, 1991).

\subsubsection{Local Comm unity Relations}

The DFB has employed a number of community outreach strategies, presumably to help ease the transition from timber harvesting to forest protection. The Bureau has provided residents in Diaoluo 
and surrounding communities with information about the Park, mainly in terms of why it was created, the attractions it offers, and the importance of forest protection. Although the vast majority of residents and business owners did note that they had been provided with information, $25 \%$ of those interviewed $(n=35)$ could not recall the content of that information.

In an effort to gain widespread community support for conservation, the DFB has also sought to enter into forest protection contracts/agreements with a number of the surrounding villages. Whether or not these contracts were voluntary or negotiable was not determined. A local official interviewed suggested that the $\mathrm{Li}$, for their cooperation in protecting the forest, do not pay education fees for their children and receive free water. Neither Li village leader interviewed noted these contracts, or that they receive any benefits in return.

According to the leader of the Li village immediately adjacent to town, in return for agricultural land that was lost when the Diaoluo Hotel was constructed, they now receive free electricity and 300 RMB ( $\$ 58 \mathrm{CDN}$ ) per year, per mu of land lost. He also noted however, that they were not given any say in the matter. Another Li leader suggested that although they had never lost any land to the DFB, that they were not compensated for reduced access to resources when the Bureau took away all of their guns in an effort to reduce illegal hunting. It seems as though the DFB's outreach efforts have essentially amounted to explaining what is being done and why it is important people support the government's decisions. Neither village residents nor the ethnic minority groups have apparently had the opportunity to actively provide input or participate in Park matters. The exclusion of communities living adjacent to protected areas in planning processes has been a common problem (Ceballos-Lascurain, 1996), and a major reason behind failed conservation and development projects, where resources become degraded and tourism's potential reduced (Cresswell et al., 2000).

In terms of access to resources, both hunting and logging are illegal in the Park. Resource use for locals is limited to fishing and agriculture in certain zones. The ability of community members to access Park resources, for agriculture, is dependent on Bureau approval and their ability to afford to rent land. While some individuals and companies have rented land for agricultural purposes, neither the Li nor Miao can apparently afford to do so. There was disagreement on whether or not the Li actually own any land within the Park. Nevertheless, the Li are currently using the Park's land in places for both grazing and agriculture. The importance of providing residents with access to resources, inside the park or elsewhere, or compensating them for reduced access, will be absolutely 
critical to gaining and maintaining community support for continued ecotourism development in the Diaoluo region.

\subsubsection{Park and Re source Management}

DNFP is currently managed according to a management plan that was developed in 1995 when it was a Provincial Park. However, they are in the process of developing an updated, National Park management plan. The Park employs a policy of multi-use zoning, which acts as a buffer for the strictly protected core (Nature Reserve) area. The DFB has a main security force of 80 , which has the authority to enforce use restrictions, for small offences, with penalties that include both fines and prison terms. Larger offences require prosecution by the Haikou Public Security Bureau. The DFB has also made an effort to sequester the conservation support of surrounding villages by entering into forest protection contracts. Partial resource inventories have also been completed for DNFP.

While these are each important components of a park/resource management strategy, a number of weaknesses must also be noted. Although the security team's effectiveness was not directly evaluated, the fact that one official is of the opinion that illegal resource use is still the biggest threat to the Park suggests that their capacity to enforce restrictions may be limited. While partial resource inventories are available, many of these were completed in the 1950s and 1960s (Ouyang et al., 2001). Four decades of human activity, including major logging, suggests that these inventories likely no longer reflect current species diversity. Furthermore, it was not evident if any sort of monitoring program exists, or if inventories are scheduled to be updated in the near future. Accurate and up-to-date data are critical to be able to manage park resources effectively. The DFB should investigate opportunities to coordinate with the CAF, HFRI and ITTO on updating/completing inventories and developing a monitoring program. Management may also want to consider applying for a grant from the Global Environment Facility (GEF) to be used for biodiversity conservation projects.

Finally, no visitor fees have ever been collected. Although visitors have been limited, a contribution from the between 20,000 and 30,000 visitors that are estimated to have entered DNFP annually in recent years would certainly have been beneficial, especially in light of the funding shortages management has faced. On a positive note, a senior official did note that they intend to begin charging a fee in 2002, arguably a relatively modest one of $50 \mathrm{RMB}(\$ 9.60 \mathrm{CDN})$. 


\subsubsection{Tourism Ma nagement}

Although a site-level tourism plan does not exist for DNFP, management is apparently dealt with in the broader Park management plan. The soon-to-be-released WTO Hainan Tourism Master Plan may also contribute in some capacity to improving site level management. Nevertheless, tourism management, like tourism itself, is at an early stage of development. Aside from basic accommodations and requiring visitors to sign a conduct code (Appendix E), very few tourism-related services or policies currently exist, especially in terms of educational opportunities and providing a means for tourists to access Park attractions without a personal vehicle. Furthermore, management does not seem to collect data on Park tourists, suggesting that relatively little is know about DNFP tourists. While tourist numbers are estimated from hotel records, a number of key questions likely remain unanswered. Where do most tourists originate? What are the ages of DNFP tourists? What are their education levels? How much money do tourists spend? Where do they spend it - in the Park or in Diaoluo? What activities do tourists most commonly engage in while at the Park? Are visitors satisfied with their DNFP experience? Would tourists be willing to pay an entrance fee? What market have the DFB captured? What market are the DFB after? Basic data about Park visitors is absolutely essential for effective management, and will be necessary if the DFB is to be able to cater to and control the greater number of tourists they are pursuing. Management should also adopt a set of rigorous, and widely accepted, guidelines for the measurement and reporting of visitor statistics (e.g. Hornback \& Eagles, 1999).

\subsubsection{DFB Funding and Staff Training}

Limited funds and staff education levels have likely both aggravated the community, resource and tourism management issues the DFB faces. DFB and HFB officials have suggested that each of these has been a barrier to effective management. Part of the problem stems from the fact that many staff remained at the DFB when its mandate switched from timber harvesting to forest protection. The education of many staff may no longer be appropriate. Two senior officials have training in business management and administration, which is arguably important for protected area and tourism management, but should ideally be complemented by staff with training in a variety of other disciplines, such as ecology, geography, marketing, recreation and sociology (Payne et al., 1993; Rollins, 1993). On a positive note, one official noted that they are currently trying to develop a specialized 3-year university program, in association with Hainan University, that will prepare students to fill key positions within the DFB. 
In the years since the logging ban, the DFB has been dependent on government funding and the sale of agro-forestry products. Tourism revenues have yet to materialize. The result has been funding shortages. Beginning in 2001, the DFB is to receive 6 million RMB ( $\$ 1.15$ million CDN) annually for the next 10 years under the NNFPP. Given the assurance of a more stable source of funds, the DFB may wish to consider developing detailed annual budgets that allocate funds for investment in conservation, facility expansion, community development initiatives, staff training and biodiversity research. However, the effectiveness with which funding increases can be used to address key management issues will, to a large extent, be dependent on the ability of staff to cope with complex protected area and tourism problems.

\subsubsection{Final Comments}

The DNFP case study yielded similar findings to those at JNFP. Ecotourism, as defined for this study, does not currently exist. There is widespread understanding that the Park was created to protect the forest and to develop tourism. All community members interviewed believe that forest protection is important, with water resources and ecology being the most common reasons given. The vast majority of respondents see the Park as a good thing overall, and close to half of respondents perceive the Park as having had only positive effects, mainly in terms of increased incomes and jobs in the local economy. However, in reality, socioeconomic benefits for the community have been limited. Indeed, one-quarter of respondents indicated that the Park has had no effect whatsoever on their lives. At the same time, residents are trying to cope with reduced access to resources. Although the majority of residents (not including business owners) did not think that tourism growth would yield personal benefits, overall, most interviewed - residents, business owners and Park officials were optimistic that tourism will bring local economic benefits to the broader community. A very limited number of respondents expressed concern over the potential for environmental damage, drugs, that there were initially some problems (like job loss) or that only officials are benefiting. Widespread optimism is not surprising given the early stage of development at DNFP, which likely reflects Doxey's 'Stage of Tourist Euphoria' (Doxey, 1976), early tourist-resident relationships under D’Amore's model (D'Amore, 1983) and Butler's 'Exploration Stage' (Butler, 1980) of a tourism development.

A number of key weaknesses in the existing tourism-park-community relationships have been identified in this chapter that will limit the ability of ecotourism to generate benefits should it expand in the future. Very limited tourist traffic in Diaoluo, coupled with few spending opportunities 
(limited tourist infrastructure/services) and the prospect of an increase in joint development ventures all suggest that the leakage of economic benefits to areas outside of Diaoluo will potentially be substantial. Community members have not had an active voice in Park/tourism planning processes. Information on DNFP tourists has not been collected and monitoring programs to provide current data on biophysical conditions are not in place. Additionally, the DFB staff has very limited experience in park/tourism management. Nevertheless, a variety of planning and management strategies can help to overcome these weaknesses. The potential for ecotourism to develop so that it provides a diversity of benefits for both the community and the Park is strengthened by recent funding increases and fairly widespread community support and optimism.

The opportunities and constraints that have been identified in this case study could potentially be used to provide the framework for the development of a park (eco)tourism plan. The creation of such a plan will be essential if ecotourism is to develop in a manner that provides broad-based benefits at DNFP. Table 6.6 outlines potential planning responses and strategies for some of the main opportunities and constraints identified in this case study.

Table 6.6: Potential Framework for the Development of a Park Tourism Plan at DNFP

Opportunity/Constraint

Potential Planning Response/Action

\section{Opportunities}

- The Park's tropical setting, features and attractions

- $\quad$ The DFB has a large number of staff

- $\quad$ The NNFPP will increase funding, providing a stable source of funds over the next 10 years

- Existing jurisdictional responsibilities requires coordination with other government bodies
- Formulate and implement a marketing strategy based on the Park's unique features and desired tourism market (clientele)

- $\quad$ Provide training opportunities, incentives and, rewards for dedication and outstanding work

- Develop a detailed budget that allocates funds for investment in conservation, facility/amenity expansion, community development projects, biodiversity research and staff education

- Ensure clear lines of responsibility and accountability, so as to make the most efficient use of institutional capacities and resources 
- The government controls the Park and tourism

- There is broad community support for the Park, tourism development and forest protection

- Community residents perceive social welfare benefits water resources, ecological protection, roads

- The presence of Li and Miao culture

\section{Constraints}

- Staff have limited and/or inappropriate training

- Resource inventories are outdated

- The Park and its attractions are difficult to access
- Ensure future developments are located in areas that minimize environmental damage and maximize community benefits through the imposition of conditions on foreign investment that requires the use of local labour and goods

- Renew and maintain community outreach efforts re. the benefits of forest protection, current initiatives, etc.

- $\quad$ Foster community stewardship through public involvement in planning and decision making resident advisory committees, participation in conservation activities, etc.

- Highlight benefits through outreach efforts to demonstrate the value of forest protection

- Work with the Li and Miao people to develop cultural attractions, over which they have substantial control, that will enhance tourist experiences and provide minority groups with an alternative source of income/compensation for reduced access to resources

- Provide (re)training opportunities for management, security and interpretive staff

- Continue to pursue the development of a special training program at Hainan University for future Park staff

- Work with research agencies (CAF, HFRI, ITTO) and universities to update inventories

- Develop and implement a resource monitoring program

- Investigate the opportunity to apply for a biodiversity conservation grant from the Global Environment Facility (GEF)

- Continue with recent road improvements

- Work with travel agencies and bus companies to establish regular transport links to and from Diaoluo 
- Consider constructing a backpacking trail network with camping facilities that would allow tourists to access Park attractions without an automobile

- Construct a Park entrance gate to provide a central location for tourists to register, obtain information on accommodations and attractions, hire a guide, etc.

- Educational opportunities for tourists are very limited

- Little is known about Park tourists

- Tourism has not contributed funds to conservation

- $\quad$ Tourism-related employment and income are very limited, and the potential for economic leakage is high
- Develop and implement an interpretive plan, perhaps learning from the existing interpretive plan at JNFP

- Construct a visitor/interpretive centre

- Support (second) language training for interpretive staff

- Design and conduct a tourist survey to collect information on demographics, activities undertaken, spending patterns and satisfaction levels

- $\quad$ Analyze survey information and prepare a marketing strategy

- Adopt and implement a set of guidelines for the measurement and reporting of visitor statistics (e.g. Hornback and Eagles, 1999)

- Implement a Park user fee based on an analysis of budgets, the desired level of visitation and willingnessto-pay information from tourists

- Establish donation mechanisms and consider implementing a special conservation tax on the sale of tourist-related goods

- Expand the amenities available in the Town of Diaoluo, thereby providing more spending opportunities for tourists and community residents

- $\quad$ Provide training opportunities and hire preferentially from the community for Park/tourism positions

- Provide information on how to start/operate a tourism business and consider developing a small grant/loan program to help community residents to do so

- Impose conditions on new/foreign-invested 
developments that require the use of local labour and goods

- Encourage tourists to stay longer at the Park through reduced room rates for extended stays, multi-day sightseeing itineraries and the provision of interpretive facilities/programs

- Local dependency on natural resources remains high, illegal harvesting continues to occur and some community residents are unhappy over lost jobs, reduced incomes and/or with the government in general

- Work with community members to develop satisfactory compensation arrangements for reduced access to Park resources

- $\quad$ Renew and maintain community outreach efforts that explain and document the benefits of forest protection

- Support diversified, not purely subsistence based, agriculture and invest in research that experiments with alternative livelihood strategies

- $\quad$ Provide training and skills development opportunities for community residents

- Encourage community stewardship for the Park through public involvement in planning and decision making

- Develop a monitoring program and investigate security staff's capacity to enforce regulations 


\section{Chapter 7 \\ Discussion and Recommendations}

In Chapter 2 it was suggested that ecotourism is a confusing term, a term that has been hotly debated and interpreted in numerous ways. Indeed, there remains little consensus over its specific meaning. Nevertheless, many have assigned ecotourism great potential, suggesting that it can provide high quality tourism experiences, while stimulating socioeconomic development, promoting environmental awareness and generating funds for resource management and conservation activities. The promise of broad-based benefits has prompted many developing regions to adopt ecotourism as a sustainable development strategy for balancing economic and conservation objectives. Although there are success stories, the reality is that ecotourism's impact has been highly variable. Fortunately, two decades of experience has resulted in the promulgation of a variety of planning and management strategies that may help to promote the development of symbiotic tourism-resource/park-community relationships and, as a result, the generation of benefits at an ecotourism destination.

Recognizing this, this study sought to assess the current status of ecotourism at two destinations where it is being promoted as a regional development strategy, through an evaluation of the existing tourism-park-community relationships and impacts, that would allow planning direction to be provided. In doing so, the study is intended to enhance the capacity of ecotourism to generate benefits for both the communities and the Parks.

This chapter makes recommendations for JNFP and DNFP based on case study findings and the salient (eco)tourism literature (7.1). This is followed by a more general discussion of ecotourism and protected areas in Hainan (7.2). The chapter concludes with some methodological comments, a consideration of further research questions and a discussion of the study's contribution (7.3).

\subsection{Recommen dations for JNFP and DNFP}

The JNFP and DNFP case studies yielded very similar findings (Sections 5.6.5 and 6.6.5) (Table 7.1). The general discussion and recommendations that follow are therefore intended to apply equally, unless otherwise noted, to both destinations. According to the definition adopted for this study, neither Park can currently be considered a successfully operating ecotourism destination socioeconomic community benefits are very limited, tourism-generated funds for conservation are absent and educational opportunities for tourists are few. Nevertheless, government officials and 
Table 7.1: Selected Community Interview Responses at JNFP and DNFP

\begin{tabular}{|c|c|c|c|c|c|}
\hline \multirow[t]{2}{*}{$\begin{array}{c}\text { Interview } \\
\text { Question }\end{array}$} & \multirow[t]{2}{*}{ Response } & \multicolumn{2}{|c|}{ Res i dents } & \multicolumn{2}{|c|}{$\begin{array}{l}\text { B u s iness } \\
\mathrm{O} \text { w ners }\end{array}$} \\
\hline & & JNFP & DNFP & JNFP & DNFP \\
\hline Why do you think it was designated a Park? & $\begin{array}{l}\text { Protect forest/animals } \\
\text { Develop tourism }\end{array}$ & $\begin{array}{c}63 \% \\
28\end{array}$ & $\begin{array}{c}57 \% \\
57\end{array}$ & $\begin{array}{c}58 \% \\
50\end{array}$ & $\begin{array}{c}80 \% \\
80\end{array}$ \\
\hline $\begin{array}{l}\text { Has Park establishment impacted your } \\
\text { livelihood in a positive \&/or negative way? }\end{array}$ & $\begin{array}{l}\text { Positive only } \\
\text { Negative only } \\
\text { Neither }\end{array}$ & $\begin{array}{l}38 \\
28 \\
18\end{array}$ & $\begin{array}{c}50 \\
7 \\
23\end{array}$ & $\begin{array}{c}74 \\
0 \\
22\end{array}$ & $\begin{array}{l}40 \\
20 \\
40\end{array}$ \\
\hline Positive effects cited & $\begin{array}{l}\text { Local economy } \\
\text { Jobs } \\
\text { Increased incomes } \\
\text { Roads } \\
\text { Water resources }\end{array}$ & $\begin{array}{c}36 \\
5 \\
0 \\
27 \\
9\end{array}$ & $\begin{array}{l}14 \\
14 \\
29 \\
14 \\
19\end{array}$ & & \\
\hline Negative effects cited & $\begin{array}{l}\text { Lost jobs } \\
\text { Only officials benefit } \\
\text { Forced to move/lost land }\end{array}$ & $\begin{array}{l}78 \\
28 \\
22\end{array}$ & $\begin{array}{c}13 \\
25 \\
0\end{array}$ & & \\
\hline Is Park designation a good or bad thing overall? & Good & 58 & 70 & 76 & 100 \\
\hline $\begin{array}{l}\text { What are your feelings about possible future } \\
\text { increases in tourism to this area? }\end{array}$ & $\begin{array}{l}\text { Welcome more - no } \\
\text { reservations }\end{array}$ & 70 & 83 & 84 & 100 \\
\hline $\begin{array}{l}\text { Is protecting the forest/resources important } \\
\text { to you? }\end{array}$ & Yes & 100 & 100 & 100 & 100 \\
\hline Why? & $\begin{array}{l}\text { Nature/ecology } \\
\text { Water resources } \\
\text { Climate }\end{array}$ & $\begin{array}{l}18 \\
36 \\
47\end{array}$ & $\begin{array}{l}41 \\
55 \\
17\end{array}$ & $\begin{array}{l}12 \\
52 \\
44\end{array}$ & $\begin{array}{l}40 \\
40 \\
40\end{array}$ \\
\hline $\begin{array}{l}\begin{array}{l}\text { Do you see any benefits or negatives if } \\
\text { tourism was to increase }\end{array} \\
\text { A) To yourself? } \\
\text { Personal benefits cited }\end{array}$ & $\begin{array}{l}\text { Benefits only } \\
\text { Neither } \\
\text { Indirect - community } \\
\text { benefits therefore I do } \\
\text { Jobs }\end{array}$ & $\begin{array}{l}63 \\
37\end{array}$ & $\begin{array}{l}37 \\
63\end{array}$ & $\begin{array}{c}92 \\
8\end{array}$ & $\begin{array}{c}100 \\
0\end{array}$ \\
\hline B) To the community? & $\begin{array}{l}\text { Benefits only } \\
\text { Both } \\
\text { Neither }\end{array}$ & $\begin{array}{l}66 \\
23 \\
11\end{array}$ & $\begin{array}{c}67 \\
30 \\
3\end{array}$ & $\begin{array}{c}88 \\
8 \\
4\end{array}$ & $\begin{array}{c}80 \\
0 \\
20\end{array}$ \\
\hline $\begin{array}{l}\text { Community benefits cited } \\
\text { Community negatives cited }\end{array}$ & $\begin{array}{l}\text { Local economy/business } \\
\text { Environmental concern } \\
\text { Drugs/safety }\end{array}$ & $\begin{array}{l}90 \\
25 \\
38\end{array}$ & $\begin{array}{l}86 \\
22 \\
22\end{array}$ & 42 & 50 \\
\hline $\begin{array}{l}\text { Have the Park staff involved you or the } \\
\text { community in any way - planning, education, } \\
\text { information, etc.? }\end{array}$ & $\begin{array}{l}\text { Yes - given information } \\
\text { No }\end{array}$ & $\begin{array}{l}47 \\
45\end{array}$ & $\begin{array}{l}90 \\
10\end{array}$ & $\begin{array}{l}48 \\
36\end{array}$ & $\begin{array}{c}100 \\
0\end{array}$ \\
\hline $\begin{array}{l}\text { Can you estimate the \% of total sales/ } \\
\text { revenues that come from tourists? }\end{array}$ & $10 \%$ or less & & & 82 & 80 \\
\hline
\end{tabular}


community members are optimistic that (eco)tourism will bring benefits. Limited benefits, optimism and positive attitudes are characteristic of an early stage of tourism development (D'Amore, 1983; Butler, 1980; Doxey, 1976). Most officials interviewed recognize that development is at an early stage. A smaller group, to their credit, is also cognizant of some of the existing weaknesses and barriers that the development of ecotourism faces. The researcher is also very aware that (eco)tourism development is in its infancy, and that neither site can realistically be expected to be operating without flaws. The comments, critical and supportive, offered in this thesis should be received in the cooperative spirit in which they are intended - to provide officials with planning direction that will help them to find a path of development that promotes synergistic tourism-parkcommunity relationships and, ultimately, the generation of broad-based local benefits.

\subsubsection{Relationships Between the Local Communities and Parks}

Forms of nature-based tourism, such as ecotourism, have emerged in recent years as a popular means for integrating parks and people in rural developing regions (Place, 1991). However, park establishment alters the local economic base, and has often resulted in reduced access to resources for local people (Lindberg et al., 1996). This has been the case at both JNFP and DNFP. Where residents face pressures due to resource use restrictions, compensation should be provided (Sherman et al., 1991). This is especially important recognizing that many of the threats protected areas face arise from the needs of local communities to use resources to survive (Norris, 1992). Dependence on natural resources is high, especially for the ethnic minority groups, in both the Jianfeng and Diaoluo regions. Although opinion is divided as to the severity, illegal resource harvesting does occur at both

Parks. Some residents also noted they had lost jobs or land, and that it is now harder to make a living, highlighting the need for compensation. At both sites, some compensation has been provided to residents, mainly the Li people, for lost land/resource access in the form of new homes, seeds, lump sum payments (at JNFP), monthly payments, free electricity, water and education fees (at DNFP). However, interviews revealed differing interpretations of what compensation was provided, with some contesting it was provided at all or complaining that it was insufficient. The Forest Bureaus are also hoping that compensation will come in the form of increased employment opportunities from the development of ecotourism. However, for now, such opportunities have yet to materialize, and other strategies are needed. For example, a portion of the Park's revenues/budget could be earmarked to go towards community development projects and services (Sherman et al., 1991). However, the Parks themselves have, in the past, been short of funds so that the potential to do this is limited unless Park 
incomes can be put on a more stable basis, perhaps through increased ecotourism. The provision of alternative resource supplies and land for agriculture, plantations, etc., outside of the Parks would also be very valuable. The creation of a buffer, multi-use, zone at JNFP is a positive step in this direction. It was not determined if such an area exists at DNFP. Others have noted that in the Jianfeng region there appears to be a direct correlation between poverty, subsistence farming and resource exploitation, and that progressive, diversified farming, including the sale of cash crops, may help to reduce pressures on natural resources (Associates in Rural Development, 1998). A similar strategy would also likely prove to be beneficial in the Diaoluo region. Although such strategies may prove useful, it is important to recognize that compensation can be a contentious issue. Is it even possible to compensate for the loss of a livelihood or a homeland? Determining what form compensation should take, how much is enough (according to whom?) and who should pay will make the implementation of any such strategies challenging.

Although the Bureaus have each made an effort to educate community members, providing them with information about the reasons behind Park establishment and the importance of protecting the forest, residents have not had the opportunity to participate actively in planning processes and decision making. This problem is not unique to JNFP and DNFP. Communities adjacent to protected areas have frequently been overlooked (Ceballos-Lascurain, 1996). This is significant, recognizing that the generation of community benefits and positive attitudes towards tourism is to a large degree dependent on local people's ability to participate effectively in decision making (Campbell, 1999; Lindberg et al., 1996; Wells et al., 1992). The failure to involve local people can lead to poorly integrated conservation-development projects that damage the resource base and reduce tourism's potential to generate benefits (Cresswell et al., 2000). Effective local participation can be defined as "the ability of local communities to influence the outcome of development projects such as ecotourism that have an impact on them." (Drake, 1991, p.132). Participation opportunities exist at all stages of a development - planning, implementation, monitoring - and may take a wide variety of forms depending on the particular socio-cultural circumstances. At DNFP and JNFP opportunities to participate could be provided using public forums to allow residents to voice their concerns and make suggestions on key issues. It might also be feasible to establish committees, comprised of local residents and business owners, which provide input to Forest Bureau planning processes and decision making. If community members have a vested interest in such processes they are more likely to become advocates for the Park and support the continued development of ecotourism. However, participation can be a time consuming and difficult process, where people can quickly become 
disillusioned and frustrated. While the overall goal may be to give people a voice in the decisions that affect them, determining who participates, via what means and for what purpose can be quite difficult. There is the danger of prematurely raising peoples' hopes that their views will actually make a difference. Do local residents even want to participate? Some have also cautioned that residents may not be in a position to make appropriate decisions (Boyd, 2000). Although there are substantial challenges, the risks associated with not providing participation opportunities arguably outweigh the potential costs.

\subsubsection{Relationships Between the Local Communities and Tourism}

Ecotourism is at an early stage of development at both JNFP and DNFP. As such, there have been relatively few socioeconomic impacts to date. Some perceive improvements in water resources, climate, roads, incomes and the local economy. This is important, recognizing that attitudes towards tourism are largely based on perceived costs and benefits (Lindberg et al., 1996). Although road improvements were observed, climate and water resource impacts are difficult to confirm and, in reality, tourism-related employment, entrepreneurship and income have been limited. Aside from employment in the hotels, Travel Companies, or as a guide, and occasional small shop sales to tourists (water, fruit, snacks, etc.), employment and income from tourism have yet to materialize on a significant scale at either site. Should ecotourism grow and employment opportunities expand, it will be important that local residents have the requisite skills to be able to fill positions. The Bureaus will want to consider developing training programs for local people before employing workers from more distant regions, who may already possess the necessary skills, but will add to the loss of economic benefits from the local community (Sherman et al., 1991). In the future, earmarking a portion of tourism revenues or the Park's budget for small loans for local people wishing to start a tourism venture may also help to generate and retain community benefits (Lindberg, 1991). Stimulating entrepreneurial activity may also require that training - how to start a business, how the tourism industry operates, etc - be made available to local community members.

Given the prospect for future foreign investment/joint ventures at both Parks, managers will want to ensure that they retain some control over the development of the industry. Foreign investment increases the potential for economic leakage and can, somewhat paradoxically, limit opportunities for locals to get involved in the industry if outside investment outpaces local capacities to accumulate capital or acquire training (Place, 1991). Local control will allow the flexibility to impose conditions on projects that will maximize community benefits (Loon et al., 2001; Sherman et al., 1991). For 
example, if the Forest Bureau was to lease management rights of a facility to a private investor, they could require that investor to train and employ local residents (Lindberg, 1991), or perhaps be required to purchase locally produced goods. The use of locally produced goods and services, and the employment of community members whenever possible are absolutely critical to generating and retaining socioeconomic benefits in the community.

Although the lack of benefits can be attributed, in part, to the relatively low levels of visitation at each Park, it is also due to the location of tourism activity (at the Park hotels) and the absence of spending opportunities for tourists in the towns. While tourist volumes can be influenced to some extent, the Bureaus have much greater control over where tourism infrastructure is located. The capacity of ecotourism to generate benefits in the future will, to a large degree, depend upon the ability of managers to encourage tourists to spend larger sums of money, in the desired locations (i.e. in both the Parks and the towns). It is inherently difficult to spend money in the wilderness, where facilities are typically limited (Wall, 1994). Simply providing tourists with opportunities to spend money locally, through the development of tourism facilities and services - interpretive media, food concessions, souvenirs, etc. - can help in this respect and also encourage tourists to return in the future (Lindberg, 1991). Encouraging tourists to lengthen their stay at the Park (one night is the current average length of stay at both DNFP and JNFP) would also help increase spending levels (Hvenegaard et al., 1998). This might be accomplished by offering reduced room rates for extended stays and publishing, multi-day, suggested sightseeing itineraries. Interpretation facilities, programs and guides may also help.

Spending opportunities are not only important for tourists, but also for local people. In small, rural economies like those at JNFP and DNFP, aside from food and basic supplies there are few goods or services available. This results in local people travelling to larger centres - Sanya, Haikou, Lingshui - to purchase clothing, major appliances, electronics and other 'big ticket' items. If (eco)tourism grows, much of the money that will be spent on accommodations, food, etc., will ultimately leave the community in the absence of locally available goods and services. Hotel managers will purchase appliances in Haikou and employees may spend their tourism-generated wages in Sanya on clothing or 'luxury' items. Although tourists' direct expenditures are important, it is also important that a portion of those expenditures be kept in the community through local secondary (indirect) and tertiary (induced) spending. The flow of tourism dollars through an economy is known as the multiplier 
effect, and, in considering overall economic impact it is important to consider both the volume of initial spending and the re-circulation and retention of money in the local economy.

Assuming that more (eco)tourists visit JNFP and DNFP in the future, that they spend larger sums of money, in both the Parks and towns, and that socioeconomic benefits begin to increase, there are still a number of important points managers will want to consider. First, the employment opportunities arising from ecotourism are often limited due to the low variety of jobs created guides, guards, cooks, porters, drivers, etc. (Brandon, 1996). Second, tourism, of any form, is an unstable source of revenue, one that is subject to seasonal fluctuations and many external (locally uncontrollable) forces, including weather and political factors (Norris, 1992). Third, (eco)tourism benefits are often inequitably distributed among community members(Hummel, 1994; Lee et al., 1992) and typically reflect disparities that existed prior to (eco)tourism's development (Nepal, 2000b). At both JNFP and DNFP, where substantial income gaps exist between (and within) the ethnic minority groups and the Han Chinese, and some have expressed concern that only the Bureaus will gain from ecotourism, strategies may be required to ensure an equitable distribution of benefits within the community. These considerations suggest that ecotourism should not be depended on as a panacea for improving socioeconomic conditions for community members.

\subsubsection{Relationships Between Tourism and the Parks}

Protected area use fees, especially in developing countries, are often nominal (Wall, 1994; Lee et al., 1992) or missing altogether (Lindberg, 1991). At JNFP and DNFP no use fees have ever been charged. Furthermore, Bureau operated hotels and travel companies have generated little, if any, profit. As a result, (eco)tourism has yet to raise funds for management or conservation activities. Although levels of visitation have been relatively low, even a small fee, such as the 50 RMB (\$9.60 $\mathrm{CDN}$ ) that management is considering implementing at DNFP, could have raised substantial funds. A fee of $50 \mathrm{RMB}$, times the approximately 20,000 visitors that have apparently visited each Park annually in recent years, would have raised about 1 million RMB $(\$ 192,300 \mathrm{CDN})$. While there is little use in dwelling on what 'could have been', it does highlight the importance of charging tourists, even nominal amounts, for the privilege of visiting a park. It is quite possible that tourists would be willing to pay more than the $50 \mathrm{RMB}$ or $20 \mathrm{RMB}$ that managers at DNFP and JNFP respectively are considering implementing in 2002. A survey of park tourists, asking what they would be willing to pay to enter the Park could help to determine appropriate use fees. The same survey could be designed to collect information on tourist demographics, spending patterns and satisfaction levels - 
information that was previously noted as being important, but missing at both JNFP and DNFP (Sections 5.6.3 and 6.6.3). There is also a need to adopt a set of rigorous, standardized, guidelines for measuring, collecting and reporting on public use (tourism) in the Parks (see Hornback and Eagles (1999) for example).

Some have also suggested that donation mechanisms should be put in place in order to capitalize on the documented willingness of nature-oriented tourists to contribute financially to conservation (Hvenegaard et al., 1998). Opportunities to contribute to conservation might be provided in the form of donation boxes at visitor centres. Management could also consider providing tourists with a letter, explaining current conservation projects, and an envelope that could be left at the visitor centre or hotel reception should they wish to make a contribution. If tourists were found to be reluctant to donate, management could consider imposing a special forest-protection tax, on the sale of touristrelated goods, hotel rooms, or popular attractions for example (Sherman et al., 1991), to raise funds for conservation activities.

Higher use fees than those currently being considered could potentially be charged if a high quality (eco)tourism experience is provided at the Parks. Both Parks offer spectacular tropical scenery, but accommodations are basic and educational opportunities few. Although ecotourists may be content with such accommodations (Eagles, 1998), they do demand high quality experiences (Eagles, 1992). Neither JNFP nor DNFP currently offer such an experience given the lack of educational opportunities and interpretive media. On a positive note, both Parks have provided some training for a small number of Chinese-speaking guides, and a new visitor centre has recently opened at JNFP. With funding increases under the NNFPP it may also be possible to begin to implement the Nature Interpretation Plan that was developed for JNFP by a consultant team from Associates in Rural Development Inc. in 1997. A similar plan needs to be developed for DNFP. Although a consultant report does not exist for DNFP, it would perhaps be a useful learning experience if members of the DFB staff were to assist the JFB with the implementation of their Interpretive Plan. It might also be beneficial to ask tourists how satisfied they are with their Park experience, the guide they had, the educational materials they used or wish had been available, etc. Visitors' opinions can help management to develop suitable educational/interpretive programs.

Many of the tourism-park-community relationship weaknesses identified in this thesis have been aggravated, if not caused, by funding shortages and limited, or inappropriate, staff education. Senior officials at both the site and Provincial level have identified each of these as key problems. Careful 
planning and management are required if ecotourism is to develop successfully (Boo, 1991). This in turn, requires a properly trained, interdisciplinary staff (Boyd, 2000; Rollins, 1993) and the presence of sufficient funds. Under the NNFPP, JNFP is to receive 10 million RMB ( $\$ 1.9$ million CDN) and DNFP 6 million RMB ( $\$ 1.15$ million $C D N$ ) annually until 2010, suggesting the potential for enhanced management effectiveness. An official at DNFP also indicated that they are trying to establish a special university training program to prepare students to fill key positions within the DFB. Aside from this, on-going training seems to be limited to occasional seminars/visits from experts and self-directed study. The effectiveness with which funding increases and training initiatives can be used to strengthen the tourism-park-community relationships will be critical to the successful development of ecotourism at both sites.

The opportunities, constraints and recommendations that have been identified at JNFP and DNFP, considered within the broader framework of the soon-to-be-released WTO Tourism Master Plan for Hainan, potentially provides the necessary information for the creation of site-level park (eco)tourism plans. Given that several agencies are involved in tourism/park management, each possessing different expertise and financial resources, it would be important to clearly identify who is responsible for implementing the various planning actions detailed in Tables 5.7 and 6.6. The second step would be to prioritize and assign an estimated cost for each action. Recent funding increases would seem to provide the local Forest Bureaus with an opportunity to formalize plans and begin implementing, with the assistance of the other agencies, some of the recommendations made in this study. The creation and implementation of site-level plans will be critical to the successful development and management of (eco)tourism at both JNFP and DNFP.

\subsection{Ecotourism in Hainan}

Although the preceding discussion was based on circumstances at JNFP and DNFP, some of the tourism-park-community management issues raised and recommendations made will likely be applicable to other tourism sites in Hainan. This thesis has also highlighted a number of more general considerations for ecotourism development and protected area management in Hainan that deserve reiteration.

If ecotourism is to develop successfully at a destination there should be some consensus among decision-makers on what the term means and what the objectives are in promoting its development. Overall, interviews revealed that most interpret ecotourism as a form of nature-oriented travel that 
balances resource conservation and human use (Table 4.2). Although less noted among site level managers, officials also see (eco)tourism as a means for producing economic benefits for the Province, protected area agencies (the Forest Bureaus) and local communities. However, interviews and secondary sources also revealed that a diversity of sites, ranging from undeveloped, wilderness areas to botanical gardens, beaches and facility-laden wildlife and cultural theme parks, have been identified as good examples of, or potential sites for, ecotourism. This suggests that some degree of confusion exists, between and among different levels of jurisdiction, over what exactly constitutes ecotourism, what ecotourists are motivated by, and what tourism market the Province is aiming to attract.

If the Hainan Government is trying to appeal to ecotourists, they may need to reconsider some of the sites they are promoting/considering as ecotourism destinations. Failure to do so may result in low satisfaction levels among visitors who arrive in Hainan expecting ecotourism sites, which do potentially exist, but are lured to inappropriate destinations as a result of indiscriminate marketing. If, on the other hand, the Province opts for a loose interpretation of ecotourism, one that might be more aptly described as general nature tourism or park tourism, then the marketing of a diversity of sites becomes more appropriate. Although Hainan possesses a wealth of natural resources and attractions, not all will be equally appealing to potential visitors. Those that would enjoy the luxurious resorts and beaches of Yalong Bay may not appreciate the basic accommodations, limited facilities and generally more rustic conditions that exist at places like JNFP and DNFP. Similarly, those attracted to an environment like that provided at JNFP and DNFP might be disappointed by the experience provided at a facility-intensive, highly manicured, but still arguably 'nature' site such as Nanshan Buddhist Cultural Park or Nanwan Monkey Island Reserve. The important point here is that the marketing of specific destinations needs to be tailored to the appropriate tourist segments.

Appropriate marketing will also be critically important for distinguishing Hainan from other competing destinations in China. The Province faces stiff competition from other, mainland locations in China. Yunnan Province, like Hainan, offers tourists tropical forests, hot weather and ethnic minority culture. Indeed, beautiful scenery and culture abound throughout China. Hainan is also an island with a peripheral location, which may make it less appealing to some tourists (but attractive to others). Careful marketing, based on the Island's unique features and the desired tourist markets (clientele), is needed in order to establish a niche for Hainan in the tourism market for China, and, especially the international markets. 
Forest, park and tourism management in Hainan involves multiple management bodies, including the Hainan Tourism Bureau, Hainan Department of Lands, Environment and Resources, local Forest Bureaus (such as the DFB and JFB) and their parent body, the Hainan Forest Bureau. Different agencies are also responsible for Parks and Reserves. Although some tensions have apparently surfaced between Park and Reserve managers in the past, interviews revealed that cooperation and relations among the diversity of agencies involved have generally been good. Nevertheless, if tourism grows, the management of visitors, and the areas they visit, will become increasingly more complex. It will be imperative that clear lines of responsibility and accountability be defined among the numerous bodies that are involved in the management and administration of tourism and protected areas (Boyd, 2000).

\subsection{Methodological Conclusions, Further Research and Study Contributions}

This study applied an evaluative framework (Ross et al., 1999b) to assess the current status of ecotourism at two destinations where it is being promoted as a regional development strategy. The framework proved to be a useful tool for both conceptualizing how ecotourism might ideally operate at a destination and for guiding the collection of data at each site. At early stages of development, such as at JNFP and DNFP, the framework can be used to highlight existing and potential weaknesses in the tourism-resource/park-community relationships. In doing so, it has the capacity to inform planning processes. However, every site is unique and subject to changing local circumstances, suggesting that the framework, as its creators have noted (Ross et al., 1999a), does not necessarily address all issues that management should be concerned with.

In the process of completing this study a number of potential opportunities for further research surfaced that due to the time frame and scope of this thesis could not be examined, but that would nonetheless be worthy research projects. Conducting a tourist survey to gather information on visitor demographics, activities, spending patterns, satisfaction levels, willingness-to-pay, etc. would provide managers at both JNFP and DNFP with much needed data on their clientele. Given that most tourists currently visit the Parks during holiday periods suggests that the timing of such a survey would need to be carefully planned. Examining how communities could most effectively be involved in planning processes would be a potentially valuable study. China is a socialist country in transition, and traditional, Western, public participation techniques may not be effective or appropriate. Given the apparent confusion over matching tourist markets with products offered, market research and the 
formulation of a marketing strategy for ecotourism sites in particular, or the Island more generally, would also be a useful exercise. Others have called for renewed and intensified efforts in collecting biophysical (scientific) information and monitoring activities in Nature Reserves in both Hainan (Ouyang et al., 2001) and elsewhere in China (Han \& Ren, 2000). Finally, research into alternative and sustainable livelihood strategies and the utility/effectiveness of buffer zones for local communities that face pressures from reduced access to resources is important, and would contribute towards the successful development of ecotourism in rural, underdeveloped areas such as JNFP and DNFP. On a positive note, the CAF and ITTO have both conducted this type of research in the past (Hainan Forest Bureau et al., 2000; Wandi, 1999), providing a foundation upon which other studies might be initiated.

Although time, language and funding constraints prevented an in-depth examination of all relationships, the broad overview of ecotourism conducted at both JNFP and DNFP has identified a number of important impacts and shortcomings. Recommendations based on these findings are intended to help promote the successful development of ecotourism at the study sites and, more generally, throughout Hainan. This study has potential practical value, in that it would be feasible to use the opportunities, constraints and recommendations identified to develop park (eco)tourism plans for each study site. A number of officials in Hainan, including senior managers at both JNFP and DNFP, have expressed an interest in receiving a translated summary of the study's results and recommendations. The Hainan Forestry Bureau, Sino-German Forestry Cooperation Hainan Office and Nanjing University have all requested full copies of this thesis upon its completion. In distributing results to interested parties, it is hoped that this thesis will contribute to ecotourism planning on the Island.

This thesis also contributes to the growing body of tourism literature by providing practical, sitespecific assessments of ecotourism at two destinations in Hainan Province, China and, by demonstrating how an evaluative framework can be applied to site-level evaluations. Furthermore, the case-study approach has not only produced site-specific recommendations, but has also identified a number of more broadly applicable findings, issues and strategies that may help destinations elsewhere to improve their capacity to benefit from ecotourism. Research designed to improve the efficiency with which ecotourism operates will be increasingly important as regional and national, governments, especially in developing nations, continue to look to ecotourism as a sustainable development strategy. 
Appendix A:

Park Manager Interview Questions 


\section{1) PARK OPERATIONS}

- When was the Park established?

- How large is the Park? How large is the Nature Reserve/core area? Is a map available?

- Who is responsible for management? Does a management plan exist? How often is it updated?

- What is the Park's mandate/goal/vision?

- Have resource inventories been completed? How often are they updated?

- Are there endangered/rare/etc. species here, or other special features?

- Are visitor statistics kept? If not, can you estimate the number of tourists received annually?

- Can you estimate the average length of stay and the percentage of visitors who are from foreign countries? What percentage arrives in tour groups versus private automobiles?

- Do tour groups come here? If so, where from/which travel agencies? Do you collect fees from tour groups?

- What is the Park's budget and funding sources? Does it operate at a profit or loss? Do you have revenue retention powers?

- Are funds put specifically towards conservation and/or monitoring activities? If so, what percentage of funds/budget?

- Are entrance fees charged? If not, have they/are they being considered?

- Is there a permit or sign-in procedure?

- What are the permitted park/resource uses? Zoning regulations? Research activities?

- How strong is the enforcement capacity, and what are the associated penalties?

- What is the biggest constraint for Park managers (time, funding, etc.)?

- What types of infrastructure exist in the Park (roads, signage, etc.)?

- Do trails exist in the Park? How many/how long? Are they marked and maintained?

- Are there interpretation/education programs, signs, or guides? If so, is any provided in English?

- Are there concessions (food, souvenirs, etc.) offered within the Park? If so, are they private or Park operated?

- What are the accommodations options for tourists? Are they private or Park operated?

- Are there other services or anything else about the Park you would like to tell me? 


\section{2) ECOTOURISM}

- What is your definition of 'ecotourism'?

- What are your feelings, expectations, concerns, etc. about tourism/ecotourism in the Park

- Where will future developments (hotels, etc.) be located?

- Since the Park has been established, what has the biggest benefit and negative been?

- Have difficulties been encountered in coordinating with the Hainan Tourism Bureau and Department of Environment on tourism management?

\section{3) PARK STAFF}

- How many staff work for the Park?

- What percentage is from the local community? How many women are on (senior) staff?

- Can you provide a brief description of the education levels of the staff? What is the educational background of the senior management?

- Are there tour guides?

- Are there any English speaking staff?

- Are there ongoing training opportunities available to staff?

- Can you comment on your impressions of the staff's dedication to their work and the Park?

- Have there been conflicts with the Nature Reserve's staff?

\section{4) LOCAL RESIDENTS \& COMMUNITY RELATIONS}

- What is the population of the town? How many Li villages/people are there?

- Were any people displaced when the Park was established? If so, were they provided with compensation? In what form?

- How many Forest Bureau workers lost jobs when the Park was established? Were they provided with compensation? In what form?

- Are local residents permitted to use Park resources? Do illegal activities occur?

- What are the major threats/pressures to the Park?

- Have there been local community outreach/education activities with regard to the Park/tourism? 
- Have locals been involved in planning and/or management in any way?

- Can you comment on the relationships between Park staff and community residents?

- What have been the benefits and negatives to the community as a result of Park establishment (infrastructure, health, employment, etc.)?

- What are your feelings on the capacity of, and opportunities for, local residents to benefit from the Park/tourism in the future?

- Will education levels limit local people's opportunities to benefit? 
Appendix B:

Local Resident and Business Owner Interview Questions 
Date:

- Are you aware that a National Park exists near your community?

- Why do you think it was designated a 'Park'?

- Has Park establishment impacted your livelihood in a positive and/or negative way?

Positive

- What are your feelings about the Park? Overall, is it a good or bad thing?

- What are your feelings about tourism/tourists and, the possibility that tourism in this region may increase in the future?

- Is the protection of tropical forest/natural resources important to you? Please explain? 
- Do you see any benefits or problems if tourism was to increase: a) to yourself? b) to the community?

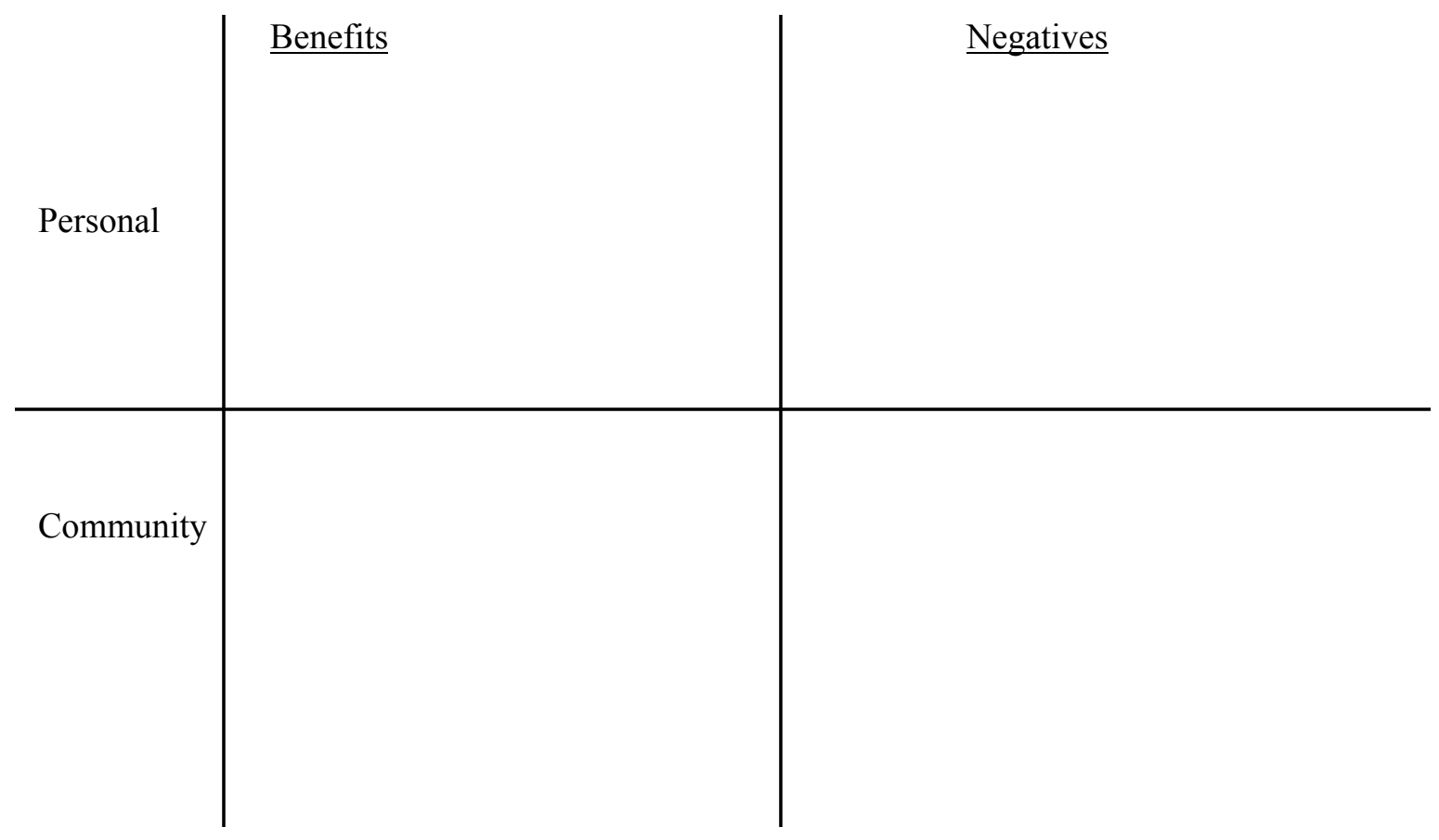

- Has the Park staff involved you personally or the community in any way (planning, education, information, etc.)?

- Where do you purchase regular household items and food? 


\section{LOCAL BUSINESS INTERVIEW}

Town:

Date:

- Are you aware that a National Park exists near your community?

- Why do you think it was designated a 'Park'?

- Has Park establishment impacted your business in a positive and/or negative way?

$\underline{\text { Positive }}$

$\underline{\text { Negative }}$

- What are your feelings about the Park? Overall, is it a good or bad thing?

- What are your feelings about tourism/tourists and, the possibility that tourism in this region may increase in the future?

- Is the protection of tropical forest/natural resources important to you? Please explain? 
- Do you see any benefits or problems if tourism was to increase: a) to your business? b) to the community?

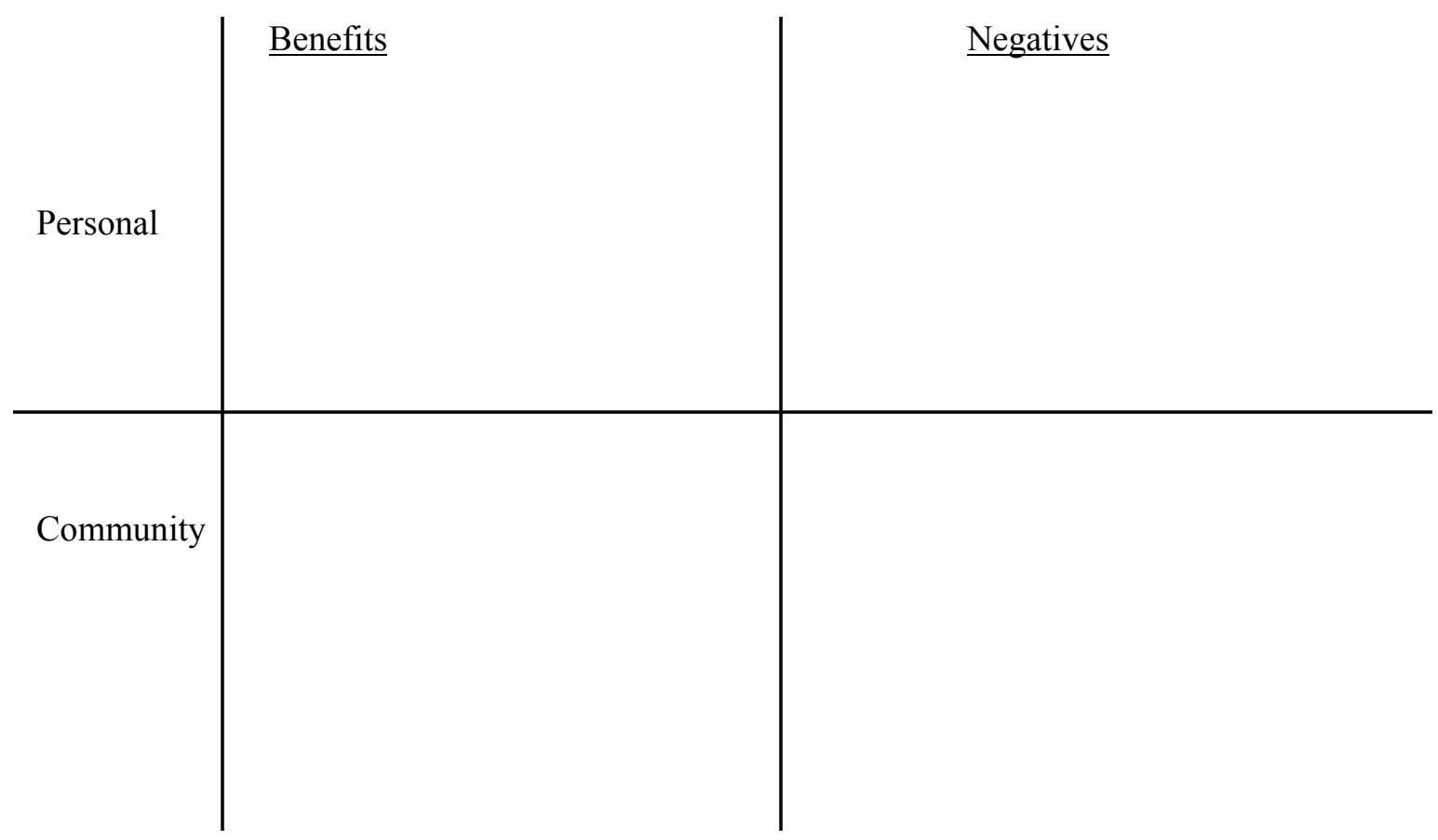

- Has the Park staff involved you personally or the community in any way (planning, education, information, etc.)?

- Where do you purchase the raw materials/supplies for your business?

- Can you estimate the percentage of total sales/revenues that come from tourists?

- Can you provide me with details on your staff (\#, percent local, sex, etc.)? 
Appendix C:

Study Description Given to Interviewees 


\section{Dear Sir/Madam:}

Hello, my name is Michael Stone. I am a graduate student from the University of Waterloo in Canada. I am conducting research on tourism and parks in Hainan over the following three months. My research is being carried out under the EcoProvince initiative and is supported by Nanjing University and the Hainan Department of Lands, Environment and Resources. In particular, I am interested in the impacts of park-related tourism developments on local communities. As a member of this community, your opinions are very valuable to this research. Your cooperation in answering some questions would be most appreciated. The questions should take between 15 and 30 minutes. Your participation is absolutely voluntary, and you are free to not answer any question(s) you are not comfortable with during the interview.

Thank you for your cooperation.

Sincerely,

Michael Stone 
Appendix D:

Tourist Survey 
Date:

Hello. My name is Michael Stone. I am a graduate student from the University of Waterloo in Canada. I am conducting research on parks and tourism in Hainan. In particular, I am interested in tourism at Jianfengling National Forest Park. It would be most appreciated if you could spend 5 to 10 minutes to complete the following survey regarding your visit to the Park. If possible, please complete the survey prior to hotel checkout and your departure from the Park. All surveys are anonymous and, you are free to not answer any question(s) you are not comfortable with. Thank you for your cooperation!

1. Sex: _ Female _ Male

2. Age:

3. Occupation:

4. Is this your first visit to Jianfengling National Forest Park? _ $\quad$ Yes _ No

5. Is the main reason for your visit to: a) See the Park $\quad$ b) Business trip

6. What is the total number of people in your group, including yourself?

7. Are you traveling: a) Alone $\quad$ b) With your spouse/partner c) With your family $\begin{array}{lll}\& \text { children } & \text { d) As part of a tour group } & \text { e) As part of a company retreat }\end{array}$

8. Which city/town and province is your group from?

9. On this visit, how many nights did you spend:

a) In a Park hotel __ nights

b) In a hotel in Jianfeng town _ nights

\section{According To Your Group Type, Please Answer Question \#10 OR \#11}

10. If traveling as part of a tour group:

a) How much did the tour cost per person? RMB

$\begin{array}{lll}\text { b) Circle everything the cost of the tour included: } & \text { i) Hotel } & \text { ii) Meals }\end{array}$

iii) Transport iv) Souvenirs v) Other (specify)

c) Please estimate any additional expenditures (not included in the cost of the tour) that you personally made during this trip on the following items, and each of the 3 locations given:

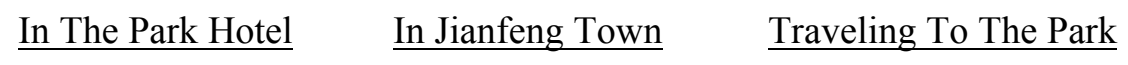

Food \& Drink

RMB

RMB

RMB

(non-alcoholic) 


\begin{tabular}{|c|c|c|c|}
\hline Alcoholic Drinks & RMB & $\mathrm{RMB}$ & $\mathrm{RMB}$ \\
\hline Hotel Room & RMB & $\mathrm{RMB}$ & RMB \\
\hline Transportation & - RMB & $\mathrm{RMB}$ & RMB \\
\hline (taxi, gas, rental, etc.) & & & \\
\hline Gifts/souvenirs & RMB & RMB & RMB \\
\hline Entertainment & RMB & $\mathrm{RMB}$ & RMB \\
\hline (including massage/bea & & & \\
\hline Other (please specify) & & & \\
\hline & RMB & RMB & RMB \\
\hline & $\mathrm{RMB}$ & RMB & RMB \\
\hline
\end{tabular}

11. If traveling alone, with your spouse, or with your family $\&$ children please estimate the total amount your whole group spent on each of the following items, at each of the 3 given locations:

\begin{tabular}{|c|c|c|c|}
\hline & In The Park Hotel & In Jianfeng Town & Traveling To The Park \\
\hline Food \& Drink & $\mathrm{RMB}$ & $\mathrm{RMB}$ & RMB \\
\hline \multicolumn{4}{|l|}{ (non-alcoholic) } \\
\hline Alcoholic Drinks & RMB & $\mathrm{RMB}$ & RMB \\
\hline Hotel Room & RMB & RMB & RMB \\
\hline Transportation & RMB & $\mathrm{RMB}$ & RMB \\
\hline \multicolumn{4}{|l|}{ (taxi, gas, rental, etc.) } \\
\hline Gifts/souvenirs & RMB & $\mathrm{RMB}$ & RMB \\
\hline Entertainment & RMB & RMB & RMB \\
\hline \multicolumn{4}{|c|}{ (including massage/beauty) } \\
\hline \multicolumn{4}{|l|}{ Other (please specify) } \\
\hline & $\mathrm{RMB}$ & RMB & $\mathrm{RMB}$ \\
\hline & RMB & RMB & $\mathrm{RMB}$ \\
\hline
\end{tabular}

11. What activities did you participate in while on this visit to the Park (circle all that apply)?
a) Climb Mt. Jianfeng
b) Climb Observation Tower
c) Visit Lookout Pavilion
d) Nature walk
e) Visit waterfall(s)
f) Fishing (at Heavenly Pool) 

g) Boat ride (at Heavenly Pool)
h) Attend Li cultural performance
i) Visit tourist centre j) Other (please specify)

13. Was any educational information/material about the Park and/or its natural features made available to your group during your visit? a) Yes (go to Q\#14) b) No (go to Q\#15)

14. Please rate your level of satisfaction with the information you were provided with according to the following scale:
a) Very Unsatisfied
b) Unsatisfied
c) Satisfied
d) Very Satisfied

15. Do you think the Park is well managed? a) Yes

b)No

Please explain/comment:

16. Please rate your overall level of satisfaction with your visit to the Park according to the following scale:
a) Very Unsatisfied
b) Unsatisfied
c) Satisfied
d) Very Satisfied

17. Would you visit the Park again in the future?
a) Yes
b) No

18. Would you be willing to pay a fee to enter the Park
a) Yes
b) No

If yes, how much would you be willing to pay?

RMB

THANK YOU VERY MUCH FOR YOUR TIME! (Please return the survey to the hotel front desk) 
Appendix E:

DNFP Tourist Pledge Form 


\section{Joint Pledge of Forest Eco-tour}

Please comply with the following pledges:

1. Cherishing forest is the responsibility of every earth citizen

2. It is the responsibility of forest eco-tourists and managers (operators) to protect vegetation in the park and prevent behaviour that damages the park

3. Wildlife should be protected in order to maintain biodiversity

4. It is our responsibility to eliminate kindling

5. It is our responsibility to supervise and urge each other to bring garbage out of the park

6. Leave nothing except footprints; take nothing except pictures

7. Implement eco-obligation, eco-ethics, and eco-civilization

Signature of tourist (representative)

Organization

Signature of manager (operator)

Organization

Date 


\section{Reference List}

Arnstein, S.R. (1969). A ladder of citizen participation. Journal of the American Institute of Planners, 35, 216-224.

Ashley, C., Roe, D. , \& Goodwin, H. (2001). Pro-Poor Tourism Strategies: Making

Tourism Work for the Poor. Nottingham: Russell Press.

Asian Development Bank. (1995). Report and Recommendation of the President to the Board of Directors on a Proposed Loan and Technical Assistance Grants to the People's Republic of

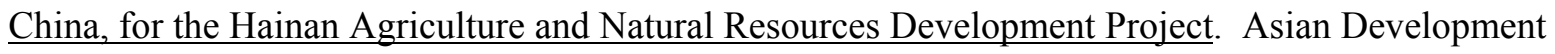
Bank. Publication \# RRP:PRC 26453.

Associates in Rural Development. (1998). Jianfengling Park Management \& Biological Diversity Protection Project: Final Report, Technical Assistance Project 2394-PRC. Burlington, VT: Associates in Rural Development. Technical Assistance Project 2394-PRC.

Baud-Bovy, M. (1982). New concepts in planning for tourism and recreation. Tourism Management, 3(4), 308-313.

Boo, E. (1990). Ecotourism: The Potentials and Pitfalls. Washington, D.C.: World Wildlife Fund.

Boo, E. (1991). Making Ecotourism Sustainable: Recommendations for Planning, Development, and Management. In Whelan, T. (Ed.), Nature Tourism: Managing for the Environment. (pp. 187-199). Washington, D.C.: Island Press.

Boyd, S.W. (2000). Tourism, national parks and sustainability. In Butler, R. W. and Boyd, S. W. (Eds.), Tourism and National Parks: Issues and Implications. (pp. 161-186). London: John Wiley \& Sons Ltd.

Brandon, K. (1996). Ecotourism and Conservation: A Review of Key Issues. Biodiversity Series. Washington, D.C.: The World Bank. Paper \#33. 
Butler, R.W. (1980). The Concept of a Tourist Area Cycle of Evolution: Implications for Management of Resources. The Canadian Geographer, xxiv(1), 5-12.

Cadario, P.M., Ogawa, K., \& Wen, Y.K. (1992). A Chinese Province as a Reform Experiment: The Case of Hainan. World Bank Discussion Papers, China and Mongolia Department Series. Washington, D.C.: The World Bank. Discussion Paper \#170.

Campbell, L.M. (1999). Ecotourism in Rural Developing Countries. Annals of Tourism Research, 26(3), 531-553.

Cater, E. (1993). Ecotourism in the Third World: Problems for sustainable tourism development. Tourism Management, 14(2), 85-90.

Cater, E. (1994). Ecotourism in the Third World: Problems and Prospects for Sustainability. In Cater, E. and Lowman, G. (Eds.), Ecotourism: A Sustainable Option? (pp. 69-86). Chichester: Wiley.

Ceballos-Lascurain, H. (1993). Ecotourism as a Worldwide Phenomenon. In Lindberg, K. and Hawkins, D. E. (Eds.), Ecotourism: A Guide for Planners \& Managers. (pp. 12-15). North Bennington: The Ecotourism Society.

Ceballos-Lascurain, H. (1996). Tourism, ecotourism and protected areas: The state of nature-based tourism around the world and guidelines for its development. Gland: IUCN.

Chambers, R. (1997). Whose Reality Counts? : putting the first last. London: Intermediate Technology.

Chon, K.S. (2000). Tourism in Southeast Asia: A New Direction. New York: Haworth Press Inc.

Chongyi, F., \& Goodman, D.S.G. (1997). Hainan: Communal politics and the struggle for identity. In Goodman, D. S. G (Ed.), China's Provinces In Reform: class, community and political culture. (pp. 53-88). London: Routledge.

Churchill, G.A., \& Peter, J.P. (1995). Marketing: creating value for customers. Burr Ridge: Irwin McGraw Hill. 
Collins, A. (1999). Tourism Development and Natural Capital. Annals of Tourism Research, 26(1), 98-109.

Cork, C. (1995). Ecotourism Planning in Cambodia: The Importance of Local Public Involvement. Plan Canada, 35(4), 34-36.

Cresswell, C., \& MacLaren, F. (2000). Tourism and national parks in emerging tourism countries. In Butler, R. W. and Boyd, S. W. (Eds.), Tourism and National Parks: Issues and Implications. (pp. 283-299). London: John Wiley \& Sons Ltd.

D'Amore, L.J. (1983). Guidelines to Planning in Harmony with the Host Community. In Murphy, P. E. (Ed.), Tourism in Canada: Selected Issues and Options. (pp. 135-159). Victoria: University of Victoria.

de Kadt, E. (1979). Tourism: Passport to Development? Oxford: Oxford University Press.

Decrop, A. (1999). Triangulation in qualitative tourism research. Tourism Management, 20(1999), 157-161.

Denzin, N.K. (1989). The Research Act: A Theoretical Introduction to Sociological Methods. ( ${ }^{\text {rd }}$ ed.). Englewood Cliffs: Prentice Hall.

Department of Lands, Environment \& Resources. (1999). Proposal for the Creation of an Eco-province in Hainan. Haikou, China: Hainan Provincial Government.

Dharmaratne, G.S., Sang, F.Y., \& Walling, L.J. (2000). Tourism Potentials for Financing Protected Areas. Annals of Tourism Research, 27(3), 590-610.

Diaoluoshan Forest Bureau. (1998). Moving Towards a New Century at Diaoluoshan: A Report Commemorating 40 Forty Years of Hard Work at the Diaoloushan Forest Bureau.

Doxey, G.V. (1976). When Enough's Enough: The Natives are Restless in Old Niagara. Heritage Canada, 2(2), 26-29. 
Drake, S.P. (1991). Local Participation in Ecotourism Projects. In Whelan, T. (Ed.), Nature Tourism: Managing for the Environment. (pp. 132-163). Washington, D.C.: Island Press.

Eagles, P.F.J. (1992). The Travel Motivations of Canadian Ecotourists. Journal of Travel Research, 31(2), 3-7.

Eagles, P.F.J. (1997). International Ecotourism Management: Using Australia and Africa as Case Studies. Paper Prepared For: IUCN World Commission on Protected Areas, Protected Areas in the 21st Century: From Islands to Networks, Albany, Australia, November 23-29, 1997.

Eagles, P.F.J. (1998). International Trends in Park Tourism and Economics: Implications for Ontario. Paper Prepared For: Parks Research Forum for Ontario, Peterborough, ON, February 5-6, 1998.

Eagles, P.F.J., McCool, S.F., \& Haynes, C. (2002). Sustainable Tourism in National Parks and Protected Areas: Guidelines for Planning and Management. Gland: World Tourism Organization.

Getz, D. (1986). Models in tourism planning: Towards integration of theory and practice. Tourism Management, 17(1), 21-32.

Gormsen, E. (1995). International Tourism in China: Its Organization and Socioeconomic Impact. In Lew, A. A. and Yu, L. (Eds.), Tourism in China: Geographic, Political, and Economic Perspectives. (pp. 64-88). Boulder, CO: Westview Press.

Guangrui, Z. (1987). Tourism education in PR China. Tourism Management, 8(3), 262266.

Guangrui, Z. (1989). Ten years of Chinese tourism: Profile and assessment. Tourism Management, $10(1), 51-62$.

Guangrui, Z. (1995). China's Tourism Development Since 1978: Policies, Experiences, and Lessons Learned. In Lew, A. A. and Yu, L. (Eds.), Tourism in China: Geographic, Political, and Economic Perspectives. (pp. 3-18). Boulder, CO: Westview Press.

Gunn, C.A. (1979). Tourism Planning. ( $1^{\text {st }}$ ed.). New York: Crane Russak. 
Gunn, C.A. (1988). Tourism Planning. ( $2^{\text {nd }}$ ed.). New York: Taylor \& Francis.

Gunn, C.A. (1991). The Role of Tourism in the Planning and Management of Special Places. Plan Canada, 31(2), 4-10.

Hainan Forest Bureau, \& Chinese Academy of Forestry. (2000). A Brief Introduction to the Sub-Project No. 4 of ITTO Hainan Project: Demonstration Area of Tropical Virgin Forest Protection. Chinese Academy of Forestry.

Hainan Tour Atlas. (1997). Beijing: Publishing House of Surveying and Mapping.

Han, N., \& Ren, Z. (2000). Ecotourism in China's Nature Reserves: An Opportunity and Challenges. Beijing: Chinese National Committee for MAB.

Hatton, M.J. (1999). Community-Based Tourism in the Asia-Pacific. Toronto: Humber College. APEC Publication \# 99-TO-01.1.

Hornback, K.E., \& Eagles, P.F.J. (1999). Guidelines for Public Use Measurement and Reporting at Parks and Protected Areas. Gland: IUCN.

Hummel, J. (1994). Ecotourism Development in Protected Areas of Developing Countries. World Leisure \& Recreation, 36(2), 17-23.

Hvenegaard, G.T., \& Dearden, P. (1998). Ecotourism Versus Tourism in a Thai National Park. Annals of Tourism Research, 25(3), 700-720.

Jian, Z. (1989). Overprovision in Chinese hotels. Tourism Management, 10(1), 63-66.

Jianfengling Forest Bureau. (2000). Jianfengling National Forest Park.

Knopf, R.C. (1990). Marketing Public Lands: Is it the Right Thing to Do? Parks and Recreation, (March)

Lee, C. (1997). Valuation of nature-based tourism resources using dichotomous choice contingent valuation method. Tourism Management, 18(8), 587-591. 
Lee, D.N.B., \& Snepenger, D.J. (1992). An Ecotourism Assessment of Tortuguero, Costa Rica. Annals of Tourism Research, 19(2), 367-370.

Lee, V.J. (2000). Assessing Ecotourism's Abilities To Generate Community Benefits: Bunaken National Park, Indonesia. M.E.S Thesis. University of Waterloo.

Lindberg, K. (1991). Policies for Maximizing Nature Tourisms Ecological and Economic Benefits. International Conservation Financing Project Working Paper. USA: World Resources Institute.

Lindberg, K., Enriquez, J., \& Sproule, K. (1996). Ecotourism Questioned: Case Studies from Belize. Annals of Tourism Research, 23(3), 543-562.

Lindberg, K., Furze, B., Staff, M., \& Black, R. (1998). Ecotourism in the Asia-Pacific Region: Issues and Outlook. Bangkok: Forestry Policy and Planning Division, FAO.

Loon, R.M., \& Polakow, D. (2001). Ecotourism Ventures: Rags or Riches? Annals of Tourism Research, 28(4), 892-907.

Lundberg, D.E., Krishnamoorthy, M., \& Stavenga, M.H. (1995). Tourism Economics. New York: John Wiley \& Sons.

MacDonald, N., \& Aumonier, S. (1998). Planning for the Deluge: National Parks' communities and tourism. Plan Canada, 38(1), 19-23.

Mathieson, A., \& Wall, G. (1982). Tourism: economic, physical and social impacts. New York: Longman.

McNeely, J.A. (1992). Parks for Life (Excerpts from the Report of the IVth World Congress on National Parks and Protected Areas). Paper Prepared For: IVth World Congress on National Parks and Protected Areas.

Mitchell, R.E., \& Reid, D.G. (2001). Community Integraton: Island Tourism in Peru. Annals of Tourism Research, 28(1), 113-139.

Murphy, P.E. (1985). Tourism: A community approach. New York: Methuen. 
Nenon, J., \& Durst, P.B. (1993). Nature Tourism in Asia: Opportunities and Constraints for Conservation and Economic Development. Washington, D. C.: Forestry Support Program, U. S. Department of Agriculture and Office of International Cooperation and Development .

Nepal, S.K. (2000a). Tourism in Protected Areas: The Nepalese Himalaya. Annals of Tourism Research, 27(3), 661-681.

Nepal, S.K. (2000b). Tourism, national parks and local communities. In Butler, R. W. and Boyd, S. W. (Eds.), Tourism and National Parks: Issues and Implications. (pp. 73-94). London: John Wiley \& Sons Ltd.

Nianyong, H., \& Zhuge, R. (2000). Ecotourism in China's Nature Reserves: An Opportunity and Challenges. Beijing: Chinese National Committee for MAB.

Norris, R. (1992). Can Ecotourism Save Natural Areas? National Parks, (January), 33-34.

Notzke, C. (1999). Indigenous Tourism Development in the Arctic. Annals of Tourism Research, 26(1), 51-76.

Orams, M.B. (1995). Towards a more desirable form of ecotourism. Tourism Management, 16, 3-8.

Outspan Group. (2000). The Economic Benefits of Protected Areas: A Guide for Estimating Personal Benefits. Amherst Island: Federal Provincial Parks Council. FPPC-510e.

Ouyang, Z., Han, Y., Xiao, H., Wang, X., Xiao, Y., \& Miao, H. (2001). Nature Reserve Network Planning of Hainan Province, China. South-South Co-operation Programme on Environmentally Sound Socio-Economic Development in the Humid Tropics Working Papers. Paris: UNESCO, Division of Ecological Sciences, South-South Co-operation Programme.

Payne, R.J., \& Graham, R. (1993). Visitor Planning and Management in Parks and Protected Areas. In Dearden, P. and Rollins, R. (Eds.), Parks and Protected Areas in Canada: Planning and Management. (pp. 185-210). Toronto: Oxford University Press.

Pearce, D.G. (2000). Tourism plan reviews: methodological considerations and issues from Samoa. Tourism Management, 21 (2000), 191-203. 
Place, S. (1991). Nature Tourism and Rural Development in Tortuguero. Annals of Tourism Research, 18, 186-201.

Richter, L.K. (1983). Political Implications of Chinese Tourism Policy. Annals of Tourism Research, 10(3), 395-413.

Rollins, R. (1993). Managing the National Parks. In Dearden, P. and Rollins, R. (Eds.), Parks and Protected Areas in Canada: Planning and Management. (pp. 75-96). Toronto: Oxford University Press.

Ross, S., \& Wall, G. (1999b). Ecotourism: towards congruence between theory and practice. Tourism Management, 20(1), 123-132.

Ross, S., \& Wall, G. (1999a). Evaluating ecotourism: The case of North Sulawesi, Indonesia. Tourism Management, 20(6), 673-682.

Scheyvens, R. (1999). Ecotourism and the empowerment of local communities. Tourism Management, 20(1999), 245-249.

Shangji, S. (1994). Population, Resources, Environment, and Development in Hainan Island: Conflicts and Resolution. Chinese Environment and Development, 4(4), 75-89.

Sherman, P.B., \& Dixon, J.A. (1991). The Economics of Nature Tourism: Determining If It Pays. In Whelan, T. (Ed.), Nature Tourism: Managing for the Environment. (pp. 89-131). Washington, D.C.: Island Press.

Slinger, V. (2000). Ecotourism in the Last Indigenous Caribbean Community. Annals of Tourism Research, 27( 2), 520-523.

Spandouis, C. (1982). Trends in tourism planning and development. Tourism Management, 3(4), 314-318.

Tisdell, C. (1996). Ecotourism, Economics, and the Environment: Observations from China. Journal of Travel Research, (Spring), 11-19. 
Tisdell, C. (1999). Biodiversity, Conservation and Sustainable Development: Principles and Practices with Asian Examples. Cheltenham, UK: Edward Elgar Publishing Ltd.

Tisdell, C., \& Wen, J. (1991). Foreign tourism as an element in PR China's economic development. Tourism Management, 12(1), 55-67.

Travis, A.S. (1982). Managing the environmental and cultural impacts of tourism and leisure development. Tourism Management, 3(4), 256-261.

Valentine, P.S. Tourism in Protected Areas: The Challenges and Opportunities (An Introductory Paper for the IVth World Congress on National Parks and Protected Areas).

Wall, G. (1994). Ecotourism: Old Wine in New Bottles? Trends, 31(2), 4-9.

Wall, G. (1997). Is Ecotourism Sustainable? Environmental Management, 21(4), 483491.

Walpole, M.J., \& Goodwin, H.J. (2000). Local Economic Impacts of Dragon Tourism in Indonesia. Annals of Tourism Research, 27(3), 559-576.

Wandi, J. (1999, August 2). Breakthrough Made in Forest Protection. Beijing Review, 42, $16-19$.

Wang, X. (1993). The Increasing Impact of Tourism on Protected Areas in China. Contours, 6(3/4), 38-43.

Weaver, D.B. (1998). Ecotourism in the Less Developed World. New York : CAB International.

Weisun, Y. (2000). Forest draws tourists. China Daily, July 2000,

Wells, M.P. (1997). Economic Perspectives on Nature Tourism, Conservation and Development. Environmental Economics Series. The World Bank. Paper \#55.

Wells, M.P., \& Brandon, K. (1992). People and Parks: Linking Protected Area Management with Local Communities. Washington, D.C.: The World Bank. 
Western, D. (1993). Defining Ecotourism. In Lindberg, K. and Hawkins, D. E. (Eds.), Ecotourism: A Guide for Planners \& Managers. (pp. 7-12). North Bennington: The Ecotourism Society.

Wheatcroft, S. (1994). The 1993 WTTC Report, Travel \& Tourism Forecasts. Belgium: World Travel \& Tourism Council.

Whelan, T. (1991). Ecotourism and its Role in Sustainable Development. In Whelan, T. (Ed.), Nature Tourism: Managing for the Environment. (pp. 3-22). Washington, D.C.: Island Press.

Woodley, S. (1999). Tourism and Sustainable Development in Parks and Protected Areas. In Nelson, G., Butler, R. W., and Wall, G (Eds.), Tourism and Sustainable Development: Monitoring, Planning, Managing, Decision Making. (pp. 159-174). Waterloo: Department of Geography, University of Waterloo.

World Tourism Organization. (1997). World Tourism Leaders' Meeting on The Social Impacts of Tourism. Paper Prepared For: World Tourism Leaders' Meeting on the Social Impacts of Tourism.

World Tourism Organization. (2001). Tourism Highlights 2001. URL $<\underline{w w w . w o r l d-~}$ tourism.org/market research/data/pdf/highlightsupdatedengl.pdf $>$. Accessed: 12-7-2001.

Xie, P.F., \& Wall, G. Cultural Tourism Experiences in Hainan, China: The Changing Distribution of Folk Villages. (un published).

Xin, H. (1998, April 13). Promising Industries Boost Island Economy. Beijing Review, $\underline{41,11-12 .}$

Zhang, Q.H., Chong, K., \& Ap, J. (1999). An analysis of tourism policy development in modern China. Tourism Management, 20(1999), 471-485.

Zhang, Y. (1995). An Assessment of China's Tourism Resources. In Lew, A. A. and Yu, L. (Eds.), Tourism in China: Geographic, Political, and Economic Perspectives. (pp. 41-59). Boulder, CO: Westview Press. 
Ziffer, K. (1989). Ecotourism. An Uneasy Alliance. Washington, D.C.: Conservation International. Working Paper No.1. 